\title{
Mapping and prevention of cardiac dyssynchrony
}

\author{
Citation for published version (APA):
}

Mafi Rad, M. (2016). Mapping and prevention of cardiac dyssynchrony: towards better substrate identification and lead implantation. [Doctoral Thesis, Maastricht University]. Maastricht University. https://doi.org/10.26481/dis.20160916mm

Document status and date:

Published: 01/01/2016

DOI:

10.26481/dis.20160916mm

Document Version:

Publisher's PDF, also known as Version of record

\section{Please check the document version of this publication:}

- A submitted manuscript is the version of the article upon submission and before peer-review. There can be important differences between the submitted version and the official published version of record.

People interested in the research are advised to contact the author for the final version of the publication, or visit the DOI to the publisher's website.

- The final author version and the galley proof are versions of the publication after peer review.

- The final published version features the final layout of the paper including the volume, issue and page numbers.

Link to publication

\footnotetext{
General rights rights.

- You may freely distribute the URL identifying the publication in the public portal. please follow below link for the End User Agreement:

www.umlib.nl/taverne-license

Take down policy

If you believe that this document breaches copyright please contact us at:

repository@maastrichtuniversity.nl

providing details and we will investigate your claim.
}

Copyright and moral rights for the publications made accessible in the public portal are retained by the authors and/or other copyright owners and it is a condition of accessing publications that users recognise and abide by the legal requirements associated with these

- Users may download and print one copy of any publication from the public portal for the purpose of private study or research.

- You may not further distribute the material or use it for any profit-making activity or commercial gain

If the publication is distributed under the terms of Article $25 \mathrm{fa}$ of the Dutch Copyright Act, indicated by the "Taverne" license above, 


\section{Mapping and prevention of cardiac dyssynchrony}

\section{Towards better substrate identification and lead implantation}

\section{Proefschrift}

Ter verkrijging van de graad van doctor aan de Universiteit Maastricht, op gezag van de Rector Magnificus, Prof. Dr. Rianne M. Letschert, volgens het besluit van het College van Decanen, in het openbaar te verdedigen op vrijdag 16 september 2016 om 10:00 uur

door

\section{Masih Mafi Rad}

geboren op 16 september 1984

te Teheran, Iran 


\section{Promotores:}

Prof. Dr. H.J.G.M. Crijns

Prof. Dr. F.W. Prinzen

\section{Copromotor:}

Dr. K. Vernooy

\section{Beoordelingscommissie:}

Prof. Dr. J.C.A. Hoorntje (voorzitter)

Prof. Dr. T. Delhaas

Dr. M. Meine (Universitair Medisch Centrum Utrecht)

Prof. Dr. U. Schotten

Prof. Dr. J.L.R.M. Smeets (Radboud Universitair Medisch Centrum Nijmegen)

Financial support for the printing of this thesis as provided by the following sponsors is gratefully acknowledged.

Stichting Hartsvrienden RESCAR | St. Jude Medical Nederland B.V. | Biotronik Nederland B.V.|

Pie Medical Imaging Maastricht Nederland B.V. 


\section{Contents}

Left ventricular lead placement in the latest activated region guided by coronary venous electroanatomic mapping

Different regions of latest electrical activation during left bundle-branch block and right ventricular pacing determined by coronary venous

electroanatomic mapping

Regional left ventricular electrical activation and peak contraction are closely related in candidates for cardiac resynchronization therapy

Identifying delayed left ventricular lateral wall activation in patients with non-specific intra-ventricular conduction delay using coronary venous

electroanatomic mapping

Vectorcardiographic QRS area identifies delayed left ventricular lateral wall activation determined by electroanatomic mapping in candidates for cardiac resynchronization therapy

Feasibility and acute hemodynamic effect of left ventricular septal pacing by transvenous approach through the interventricular septum

Evaluation of left ventricular endocardial cardiac resynchronization therapy in a non-responder with ventricular arrhythmias 


\section{General introduction: Background and general aims of the thesis}




\section{Introduction}

In a normal heart, electrical activation starts in the sinus node, the physiological pacemaker of the heart which is located in the right atrium, and from there spreads through the atria. Afte reaching the atrio-ventricular node, the electrical activation is rapidly conducted toward the right (RV) and left ventricle (LV) through the specialized ventricular conduction system consisting of the His bundle, the right and left bundle-branches and the Purkinje fibers. Because conduction through the Purkinje fibers is much faster than myocyte-to-myocyte conduction, physiological depolarization of the RV and LV occurs fast and synchronously (Figure 1a). A fast and synchronous ventricular activation is considered of utmost importance for maintaining coordinate ventricular contraction and optimal cardiac pump function.

\section{Dyssynchronous ventricular activation}

In patients with left bundle-branch block (LBBB) or patients that receive RV pacing because of symptomatic bradycardia, the LV is no longer rapidly activated through the fast conducting left bundle-branch. Instead, activation starts from the RV side of the septum and travels from the right- to the left side of the heart by relatively slow myocyte-to-myocyte conduction, which results in a delayed and dyssynchronous activation and contraction of the LV (Figure 1B and $1 C){ }^{1-3}$ The dyssynchronous $L V$ electrical activation and contraction resulting from LBBB or RV pacing impairs LV pump function and, on the long run, is associated with adverse structura

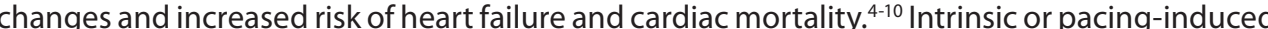
dyssynchrony are pathophysiological conditions that should be prevented or treated to maintain or improve cardiac pump function.

\section{Treatment of dyssynchrony}

Cardiac resynchronization therapy (CRT) aims to restore synchronous ventricular electrical activation and contraction by paced pre-excitation of the delayed activated LV (Figure 1D). CRT is most commonly applied by simultaneous electrical stimulation of the RV and LV. The RV

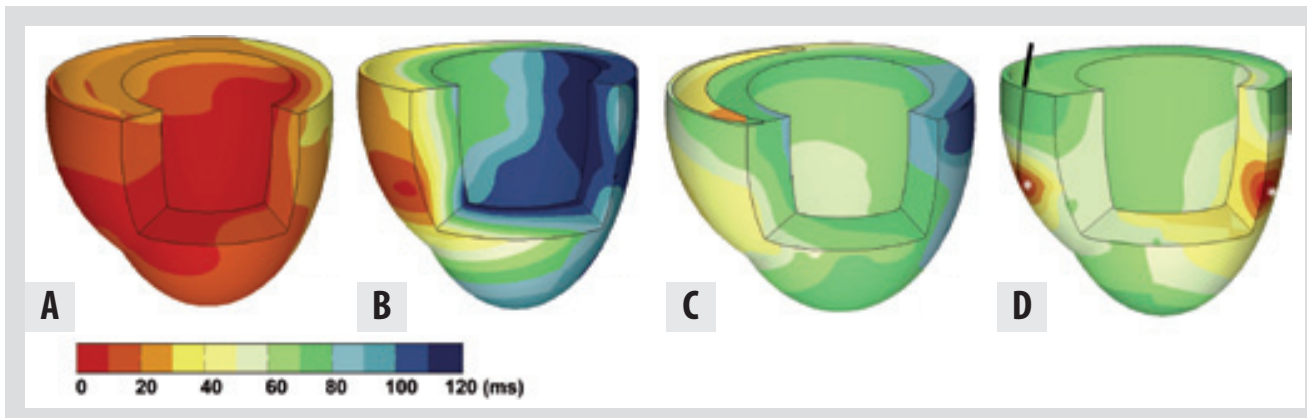

Figure 1. Reconstruction of the electrical activation in the ventricles based on contact mapping at the epicardium and non-contact mapping of the LV endocardium of a canine heart during normal conduction (A), LBBB (B), right ventricular apex pacing (C), and after (RT (D). During normal conduction fast and synchronous activation of the RV and LV are observed. During LBBB and RV apex pacing, the RV wall is activated earliest, followed by slow progression of the electrical wave front to the LV septum (green colors) and then the LV basal lateral wall (blue colors). Simultaneous pacing at the RV apex and the epicardium of the mid lateral LV wall during CRT results in a faster and more synchronous electrical ventricular activation. (Adapted from Gorscan et al., Strik et al., and Mills et al.17-19) 


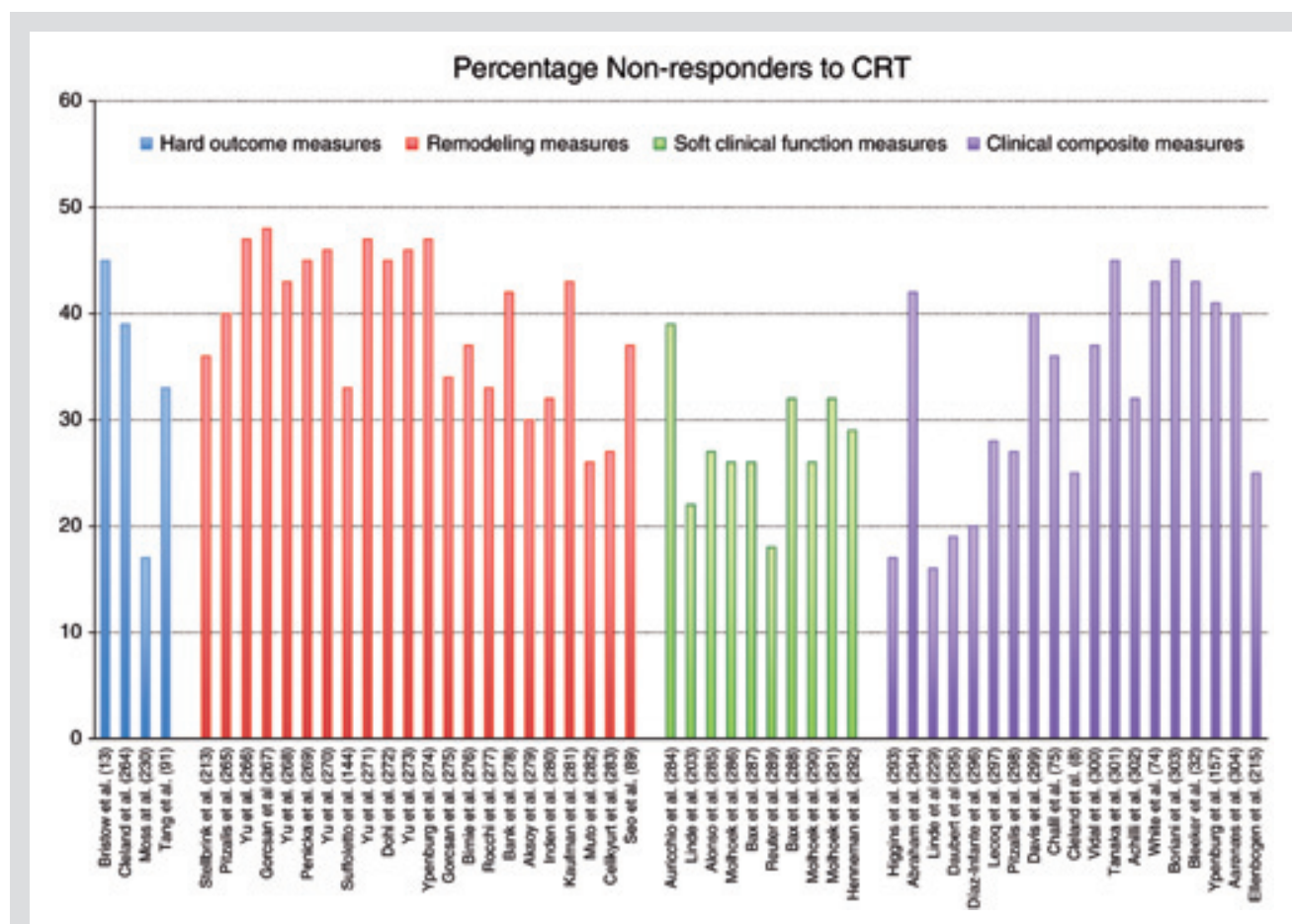

Figure 2. Comparison of outcome after CRT implantation among different studies according to outcome criteria used. (Reproduced from Daubert et al..$^{16}$ )

pacing electrode is usually positioned in the RV apex and the LV pacing electrode is inserted into the coronary sinus and positioned in one of its side branches running on the LV epicardium. In the last decade and a half, CRT has emerged as a successful treatment for symptomatic heart failure patients with impaired LV systolic function and electrocardiographic evidence of electrical dyssynchrony manifesting itself by a wide QRS complex. Several large clinical trials have shown that CRT reduces morbidity and mortality, improves cardiac pump function and clinical status and reverses LV remodeling in this group of patients. ${ }^{11-15}$ However, despite its obvious benefits, a substantial proportion of apparently suitable patients fail to show clinical and / or echocardiographic signs of response. ${ }^{16}$ Depending on the outcome measure used in clinical studies, the non-response rate varies from 15\% to almost 50\% (Figure 2). ${ }^{16}$ Such lack of response is not desirable for a treatment which involves a relatively expensive therapy and requires essentially irreversible implantation of a device and leads. Efforts to increase the response rate have mainly been focused on improving patient selection and optimizing therapy delivery by better lead positioning and device programming.

\section{Patient selection for CRT}

Major efforts have been focused on finding echocardiography-based indices of mechanical dyssynchrony that can predict CRT response. However, such measures of mechanical dyssynchrony have yet failed to provide additive predictive value for CRT response in prospective trials. ${ }^{20-22}$ This has refocused interest in the electrical substrate. Sub-analyses of large CRT trials

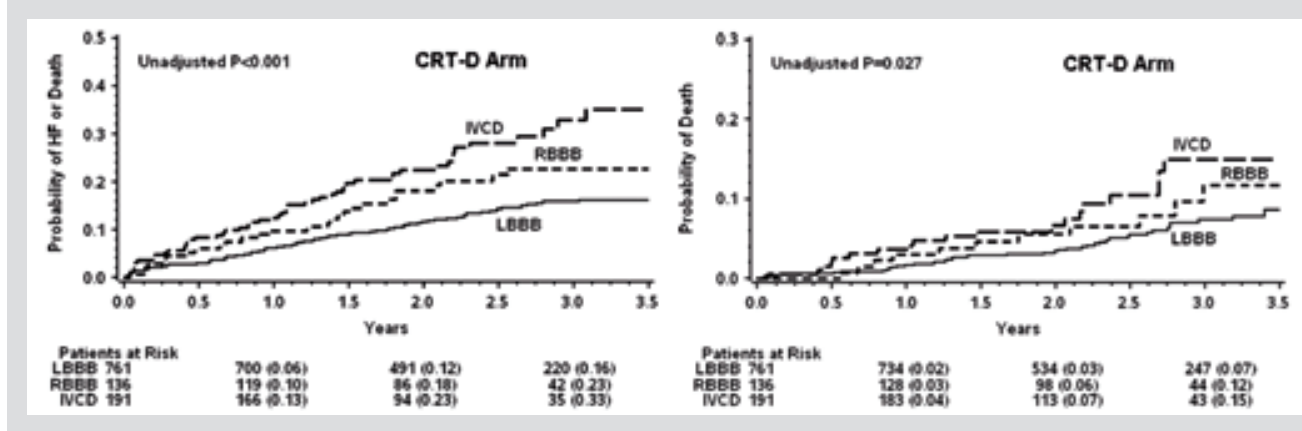

Figure 3. Cumulative probability of heart failure (HF) or death (left) and of death (right) according to QRS morphology in the cardiac resynchronization therapy with defibrillator (CRT-D) arm of the Multi-Centre Automatic Defibrillator Implantation trial-Cardiac Resynchronization Therapy (MADIT-CRT). (Adapted from Gold et al.23)

have revealed that patients with LBBB are most likely to respond favorably to CRT (Figure 3), whereas the effect of CRT in patients with right bundle-branch block (RBBB) is indifferent and even tends to be deleterious in patients with intraventricular conduction delay (IVCD) (Figure 4). ${ }^{23-29}$ On the other hand, several studies have suggested that CRT may be beneficial in a subset of non-LBBB patients with evidence of LV activation delay. ${ }^{30-33}$ The clinical importance of $L V$ activation delay is further evidenced by efficacy of CRT in animal models of isolated LBBB and by studies that have shown that a greater delay in time from onset of the QRS complex to the local intrinsic activation at the LV stimulation site (Q-LV) is associated with a greater benefit from CRT (Figure 5). ${ }^{34-37}$ Taken together, these observations indicate the importance of LV activation delay as an electrical substrate for CRT.

The key clinical investigation to detect and evaluate the extent of LV activation delay remains the surface ECG. Yet, the conventional electrocardiographic markers for delayed ventricular electrical activation, QRS duration and LBBB morphology, remain insufficient in accurately identifying patients likely to benefit from CRT. To improve patient selection, tools are required that provide more accurate identification of patients with an electrical substrate for CRT.

\section{LV lead placement}

With regard to LV lead positioning, increasing evidence supports the practice of placing the LV lead in the latest activated region as a means of maximizing CRT response. ${ }^{36-43}$ Conventional LV lead placement strategy targets a lateral or posterolateral vein, which is based on the contention that most patients eligible for CRT have LBBB, where the lateral or posterolateral wall is typically the latest activated region. ${ }^{16}$ However, studies have shown that the LV activation pattern varies considerably between patients, even in patients with LBBB, resulting in interindividual variability in the region of latest activation. ${ }^{30,44-47}$ Also, a significant percentage of CRT candidates do not have the typical LBBB morphology or have an indeterminate ventricular conduction defect indicating a more heterogeneous activation sequence making the latest activated site less predictable. These observations imply that a one size-fits-all strategy may not provide optimal therapy delivery on the individual level and emphasize the need for a patient-tailored approach to optimize LV lead positioning. Yet, the best method to guide LV lead placement to the latest activated region still needs to be established. Echocardiography 

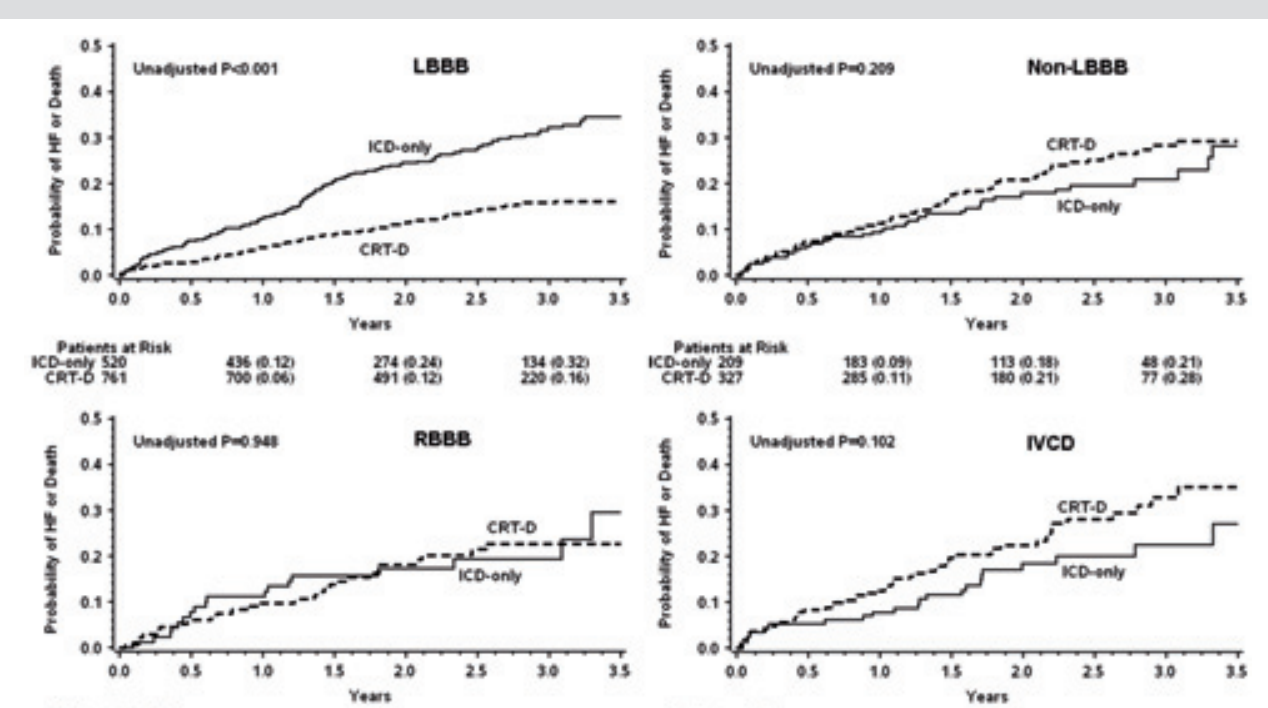

130.13
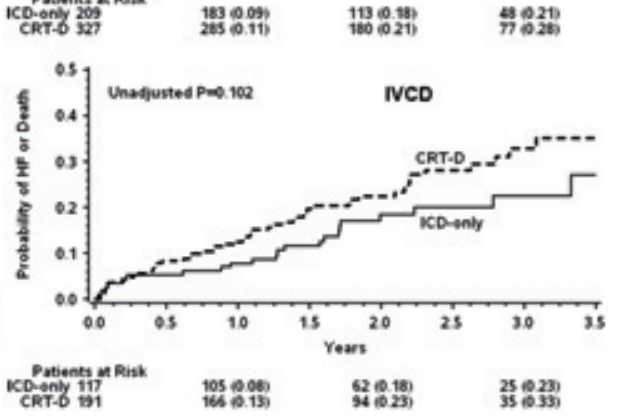

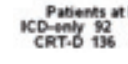
790.110 เมำ 2329193 เ幺:

Figure 4. Cumulative probability of heart failure (HF) event or death according to treatment (cardiac resynchronization therapy with debrillator [CRT-D] vs. implantable cardioverter defibrillator [ICD] only in patients with LBBB, non-LBBB, RBBB and IVCD) in Multi-Centre Automatic Defibrillator Implantation trial-Cardiac Resynchronization Therapy (MADIT-CRT) patients. (Reproduced from Gold et a...3)

and other imaging modalities have been proposed as methods to assess the LV mechanical activation pattern and quide LV lead placement, ${ }^{39,48-51}$ but these techniques are challenging to apply during CRT implantation and often require a separate pre-operative assessment. In order to assess the electrical activation pattern some investigators used complicated invasive electrical mapping techniques that are time-consuming and not without risk. ${ }^{2,44-46,52}$ Others simply measured the electrical delay at the LV pacing site using the intra-cardiac electrogram recorded from the LV lead, which provides only limited information on LV electrical activation 38,40 More detailed, yet practical techniques are thus required to optimize LV lead targeting in clinical practice.

\section{Controversies in LV lead targeting to the latest activated region}

Current strategies of targeted LV lead placement are based on targeting either the region of latest electrical activation ${ }^{38}$ or the segment of latest peak contraction assessed by speckletracking echocardiography. ${ }^{42}$ The choice between targeting the region of latest electrical activation or the segment of latest peak contraction is currently a matter of debate. On the one hand, pre-clinical studies have shown that electrical and mechanical activation of the heart are closely coupled. On the other hand, several recent clinical studies, like the PROSPECT and EchoCRT trials, showed the inability of time-to-peak measures of mechanical dyssynchrony to predict CRT response. ${ }^{21,22}$ Two recent small-scale studies compared LV electrical and mechanical activation in patients with dyssynchronous heart failure, but showed conflicting results. ${ }^{53,54}$ More research on LV electromechanical coupling is therefore required to determine whether current LV lead targeting strategies are comparable.

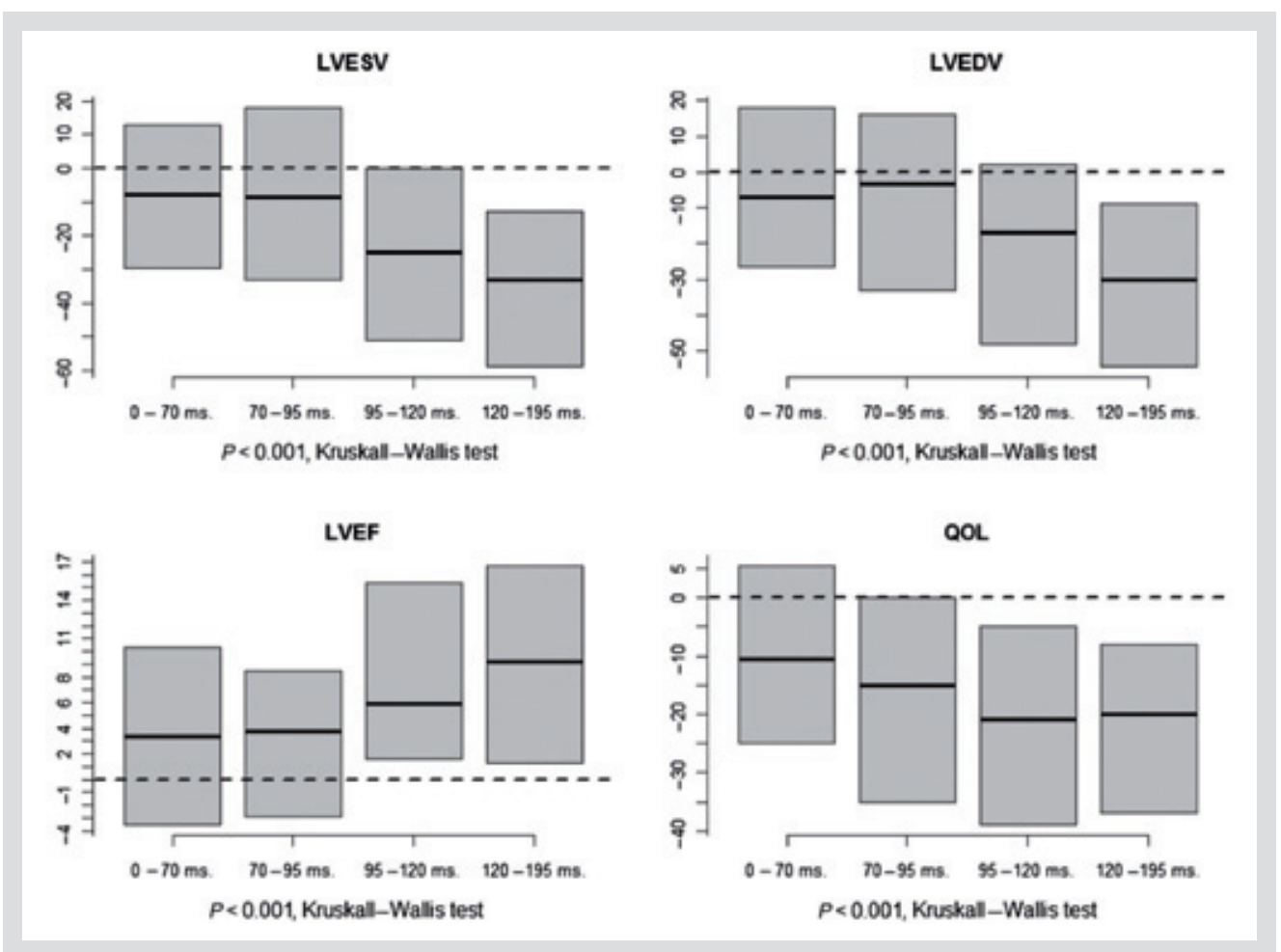

Figure 5. Comparisons of the changes in LV end-systolic volume (LVESV), end-diastolic volume (LVEDV), ejection fraction (LVEF), and quality of life (QOL) from CRT implantation to 6 months follow-up for Q-LV quartiles. ("Reproduced from Gold et al. ${ }^{36}$ )

The latest activated region is typically assessed during intrinsic ventricular activation. Yet, in daily clinical practice, CRT is most commonly applied by (almost) simultaneous RV and LV pacing, i.e. biventricular pacing, which bypasses contribution from intrinsic conduction. Although LBBB and RV apex pacing have similar QRS morphologies, suggesting that the conditions are electrically equivalent, their activation patterns may be quite different. ${ }^{55}$ Whether this has implications for the choice of the optimal pacing site needs to be investigated.

\section{Prevention of pacing-induced dyssynchrony}

While in patients with LBBB, CRT pacing can be used to reduce dyssychrony, in patients with symptomatic bradycardia, cardiac pacing often creates dyssynchrony, even though bradycardia is prevented. Especially pacing at the RV apex seems to be hemodynamically unfavorable. ${ }^{56,57}$ Yet, the RV apex has become the most commonly applied site for ventricular pacing because it is easily accessible and yields chronically stable lead positions and stimulation thresholds. In patients with unreliable or absent AV conduction, continuous ventricular pacing is unavoidable. In these patients, pacing at alternative ventricular sites may produce less ventricular dyssynchrony and preserve LV pump function. ${ }^{17,57-63}$ Yet, most alternative sites investigated so far have either shown inconsistent results, ${ }^{58,64}$ or are technically too challenging for widespread application in clinical practice.$^{65}$ Studies in canine hearts suggested that pacing at the LV septum yields LV pump function closely approximating that during normal ventricular conduction. . $^{17,63}$ 


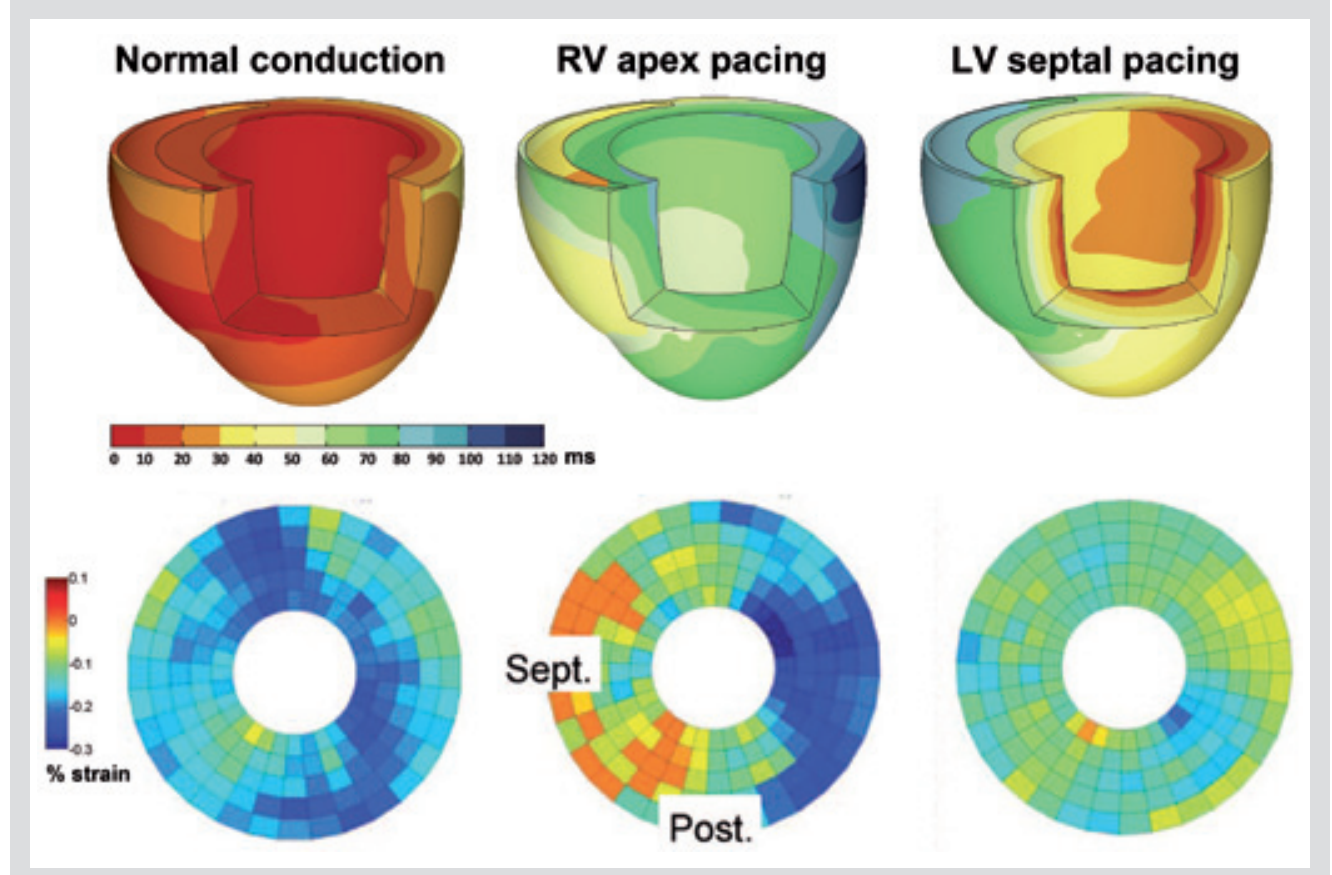

Figure 6. Electrical and mechanical activation during LV septal pacing as compared to RV apex pacing and normal conduction in a canine heart. Upper panels, electrical activation maps. During RV apical pacing, the RV wall is activated first, followed by slow progression of activation to the LV septum (green colors) and then the LV lateral wall (blue colors). In contrast, LV septal pacing leads to rapid activation around the LV endocardium, resulting in a pattern that resembles the pattern during normal conduction, although activation of the RV wall is now moderately delayed. Lower panels, bull's eye plots showing distribution of systolic shortening in the LV wall, as determined in 160 regions (5 short-axis slices, 32 regions per slice). LV septal pacing results in a more homogeneous distribution of systolic shortening compared with RV apex pacing, resembling that during normal conduction. (Adapted from Mills et al. ${ }^{17}$ )

The hemodynamic benefit of LV septal pacing has been related to a more physiologica sequence of LV electrical activation and contraction (Figure 6), resulting in less LV electrical and mechanical dyssynchrony. ${ }^{17}$ In the canine experiments, permanent and stable implantation of an LV septal lead was achieved by introducing a custom pacing lead with extended helix transvenously into the $\mathrm{RV}$ and driving it from the $\mathrm{RV}$ side through the interventricular septum to the LV septum. ${ }^{17}$ Whether permanent placement of a pacing lead in the LV septum using a transvenous approach through the interventricular septum is also feasible and safe in patients has not been investigated yet.

\section{Aim of the thesis}

The aims of thist

1. To develop a useful method for patient-tailored LV lead placement focused on targeting the latest activated region.

2. To investigate the difference in LV electrical activation sequence between intrinsic LBBB and $\mathrm{RV}$ apex pacing in candidates for CRT.
3. To determine the relationship between the timing of LV electrical and mechanical activation in candidates for CRT.

4. To improve identification of patients with an appropriate electrical substrate for CRT.

5. To perform a first-in man study investigating the feasibility of a novel method of ventricular lead placement for anti-bradycardia pacing therapy that targets the LV septum, which may reduce the extent of pacing-induced dyssynchrony and the adverse effects associated with this condition.

\section{Outline of the thesis}

In chapter $\mathbf{2}$ of the thesis we describe a novel method of epicardial electroanatomic mapping via the coronary veins that can be used during the procedure of CRT implantation to assess the LV electrical activation sequence and guide LV lead placement to the latest activated region. This coronary venous electroanatomic mapping technique does not increase the invasiveness of the procedure and causes only minor prolongation of procedure time.

In chapter $\mathbf{3}$ we investigated differences in LV electrical activation between intrinsic LBBB and RV apex pacing and the potential implications thereof for LV lead placement. For this purpose, we assessed the LV electrical activation pattern of CRT candidates during both intrinsic LBBB and RV apex pacing using the coronary venous electroanatomic mapping technique described in chapter 2.

In the study described in chapter $\mathbf{4}$ we investigated whether current LV lead targeting strategies, which are based on targeting either the region of latest electrical activation or the segment of latest peak contraction, are comparable. For this purpose we performed a within patient comparison of the timing of LV electrical activation obtained from coronary venous electroanatomic mapping and the timing of LV peak contraction derived from speckle-tracking echocardiography in CRT candidates.

In chapter $\mathbf{5}$ and $\mathbf{6}$ we investigated whether coronary venous electroanatomic mapping can be used at the time of CRT implantation to determine the presence of delayed LV lateral wall activation, an electrical substrate amenable to CRT.

Ideally, characterization of the electrical substrate is performed in advance so that this information can be used to guide the decision on whether or not to implant a CRT device. In this regard, ORS characteristics other than QRS duration and morphology may provide valuable additional information. Therefore, in chapter $\mathbf{5}$ we also investigated whether such alternative QRS characteristics can identify delayed LV lateral wall activation in a cohort of IVCD patients by comparing ECG measurements with data from coronary venous electroanatomic mapping. We also hypothesized in chapter 6 that the vectorcardiogram (VCG), which contains threedimensional information of electrical forces within the heart, can provide markers that identify delayed LV lateral wall activation better than the conventional electrical markers QRS duration and LBBB morphology. To investigate this we compared VCG measurement with data from coronary venous electroanatomic mapping in a cohort of LBBB and non-LBBB patients.

In chapter $\mathbf{7}$ we aimed to translate the results of previous canine experiments into clinica practice by performing a first-in-man study in which we investigated the feasibility of permanently implanting an LV septal lead in patients using a transvenous approach through the interventricular septum. At first instance, this novel pacing mode is meant to prevent the development of pacing-induced dyssynchrony in patients requiring pacing because of bradycardia. 
Besides the abovementioned studies, the thesis also contains a case report (chapter 8) and an editorial (chapter 9) on the value of measurements of acute hemodynamic response to CRT for improving patient selection and optimizing CRT delivery by systematic hemodynamic evaluation of potential LV pacing sites and atrio-ventricular and inter-ventricular stimulation intervals. The thesis ends with a general discussion (chapter 10) where the findings of the abovementioned studies are put in a broader perspective with special emphasis on clinical implications and future studies.

\section{References}

Grines CL, Bashore TM, Boudoulas H, Olson S, Shafer P, Wooley CF. Functional abnormalities in isolated left bundle branch block. The effect of interventricular asynchrony. Circulation. 1989;79:845-853

2. Vassallo JA, Cassidy DM, Marchlinski FE, Buxton AE, Waxman HL, Doherty JU, Josephson ME. Endocardial activation of left bundle branch block. Circulation. 1984;69:914-923

3. Vassallo JA, Cassidy DM, Miller JM, Buxton AE, Marchlinski FE, Josephson ME. Left ventricular endocardia activation during right ventricular pacing: Effect of underlying heart disease. Journal of the American College of Cardiology. 1986; $7: 1228-1233$

4. Lieberman R, Padeletti L, Schreuder J, Jackson K, Michelucci A, Colella A, Eastman W, Valsecchi S, Hettrick DA. Ventricular pacing lead location alters systemic hemodynamics and left ventricular function in patients with and without reduced ejection fraction. Journal of the American College of Cardiology. 2006;48:1634-1641

5. Tops LF, Schalij MJ, Holman ER, van Erven L, van der Wall EE, Bax JJ. Right ventricular pacing can induce ventricular dyssynchrony in patients with atrial fibrillation after atrioventricular node ablation. Journal of the American College of Cardiology. 2006;48:1642-1648

6. Vernooy K, Verbeek XA, Peschar M, Crijns HJ, Arts T, Cornelussen RN, Prinzen FW. Left bundle branch block induces ventricular remodelling and functional septal hypoperfusion. European heart journal. 2005;26:91-98

7. Vernooy K, Dijkman B, Cheriex EC, Prinzen FW, Crijns HJ. Ventricular remodeling during long-term right ventricular pacing following his bundle ablation. The American journal of cardiology. 2006;97:1223-1227

8. van Oosterhout MF, Prinzen FW, Arts T, Schreuder JJ, Vanagt WY, Cleutjens JP, Reneman RS. Asynchronous electrical activation induces asymmetrical hypertrophy of the left ventricular wall. Circulation. 1998;98:588-595

9. Sweeney MO, Hellkamp AS, Ellenbogen KA, Greenspon AJ, Freedman RA, Lee KL, Lamas GA. Adverse effect of ventricular pacing on heart failure and atrial fibrillation among patients with normal baseline qrs duration in a clinical trial of pacemaker therapy for sinus node dysfunction. Circulation. 2003;107:2932-2937

10. Wilkoff BL, Cook JR, Epstein AE, Greene HL, Hallstrom AP, Hsia H, Kutalek SP, Sharma A. Dual-chamber pacing or ventricular backup pacing in patients with an implantable defibrillator: The dual chamber and vvi implantable defibrillator (david) trial. Jama. 2002;288:3115-3123

11. Abraham WT, Fisher WG, Smith AL, Delurgio DB, Leon AR, Loh E, Kocovic DZ, Packer M, Clavell AL, Hayes DL, Ellestad M, Trupp RJ, Underwood J, Pickering F, Truex C, McAtee P, Messenger J. Cardiac resynchronization in chronic heart failure. The New England journal of medicine. 2002;346:1845-1853

12. Cleland JG, Daubert JC, Erdmann E, Freemantle N, Gras D, Kappenberger L, Tavazzi L. The effect of cardiac resynchronization on morbidity and mortality in heart failure. The New England journal of medicine 2005;352:1539-1549

13. Bristow MR, Saxon LA, Boehmer J, Krueger S, Kass DA, De Marco T, Carson P, DiCarlo L, DeMets D, White BG, DeVries DW, Feldman AM. Cardiac-resynchronization therapy with or without an implantable defibrillator in advanced chronic heart failure. The New England journal of medicine. 2004:350:2140-2150

14. Linde C, Abraham WT, Gold MR, St John Sutton M, Ghio S, Daubert C. Randomized trial of cardiac resynchronization in mildly symptomatic heart failure patients and in asymptomatic patients with left ventricular dysfunction and previous heart failure symptoms. Journal of the American College of Cardiology. 2008:52:1834-1843

15. Moss AJ, Hall WJ, Cannom DS, Klein H, Brown MW, Daubert JP, Estes NA, 3rd, Foster E, Greenberg H, Higgin SL, Pfeffer MA, Solomon SD, Wilber D, Zareba W. Cardiac-resynchronization therapy for the prevention of heart-failure events. The New England journal of medicine. 2009:361:1329-1338

16. Daubert JC, Saxon L, Adamson PB, Auricchio A, Berger RD, Beshai JF, Breithard O, Brignole M, Cleland $J$ Delurgio DB, Dickstein K, Exner DV, Gold M, Grimm RA, Hayes DL, Israel C, Leclercq C, Linde C, Lindenfeld Merkely B, Mont L, Murgatroyd F, Prinzen F, Saba SF, Shinbane JS, Singh J, Tang AS, Vardas PE, Wilkoff BL, Zamorano JL. 2012 ehra/hrs expert consensus statement on cardiac resynchronization therapy in heart failure: Implant and follow-up recommendations and management. Heart rhythm: the official journal of the Heart Rhythm Society. 2012;9:1524-1576 
17. Mills RW, Cornelussen RN, Mulligan LJ, Strik M, Rademakers LM, Skadsberg ND, van Hunnik A, Kuiper M Lampert A, Delhaas T, Prinzen FW. Left ventricular septal and left ventricular apical pacing chronically maintain cardiac contractile coordination, pump function and efficiency. Circ Arrhythm Electrophysiol. 2009;2:571-579

18. Strik M, Ploux S, Vernooy K, Prinzen FW. Cardiac resynchronization therapy: Refocus on the electrical substrate. Circ J. 2011;75:1297-1304

19. Gorcsan J, 3rd, Prinzen FW. Understanding the cardiac substrate and the underlying physiology: Implication for individualized treatment algorithm. Heart rhythm: the official journal of the Heart Rhythm Society. 2012;9:S18-26

20. Seo Y, Ito H, Nakatani S, Takami M, Naito S, Shiga T, Ando K, Wakayama Y, Aonuma K, investigators JC. The role of echocardiography in predicting responders to cardiac resynchronization therapy. Circ J. 2011; 75:1156-1163

21. Chung ES, Leon AR, Tavazzi L, Sun JP, Nihoyannopoulos P, Merlino J, Abraham WT, Ghio S, Leclercq C, Bax $J$ J, Yu CM, Gorcsan J, 3rd, St John Sutton M, De Sutter J, Murillo J. Results of the predictors of response to cr (prospect) trial. Circulation. 2008;117:2608-2616

22. Ruschitzka F, Abraham WT, Singh JP, Bax JJ, Borer JS, Brugada J, Dickstein K, Ford I, Gorcsan J, 3rd, Gras D, Krum H, Sogaard P, Holzmeister J, Echo CRTSG. Cardiac-resynchronization therapy in heart failure with narrow qrs complex. The New England journal of medicine. 2013;369:1395-1405

23. Gold MR, Thebault C, Linde C, Abraham WT, Gerritse B, Ghio S, St John Sutton M, Daubert JC. Effect of qrs duration and morphology on cardiac resynchronization therapy outcomes in mild heart failure: Results from the resynchronization reverses remodeling in systolic left ventricular dysfunction (reverse) study. Circulation. 2012;126:822-829

24. Zareba W, Klein H, Cygankiewicz I, Hall WJ, McNitt S, Brown M, Cannom D, Daubert JP, Eldar M, Gold MR, Goldberger JJ, Goldenberg I, Lichstein E, Pitschner H, Rashtian M, Solomon S, Viskin S, Wang P, Moss A Investigators $\mathrm{M}$-C. Effectiveness of cardiac resynchronization therapy by qrs morphology in the multicente automatic defibrillator implantation trial-cardiac resynchronization therapy (madit-crt). Circulation. 2011;123:1061-1072

25. Bilchick KC, Kamath S, DiMarco JP, Stukenborg GJ. Bundle-branch block morphology and other predictors of outcome after cardiac resynchronization therapy in medicare patients. Circulation. 2010;122:2022-2030

26. Peterson PN, Greiner MA, Qualls LG, Al-Khatib SM, Curtis JP, Fonarow GC, Hammill SC, Heidenreich PA, Hammill BG, Piccini JP, Hernandez AF, Curtis LH, Masoudi FA. Qrs duration, bundle-branch block morphology, and outcomes among older patients with heart failure receiving cardiac resynchronization therapy. Jama. 2013;310:617-626

27. Adelstein EC, Saba S. Usefulness of baseline electrocardiographic qrs complex pattern to predict response to cardiac resynchronization. The American journal of cardiology. 2009;103:238-242

28. Rickard J, Kumbhani DJ, Gorodeski EZ, Baranowski B, Wazni O, Martin DO, Grimm R, Wilkoff BL. Cardia resynchronization therapy in non-left bundle branch block morphologies. Pacing Clin Electrophysiol. 2010;33:590-595

29. Wokhlu A, Rea RF, Asirvatham SJ, Webster T, Brooke K, Hodge DO, Wiste HJ, Dong Y, Hayes DL, Cha YM. Upgrade and de novo cardiac resynchronization therapy: Impact of paced or intrinsic qrs morphology on outcomes and survival. Heart rhythm: the official journal of the Heart Rhythm Society. 2009;6:1439-1447

30. Ploux S, Lumens J, Whinnett Z, Montaudon M, Strom M, Ramanathan C, Derval N, Zemmoura A, Denis A, D Guillebon M, Shah A, Hocini M, Jais P, Ritter P, Haissaguerre M, Wilkoff BL, Bordachar P. Noninvasive electro cardiographic mapping to improve patient selection for cardiac resynchronization therapy: Beyond qrs duration and left bundle branch block morphology. Journal of the American College of Cardiology. 2013;61:2435-2443

31. Chandra R, Zolty R, Palma E. A left hemiblock improves cardiac resynchronization therapy outcomes in patients with a right bundle branch block. Clin Cardiol. 2010;33:89-93

32. Kandala J, Upadhyay GA, Altman RK, Parks KA, Orencole M, Mela T, Kevin Heist E, Singh JP. Qrs morphology, left ventricular lead location, and clinical outcome in patients receiving cardiac resynchronization therapy. European heart journal. 2013;34:2252-2262

33. Hara H, Oyenuga OA, Tanaka H, Adelstein EC, Onishi T, McNamara DM, Schwartzman D, Saba S, Gorcsan 3rd. The relationship of qrs morphology and mechanical dyssynchrony to long-term outcome following cardiac resynchronization therapy. European heart journal. 2012;33:2680-2691

34. Liu L, Tockman B, Girouard S, Pastore J, Walcott G, KenKnight B, Spinelli J. Left ventricular resynchronization therapy in a canine model of left bundle branch block. American journal of physiology. Heart and circulatory physiology. 2002;282:H2238-2244

35. Vernooy K, Cornelussen RN, Verbeek XA, Vanagt WY, van Hunnik A, Kuiper M, Arts T, Crijns HJ, Prinzen FW. Cardiac resynchronization therapy cures dyssynchronopathy in canine left bundle-branch block hearts. European heart journal. 2007;28:2148-2155

36. Gold MR, Birgersdotter-Green U, Singh JP, Ellenbogen KA, Yu Y, Meyer TE, Seth M, Tchou PJ. The relationship between ventricular electrical delay and left ventricular remodelling with cardiac resynchronization therapy. European heart journal. 2011;32:2516-2524

37. Singh JP, Fan D, Heist EK, Alabiad CR, Taub C, Reddy V, Mansour M, Picard MH, Ruskin JN, Mela T. Left ventricular lead electrical delay predicts response to cardiac resynchronization therapy. Heart rhythm the official journal of the Heart Rhythm Society. 2006;3:1285-1292

38. Zanon F, Baracca E, Pastore G, Fraccaro C, Roncon L, Aggio S, Noventa F, Mazza A, Prinzen F. Determination of the longest intrapatient left ventricular electrical delay may predict acute hemodynamic improvement in patients after cardiac resynchronization therapy. Circ Arrhythm Electrophysiol. 2014;7:377-383

39. Ypenburg C, van Bommel RJ, Delgado V, Mollema SA, Bleeker GB, Boersma E, Schalij MJ, Bax JJ. Optimal left ventricular lead position predicts reverse remodeling and survival after cardiac resynchronization therapy. Journal of the American College of Cardiology. 2008;52:1402-1409

40. Gold MR, Leman RB, Wold N, Sturdivant JL, Yu Y. The effect of left ventricular electrical delay on the acute hemodynamic response with cardiac resynchronization therapy. Journal of cardiovascular electrophysiology. 2014;25:624-630

41. Becker M, Franke A, Breithardt OA, Ocklenburg C, Kaminski T, Kramann R, Knackstedt C, Stellbrink C Hanrath P, Schauerte P, Hoffmann R. Impact of left ventricular lead position on the efficacy of cardiac resynchronisation therapy: A two-dimensional strain echocardiography study. Heart. 2007;93:1197-1203

42. Khan FZ, Virdee MS, Palmer CR, Pugh PJ, O'Halloran D, Elsik M, Read PA, Begley D, Fynn SP, Dutka DP. Targeted left ventricular lead placement to guide cardiac resynchronization therapy: The target study: $A$ randomized, controlled trial. Journal of the American College of Cardiology. 2012;59:1509-1518

43. Saba S, Marek J, Schwartzman D, Jain S, Adelstein E, White P, Oyenuga OA, Onishi T, Soman P, Gorcsan J, 3rd. Echocardiography-guided left ventricular lead placement for cardiac resynchronization therapy: Results of the speckle tracking assisted resynchronization therapy for electrode region trial. Circulation. Heart failure. 2013;6:427-434

44. Fung JW, Yu CM, Yip G, Zhang Y, Chan H, Kum CC, Sanderson JE. Variable left ventricular activation pattern in patients with heart failure and left bundle branch block. Heart. 2004;90:17-19

45. Rodriguez LM, Timmermans C, Nabar A, Beatty G, Wellens HJ. Variable patterns of septal activation in patients with left bundle branch block and heart failure. Journal of cardiovascular electrophysiology. 2003;14:135-141

46. Auricchio A, Fantoni C, Regoli F, Carbucicchio C, Goette A, Geller C, Kloss M, Klein H. Characterization of left ventricular activation in patients with heart failure and left bundle-branch block. Circulation 2004;109:1133-1139

47. Lambiase PD, Rinaldi A, Hauck J, Mobb M, Elliott D, Mohammad S, Gill JS, Bucknall CA. Non-contact left ventricular endocardial mapping in cardiac resynchronisation therapy. Heart. 2004;90:44-51

48. Ansalone G, Giannantoni P, Ricci R, Trambaiolo P, Fedele F, Santini M. Doppler myocardial imaging to evaluate the effectiveness of pacing sites in patients receiving biventricular pacing. Journal of the American College of Cardiology. 2002;39:489-499 
49. Becker M, Altiok E, Ocklenburg C, Krings R, Adams D, Lysansky M, Vogel B, Schauerte P, Knackstedt C Hoffmann R. Analysis of Iv lead position in cardiac resynchronization therapy using different imaging modalities. JACC Cardiovasc Imaging. 2010;3:472-481

50. Becker M, Kramann R, Franke A, Breithardt OA, Heussen N, Knackstedt C, Stellbrink C, Schauerte P, Kelm M Hoffmann R. Impact of left ventricular lead position in cardiac resynchronization therapy on left ventricular remodelling. A circumferential strain analysis based on $2 \mathrm{~d}$ echocardiography. European heart journal. 2007;28:1211-1220

51. Boogers MJ, Chen J, van Bommel RJ, Borleffs CJ, Dibbets-Schneider P, van der Hiel B, Al Younis I, Schalij MJ van der Wall EE, Garcia EV, Bax JJ. Optimal left ventricular lead position assessed with phase analysis on gated myocardial perfusion spect. Eur J Nucl Med Mol Imaging. 2011;38:230-238

52. Fung JW, Chan JY, Yip GW, Chan HC, Chan WW, Zhang Q, Yu CM. Effect of left ventricular endocardial activation pattern on echocardiographic and clinical response to cardiac resynchronization therapy. Heart. 2007;93:432-437

53. Fujiwara R, Yoshida A, Fukuzawa K, Takei A, Kiuchi K, Itoh M, Imamura K, Suzuki A, Nakanishi T, Yamashita S, Matsumoto A, Tanaka H, Hirata KI. Discrepancy between electrical and mechanical dyssynchrony in patients with heart failure and an electrical disturbance. Pacing Clin Electrophysiol. 2013

54. Suever JD, Hartlage GR, Magrath RP, 3rd, Iravanian S, Lloyd MS, Oshinski JN. Relationship between mechanical dyssynchrony and intra-operative electrical delay times in patients undergoing cardiac resynchronization therapy. Journal of cardiovascular magnetic resonance: official journal of the Society for Cardiovascular Magnetic Resonance. 2014;16:4

55. Ludwig DR, Tanaka H, Friehling M, Gorcsan J, 3rd, Schwartzman D. Further deterioration of Iv ejection fraction and mechanical synchrony during $\mathrm{rv}$ apical pacing in patients with heart failure and lbbb. Journal of cardiovascular translational research. 2013:6:425-429

56. Prinzen FW, Peschar M. Relation between the pacing induced sequence of activation and left ventricular pump function in animals. Pacing Clin Electrophysiol. 2002;25:484-498

57. Janousek J, van Geldorp IE, Krupickova S, Rosenthal E, Nugent K, Tomaske M, Fruh A, Elders J, Hiippala A, Kerst G, Gebauer RA, Kubus P, Frias P, Gabbarini F, Clur SA, Nagel B, Ganame J, Papagiannis J, Marek Tisma-Dupanovic S, Tsao S, Nurnberg JH, Wren C, Friedberg M, de Guillebon M, Volaufova J, Prinzen FW, Delhaas T. Permanent cardiac pacing in children: Choosing the optimal pacing site: A multicenter study. Circulation. 2013;127:613-623

58. de Cock CC, Giudici MC, Twisk JW. Comparison of the haemodynamic effects of right ventricular outflow-trac pacing with right ventricular apex pacing: A quantitative review. Europace. 2003;5:275-278

59. Occhetta E, Bortnik M, Magnani A, Francalacci G, Piccinino C, Plebani L, Marino P. Prevention of ventricular desynchronization by permanent para-hisian pacing after atrioventricular node ablation in chronic atria fibrillation: A crossover, blinded, randomized study versus apical right ventricular pacing. Journal of the American College of Cardiology. 2006;47:1938-1945

American College of Cardiology. 2006; $47: 1938-1945$
60. Hirao K, Otomo K, Wang X, Beckman KJ, McClelland JH, Widman L, Gonzalez MD, Arruda M, Nakagawa H Lazzara R, Jackman WM. Para-hisian pacing. A new method for differentiating retrograde conduction over an accessory av pathway from conduction over the av node. Circulation. 1996;94:1027-1035

61. Deshmukh P, Casavant DA, Romanyshyn M, Anderson K. Permanent, direct his-bundle pacing: A nove approach to cardiac pacing in patients with normal his-purkinie activation. Circulation. 2000101:869-877

62. Zanon F, Bacchiega E, Rampin L, Aggio S, Baracca E, Pastore G, Marotta T, Corbucci G, Roncon L, Rubello D, Prinzen FW. Direct his bundle pacing preserves coronary perfusion compared with right ventricular apica pacing: A prospective, cross-over mid-term study. Europace. 2008;10:580-587

63. Peschar M, de Swart H, Michels KJ, Reneman RS, Prinzen FW. Left ventricular septal and apex pacing for optima pump function in canine hearts. Journa of the American College of Cardiology. 2003:41:1218-1226 Effect of right ventricular pacing lead site on left ventricular function in patients with high-grade atrioventricular block: Results of the protect-pace study. European heart journal. 2015;36:856-862
65. Kronborg MB, Mortensen PT, Gerdes JC, Jensen HK, Nielsen JC. His and para-his pacing in av block: Feasibility and electrocardiographic findings. Journal of interventional cardiac electrophysiology: an internationa journal of arrhythmias and pacing. 2011;31:255-262 


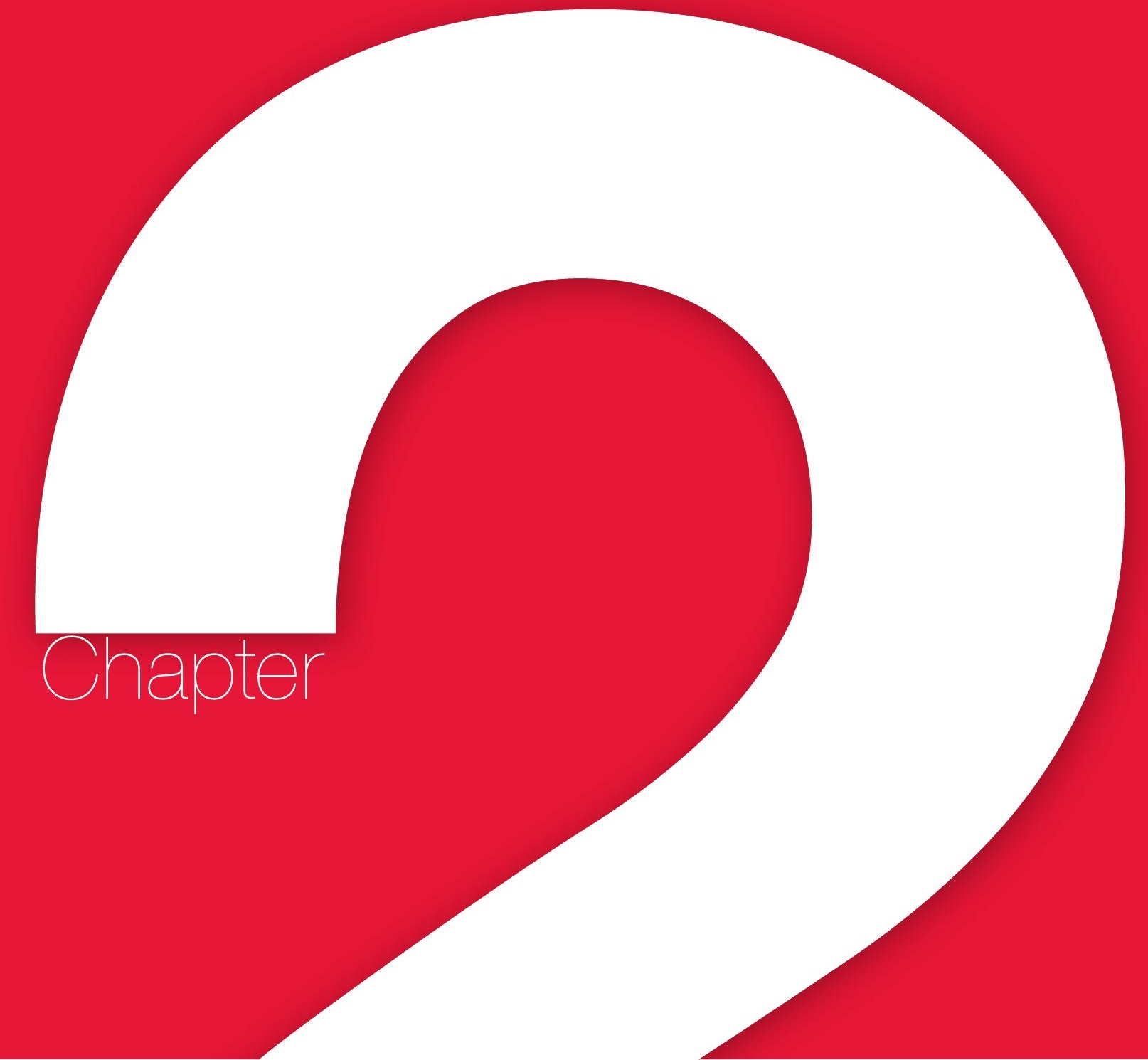

\section{Left ventricular lead placement in the latest activated region guided by coronary venous electroanatomic mapping}

Masih Mafi Rad, Yuri Blaauw, Trang Dinh, Laurent Pison, Harry J. Crijns, Frits W. Prinzen, Kevin Vernooy 


\section{Abstract}

Aim: Left ventricular (LV) lead placement in the latest activated region is an important determinant of response to cardiac resynchronization therapy (CRT). We investigated the feasibility of coronary venous electroanatomic mapping (EAM) to guide LV lead placement to the latest activated region.

Methods: Twenty-five consecutive CRT candidates with left bundle-branch block underwent intra-procedural coronary venous EAM using EnSite NavX. A guidewire was used to map the coronary veins during intrinsic activation, and to test for phrenic nerve stimulation (PNS)

Results: The latest activated region, defined as the region with an electrical delay $>75 \%$ of total QRS duration, was located anterolaterally in 18 (basal, $n=10$; mid, $n=8$ ) and inferolaterally in 6 (basal, $n=3$; mid, $n=3$ ). In 1 patient, identification of the latest activated region was impeded by limited coronary venous anatomy. In patients with $>1$ target vein $(n=12)$, the anatomically targeted inferolateral vein was rarely the vein with maximal electrical delay $(n=3)$. A concordant LV lead position was achieved in 18 of 25 patients. In 6 patients, this was hampered by PNS $(n=4)$, lead instability $(n=1)$ and coronary vein stenosis $(n=1)$

Conclusion: Coronary venous EAM can be used intraprocedurally to guide LV lead placement to the latest activated region free of PNS. This approach especially contributes to optimization of LV lead electrical delay in patients with multiple target veins. Conventional anatomical LV lead placement strategy does not target the vein with maximal electrical delay in many of these patients.

\section{Introduction}

Cardiac resynchronization therapy (CRT) reduces morbidity and mortality and reverses left ventricular (LV) remodeling in heart failure patients with LV systolic impairment and electrical dyssynchrony..$^{1-3}$ Despite the striking effectiveness of CRT, a substantial proportion of apparently eligible patients fail to benefit. ${ }^{4}$ Part of this reduced benefit has been attributed to a suboptimal LV lead position. ${ }^{4}$ There is increasing evidence to suggest that positioning of the LV lead in the region of latest electrical activation provides superior clinical outcome. ${ }^{5,6}$ The conventional LV lead placement strategy involves an anatomical approach, targeting a coronary venous branch situated on the posterolateral wall. This strategy is based on the contention that the posterolateral wall is typically the latest activated site of the ventricle in patients with left bundle-branch block (LBBB). However, studies have shown a considerable variability in the ventricular activation pattern in LBBB, resulting in inter-individual variability in the optimal pacing site. ${ }^{8-10}$ Therefore a more patient-specific physiological approach focused on achieving maximal LV lead electrica delay may improve CRT response. Electroanatomic mapping (EAM) is typically used in the electrophysiology lab to guide diagnostic or ablation procedures of cardiac arrhythmias. Recently, the technique has also been applied during CRT implantation to determine the electrical activation pattern of the coronary venous system.11, 12 Final LV lead position, however, depends on several factors such as cardiac venous anatomy, performance and stability of the lead and the absence of phrenic nerve stimulation (PNS). The feasibility of coronary venous EAM to guide LV lead placement to the latest activated region during CRT implantation remains to be assessed. The aim of the present study was to assess the feasibility of positioning the LV lead in the latest activated region guided by coronary venous EAM in patients undergoing CRT implantation.

\section{Methods}

Population

From December 2012 to May 2013, consecutive patients referred for CRT device implantation, with LV ejection fraction (LVEF) $<35 \%$, New York Heart Association (NYHA) functional class 2, 3 or ambulatory 4, and LBBB according to ESC guidelines, ${ }^{13}$ were prospectively enrolled. The study complied with the declaration of Helsinki. Our locally appointed ethics committee approved the study protocol and waived the need for informed consent.

\section{Electroanatomic mapping and LV lead placement}

All patients underwent intraprocedural coronary venous three-dimensional (3D) EAM using EnSite NavX (St. Jude Medical). Prior to LV lead placement, an occlusive coronary venogram was recorded under fluoroscopy in right anterior oblique (RAO) and left anterior oblique (LAO) view for optimal visualization of the coronary veins. Subsequently a 0.014 inch quidewire (Vision Wire, Biotronik SE \& Co.KG) was inserted into the coronary sinus (CS) and connected to EnSite NavX along with the surface electrocardiogram (ECG). This guidewire has complete polyethylene isolation except for $15 \mathrm{~mm}$ at the distal "J"-shaped tip and $30 \mathrm{~mm}$ at the proximal end permitting unipolar sensing and pacing. ${ }^{14}$ The guidewire was used to map all target veins located on the anterolateral or inferolateral LV wall as defined by the American Heart Association (AHA) 17-segment heart model. ${ }^{15} \mathrm{~A} 3 \mathrm{D}$ electrical activation map was constructed during intrinsic ventricular activation. Electrical delay was measured in milliseconds $(\mathrm{ms})$ from QRS onset on the surface ECG to the peak negative slope on the unipolar intra-cardiac electrogram (EGM) and expressed as a percentage of total QRS duration. All measurements were performed in EnSite NavX at a screen speed of $400 \mathrm{~mm} / \mathrm{s}$. The latest activated region of the LV was defined 
as the region with an electrical delay comprising $>75 \%$ of total QRS duration. This definition was chosen because epicardial mapping via the coronary veins is limited by coronary venous anatomy, which means that some areas cannot be mapped because they do not contain any veins. Therefore, the latest activated LV region can only be identified using coronary venous mapping by relating the electrical activation time of the anatomic region to its timepoint within the QRS complex. Candidate pacing sites were tested for PNS by $10 \mathrm{~V}$ unipolar pacing on the tip of the guidewire and regions with PNS or absence thereof were annotated on the EAM using EnSite NavX. After the mapping procedure, the LV lead was connected to EnSite NavX for real-time

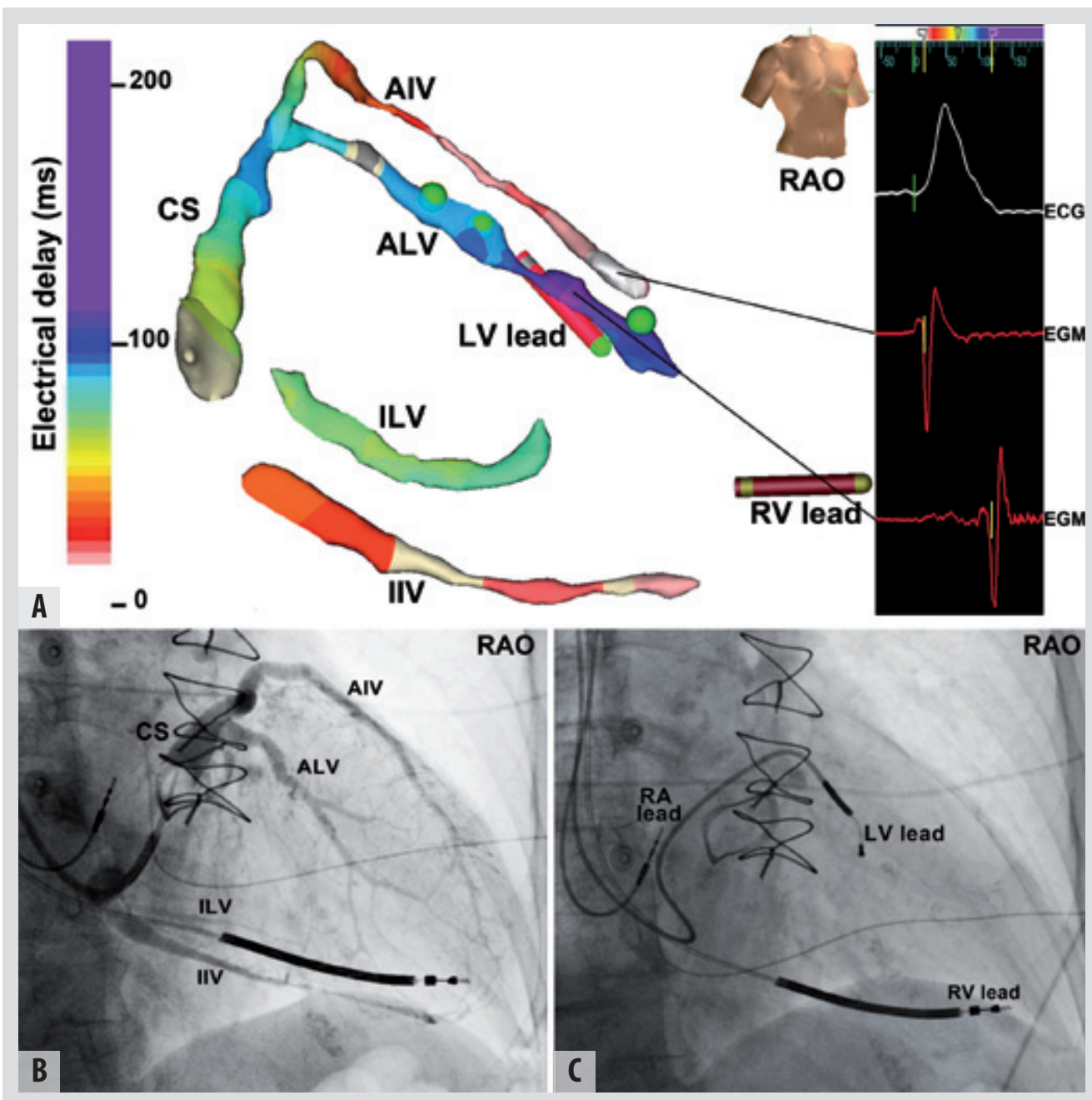

Figure 1. (A) Coronary venous EAM of a patient during intrinsic ventricular activation together with the corresponding unipolar EGMs collected from the regions of earliest and latest activation. The $\mathrm{CS}$ and all side branches have been mapped and the anterolateral vein has been tested for PNS. Connecting the LV lead to EnSite NavX allowed real-time visualization and navigation of the lead to the latest activated region in the electroanatomic map. (B) Corresponding coronary venogram. (C) X-ray of final LV lead placement. AIV, anterior inter-ventricular vein; ALV, anterolateral vein; CS, coronary sinus; IIV, inferior inter-ventricular vein; ILV, inferolateral vein; RV, right ventricular; RA, right atrial; Red dot, PNS; Green dot, no PNS.

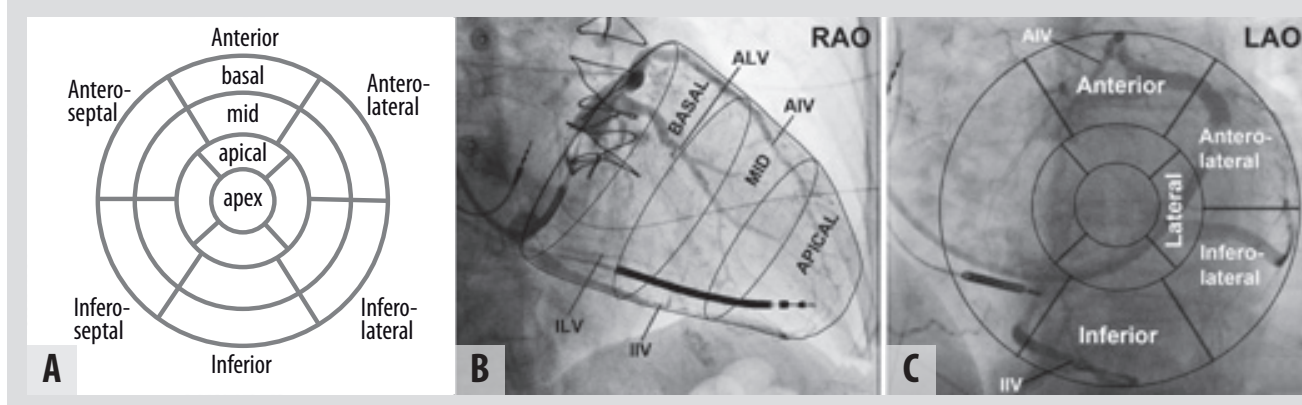

Figure 2. Angiographic classification of the latest activated region and final LV lead position. (A) The AHA standardized 17-segment heart model, adapted from Cerqueira et al. ${ }^{15}$ (B) Coronary venogram in RA0. This view, representative of the long axis of the heart, was used to classify the latest activated region and final LV lead position into basal, mid-ventricular, and apical segments. (C) Coronary venogram in LAO. This view, comparable to the short axis of the heart, was used to divide the LV wall into four equal parts; anterior, anterolateral, inferolateral and inferior. AIV, anterior inter-ventricular vein; ALV, anterolateral vein; IIV, inferior inter-ventricular vein; ILV, inferolateral vein.

visualization and navigation of the lead to the latest activated region free of PNS in the created EAM. Standard bipolar leads of various vendors were used. Figure 1 shows an example of a coronary venous EAM together with the results of PNS testing and the final LV lead position. The latest activated region and final LV lead position were classified according to the AHA 17-segments heart model by detailed evaluation of pre-implantation venograms and postimplantation LV lead fluoroscopy images (Figure 2). The final LV lead position was described as concordant if the lead was located in the same myocardial segment as the latest activated region.

\section{Statistical analysis}

Continuous variables are expressed as mean \pm SD. Categorical variables are expressed as observed number and percentage values. Continuous variables were compared using Mann-Whitney U test. Statistical significance was accepted at the $95 \%$ confidence interval $(\mathrm{P}<0.05)$. Statistical analysis was performed using SPSS version 20.0 (SPSS Inc.) software.

\section{Results}

Patient characteristics

Twenty-five consecutive patients with LBBB referred for CRT device implantation were included in this study. The patient characteristics are described in Table 1.

\section{CRT implantation}

In 21 patients a de novo CRT defibrillator was implanted. Two patients were upgraded from an Implantable cardioverter-defibrillator to a CRT defibrillator and 2 patients received a CRT pacemaker. LV lead implantation was successful in all patients. There were no procedural complications.

\section{Coronary venous electroanatomic mapping}

In all patients, occlusive coronary venography revealed at least one target vein on the anterolateral or inferolateral LV wall. In 12 of 25 patients, 2 target veins were available. All target veins were successfully mapped. Three-dimensional electrical activation maps were generated from an 


\section{Table 1. Patient characteristics $(n=25)$}

\begin{tabular}{|l|l|}
\hline Age, years & $72 \pm 6$ \\
\hline Male gender $(n, \%)$ & $14(56)$ \\
\hline Ischemic heart disease $(n, \%)$ & $8(32)$ \\
\hline NYHA functional class $(n, \%)$ & $11(44)$ \\
\hline II & $14(56)$ \\
\hline III & \\
\hline Echocardiography characteristics & $27 \pm 5$ \\
\hline$\quad$ LV ejection fraction $(\%)$ & $59 \pm 4$ \\
\hline LV end-diastolic diameter $(\mathrm{mm})$ & $55 \pm 5$ \\
\hline LV end-systolic diameter $(\mathrm{mm})$ & $146 \pm 30$ \\
\hline LV end-diastolic volume $(\mathrm{mL})$ & $107 \pm 24$ \\
\hline LV end-systolic volume $(\mathrm{mL})$ & \\
\hline ECG characteristics & $25(100)$ \\
\hline LBBB $(n, \%)$ & $154 \pm 15$ \\
\hline QRS duration $(\mathrm{ms})$ & \\
\hline Intrinsic rhythm $(n, \%)$ & $22(88)$ \\
\hline Sinus rhythm & $3(12)$ \\
\hline Atrial fibrillation & \\
\hline Treatment $(n, \%)$ & $17(68)$ \\
\hline Diuretics & $24(96)$ \\
\hline ACE-i/ARB & $22(88)$ \\
\hline Beta-blockers & $15(60)$ \\
\hline Spironolactone & $1(4)$ \\
\hline Digoxin & $3(12)$ \\
\hline Amiodarone & \\
\hline
\end{tabular}

ACE-I, angiotensin converting enzyme inhibitor; ARB, angiotensin receptor blocker.

average of $46 \pm 28$ unique anatomic points. Mapping time was $19 \pm 6 \mathrm{~min}$ and fluoroscopy time during the entire procedure $20 \pm 6 \mathrm{~min}$. Figure 3 shows the distribution of the latest activated regions in all patients. The latest activated region was located anterolaterally in 18 (basal, $n=10$; mid, $n=8$ ) and inferolaterally in 6 (basal, $n=3$; mid, $n=3$ ). In 1 patient (No. 7), identification of the latest activated region was impeded by limited coronary venous anatomy.

\section{LV lead placement}

Figure 4 shows the distribution of the final LV lead position in all patients. The LV lead was positioned anterolaterally in 16 (basal, $n=9$; mid, $n=7$ ) and inferolaterally in 9 (basal, $n=4$; mid, $n=5)$. The final LV lead position was concordant with the latest activated region in 18 of 25 patients. In 6 patients, concordant LV lead placement was hampered by PNS ( $n=4$, one of them depicted in Figure 5), lead instability $(n=1)$ and coronary vein stenosis $(n=1)$. In the patient in whom the latest activated region could not be identified (No. 7), the LV lead was positioned at the site where maximal electrical delay was measured with coronary venous EAM. An overview of the latest activated regions and final LV lead positions of all patients together with the corresponding electrical delays at these sites is provided in Table 2. In patients with a concordant LV lead position, electrical delay was $132 \pm 15 \mathrm{~ms}$ ( $85 \pm 6 \%$ of QRS duration) at the latest activated region and $128 \pm 13 \mathrm{~ms}(83 \pm 5 \%$ of QRS duration) at the final lead position ( $P=0.17$ ). In patients with a discordant LV lead position electrical delay was $125 \pm 10 \mathrm{~ms}(84 \pm 3 \%$ of QRS duration) at the latest activated region and $94 \pm 15 \mathrm{~ms}$ ( $63 \pm 7 \%$ of QRS duration) at the final lead position $(P=0.002)$. LV lead electrical delay was significantly longer in patients with a concordant compared to patients with a discordant LV lead position $(P<0.001)$.

In 9 of 12 patients with 2 available target veins (Nos. 1, 11, 12, 13, 14, 15, 18, 23, and 24) the latest activated region was located in a different vein than the anatomically targeted inferolateral vein (Table 2). In these patients, maximal electrical delay was $89 \pm 14 \mathrm{~ms}$ (58 $\pm 6 \%$ of QRS duration) in the anatomically targeted vein vs. $133 \pm 15 \mathrm{~ms}(87 \pm 5 \%$ of QRS duration) at the latest activated region $(P<0.001)$. The LV lead was positioned in the latest activated region in 7 of 9 patients (Nos. 1, 11 $12,14,15,23$, and 24). In these patients, maxima electrical delay was $89 \pm 16 \mathrm{~ms}(57 \pm 7 \%$ of QRS duration) in the anatomically targeted vein vs. $131 \pm 14 \mathrm{~ms}(85 \pm 4 \%$ of $Q R S$ duration) at the final LV lead position $(P=0.001)$. In the other 2 patients (Nos. 13 and 18), coronary vein stenosis and PNS hampered concordant LV lead placement. Figure 6 illustrates the additional value of mapping-guided LV lead placement as compared with the conventional anatomical LV lead placement approach. In this example, the coronary venous EAM of patient no. 24 is shown where a pure anatomical

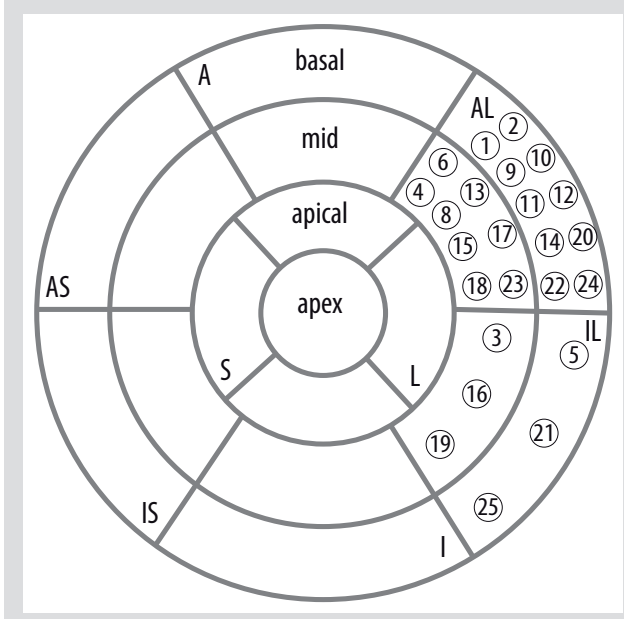

Figure 3. Distribution of the latest activated region. Each circled number represents a patient. Numbers refer to the order of inclusion. The latest activated region was mainly located on the anterolateral LV wall. In one patient ( $N$ o. 7) the latest activated region could not be identified by coronary venous EAM due to limited coronary venous anatomy A, anterior; AL, anterolateral; $\mathrm{AS}$, anteroseptal; I, inferior; IL, inferolateral; IS, inferoseptal; L, lateral; S, septal.

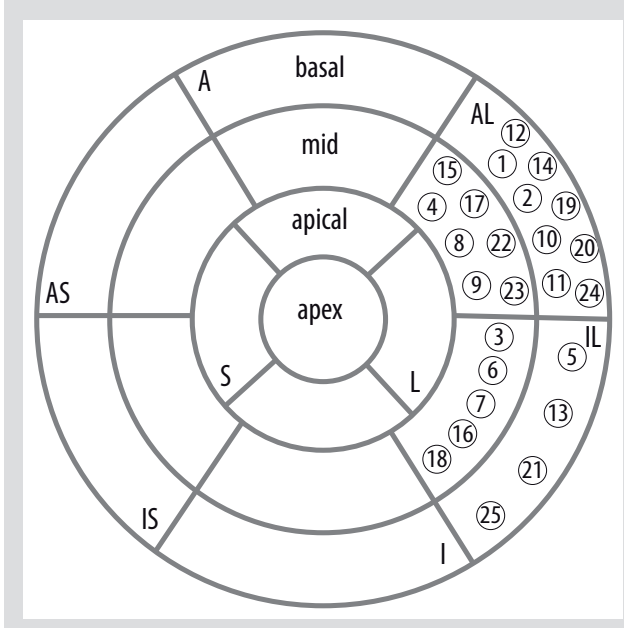

Figure 4. Distribution of the final LV lead position. Each circled number represents a patient. Numbers refer to the order of inclusion and correspond with the numbers in Figure 3 . $A$, anterior; AL, anterolateral; AS, anteroseptal; I, inferior; IL, inferolateral; IS, inferoseptal; L, lateral; S, septal. 
approach would have resulted in a suboptimal LV lead position in the inferolateral vein with maximal electrical delay of only $90 \mathrm{~ms}$. However, additional mapping of the small anterolatera vein resulted in a potentially far better LV lead position with an electrical delay close to $140 \mathrm{~ms}$.

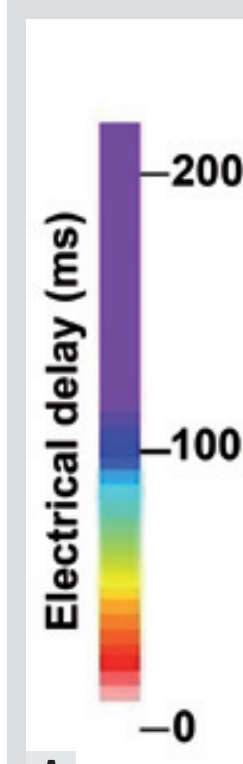

A

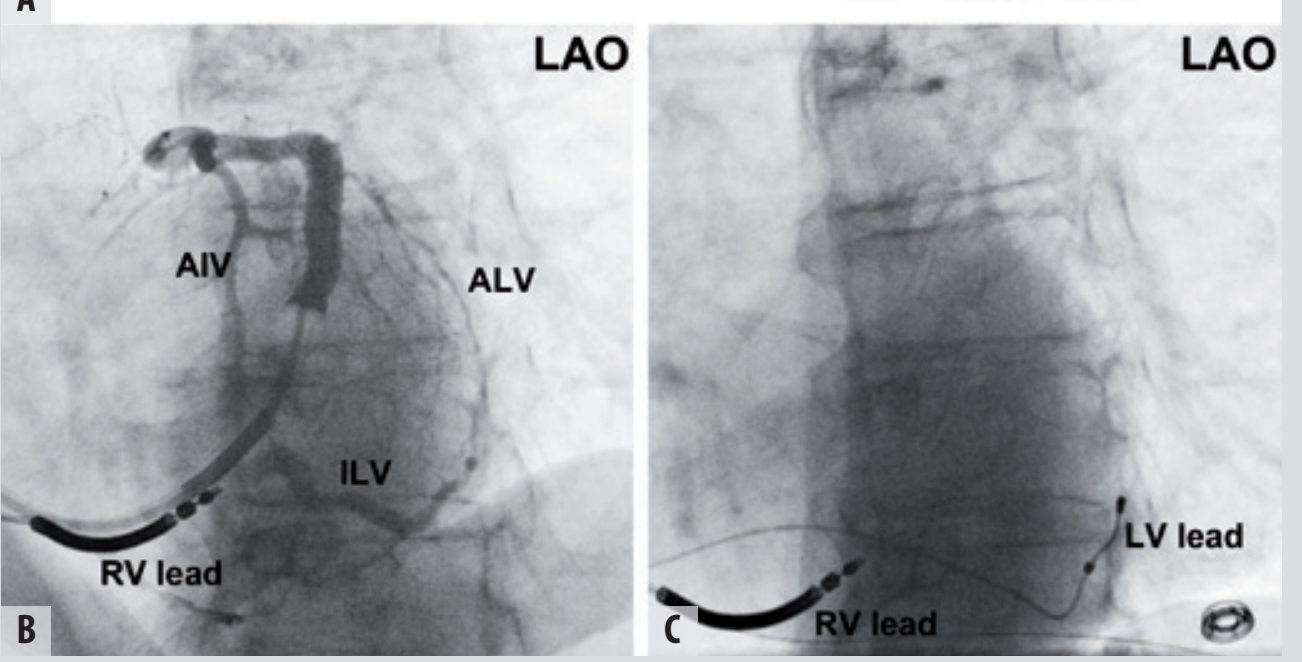

Figure 5. (A) Coronary venous $3 \mathrm{D}$ electrical activation map during intrinsic ventricular activation of a patient in whom PNS hampered placement of the LV lead in the latest activated region. Mapping of the anterolateral and inferolateral vein revealed the latest activated region at the mid-anterolateral LV wall. Unfortunately this was also a region with PNS. The LV lead was eventually placed as close as possible to the latest activated region and pacing was performed at the ring of the LV lead, which in contrast to the tip still offered some space between ventricular capture and PNS. (B) Corresponding coronary venogram. (C) X-ray of final LV lead placement. Red dot, PNS; Green dot, no PNS; R, LV lead ring; T, LV lead tip. AIV, anterior inter-ventricular vein; ALV, anterolateral vein; IIV, inferior inter-ventricular vein; ILV, inferolateral vein; RV, right ventricular.

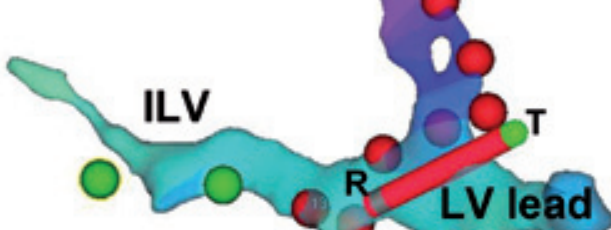

AO
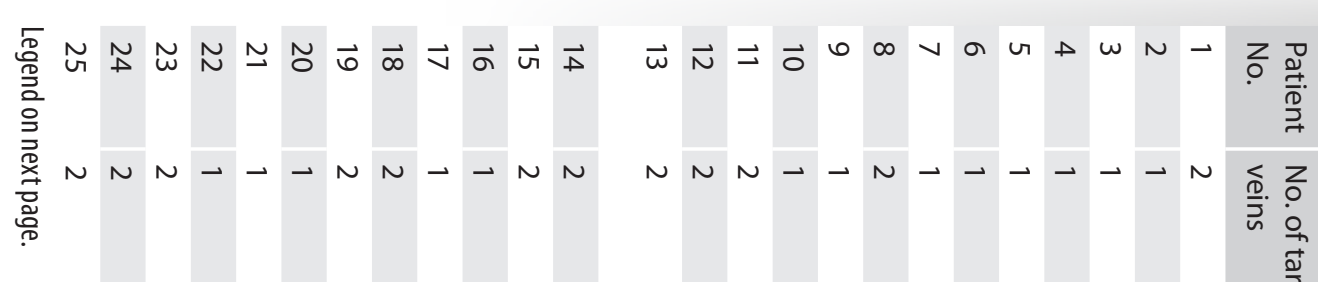

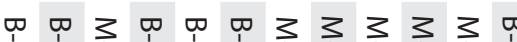

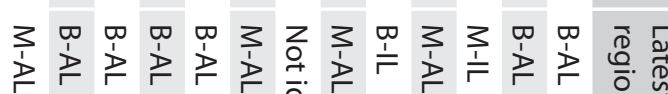
i)

票

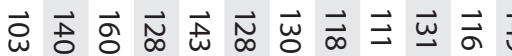

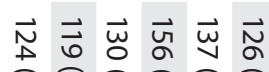

$\vec{\sigma} \underset{\underline{\omega}}{\vec{\omega}} \vec{N} \vec{\sim} \vec{\omega} \quad \frac{m}{D}$

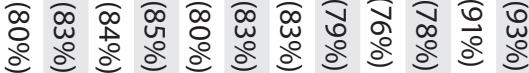

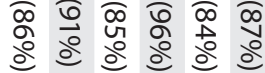

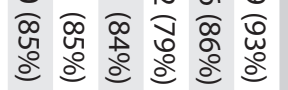

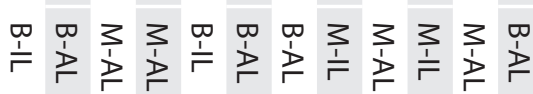

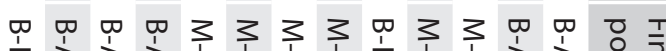

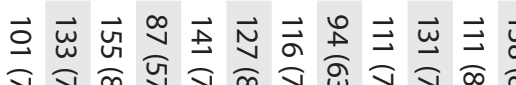

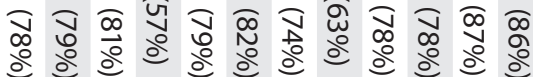

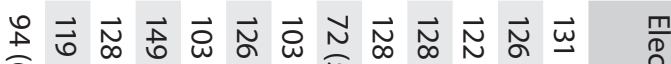

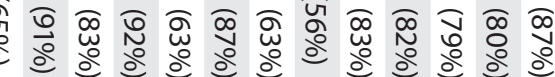

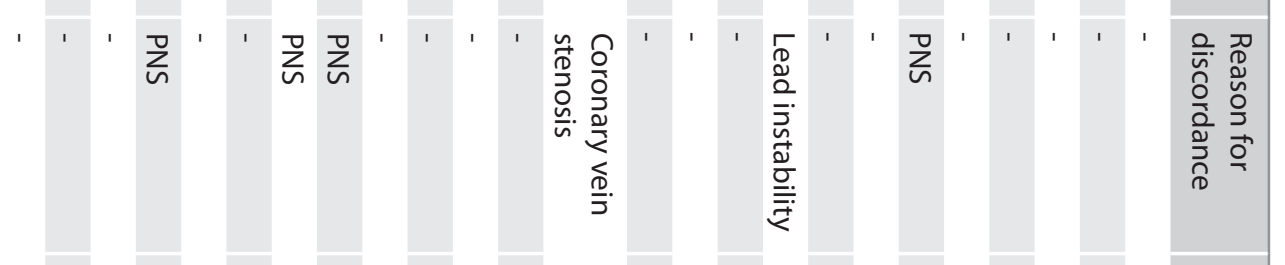

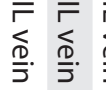
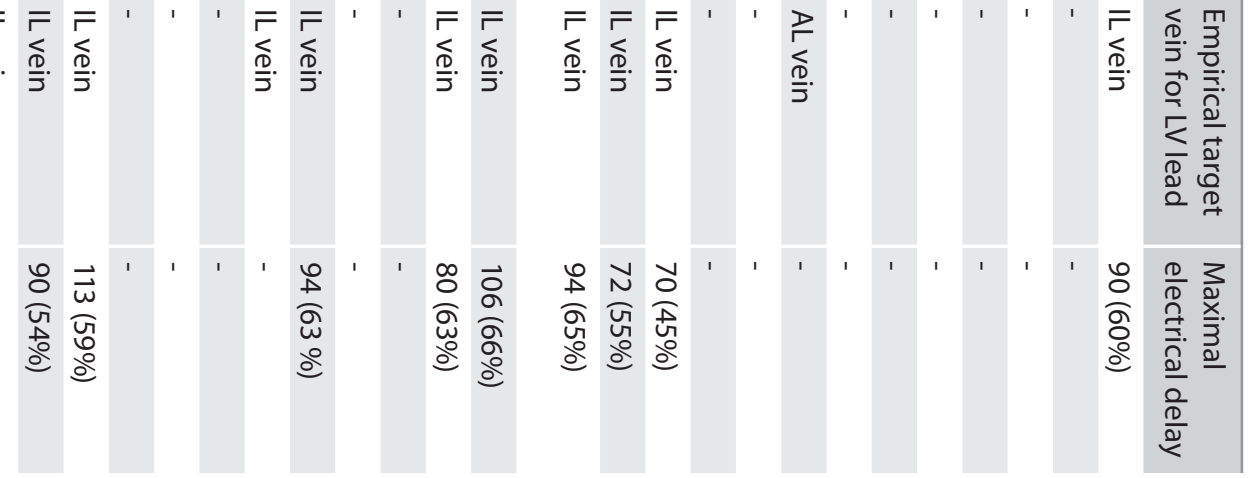
Legend of Table 2: Patient numbers correspond with the numbers provided in Figure 3 and 4 . Electrical delay is reported in ms (percentage of total ORS duration). In patient №. 6, the anterolateral vein anastomosed with the inferior inter-ventricular vein, which made it possible to position the LV lead inferolaterally (via the anastomosis) despite the patient having only one target vein on the anterolateral LV wall. In patient No. 7, identification of the latest activated region was impeded by limited coronary venous anatomy. Patient No. 8 had 2 target veins on the anterolateral wall. For patients with 2 target veins, the second column from the right reports the target vein for the LV lead if the conventional anatomical lead placement approach would be used. The right-most column provides the maximal electrical delay measured within that vein. B, basal; M, mid; $\mathrm{AL}$, anterolateral; $\mathrm{L}$, inferolateral; PNS, phrenic nerve stimulation.

\section{Discussion}

Pacing at the latest activated region of the LV appears to improve the outcome of CRT. The present study demonstrates that coronary venous EAM using EnSite NavX in combination with a mapping guidewire can be used intraprocedurally to guide LV lead placement to the region of latest electrical activation. In addition, the potential of this mapping approach to facilitate comprehensive identification of regions free of PNS is demonstrated.

\section{Targeted LV lead placement at the latest activated LV region}

Several studies have investigated the relationship between pacing in the region of latest activation and the response to CRT. Studies on mechanical activation suggest superior CRT outcome when the LV lead position coincides with the region of latest mechanical contraction compared with discordant positions. ${ }^{16-21}$ Two recent prospective single-center trials randomized a total of 407 patients to speckle-tracking echocardiography-guided LV lead placement targeting the site of latest mechanical activation or to standard unguided LV lead placement. In both trials, patients with an LV lead position concordant with the site of latest activation had a higher echocardiographic response rate, more clinical responders, and a reduced risk of mortality and heart failure hospitalization. ${ }^{22,23}$ Studies focusing on the electrical activation pattern have demonstrated that a greater delay in time from onset of the QRS complex to the local sensed LV lead EGM (Q-LV) is also associated with a greater likelihood of benefit from CRT. ${ }^{24,25}$ Recently, Zanon et al. measured the Q-LV interval of various pacing sites within patients, and evaluated the hemodynamic effect of pacing at the different sites by invasive measurement of LVdP/dtmax. Pacing the LV at the latest activated site resulted in greatest hemodynamic improvement. ${ }^{6}$ The choice between targeting the region of latest electrical or latest mechanical activation is still a matter of debate and definitive randomized trials that support the use of either approach to reliably select an optimal LV pacing site are lacking. Accordingly, current ESC guidelines have assigned a class $2 \mathrm{~b}$ indication to targeted LV lead placement at the latest activated LV segment.? A slightly stronger recommendation (class 2a) has been assigned to avoiding an apical LV lead position ${ }^{7}$ despite conflicting results in the literature. ${ }^{26-29}$ Therefore, larger prospective studies are required to settle the issue of whether pacing the latest activated LV region provides the best outcome of CRT.

While the position of the LV lead with respect to the site of latest activation is a factor that can influence CRT response, several studies have shown that the proximity of the LV lead to an area with myocardial scar is an important factor as well. ${ }^{30-34}$ Assessment of scar tissue should therefore be considered before CRT, especially in the population with ischemic heart disease. Integrating information obtained from scar imaging with measurements of electrical and mechanical delay may further optimize LV lead positioning and the clinical response rate.

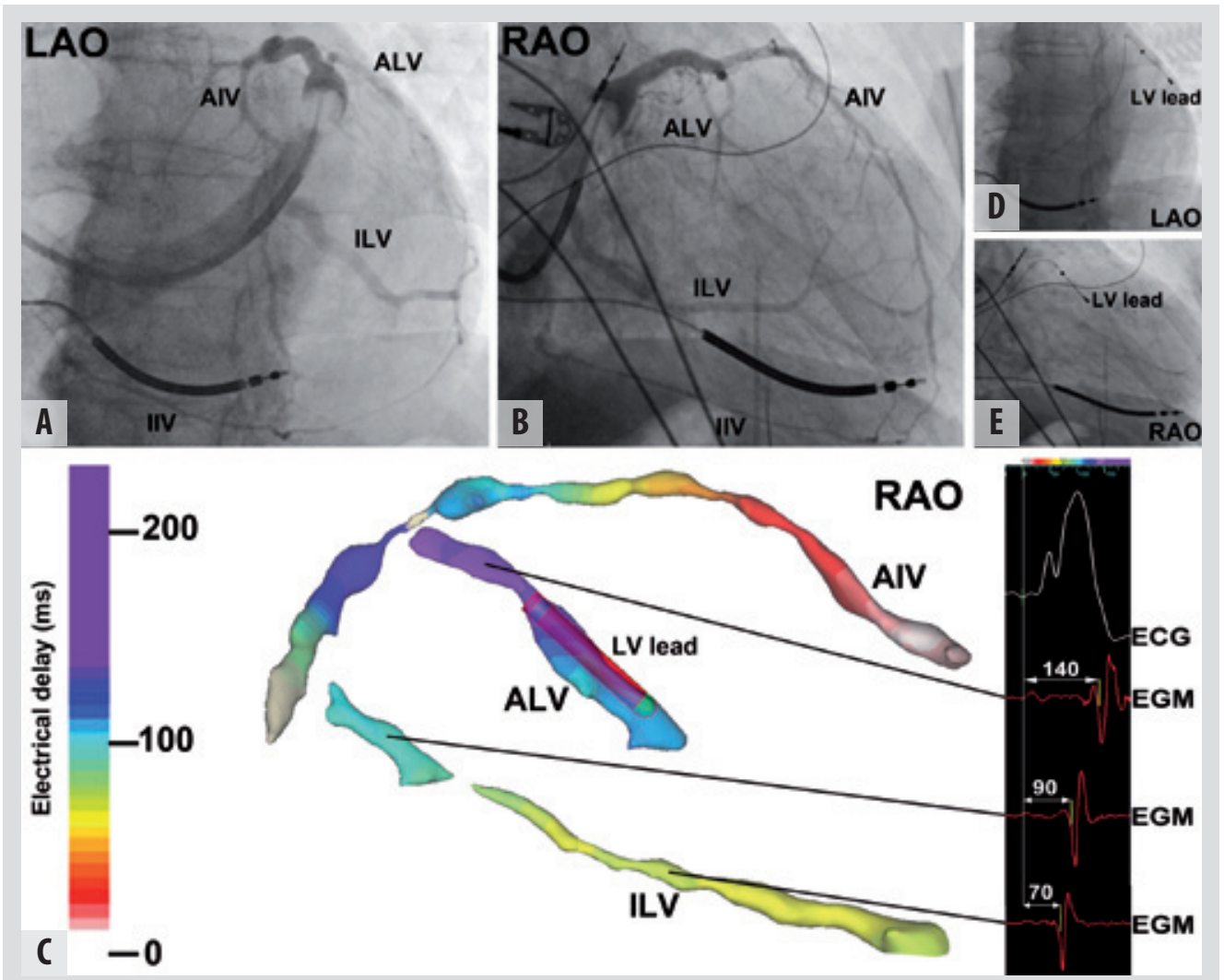

Figure 6. Coronary venous EAM of patient No. 24, illustrating the additional value of LV lead placement guided by coronary venous mapping. Pre-implantation coronary venograms in $L A O(A)$ and $R A O$ (B) view revealed a large inferolateral and a smal anterolateral vein. The conventional anatomical LV lead placement approach would target the inferolateral vein. However, coronary venous mapping during intrinsic ventricular activation (C) revealed a maximal electrical delay of only $90 \mathrm{~ms}$ in the basal inferolateral vein, which further decreased in the more distal segments, whereas a maximal electrical delay of $140 \mathrm{~ms}$ could be measured in the anterolateral vein. Based on the outcome of coronary venous mapping, the LV lead was positioned in the anterolateral vein, thereby achieving a clear benefit in LV lead electrical delay. (D) X-ray of final LV lead position in LAO view. (E) X-ray of final LV lead position in RAO view. AIV, anterior inter-ventricular vein; ALV, anterolateral vein; IIV, inferior inter-ventricular vein; ILV, inferolateral vein.

\section{Feasibility of coronary venous EAM to guide LV lead placement to the latest} activated region

Our observation that the location of the latest activated region varies between patients agrees with previous EAM studies in patients with heart failure and $\mathrm{LBBB}^{8-10}$ and emphasizes the need for a patient-tailored approach to optimize LV lead positioning. The present study demonstrates that coronary venous EAM using EnSite NavX in combination with a mapping guidewire is a feasible method to tailor LV lead placement to the individual patient at the time of implantation. Using this approach, we were able to position the LV lead in the latest activated region in $>70 \%$ of our patients. Conventional LV lead placement strategy involves an anatomical approach, targeting a coronary vein situated on the posterolateral wall. Approximately half the patients in our study cohort had more than one target vein available on the lateral LV free wall. In most 
of these patients, the empirically targeted posterolateral vein was not the vein with maxima electrical delay, which is consistent with the findings of a previous study that also used coronary venous EAM to assess LV epicardial activation. ${ }^{35}$ In the present study, coronary venous EAM resulted in targeting of an alternative vein in many of these patients, significantly increasing LV lead electrical delay from an average of $57 \%$ to $85 \%$ of total QRS duration. In addition, in patients with a single target vein, coronary venous EAM enabled targeting of the vein segment with maximal electrical delay. These results demonstrate the additional value of coronary venous EAM-guided LV lead placement as compared with the conventional anatomical LV lead placement approach for optimization of LV lead electrical delay.

The use of EnSite NavX to create an EAM of the coronary veins at the time of CRT implantation has previously been described by Ryu et al. ${ }^{11}$ In addition, Del Greco et al. demonstrated that lead placement guided by the 3D navigation system of EnSite NavX is beneficial in terms of reducing X-ray exposure during CRT implantation. ${ }^{2}$ Recently, Fujiwara et al. compared electrical and mechanical dyssynchrony using coronary venous EAM and speckle-tracking echocardiography. However, sample sizes of these studies were small, LV lead placement was not targeted at the latest activated region, and constraints imposed by coronary venous anatomy for identifying the latest activated LV region were not taken into account. Therefore, the present study is the first to demonstrate, in a larger and representative CRT population, the feasibility of positioning the LV lead in the latest activated region guided by coronary venous EAM.

Unfortunately, concordant LV lead placement was still hampered in one-quarter of patients due to PNS, lead instability and unfavourable coronary venous anatomy. The use of additional technologies may increase the success rate of targeted LV lead placement on the basis of electrica delay. Venous angioplasty, for example, may have benefited one of our patients in whom coronary venous stenosis hampered LV lead placement in the latest activated region. In addition, the use of new lead technologies, such as active-fixation leads and multipolar leads could overcome the problem of lead instability and avoid PNS, which hindered concordant LV lead positioning in several other patients in our study. When confronted with PNS, also alternative pacing strategies such as thoracoscopic epicardial or LV endocardial pacing may be considered to stimulate the site of optimal electrical delay.

Our mapping approach was easy to implement intraprocedurally using a commercially available EAM system in combination with a guidewire that allows mapping and pacing of the coronary veins, making the approach applicable in any catheter laboratory that has access to the relevant instruments. In addition, the same wire used to guide the LV lead was also used to map the coronary veins which obviated the need for inserting additional electrophysiology mapping catheters during implantation. Echocardiography and other imaging modalities have also been proposed as methods to assess the LV activation pattern and guide LV lead placement ${ }^{16-18,20,21,36}$ but these techniques are challenging to apply in the catheter laboratory and often require a separate pre-operative assessment.

In current clinical practice, most implanters that tend to target LV lead placement to a region with significant electrical delay do not perform full EAM in favor of a simpler approach where electrical mapping of the anatomically targeted region is performed using the LV lead to test if electrical delay is sufficiently late. However, using this approach the latest activated region may be missed because other potential LV pacing sites are generally not tested when electrical delay at the empirically targeted LV region is considered late enough. Previous reports suggest that Q-LV $>95 \mathrm{~ms}$ or $>50 \%$ of total QRS duration is sufficient to increase the odds of a favorable response. ${ }^{5,37}$ However, further increase of the Q-LV to $>120$ ms has been shown to considerably improve these odds, ${ }^{5}$ suggesting that implanters should aim to optimize LV lead electrical delay in order to maximize the chance of a positive CRT outcome. Besides, with simple electrical mapping, measurements are generally performed after final LV lead implantation. If the measured electrical delay is judged unsatisfactory, the implanter may have to relocate the LV lead to an alternative target vein, thus extending procedure and fluoroscopy time. Compared with simple electrical mapping using the LV lead, our 3D EAM approach has important advantages that can significantly contribute to LV lead placement optimization. The EnSite NavX system can be used to create an anatomic geometry of the coronary veins while electrical delay and PNS are assessed for any anatomic region accessible with the mapping guide wire. The small and flexible mapping guidewire allows for more detailed data collection by easy and quick mapping of multiple coronary veins and multiple points per vein which provides information on electrical activation timing and PNS of all potential LV pacing sites. Thus, all information about coronary venous anatomy, LV electrical activation and PNS can be readily obtained prior to LV lead placement. The LV lead can then be targeted to the latest activated region free of PNS in a single approach, thus reducing placement attempts at unsuitable sites. Targeted LV lead placement is further facilitated by real-time visualization and navigation of the lead in the NavX-created EAM.

\section{Avoiding phrenic nerve stimulation}

Phrenic nerve stimulation accounts for failure to deliver proper CRT or urgent need for LV lead relocation in a substantial number of patients. Studies addressing the issue have reported PNS at implantation in $7.6-37 \%$ of patients, resulting in failure to pace the target site in $10-14 \% \cdot{ }^{38-40}$ PNS at follow-up has been reported in $11-33 \%$ of patients, requiring LV lead replacement in a substantial proportion of patients and eventual turn-off of CRT in some. ${ }^{38-40}$ In the present study, PNS was assessed by systematic pacing of the coronary veins with the tip of the mapping guidewire. The usefulness of this approach for detecting PNS has previously been demonstrated by de Cock et al..$^{14}$ In addition, the EAM system used in our study allowed comprehensive annotation of PNS-free areas on the created coronary venous geometry, consequently providing $3 \mathrm{D}$ visualization of the anatomical location of these areas with respect to the target $L V$ pacing site and the position of the LV lead tip. Subsequently, real time navigation of the LV lead in the geometry allowed targeting of a PNS-free zone with optimal electrical delay. This approach proved to be effective to avoid PNS at medium-term follow-up ( $4 \pm 1$ months) in all study patients.

\section{Limitations}

The sample size of this study was relatively small. However, the study was performed on consecutive patients and the study population resembled the typical population of patients with LBBB and heart failure referred for CRT implantation.

Only standard bipolar LV leads were used. The use of new lead technologies, such as multipolar leads and active-fixation leads, may increase the success rate of targeted LV lead placement at the latest activated LV region by improving lead stability and avoiding PNS. Unfortunately, most device vendors did not have multipolar LV leads available at the time the current study was conducted.

Cardiac magnetic resonance imaging was not performed in this study. Therefore, we could not assess the distribution and extent of scar and its potential effect on electrical activation. Also, the mapping method used in the current study did not allow for reliable differentiation between scar and healthy myocardium. Thus, the position of the LV lead with respect to regions of myocardial scar was not taken into account during LV lead placement.

The current study demonstrates a feasible method to guide LV lead placement to the region of latest electrical activation. However, the clinical value of this lead placement strategy 
was not proven by acute hemodynamic measurements or long-term echocardiographic or clinical follow-up. Subsequent larger and long-term follow-up studies are therefore required to evaluate the impact of coronary venous mapping-guided LV lead placement on CRT outcome.

\section{Conclusion}

Coronary venous EAM using EnSite NavX in combination with a mapping guidewire can be used at the time of CRT implantation to guide LV lead placement to the latest activated region free of PNS. This approach especially contributes to optimization of LV lead electrical delay in patients with multiple target veins. The conventional anatomical LV lead placement strategy does not target the vein with maximal electrical delay in many of these patients. The clinical value of coronary venous mapping-guided LV lead placement needs prospective evaluation.

\section{Acknowledgments}

The authors are indebted to Peter Bakker and Arjan Bennink from St. Jude Medical for their assistance in operating the EnSite NavX system.

\section{References}

. Cleland JG, Daubert JC, Erdmann E, Freemantle N, Gras D, Kappenberger L and Tavazzi L. The effect of cardiac resynchronization on morbidity and mortality in heart failure. The New England journal of medicine. 2005;352:1539-49.

2. Linde C, Abraham WT, Gold MR, St John Sutton M, Ghio S and Daubert C. Randomized trial of cardiac resynchronization in mildly symptomatic heart failure patients and in asymptomatic patients with left ventricular dysfunction and previous heart failure symptoms. Journal of the American College of Cardiology. 2008;52:1834-43.

3. Moss AJ, Hall WJ, Cannom DS, Klein H, Brown MW, Daubert JP, Estes NA, 3rd, Foster E, Greenberg H, Higgins SL, Pfeffer MA, Solomon SD, Wilber D and Zareba W. Cardiac- resynchronization therapy for the prevention of heart-failure events. The New England journal of medicine. 2009;361:1329-38.

4. Daubert JC, Saxon L, Adamson PB, Auricchio A, Berger RD, Beshai JF, Breithard O, Brignole M, Cleland J, Delurgio DB, Dickstein K, Exner DV, Gold M, Grimm RA, Hayes DL, Israel C, Leclercq C, Linde C, Lindenfeld $\mathrm{J}_{\mathrm{f}}$ Merkely B, Mont L, Murgatroyd F, Prinzen F, Saba SF, Shinbane JS, Singh J, Tang AS, Vardas PE, Wilkoff BL an Zamorano JL. 2012 EHRA/HRS expert consensus statement on cardiac resynchronization therapy in heart failure: implant and follow-up recommendations and management. Heart rhythm: the official journal of the Heart Rhythm Society. 2012;9:1524-76.

5. Gold MR, Birgersdotter-Green U, Singh JP, Ellenbogen KA, Yu Y, Meyer TE, Seth M and Tchou PJ. The relationship between ventricular electrical delay and left ventricular remodelling with cardiac resynchronization therapy. European heart journal. 2011;32:2516-24.

6. Zanon F, Baracca E, Pastore G, Fraccaro C, Roncon L, Aggio S, Noventa F, Mazza A and Prinzen F. Determination of the Longest Intra-Patient Left Ventricular Electrical Delay May Predict Acute Hemodynamic Improvemen in Cardiac Resynchronization Therapy Patients. Circ Arrhythm Electrophysiol. 2014.

7. Authors/Task Force M, Brignole M, Auricchio A, Baron-Esquivias G, Bordachar P, Boriani G, Breithardt OA Cleland J, Deharo JC, Delgado V, Elliott PM, Gorenek B, Israel CW, Leclercq C, Linde C, Mont L, Padeletti L, Sutton R, Vardas PE, Guidelines ESCCfP, Zamorano JL, Achenbach S, Baumgartner H, Bax JJ, Bueno H, Dea V, Deaton C, Erol C, Fagard R, Ferrari R, Hasdai D, Hoes AW, Kirchhof P, Knuuti J, Kolh P, Lancellotti P, Linhart A Nihoyannopoulos P, Piepoli MF, Ponikowski P, Sirnes PA, Tamargo JL, Tendera M, Torbicki A, Wijns W, Windecker S, Document R, Kirchhof P, Blomstrom-Lundqvist C, Badano LP, Aliyev F, Bansch D, Baumgartner H, Bsata W, Buser P, Charron P, Daubert JC, Dobreanu D, Faerestrand S, Hasdai D, Hoes AW, Le Heuzey JY, Mavrakis H, McDonagh T, Merino JL, Nawar MM, Nielsen JC, Pieske B, Poposka L, Ruschitzka F, Tendera M, Van Gelder IC and Wilson CM. 2013 ESC Guidelines on cardiac pacing and cardiac resynchronization therapy: The Task Force on cardiac pacing and resynchronization therapy of the European Society of Cardiology (ESC). Developed in collaboration with the European Heart Rhythm Association (EHRA). European hea journal. 2013;34:2281-329.

8. Fung JW, Yu CM, Yip G, Zhang Y, Chan H, Kum CC and Sanderson JE. Variable left ventricular activation pattern in patients with heart failure and left bundle branch block. Heart. 2004;90:17-9.

9. Auricchio A, Fantoni C, Regoli F, Carbucicchio C, Goette A, Geller C, Kloss M and Klein H. Characterization of left ventricular activation in patients with heart failure and left bundle-branch block. Circulation. 2004;109:1133-9.

10. Rodriguez LM, Timmermans C, Nabar A, Beatty $G$ and Wellens $\mathrm{HJ}$. Variable patterns of septal activation in patients with left bundle branch block and heart failure. Journal of cardiovascular electrophysiology. 2003:14:135-41.

11. Ryu K, D'Avila A, Heist EK, Rosenberg SP, Chou J, Yang M and Singh JP. Simultaneous electrical and mechanical mapping using 3D cardiac mapping system: novel approach for optimal cardiac resynchronization therapy. Journal of cardiovascular electrophysiology. 2010;21:219- 22.

12. Del Greco M, Marini M and Bonmassari R. Implantation of a biventricular implantable cardioverterdefibrillator guided by an electroanatomic mapping system. Europace. 2012;14:107-11. 
13. Cosio FG. The Electrocardiogram. In: Camm AJ, editor The ESC Textbook of Cardiovascular Medicine. 2009;2nd ed. UK: Oxford University Press; 2009.

14. de Cock CC, Res JC, Hendriks ML and Allaart CP. Usefulness of a pacing guidewire to facilitate left ventricular lead implantation in cardiac resynchronization therapy. Pacing Clin Electrophysiol. 2009;32:446-9.

15. Cerqueira MD, Weissman NJ, Dilsizian V, Jacobs AK, Kaul S, Laskey WK, Pennell DJ, Rumberger JA, Ryan T and Verani MS. Standardized myocardial segmentation and nomenclature for tomographic imaging of the heart. A statement for healthcare professionals from the Cardiac Imaging Committee of the Council on Clinical Cardiology of the American Heart Association. Circulation. 2002;105:539-42.

16. Ypenburg C, van Bommel RJ, Delgado V, Mollema SA, Bleeker GB, Boersma E, Schalij MJ and Bax JJ. Optim left ventricular lead position predicts reverse remodeling and survival after cardiac resynchronization therapy. Journal of the American College of Cardiology. 2008;52:1402-9.

17. Ansalone G, Giannantoni P, Ricci R, Trambaiolo P, Fedele F and Santini M. Doppler myocardial imaging to evaluate the effectiveness of pacing sites in patients receiving biventricular pacing. Journal of the American College of Cardiology. 2002;39:489-99.

18. Becker M, Altiok E, Ocklenburg C, Krings R, Adams D, Lysansky M, Vogel B, Schauerte P, Knackstedt C and Hoffmann R. Analysis of $L V$ lead position in cardiac resynchronization therapy using different imaging modalities. JACC Cardiovasc Imaging. 2010;3:472-81.

19. Becker M, Franke A, Breithardt OA, Ocklenburg C, Kaminski T, Kramann R, Knackstedt C, Stellbrink C, Hanrath P, Schauerte P and Hoffmann R. Impact of left ventricular lead position on the efficacy of cardiac resynchronisation therapy: a two-dimensional strain echocardiography study. Heart. 2007;93:1197-203.

20. Becker M, Hoffmann R, Schmitz F, Hundemer A, Kuhl H, Schauerte P, Kelm M and Franke A. Relation of optimal lead positioning as defined by three-dimensional echocardiography to long-term benefit of cardiac resynchronization. The American journal of cardiology. 2007;100:1671-6.

21. Becker M, Kramann R, Franke A, Breithardt OA, Heussen N, Knackstedt C, Stellbrink C, Schauerte P, Kelm M and Hoffmann R. Impact of left ventricular lead position in cardiac resynchronization therapy on lef ventricular remodelling. A circumferential strain analysis based on $2 \mathrm{D}$ echocardiography. European heart journal. 2007;28:1211-20.

22. Khan FZ, Virdee MS, Palmer CR, Pugh PJ, O'Halloran D, Elsik M, Read PA, Begley D, Fynn SP and Dutka DP. Targeted left ventricular lead placement to guide cardiac resynchronization therapy: the TARGET study: a randomized, controlled trial. Journal of the American College of Cardiology. 2012;59:1509-18.

23. Saba S, Marek J, Schwartzman D, Jain S, Adelstein E, White P, Oyenuga OA, Onishi T, Soman P and Gorcsan J, 3rd. Echocardiography-guided left ventricular lead placement for cardiac resynchronization therapy: results of the Speckle Tracking Assisted Resynchronization Therapy for Electrode Region trial. Circulation Heart failure. 2013;6:427-34.

24. Singh JP, Fan D, Heist EK, Alabiad CR, Taub C, Reddy V, Mansour M, Picard MH, Ruskin JN and Mela T. Left ventricular lead electrical delay predicts response to cardiac resynchronization therapy. Heart rhythm: the official journal of the Heart Rhythm Society. 2006;3:1285-92.

25. van Gelder BM, Meijer A and Bracke FA. Timing of the left ventricular electrogram and acute hemodynamic changes during implant of cardiac resynchronization therapy devices. Pacing Clin Electrophysiol. 2009;32 Suppl 1:S94-7.

26. Singh JP, Klein HU, Huang DT, Reek S, Kuniss M, Quesada A, Barsheshet A, Cannom D, Goldenberg I, McNitt S, Daubert JP, Zareba W and Moss AJ. Left ventricular lead position and clinical outcome in the multicenter automatic defibrillator implantation trial-cardiac resynchronization therapy (MADIT-CRT) trial. Circulation. 2011;123:1159-66.

27. Gold MR, Auricchio A, Hummel JD, Giudici MC, Ding J, Tockman B and Spinelli J. Comparison of stimulation sites within left ventricular veins on the acute hemodynamic effects of cardiac resynchronization therapy. Heart rhythm: the official journal of the Heart Rhythm Society. 2005;2:376-81.

28. Foley PW, Chalil S, Ratib K, Smith R, Prinzen F, Auricchio A and Leyva F. Fluoroscopic left ventricular lead position and the long-term clinical outcome of cardiac resynchronization therapy. Pacing Clin Electrophysiol. 2011;34:785-97.
29. Saxon LA, Olshansky B, Volosin K, Steinberg JS, Lee BK, Tomassoni G, Guarnieri T, Rao A, Yong P, Galle E, Leigh J, Ecklund $F$ and Bristow MR. Influence of left ventricular lead location on outcomes in the COMPANION study. Journal of cardiovascular electrophysiology. 2009;20:764-8.

30. Bleeker GB, Schalij MJ, Van Der Wall EE and Bax JJ. Postero-lateral scar tissue resulting in non-response to cardiac resynchronization therapy. Journal of cardiovascular electrophysiology. 2006;17:899-901.

31. Hummel JP, Lindner JR, Belcik JT, Ferguson JD, Mangrum JM, Bergin JD, Haines DE, Lake DE, DiMarco JP and Mounsey JP. Extent of myocardial viability predicts response to biventricular pacing in ischemic cardiomyopathy. Heart rhythm: the official journal of the Heart Rhythm Society. 2005;2:1211-7.

32. Ypenburg C, Roes SD, Bleeker GB, Kaandorp TA, de Roos A, Schalij MJ, van der Wall EE and Bax JJ. Effect of total scar burden on contrast-enhanced magnetic resonance imaging on response to cardiac resynchronization therapy. The American journal of cardiology. 2007;99:657-60.

33. Ypenburg C, Schalij MJ, Bleeker GB, Steendijk P, Boersma E, Dibbets-Schneider P, Stokkel MP, van der Wall EE and Bax JJ. Impact of viability and scar tissue on response to cardiac resynchronization therapy in ischaemic heart failure patients. European heart journal. 2007;28:33-41.

34. Chali S, Stegemann B, Muhyaldeen SA, Khadjooi K, Foley PW, Smith RE and Leyva F. Effect of posterolater left ventricular scar on mortality and morbidity following cardiac resynchronization therapy. Pacing Clin Electrophysiol. 2007;30:1201-9.

35. Fujiwara R, Yoshida A, Fukuzawa K, Takei A, Kiuchi K, Itoh M, Imamura K, Suzuki A, Nakanishi T, Yamashita S, Matsumoto A, Tanaka $\mathrm{H}$ and Hirata KI. Discrepancy between Electrical and Mechanical Dyssynchrony in Patients with Heart Failure and an Electrical Disturbance. Pacing Clin Electrophysiol. 2013.

36. Boogers MJ, Chen J, van Bommel RJ, Borleffs CJ, Dibbets-Schneider P, van der Hiel B, AI Younis I, Schalij M van der Wall EE, Garcia EV and Bax JJ. Optimal left ventricular lead position assessed with phase analysis on gated myocardial perfusion SPECT. Eur J Nucl Med Mol Imaging. 2011;38:230-8.

37. Kandala J, Upadhyay GA, Altman RK, Parks KA, Orencole M, Mela T, Kevin Heist E and Singh JP. QRS morphology, left ventricular lead location, and clinical outcome in patients receiving cardiac resynchronization therapy. European heart journal. 2013;34:2252-62

38. Gurevitz O, Nof E, Carasso S, Luria D, Bar-Lev D, Tanami N, Eldar M and Glikson M. Programmable multiple pacing configurations help to overcome high left ventricular pacing thresholds and avoid phrenic nerve stimulation. Pacing Clin Electrophysiol. 2005;28:1255-9.

39. Biffi M, Moschini C, Bertini M, Saporito D, Ziacchi M, Diemberger I, Valzania C, Domenichini G, Cervi E, Martignani C, Sangiorgi D, Branzi A and Boriani G. Phrenic stimulation: a challenge for cardiac resynchronization therapy. Circ Arrhythm Electrophysiol. 2009;2:402-10.

40. Seifert M, Schau T, Moeller V, Neuss M, Meyhoefer J and Butter C. Influence of pacing configurations, body mass index, and position of coronary sinus lead on frequency of phrenic nerve stimulation and pacing thresholds under cardiac resynchronization therapy. Europace. 2010;12:961-7 


\section{Different regions of latest electrical activation during left bundle-branch block and right ventricular pacing determined by coronary venous electroanatomic mapping}

Masih Mafi Rad, Yuri Blaauw, Trang Dinh, Laurent Pison, Harry J. Crijns, Frits W. Prinzen, Kevin Vernooy 


\section{Abstract}

Aim: Current targeted left ventricular (LV) lead placement strategy is directed at the latest activated region during intrinsic activation. However, cardiac resynchronization therapy (CRT) is most commonly applied by simultaneous LV and right ventricular (RV) pacing without contribution from intrinsic conduction. Therefore, targeting the LV lead to the latest activated region during RV pacing might be more appropriate. We investigated the difference in LV electrical activation sequence between left bundle-branch block (LBBB) and RV apex (RVA) pacing using coronary venous electroanatomic mapping (EAM).

Methods: Twenty consecutive CRT candidates with LBBB underwent intraprocedural coronary venous EAM during intrinsic activation and RVA pacing using EnSite NavX. Left ventricular lead placement was aimed at the latest activated region during LBBB according to current recommendations.

Results: In all patients, LBBB was associated with a circumferential LV activation pattern whereas RVA pacing resulted in activation from the apex of the heart to the base. In 10 of 20 patients, RVA pacing shifted the latest activated region relative to LBBB. In 18 of 20 patients, the LV lead was successfully positioned in the latest activated region during LBBB. For the whole study population, LV lead electrical delay, expressed as percentage of QRS duration, was significantly shorter during RVA pacing than during LBBB $(72 \pm 13$ vs. $82 \pm 5 \%, P=0.035$

Conclusion: Right ventricular apex pacing alters LV electrical activation pattern in CRT patients with LBBB, and shifts the latest activated region in a significant proportion of these patients. These findings warrant reconsideration of the current practice of LV lead targeting for CRT.

\section{Introduction}

Cardiac resynchronization therapy (CRT) reduces morbidity and mortality and reverses lef ventricular (LV) remodelling in heart failure patients with LV systolic impairment and electrical dyssynchrony. ${ }^{1-3}$ Unfortunately, a significant proportion of apparently suitable patients do not derive any detectable benefit. ${ }^{4}$ The position of the LV lead with respect to the site of latest activation is considered an important determinant of CRT response. Recent studies have suggested that positioning of the LV lead in the region of latest electrical activation or the segment of latest mechanical contraction provides superior clinical outcome compared with the conventiona anatomical LV lead placement approach. ${ }^{5-10}$ Studies investigating targeted LV lead placement have typically focused on the latest activated region during intrinsic ventricular activation. ${ }^{9}, 10$ However, in daily clinical practice the CRT device is most commonly programmed to (almost) simultaneous right ventricular (RV) and LV pacing (i.e. biventricular pacing) without fusion with intrinsic ventricular activation. Ludwig et al. recently demonstrated that the region of latest mechanical activation during RV apex (RVA) pacing often differs from that during LBBB. ${ }^{11}$ The purpose of the present study was to investigate the difference in LV electrical activation sequence between intrinsic LBBB and RVA pacing using coronary venous electroanatomic mapping (EAM) in patients undergoing CRT implantation.

\section{Methods}

\section{Population}

Twenty consecutive patients referred for CRT device implantation, with LV ejection fraction (LVEF) $<35 \%$, NYHA functional class 2, 3 or ambulatory 4, and LBBB according to European Society of Cardiology (ESC) guidelines ${ }^{12}$ were prospectively enrolled. The study protocol was approved by the Institutional Review Board.

\section{CRT implantation and mapping}

All patients underwent intraprocedural coronary venous three-dimensional EAM using EnSite NavX (St. Jude Medical). The right atrial lead was placed in the right atrial appendage and the RV lead was placed in the RVA by current practice. Before LV lead placement, an occlusive coronary venous angiogram was recorded under fluoroscopy in right anterior oblique (RAO) and left anterior oblique (LAO) view for optimal visualization of the coronary veins. Subsequently a 0.014 inch guidewire (Vision Wire, Biotronik SE \& Co.KG) was inserted into the coronary sinus (CS) and connected to EnSite NavX along with the surface electrocardiogram (ECG). This guidewire has complete polyethylene isolation except for $15 \mathrm{~mm}$ at the distal J-shaped tip and $30 \mathrm{~mm}$ at the proximal end permitting unipolar sensing and pacing. ${ }^{13}$ The guidewire was manipulated to various branches of the CS, creating an anatomical map along with determining the electrical activation time associated with each anatomic region during both intrinsic LBBB and RVA pacing. Right ventricular apex pacing was performed with the implanted RV lead at 10 beats above intrinsic heart rate, in DDD mode (AV-sequential pacing) with a short AV-delay to ensure full ventricular capture. Local electrical activation time was measured in $\mathrm{ms}$ from QRS onset on surface ECG to the peak negative slope on the unipolar intra-cardiac electrogram (EGM) and expressed as a percentage of total QRS duration. All measurements were performed in EnSite NavX at a screen speed of $400 \mathrm{~mm} / \mathrm{s}$. After the mapping procedure, the LV lead was connected to EnSite NavX for real-time visualization and navigation of the lead to the latest activated region during intrinsic LBBB based on current evidence and recommendations. ${ }^{5,9,14}$ Standard bipolar leads of various vendors were used. Finally, the device implantation was completed. 


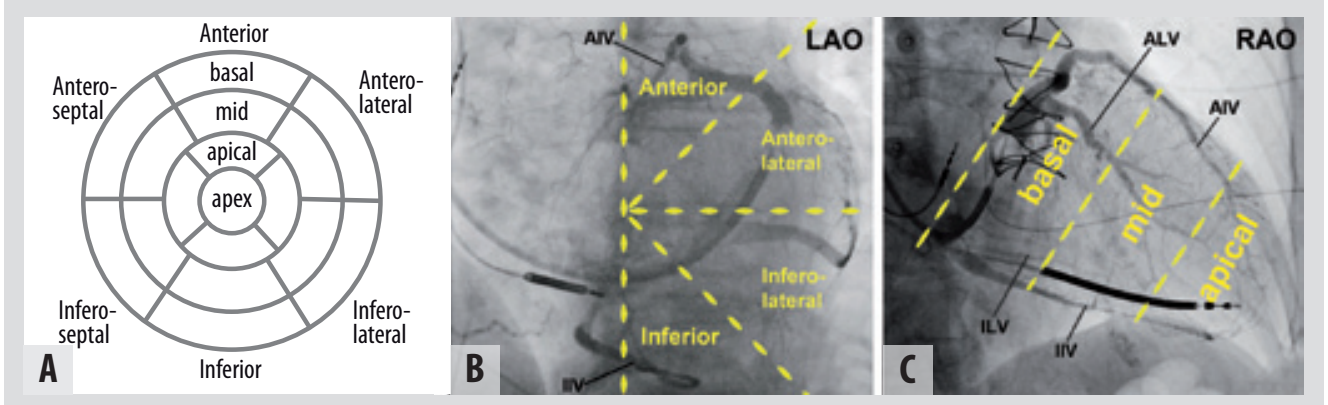

Figure 1. Angiographic classification of the latest activated region and final LV lead position. (A) The American Heart Association standardized 17-segment heart model, adapted from Cerqueira et al..$^{15}$ (B) Coronary venous angiogram in left anterior oblique (LAO). This view, which is comparable to the short axis of the heart, was used to divide the LV wall into four equal parts; anterior, anterolateral, inferolateral and inferior. (C) Coronary venous angiogram in right anterior oblique (RA0). This view, which is representative of the long axis of the heart, was used to classify the latest activated regions and final LV lead position into basal, mid-ventricular and apical segments. AIV, anterior inter-ventricular vein; ALV, anterolateral vein; IIV, inferior inter-ventricular vein; ILV, inferolateral vein.

\section{Classification of the latest activated region and final LV lead position}

The location of the latest activated region and the final LV lead position were classified according to the American Heart Association 17-segment heart model ${ }^{15}$ by detailed evaluation of pre-implantation coronary venous angiograms and post-implantation LV lead fluoroscopy images (Figure 1). The latest activated regions during intrinsic LBBB and RVA pacing were described as different if located in different myocardial segments according to the 17-segment heart model. The final LV lead position was described as concordant if the LV electrode was located in the same myocardial segment as the latest activated region during intrinsic LBBB.

\section{Statistical analysis}

Continuous variables are expressed as mean \pm SD. Categorical variables are expressed as observed number and percentage values. Continuous variables were compared using Mann-Whitney U test. Statistical significance was accepted at the $95 \%$ confidence interval $(P<0.05)$. Statistical analysis was performed using SPSS version 20.0 (SPSS Inc.) software.

\section{Results}

\section{Patient characteristics}

Twenty consecutive patients with LBBB referred for CRT device implantation were included in this study. The patient characteristics are described in Table 1.

\section{CRT implantation and mapping}

In 18 patients a de novo CRT defibrillator was implanted. One patient was upgraded from an implantable cardioverter-debrillator to a CRT defibrillator and one patient received a CRT pacemaker. LV lead implantation was successful in all patients. The RV lead was positioned in the RVA in all patients. There were no intra- or post-procedural complications. All patients underwent successful coronary venous EAM during both intrinsic LBBB as well as RVA pacing. Three-dimensional electrical activation maps during intrinsic LBBB and RVA pacing were
Table 1. Patient characteristics $(n=20)$

\begin{tabular}{|l|l|}
\hline Age, years & $70 \pm 10$ \\
\hline Male gender $(n, \%)$ & $11(55)$ \\
\hline Ischemic heart disease $(n, \%)$ & $6(30)$ \\
\hline NYHA functional class $(n, \%)$ & $9(45)$ \\
\hline II & $11(55)$ \\
\hline III & \\
\hline Echocardiography characteristics & $27 \pm 4$ \\
\hline$\quad$ LV ejection fraction $(\%)$ & $62 \pm 7$ \\
\hline LV end-diastolic diameter $(\mathrm{mm})$ & $53 \pm 9$ \\
\hline LV end-systolic diameter $(\mathrm{mm})$ & $158 \pm 43$ \\
\hline LV end-diastolic volume $(\mathrm{mL})$ & $115 \pm 36$ \\
\hline \multicolumn{1}{|c|}{ LV end-systolic volume $(\mathrm{mL})$} & \\
\hline ECG characteristics & $20(100)$ \\
\hline LBBB $(n, \%)$ & $156 \pm 18$ \\
\hline QRS duration $(\mathrm{ms})$ & \\
\hline Intrinsic rhythm $(n, \%)$ & $17(85)$ \\
\hline Sinus rhythm & $3(15)$ \\
\hline Atrial fibrillation & \\
\hline Treatment $(n, \%)$ & $15(75)$ \\
\hline Diuretics & $18(90)$ \\
\hline ACE-i/ARB & $16(80)$ \\
\hline Beta-blockers & $10(50)$ \\
\hline Spironolactone & $1(5)$ \\
\hline Digoxin & $3(15)$ \\
\hline Amiodarone & \\
\hline
\end{tabular}

ACE-i, angiotensin converting enzyme inhibitor; ARB, angiotensin receptor blocker.

generated from $65 \pm 28$ and $59 \pm 25$ unique anatomic points, respectively Mapping time was $18 \pm 7$ minutes, fluoroscopy time during the entire procedure $21 \pm 3$ minutes, and total radiation dosage $4492 \pm 2097 \mathrm{cGy} \times \mathrm{cm}^{2}$

\section{LV electrical activation pattern during intrinsic LBBB and RVA pacing}

Figure 2 shows the coronary venous EAMs of five different study patients during both intrinsic $\angle B B B$ and RVA pacing. These examples show a distinct difference in LV electrical activation pattern between intrinsic LBBB and RVA pacing, which was consistently observed in all study patients. During intrinsic LBBB, first, activation of the LV septum occurred, as shown by the virtually uniform early electrical activation of all segments of the inter-ventricular veins. From the septum, activation spread across the inferior or anterior wall toward the lateral free wall in a more or less circumferential pattern of activation, and ended in the anterolateral or 


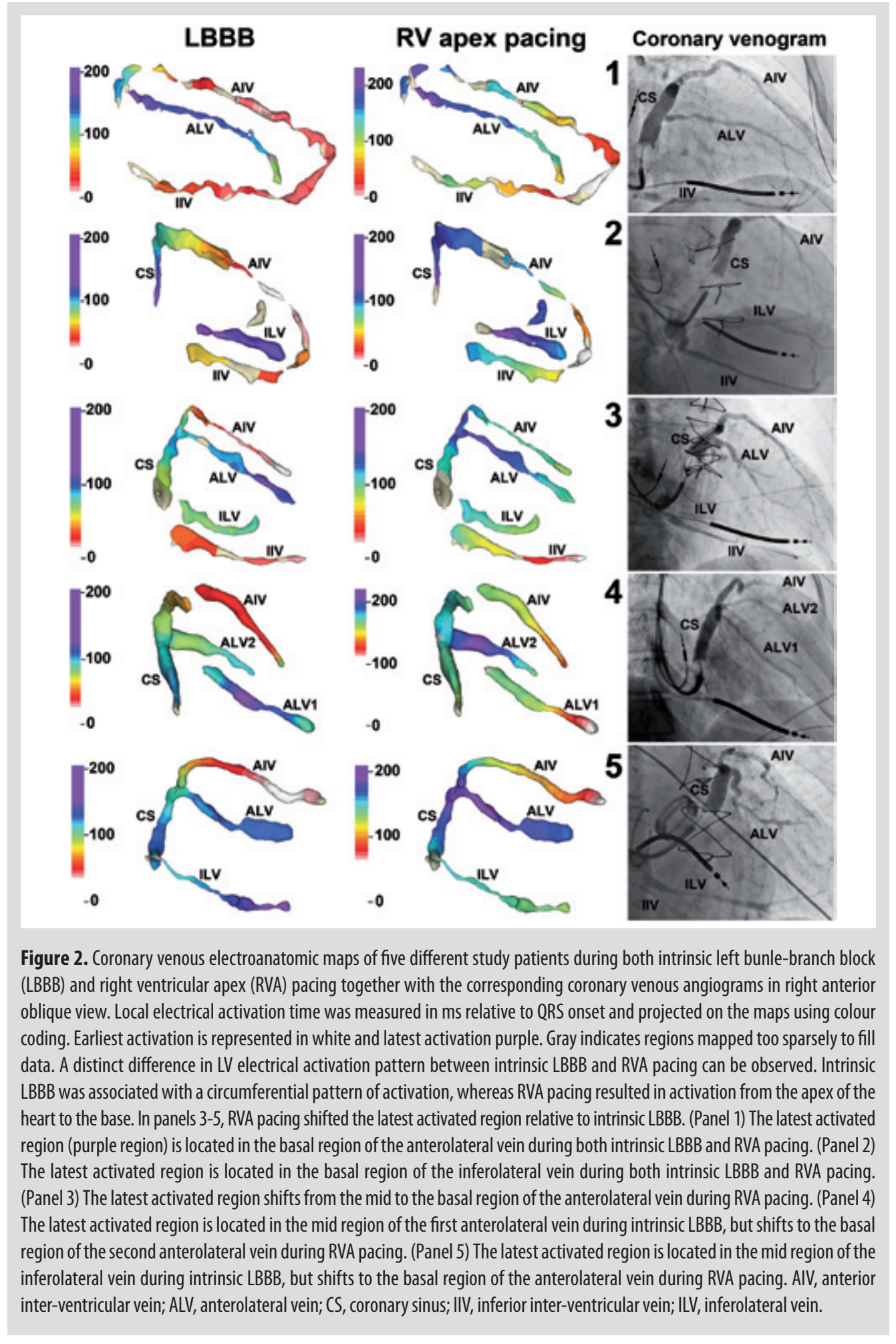

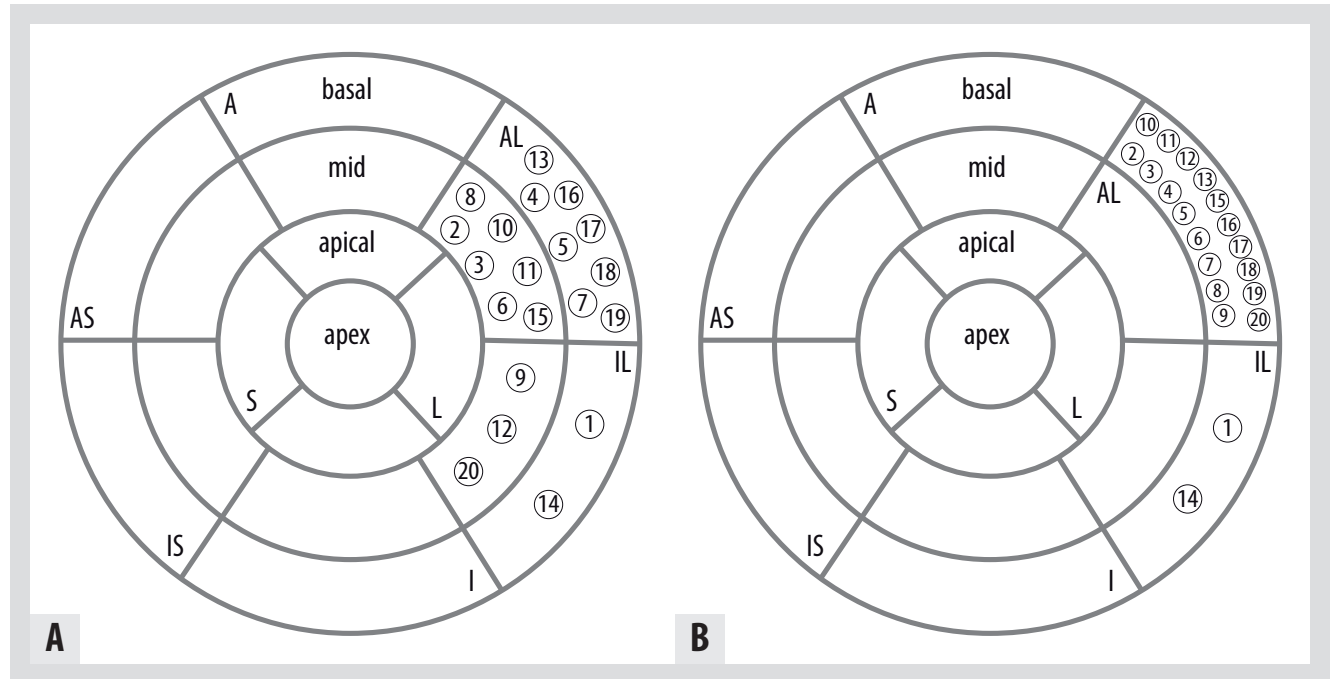

Figure 3. Location of the latest activated regions during intrinsic LBBB (A) and RVA pacing (B). Each circled number represents a patient. In 10 of 20 patients, the latest activated region during LBBB differed from that during RVA pacing. A, anterior AL, anterolateral; AS, antero-septal; I, inferior; IL, inferolateral; IS, inferoseptal; L, lateral; S, septal.

inferolateral region at either mid or basal level. In contrast, RVA pacing resulted in LV electrical activation from the apex of the heart to the base. This is illustrated in the EAMs by the gradual increase in local electrical activation time from the distal to the proximal regions of both the inter-ventricular and lateral coronary veins. In the patients depicted in panel 3-5 of Figure 2 the change in activation pattern induced by RVA pacing shifted the latest activated region (purple region) relative to intrinsic LBBB. In contrast, the patients depicted in panel 1 and 2 of Figure 2 had similar latest activated regions during intrinsic LBBB and RVA pacing despite the clear difference in activation pattern observed between both conditions. Figure 3 shows the distribution of the latest activated region during intrinsic LBBB and RVA pacing in the whole study population. The location of the latest activated region during intrinsic LBBB varied between patients, being located anterolaterally in 15 (basal, $n=8 ; \mathrm{mid}, n=7$ ) and inferolaterally in 5 (basal, $n=2 ;$ mid, $n=3$ ). The latest activated region during RVA pacing showed a more uniform distribution, being located in the basal anterolateral segment in all but two patients. In total, 10 of 20 patients had different latest activated regions during LBBB and RVA pacing (Nos. 2, 3, $6,8-12,15$, and 20). In this subgroup of patients, the latest activated region was located in the mid anterolateral (Nos. 2, 3, 6, 8, 10, 11, and 15) or mid inferolateral segment (Nos. 9, 12, and 20) during intrinsic LBBB, but shifted to the basal anterolateral segment during RVA pacing. An overview of the latest activated regions during intrinsic LBBB and RVA pacing of all patients together with the corresponding electrical delays at these sites is provided in Table 2. For the whole study population, local electrical activation time measured during RVA pacing, was significantly shorter at the region that was activated latest during intrinsic LBBB than at the region that was activated latest during RVA pacing [ $149 \pm 39$ vs. $171 \pm 30 \mathrm{~ms}$ ( $75 \pm 12$ vs. $87 \pm 5 \%$ of QRS duration), $\mathrm{P}<0.01]$. In patients with different latest activated regions, local electrical activation time measured during RVA pacing, was $120 \pm 18 \mathrm{~ms}$ ( $65 \pm 7 \%$ of QRS duration) at the region that was latest activated during intrinsic LBBB and $161 \pm 26 \mathrm{~ms}$ ( $87 \pm 4 \%$ of QRS duration) at the region that was latest activated during RVA pacing $(\mathrm{P}<0.001)$. 


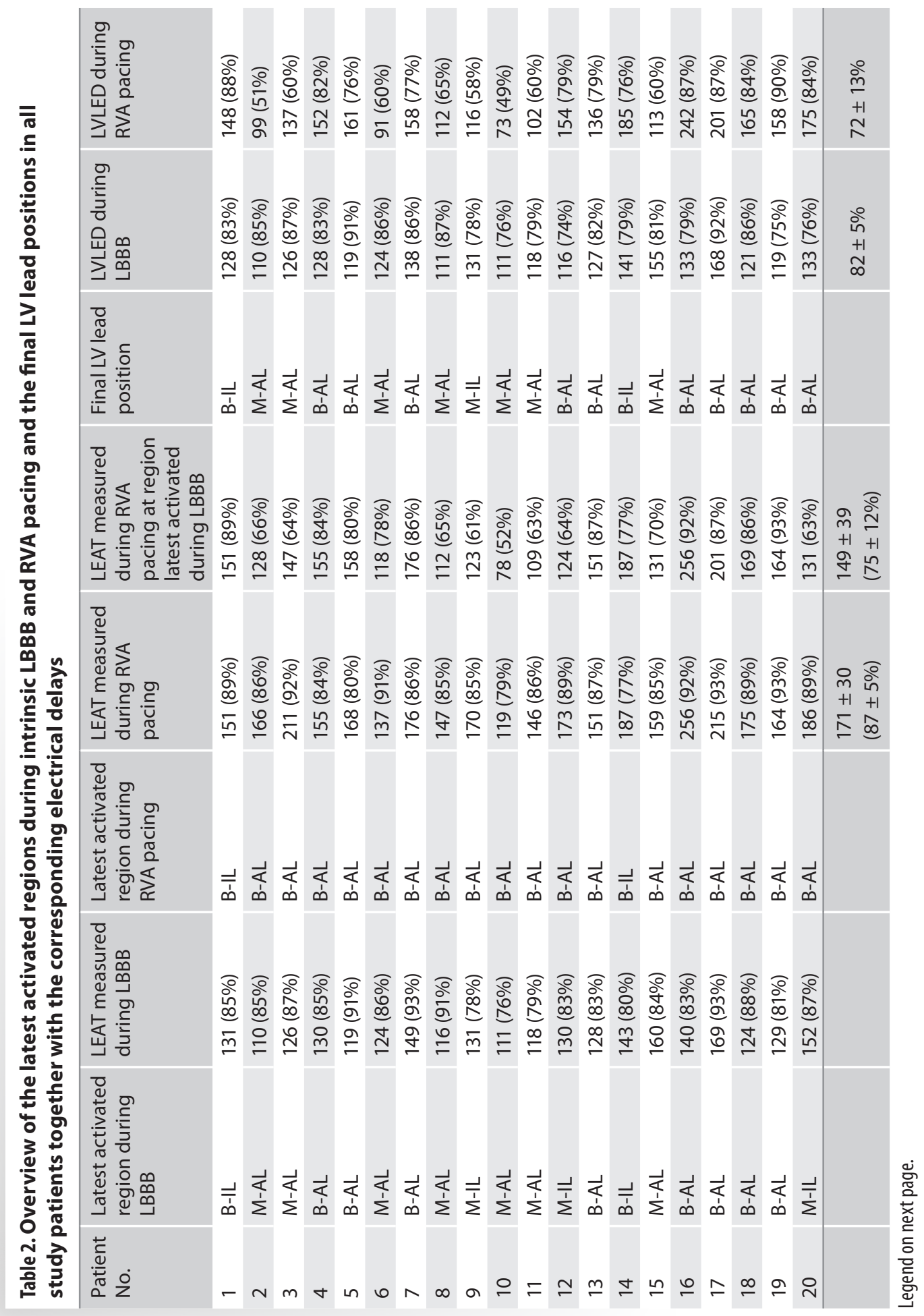

Legend of Table2. Patient numbers correspond with the numbers provided in figure 3 and 5. Local electrical activation time (LEAT) and LV lead electrical delay (LVLED) are reported in ms (percentage of total QRS duration). B, basal; M, mid $\mathrm{AL}$, anterolateral; IL, inferolateral.

QRS duration was longer during RVA pacing than during intrinsic LBBB $(197 \pm 32$ vs. $156 \pm 18 \mathrm{~ms}$ $P<0.001)$. Right ventricular apex pacing was also associated with a longer total LV electrica activation time than intrinsic LBBB, as measured by coronary venous EAM $(171 \pm 30 \mathrm{vs} .132 \pm 16 \mathrm{~ms}$, $P<0.001)$. This increased delay in LV electrical activation during RVA pacing as compared to intrinsic LBBB is illustrated in Figure 4, which highlights one of the examples depicted in Figure 2, only this time with LV electrical activation time projected on the coronary venous geometry using the same color coding for both intrinsic LBBB and RVA pacing.

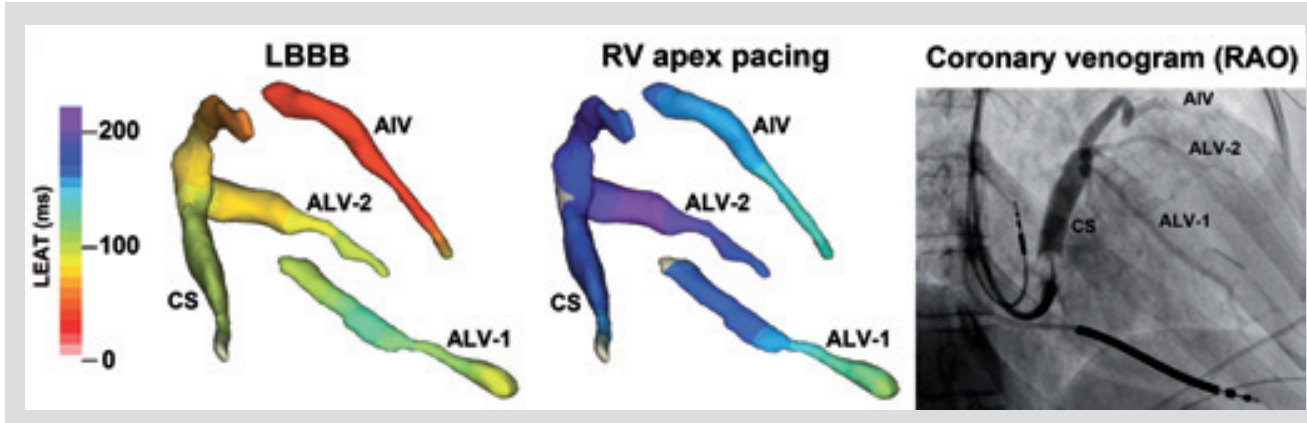

Figure 4. Increased delay in LV electrical activation during RVA pacing compared with intrinsic LBBB. Local electrical activation time has been projected on the coronary venous EAMs of the patient depicted in panel 4 of Figure 2 using the same colour coding for both intrinsic LBBB and RVA pacing. AIV, anterior inter-ventricular vein; ALV-1, first anterolateral vein; ALV-2, second anterolateral vein; $C$, coronary sinus; LEAT, local electrical activation time; RAO, right anterior oblique view.

\section{LV lead electrical delay with respect to mode of ventricular activation}

The study protocol involved targeting of the LV lead to the latest activated region during intrinsic LBBB. Figure 5 shows the distribution of the final LV lead position in all patients. The LV lead was positioned anterolaterally in 17 (basal, $n=10 ; \mathrm{mid}, n=7$ ) and inferolaterally in three (basal, $n=2 ; \mathrm{mid}, n=1)$. The final LV lead position was concordant with the latest activated region during intrinsic LBBB in 18 of 20 patients. In 2 patients (Nos. 12 and 20), concordant LV lead placement was hampered by phrenic nerve stimulation and lead instability, respectively. These two patients happened to have different latest activated regions during LBBB and RVA pacing, and the LV lead was positioned concordant with the latest activated region during RVA pacing in both. As a result, the final LV lead position was concordant with the latest activated region during RVA pacing in 12 out of 20 patients. An overview of the final LV lead positions in all patients together with the LV lead electrical delays (LVLED) measured during both intrinsic LBBB and RVA pacing is provided in Table 2. For the whole study population, LVLED, expressed as a percentage of QRS duration, was shorter during RVA pacing than during LBBB $(72 \pm 13$ vs. $82 \pm 5 \%, P=0.035)$. In the 10 patients with different latest activated regions, there was an even more pronounced reduction in LVLED during RVA pacing as compared with LBBB $(63 \pm 11$ vs. $81 \pm 5 \%, P=0.002$ ). 


\section{Discussion}

Increasing evidence supports the practice of placing the LV lead in the latest activated region as a means of maximizing CRT response. ${ }^{5-10}$ At present, the latest activated region is assessed during intrinsic ventricular activation. ${ }^{9,10}$ However, CRT is most commonly applied by biventricular pacing without contribution from intrinsic conduction. The present study demonstrates that RVA pacing significantly alters the pattern of LV electrical activation in CRT patients with LBBB. This change in activation pattern shifted the latest activated region in half the patients in the present study. Positioning of the LV lead in the region of latest activation during intrinsic LBBB significantly reduced LV lead electrical delay during RVA pacing. Our findings urge reconsideration of the current practice of LV lead targeting for CRT.

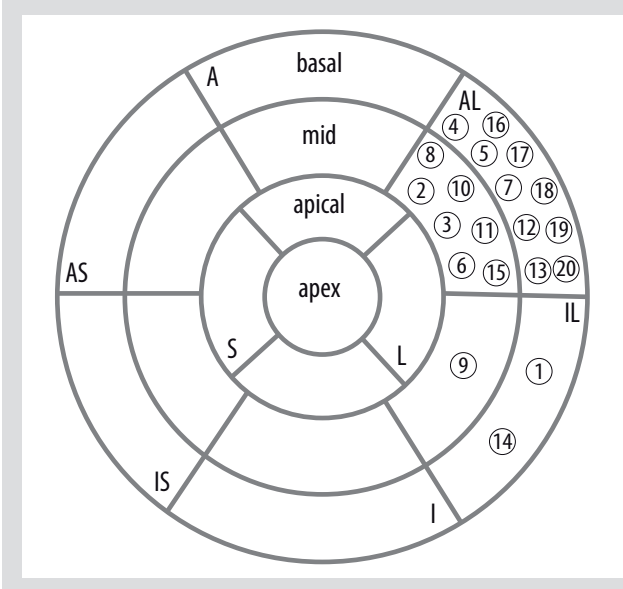

Figure 5. Location of the final LV lead positions. Each circled number represents a patient. Numbers correspond with the numbers in Figure 3 and Table 2. A, anterior; AL, anterolateral: $A S$, antero-septal: $L$ inferior: 1 , inferolateral, IS, inferoseptal; L, lateral; S, septal.

\section{Difference between intrinsic LBBB and LBBB induced by RVA pacing}

The present study demonstrates that intrinsic LBBB and RVA pacing, despite having similar QRS morphologies, have different electrical activation patterns. Previous studies have provided detailed information about LV electrical activation pattern in patients with LBBB and during RV pacing. Auricchio et al. previously showed that in patients with LBBB and heart failure, the earliest electrical activation occurs in the septum and that all septal segments are activated relatively simultaneously. Subsequent conduction of electrical activation from the septum to the lateral LV free wall was shown to be impeded by functional lines of block that are usually located on the anterior LV wall, resulting in a U-shaped pattern of activation that turns around the apex and inferior wall of the LV. Other investigators showed that in contrast to LBBB, activation during RV pacing is likely to start at a single point and spreads both circumferentially and longitudinally. ${ }^{17,18}$ However, within-patien comparisons of intrinsic LBBB with RVA pacing-induced LBBB are limited. In the present study, LBBB was associated with a circumferential course of LV activation, while RVA pacing resulted in activation from the apex of the heart to the base. This finding is in agreement with previous observations by Ludwig et al., who demonstrated a similar difference in LV mechanical activation pattern between LBBB and RVA pacing using three-dimensional speckle-tracking echocardiography. ${ }^{11}$ The same investigators also demonstrated that RVA pacing results in greater mechanical dyssynchrony than LBBB.1" This finding corresponds with our observation that QRS duration and total LV electrical activation time were longer during RVA pacing compared with LBBB.

The LV activation pattern has been shown to vary depending on the site of ventricular pacing. ${ }^{16,19}$ In the present study, the RV pacing electrode was positioned in the RV apex in all patients, which may explain the fairly uniform location of the latest activated region observed during RVA pacing. Conversely, conduction delay in LBBB can be located at different anatomical levels in the conduction system, which may explain our observation of a variable location of the latest activated region during LBBB, consistent with earlier reports. ${ }^{16,20,21}$
Implications for the current practice of LV lead targeting for CRT

There is increasing evidence to suggest that positioning of the LV lead in the region of lates activation provides superior acute and long-term outcome of CRT..$^{5-10,22}$ Studies investigating this lead placement strategy determined the region of latest mechanical activation preoperatively during intrinsic activation, and this information was subsequently used to guide LV lead placement., 10 Targeting the latest activated region during intrinsic activation is reasonable when CRT involves only LV pacing fused with intrinsic activation. ${ }^{23}$ However, CRT is most commonly applied by biventricular pacing without contribution from intrinsic conduction The present study demonstrates that the region of latest electrical activation during RVA pacing differs from that during LBBB in a significant proportion of CRT patients. In addition, our data show that the practice of placing the LV lead in the latest activated region during LBBB markedly reduces LVLED when CRT utilizes RVA pacing. Our findings, added to previous results of Ludwig et al. showing a similar discordance in the segment of latest mechanical contraction between LBBB and RVA pacing ${ }^{11}$, imply that LV lead targeting for CRT which is applied by biventricular pacing should rather be directed at the latest activated region assessed during RVA pacing. Alternatively, when limitations of transvenous LV lead placement hamper targeting of the latest activated region during RVA pacing, positioning of the LV lead in the latest activated region during intrinsic activation combined with LV fusion pacing may be considered to achieve optimal ventricular resynchronization. Previously, Singh et al. proposed the "dial in" strategy to overcome the limitations of transvenous LV lead placement when aiming for maximal electrical separation of the LV and RV leads. Their approach involved initial placement of the LV lead at the most suitable anatomic site, and then subsequent selection of an $\mathrm{RV}$ pacing site as electrically distant as possible from the obtained LV pacing site. ${ }^{24}$

While the position of the LV lead with respect to the region of latest activation is a factor that can influence CRT response, several studies have shown that the proximity of the LV lead to an area with myocardial scar is also an important factor. ${ }^{25-29}$ Assessment of scar tissue should therefore be considered before CRT, especially in the population with ischemic heart disease. Integrating information obtained from preprocedural scar imaging with intraprocedural information on LV electrical activation pattern may further optimize LV lead positioning and the clinical response rate.

Clinical applicability of coronary venous EAM for assessment of $L V$ electrical activation pattern during LBBB and RVA pacing

Coronary venous EAM was easy to implement intraprocedurally using a commercially available EAM system in combination with a guidewire that allows mapping and pacing of the coronary veins, making the approach applicable in any catheter laboratory that has access to the relevant instruments. In addition, the same wire used to guide the LV lead was also used to map the coronary veins, which obviated the need for inserting additional electrophysiology mapping catheters during implantation. The mean total fluoroscopy time for CRT implantation in previous studies ranged from $23.9 \pm 18.1 \mathrm{~min}^{30}$ to $46 \pm 23 \mathrm{~min}^{31}$ In the present study, mean total fluoroscopy time was $21 \pm 3$ minutes, which indicates that coronary venous EAM can be accomplished intraprocedurally without excessive use of radiation. The intraprocedural setup, which involved initial placement of the RV lead followed by coronary venous EAM allowed assessment of LV electrical activation pattern during both LBBB and RVA pacing. In addition the NavX system allowed for real-time visualization and navigation of the indwelling LV lead in the created three-dimensional EAM of the cardiac veins, which facilitated targeting of the anatomical area of latest electrical activation. Not every implanting centre has access to an 
EAM system. In that case, electrical mapping with the LV lead may be considered as a simpler alternative to assess LV electrical activation sequence during intrinsic LBBB and RVA pacing and target LV lead placement to the latest activated region. Echocardiography and other imaging modalities have also been proposed as methods to assess LV activation pattern. $7,8,31-34$ However, these techniques are challenging to apply in the catheter laboratory and require a preoperative assessment, which limits the possibility of assessing $\mathrm{LV}$ activation pattern during $\mathrm{RV}$ pacing in patients without a previously implanted pacing device.

\section{Limitations}

The sample size of this study was relatively small. However, the study was performed on consecutive patients and the population resembled the typical population of patients with LBBB and heart failure referred for CRT implantation.

In the present study, the RV pacing electrode was implanted in the RVA in all patients, which is common practice in CRT. The impact of alternative RV pacing sites, such as the basal or mid RV septum, on LV electrical activation was not assessed.

Cardiac magnetic resonance imaging was not performed in this study. Therefore, we could not assess the distribution and extent of myocardial scar and its potential effect on LV electrical activation.

The findings of the current study indicate that during LV lead targeting for CRT, one should consider that the latest activated region during RVA pacing may differ from that during intrinsic LBBB. Thus, positioning of the LV lead in the latest activated region during RVA pacing, rather than targeting the latest activated region during intrinsic activation may be more appropriate when CRT is applied by biventricular pacing. However, the small number of patients precluded any systematic analysis of the impact of LV lead positioning based on the latest activated region during RVA pacing on CRT outcome. Neither was the clinical value of this approach proven by acute hemodynamic measurements. Whether such a LV lead placement strategy actually increases the likelihood of a favourable CRT response needs prospective evaluation in larger and preferably randomized studies.

\section{Conclusion}

Current targeted LV lead placement strategy is directed at the latest activated region assessed during intrinsic ventricular activation. In contrast, CRT is most commonly applied by biventricular pacing without contribution from intrinsic conduction. The present study demonstrates that right ventricular apex pacing alters the pattern of LV electrical activation in CRT patients with $\angle B B B$, and shifts the latest activated region in a substantial proportion of these patients. These findings raise questions about the current practice of LV lead targeting for CRT.

\section{Acknowledgements}

The technical support during the mapping procedures provided by Peter Bakker and Arjan Bennink from St. Jude Medical is gratefully acknowledged.
References

1. Cleland JG, Daubert JC, Erdmann E, Freemantle N, Gras D, Kappenberger L and Tavazzi L. The effect of cardiac resynchronization on morbidity and mortality in heart failure. The New England journal of medicine. 2005;352:1539-49.

2. Linde C, Abraham WT, Gold MR, St John Sutton M, Ghio S and Daubert C. Randomized trial of cardiac resynchronization in mildly symptomatic heart failure patients and in asymptomatic patients with left ventricular dysfunction and previous heart failure symptoms. Journal of the American College of Cardiology. 2008;52:1834-43.

3. Moss AJ, Hall WJ, Cannom DS, Klein H, Brown MW, Daubert JP, Estes NA, 3rd, Foster E, Greenberg H, Higgin SL, Pfeffer MA, Solomon SD, Wilber D and Zareba W. Cardiac- resynchronization therapy for the prevention of heart-failure events. The New England journal of medicine. 2009;361:1329-38.

4. Daubert JC, Saxon L, Adamson PB, Auricchio A, Berger RD, Beshai JF, Breithard O, Brignole M, Cleland J, Delurgio DB, Dickstein K, Exner DV, Gold M, Grimm RA, Hayes DL, Israel C, Leclercq C, Linde C, Lindenfeld J, Merkely B, Mont L, Murgatroyd F, Prinzen F, Saba SF, Shinbane JS, Singh J, Tang AS, Vardas PE, Wilkoff BL and Zamorano JL. 2012 EHRA/HRS expert consensus statement on cardiac resynchronization therapy in heart failure: implant and follow-up recommendations and management. Heart rhythm: the official journal of the Heart Rhythm Society. 2012;9:1524-76.

5. Gold MR, Birgersdotter-Green U, Singh JP, Ellenbogen KA, Yu Y, Meyer TE, Seth M and Tchou PJ. The relationship between ventricular electrical delay and left ventricular remodelling with cardiac resynchronization therapy. European heart journal. 2011;32:2516-24.

6. Zanon F, Baracca E, Pastore G, Fraccaro C, Roncon L, Aggio S, Noventa F, Mazza A and Prinzen F. Determination of the Longest Intra-Patient Left Ventricular Electrical Delay May Predict Acute Hemodynamic Improvemen in Cardiac Resynchronization Therapy Patients. Circ Arrhythm Electrophysiol. 2014.

7. Ypenburg C, van Bommel RJ, Delgado V, Mollema SA, Bleeker GB, Boersma E, Schalij MJ and Bax JJ. Optimal left ventricular lead position predicts reverse remodeling and survival after cardiac resynchronization therapy. Journal of the American College of Cardiology. 2008;52:1402-9.

8. Becker M, Kramann R, Franke A, Breithardt OA, Heussen N, Knackstedt C, Stellbrink C, Schauerte P, Kelm M and Hoffmann R. Impact of left ventricular lead position in cardiac resynchronization therapy on left ventricular remodelling. A circumferential strain analysis based on 2D echocardiography. European heart journal. 2007:28:1211-20.

9. Khan FZ, Virdee MS, Palmer CR, Pugh PJ, O'Halloran D, Elsik M, Read PA, Begley D, Fynn SP and Dutka DP. Targeted left ventricular lead placement to guide cardiac resynchronization therapy: the TARGET study: a randomized, controlled trial. Journal of the American College of Cardiology. 2012;59:1509-18.

10. Saba S, Marek J, Schwartzman D, Jain S, Adelstein E, White P, Oyenuga OA, Onishi T, Soman P and Gorcsan $J$, 3rd. Echocardiography-guided left ventricular lead placement for cardiac resynchronization therapy: results of the Speckle Tracking Assisted Resynchronization Therapy for Electrode Region trial. Circulation results of the Speckle Tracking

11. Ludwig DR, Tanaka H, Friehling M, Gorcsan J, 3rd and Schwartzman D. Further deterioration of LV ejection fraction and mechanical synchrony during RV apical pacing in patients with heart failure and LBBB. Journal of cardiovascular translational research. 2013;6:425-9.

12. Cosio FG. The Electrocardiogram. In: Camm AJ, editor The ESC Textbook of Cardiovascular Medicine. 2009;2nd ed. UK: Oxford University Press; 2009.

13. de Cock CC, Res JC, Hendriks ML and Allaart CP. Usefulness of a pacing guidewire to facilitate left ventricular lead implantation in cardiac resynchronization therapy. Pacing Clin Electrophysiol. 2009;32:446-9.

14. Authors/Task Force M, Brignole M, Auricchio A, Baron-Esquivias G, Bordachar P, Boriani G, Breithardt OA Cleland J, Deharo JC, Delgado V, Elliott PM, Gorenek B, Israel CW, Leclercq C, Linde C, Mont L, Padeletti L, Sutton $R$, Vardas PE, Guidelines ESCCfP, Zamorano JL, Achenbach S, Baumgartner H, Bax JJ, Bueno H, Dean V, Deaton C, Erol C, Fagard R, Ferrari R, Hasdai D, Hoes AW, Kirchhof P, Knuuti J, Kolh P, Lancellotti P, Linhart A, 
Nihoyannopoulos P, Piepoli MF, Ponikowski P, Sirnes PA, Tamargo JL, Tendera M, Torbicki A, Wijns W, Windecker S, Document R, Kirchhof P, Blomstrom-Lundqvist C, Badano LP, Aliyev F, Bansch D, Baumgartner H, Bsata W, Buser P, Charron P, Daubert JC, Dobreanu D, Faerestrand S, Hasdai D, Hoes AW, Le Heuzey JY, Mavrakis H, McDonagh T, Merino JL, Nawar MM, Nielsen JC, Pieske B, Poposka L, Ruschitzka F, Tendera M, Van Gelder IC and Wilson CM. 2013 ESC Guidelines on cardiac pacing and cardiac resynchronization therapy: The Task Force on cardiac pacing and resynchronization therapy of the European Society of Cardiology (ESC). Developed in collaboration with the European Heart Rhythm Association (EHRA). European heart journal. 2013;34:2281-329.

15. Cerqueira MD, Weissman NJ, Dilsizian V, Jacobs AK, Kaul S, Laskey WK, Pennell DJ, Rumberger JA, Ryan and Verani MS. Standardized myocardial segmentation and nomenclature for tomographic imaging of the heart. A statement for healthcare professionals from the Cardiac Imaging Committee of the Council on Clinical Cardiology of the American Heart Association. Circulation. 2002;105:539-42.

16. Auricchio A, Fantoni C, Regoli F, Carbucicchio C, Goette A, Geller C, Kloss M and Klein H. Characterization of left ventricular activation in patients with heart failure and left bundle-branch block. Circulation. 2004:109:1133-9.

17. Vassallo JA, Cassidy DM, Marchlinski FE, Buxton AE, Waxman HL, Doherty JU and Josephson ME. Endocardial activation of left bundle branch block. Circulation. 1984;69:914-23.

18. Vassallo JA, Cassidy DM, Miller JM, Buxton AE, Marchlinski FE and Josephson ME. Left ventricular endocardia activation during right ventricular pacing: effect of underlying heart disease. Journal of the American College of Cardiology. 1986;7:1228-33.

19. Schwaab B, Frohlig G, Alexander C, Kindermann M, Hellwig N, Schwerdt H, Kirsch CM and Schieffer $H$. Influence of right ventricular stimulation site on left ventricular function in atrial synchronous ventricular pacing. Journal of the American College of Cardiology. 1999;33:317-23.

20. Fung JW, Yu CM, Yip G, Zhang Y, Chan H, Kum CC and Sanderson JE. Variable left ventricular activation pattern in patients with heart failure and left bundle branch block. Heart. 2004;90:17-9.

21. Rodriguez LM, Timmermans C, Nabar A, Beatty G and Wellens $\mathrm{HJ}$. Variable patterns of septal activation in patients with left bundle branch block and heart failure. Journal of cardiovascular electrophysiology. 2003;14:135-41.

22. Singh JP, Fan D, Heist EK, Alabiad CR, Taub C, Reddy V, Mansour M, Picard MH, Ruskin JN and Mela T. Le ventricular lead electrical delay predicts response to cardiac resynchronization therapy. Heart rhythm: the official journal of the Heart Rhythm Society. 2006;3:1285-92.

23. Auricchio A, Stellbrink C, Butter C, Sack S, Vogt J, Misier AR, Bocker D, Block M, Kirkels JH, Kramer A and Huvelle E. Clinical efficacy of cardiac resynchronization therapy using left ventricular pacing in heart failur patients stratified by severity of ventricular conduction delay. Journal of the American College of Cardiology. 2003;42:2109-16.

24. Singh JP, Heist EK, Ruskin JN and Harthorne JW. "Dialing-in" cardiac resynchronization therapy: overcoming constraints of the coronary venous anatomy. Journal of interventional cardiac electrophysiology: an international journal of arrhythmias and pacing. 2006;17:51-8.

25. Bleeker GB, Schalij MJ, Van Der Wall EE and Bax JJ. Postero-lateral scar tissue resulting in non-response to cardiac resynchronization therapy. Journal of cardiovascular electrophysiology. 2006;17:899-901.

26. Hummel JP, Lindner JR, Belcik JT, Ferguson JD, Mangrum JM, Bergin JD, Haines DE, Lake DE, DiMarco JP an Mounsey JP. Extent of myocardial viability predicts response to biventricular pacing in ischemic cardiomyopathy. Heart rhythm: the official journal of the Heart Rhythm Society. 2005;2:1211-7.

27. Ypenburg C, Roes SD, Bleeker GB, Kaandorp TA, de Roos A, Schalij MJ, van der Wall EE and Bax JJ. Effect of total scar burden on contrast-enhanced magnetic resonance imaging on response to cardiac resynchronization therapy. The American journal of cardiology. 2007;99:657-60.

28. Ypenburg C, Schalij MJ, Bleeker GB, Steendijk P, Boersma E, Dibbets-Schneider P, Stokkel MP, van der Wal $E E$ and Bax JJ. Impact of viability and scar tissue on response to cardiac resynchronization therapy in ischaemic heart failure patients. European heart journal. 2007;28:33-41.
29. Chali S, Stegemann B, Muhyaldeen SA, Khadjooi K, Foley PW, Smith RE and Leyva F. Effect of posterolateral left ventricular scar on mortality and morbidity following cardiac resynchronization therapy. Pacing Clin Electrophysiol. 2007;30:1201-9.

30. Khan FZ, Virdee MS, Fynn SP and Dutka DP. Left ventricular lead placement in cardiac resynchronization therapy: where and how? Europace. 2009;11:554-61.

31. Ansalone G, Giannantoni P, Ricci R, Trambaiolo P, Fedele F and Santini M. Doppler myocardial imaging to evaluate the effectiveness of pacing sites in patients receiving biventricular pacing. Journal of the American College of Cardiology. 2002;39:489-99.

32. Becker M, Altiok E, Ocklenburg C, Krings R, Adams D, Lysansky M, Vogel B, Schauerte P, Knackstedt C and Hoffmann R. Analysis of LV lead position in cardiac resynchronization therapy using different imaging modalities. JACC Cardiovasc Imaging. 2010;3:472-81.

33. Becker M, Hoffmann R, Schmitz F, Hundemer A, Kuhl H, Schauerte P, Kelm M and Franke A. Relation of optimal lead positioning as defined by three-dimensional echocardiography to long-term benefit of cardiac resynchronization. The American journal of cardiology. 2007;100:1671-6.

34. Boogers MJ, Chen J, van Bommel RJ, Borleffs CJ, Dibbets-Schneider P, van der Hiel B, Al Younis I, Schalij M van der Wall EE, Garcia EV and Bax JJ. Optimal left ventricular lead position assessed with phase analysis on gated myocardial perfusion SPECT. Eur J Nucl Med Mol Imaging. 2011;38:230-8. 


\section{Regional left ventricular electrical activation and peak contraction are closely related in candidates for cardiac resynchronization therapy}

Masih Mafi Rad*, Jetske van 't Sant*, Yuri Blaauw, Pieter A. Doevendans, Maarten J. Cramer, Harry J. Crijns, Frits W. Prinzen, Mathias Meine, Kevin Vernooy

*Authors contributed equally to this manuscript JACC Clin Electrophysiol. (under revision) 


\section{Abstract}

Aim: Targeting the left ventricular (LV) lead to the region of latest electrical activation or the segment of latest peak contraction has both been shown to improve response to cardiac resynchronization therapy (CRT). Whether these regions correspond within CRT patients is uncertain. We determined the relationship between the timing of LV electrical activation and peak contraction at potential LV pacing locations in candidates for CRT

Methods: Twenty-eight consecutive CRT candidates underwent intraprocedural coronary venous electroanatomic mapping using EnSite NavX. Peak contraction time of the mapped LV regions was determined using longitudinal strain derived from speckletracking echocardiography. Electrical activation and peak contraction times were correlated on a per-patient basis and the regions of latest electrical activation and latest peak contraction were compared.

Results: Successful measurements by both techniques allowed analysis in 23 of 28 patients. There was a strong positive correlation between electrical activation and peak contraction times within each patient $\left(R^{2}=0.85 \pm 0.09\right)$. However, the magnitude of the electrical activation-peak contraction relationship varied greatly between patients (slope of regression line $=4.05 \pm 3.23$ ). The regions of latest electrical activation and latest peak contraction corresponded in 19 of 23 (83\%) patients and were adjacent in 4 patients.

Conclusion: There is a strong positive correlation between the timing of LV electrical activation and peak contraction measured at potential LV pacing locations in typical CRT candidates. This finding suggests that a strategy of determining the latest activated $\mathrm{LV}$ region based on speckle-tracking echocardiography is equivalent to that based on intra-cardiac measurements of electrical activation.

\section{Introduction}

Cardiac resynchronization therapy (CRT) has become an important treatment for heart failure patients with left ventricular (LV) systolic dysfunction and evidence of LV conduction delay. CRT aims to resynchronize the electrical ventricular activation by paced pre-excitation of the delayed LV lateral wall. Doing so, it restores coordinated ventricular contraction, improves LV systolic function and reverses ventricular remodeling. 'The position of the LV lead with respect to the region of latest activation has been shown to be an important determinant of CRT response. Studies focusing on electrical activation have demonstrated that a greater delay in time from onset of the QRS complex to the locally sensed LV lead electrogram is associated with a greater likelihood of benefit from CRT. ${ }^{2}$ Other studies used speckle-tracking based strain measures of mechanical activation and suggest better CRT outcome when the LV lead position coincides with the segment of latest peak contraction. ${ }^{3}$ The choice between targeting the region of latest electrical activation or the segment of latest peak contraction is currently a matter of debate. On the one hand preclinical studies in non-failing canine hearts have previously shown that electrical and mechanical activation of the heart are closely coupled. ${ }^{4-6}$ On the other hand, echocardiography based time-to-peak measures of mechanical dyssynchrony have recently been questioned for their ability to predict CRT response., ${ }^{7}$ Therefore, it remains unclear whether the preclinical results can be extrapolated to the dyssynchronous failing human heart. The results of two recent small-scale studies on this subject have been conflicting., 10 The purpose of the present study was to perform a within-patient comparison of the timing of LV electrical activation and peak contraction at potential LV pacing locations accessible via the coronary veins in patients undergoing CRT.

\section{Methods}

\section{Study population}

This study was conducted in 28 consecutive patients enrolled for CRT with LV ejection fraction (LVEF) $<35 \%$, New York Heart Association (NYHA) functional class II, III or ambulatory IV, left bundle-branch block (LBBB) according to specific criteria"1 or non-LBBB with QRS duration $>150$ ms. The study protocol was approved by the Maastricht University Medical Center's (MUMC) Institutional Review Board.

\section{Electroanatomic mapping}

All patients underwent intraprocedural coronary venous electroanatomic mapping (EAM) at the MUMC as described previously. ${ }^{2}$ In brief, prior to LV lead placement, a 0.014 inch guidewire (Vision Wire, Biotronik SE \& Co.KG), which permits unipolar sensing and pacing was inserted into the coronary sinus (CS) and connected to EnSite NavX (St Jude Medical). The guidewire was manipulated to various CS branches, creating an anatomic map along with determining local electrical activation time during intrinsic ventricular activation. After the mapping procedure, the LV lead was positioned in a lateral or posterolateral vein according to routine clinical practice.

\section{Classification of coronary venous anatomy}

The coronary venous anatomy was classified using the segmental approach ${ }^{13}$ by detailed evaluation of biplane coronary venograms. In the left anterior oblique (LAO) image, the CS was divided into anterior, lateral, and posterior areas, and the distribution of the branches was described similarly. The right anterior oblique (RAO) image was used to divide CS branches into basal, mid-ventricular and apical segments. 


\section{Echocardiography}

Standard 2-dimensional echocardiography was performed within two weeks prior to CRT implantation at the MUMC using a commercial machine (Philips IE 33, Philips Medical Systems). Routine gray-scale cine loop images were acquired in standard apical views with a frame rate of at least $50 \mathrm{~Hz}$ and digitally stored for post-processing offline (Xcelera software R3.3L1). Left ventricular end-diastolic volume, LV end-systolic volume and LVEF were calculated using Simpson's biplane method. Speckle-tracking 2-dimensional longitudinal strain analysis was performed at the University Medical Center Utrecht (UMCU) by an experienced observer blinded to the electrical data using Cardiac Performance Analysis software version 1.2 (Tomtec Imaging Systems). The endocardial border was manually traced in end-systole. Subsequently, the speckle tracking software automatically analyzed frame-by-frame movement of the stable patterns of acoustic markers (speckles) to generate time-strain curves over the cardiac cycle of the myocardial segments. Since the area of the LV that can be approached for EAM via the CS is limited to the LV free wall, the assessment of segmental time-to-peak contraction was also limited to the LV free wall segments. The time-to-peak contraction of each mapped myocardial segment was measured in ms from QRS onset to peak longitudinal strain. If segmental time-strain curves showed more than one peak, the first peak was assessed. Echocardiographic images that were of insufficient quality for speckle-tracking strain analysis and myocardia segments with likely scar (low amplitude longitudinal strain curves $<5.3 \%$, thin wall $\leq 0.5 \mathrm{~cm}$ abnormal increase in acoustic reflectance, and akinetic wall motion) $)^{14,15}$ were handled as missing data. Previously, the intra- and interobserver coefficients of variation for the determination of timing of peak myocardial wall shortening were assessed at the echocardiography laboratory of the UMCU and were $14.2 \%$ and $15.6 \%$, respectively. ${ }^{16}$

\section{Comparison of electrical activation and peak contraction times}

After classification of the coronary venous anatomy according to the segmental approach as described above, the electrical activation time of each mapped myocardial segment was calculated as the average of all electrical activation times measured within a segment during mapping. The electrical activation and peak contraction times of each mapped myocardia segment were then directly compared. Pearson's correlation coefficient was computed between the electrical activation and peak contraction times observed for each patient. The segments of latest electrical activation and latest peak contraction were determined in each patient.

\section{Statistical analysis}

Continuous variables are expressed as mean \pm standard deviation. Categorical values are expressed as observed number and percentage values. Paired samples t-test was used to compare means of continuous variables among different measurement conditions and Mann-Whitney $U$ test was used to compare means of continuous variables among different groups. Within-patient correlation between electrical activation and peak contraction times was calculated using Pearson's correlation coefficient. Statistical significance was accepted at the 95\% confidence interval. Statistical analysis was performed using SPSS version 20.0 (SPSS Inc.) software.

\section{Results}

\section{Patient characteristics}

Twenty-eight consecutive patients enrolled for CRT were included in the study. The patient characteristics are described in Table 1.

\section{Table 1. Patient characteristics $(n=28)$}

\begin{tabular}{|l|l|}
\hline Characteristic & Value \\
\hline Age, years & $71 \pm 9$ \\
\hline Male gender $(n, \%)$ & $18(64)$ \\
\hline Ischemic heart disease $(n, \%)$ & $13(46)$ \\
\hline NYHA functional class $(n, \%)$ & $13(46)$ \\
\hline II & $15(54)$ \\
\hline III & \\
\hline Echocardiography characteristics & $28 \pm 6$ \\
\hline \multicolumn{1}{|c|}{ LV ejection fraction $(\%)$} & $61 \pm 7$ \\
\hline LV end-diastolic diameter $(\mathrm{mm})$ & $52 \pm 7$ \\
\hline LV end-systolic diameter $(\mathrm{mm})$ & $169 \pm 51$ \\
\hline LV end-diastolic volume $(\mathrm{mL})$ & $123 \pm 38$ \\
\hline LV end-systolic volume $(\mathrm{mL})$ & \\
\hline ECG characteristics & $154 \pm 15$ \\
\hline QRS duration $(\mathrm{ms})$ & $18(64)$ \\
\hline LBBB $(n, \%)$ & $10(36)$ \\
\hline IVCD $(n, \%)$ & \\
\hline Intrinsic rhythm $(n, \%)$ & $23(82)$ \\
\hline Sinus rhythm & $5(18)$ \\
\hline Atrial fibrillation & \\
\hline Treatment $(n, \%)$ & $19(68)$ \\
\hline Diuretics & $27(96)$ \\
\hline ACE-i/ARB & $24(86)$ \\
\hline Beta-blockers & $15(54)$ \\
\hline Spironolactone & $2(7)$ \\
\hline Digoxin & $4(14)$ \\
\hline Amiodarone & \\
\hline
\end{tabular}

BBB, left bundle-branch block; IVCD, intra-ventricular conduction delay; ACE-I, angiotensin converting enzyme inhibitor $A R B$, angiotensin receptor blocker. 
Coronary venous EAM and speckle-tracking strain analysis

Intraprocedural coronary venous EAM was accomplished in all 28 patients without complications. Coronary venous angiography in the 28 patients revealed a total of 96 coronary venous branches, of which $83(86 \%)$ could be mapped. Three-dimensional electrical activation maps were generated from $62+25$ unique anatomic points. Mapping time was $19 \pm 7$ minutes, and fluoroscopy time during the entire procedure was $21 \pm 4$ minutes.

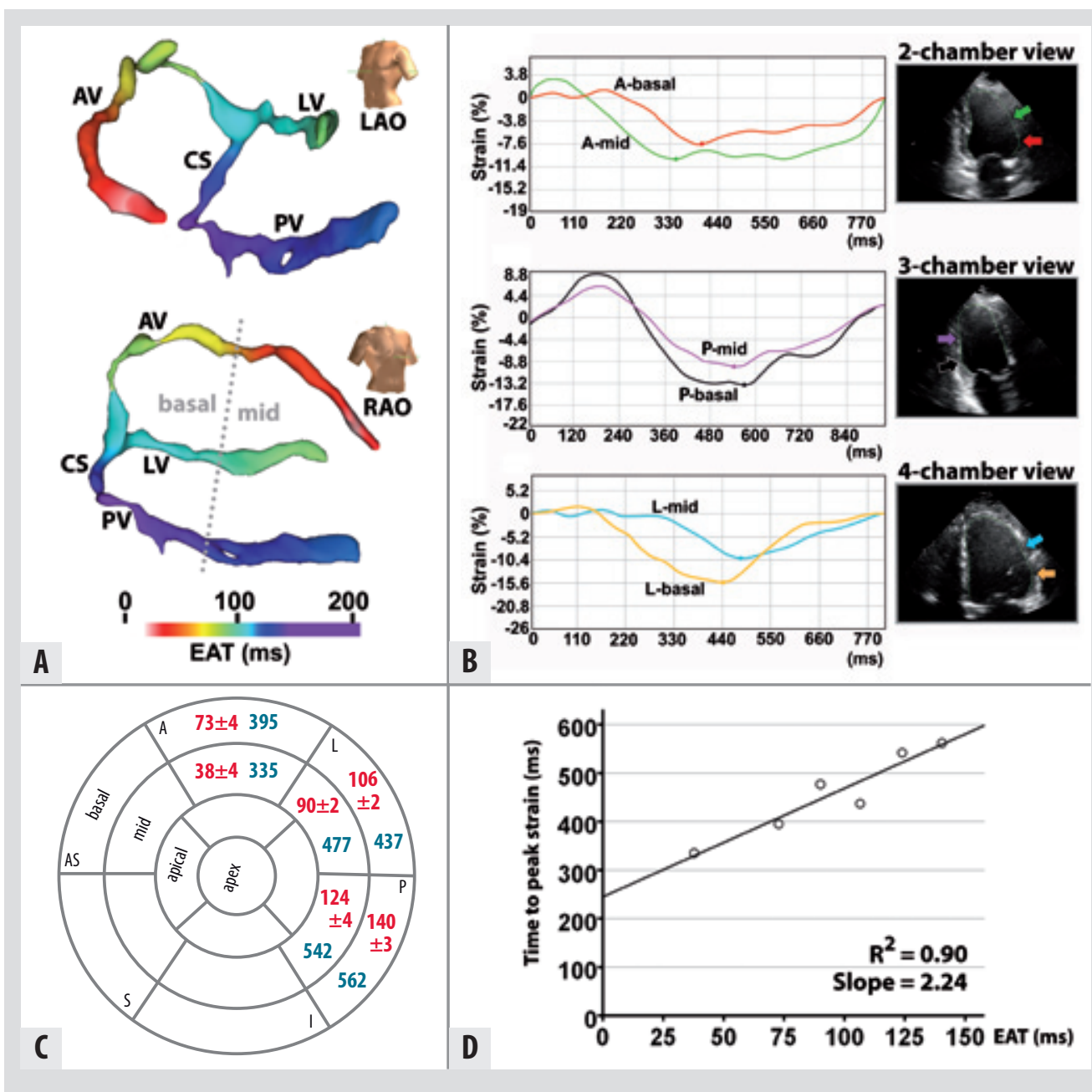

Figure 1. Analysis of electrical activation-peak contraction relationship in one patient. (A) Coronary venous EAM. The CS and three side branches (basal-and mid-segments) were mapped. Earliest activation is represented in white and red and latest activation in blue and purple. (B) Corresponding time strain curves of the mapped myocardial segments. (C) Electrical activation times (mean \pm standard deviation, red numbers) and corresponding peak contraction times (blue numbers) of the mapped myocardial segments of this patient displayed on a 17-segment bullseye of the heart. (D) Correlation between electrical activation and peak contraction times in this patient. $\mathrm{L} / \mathrm{RAO}$, left/right anterior oblique view; $\mathrm{CS}$, coronary sinus; $\mathrm{AV}$, anterior inter-ventricular vein; LV, lateral marginal vein; PV, posterior vein; EAT, electrical activation time; A, anterior; P, posterior; I, inferior; L, lateral; S, septal; $A S$, anteroseptal.
Speckle-tracking strain analysis was accomplished in 23 of 28 patients. In the other 5 patients, this was hampered by insufficient quality of the acquired echocardiographic images $(n=4)$ and frequent premature ventricular beats $(n=1)$. These 5 patients were excluded from further analysis. Myocardial segments with likely scar on echocardiography, which were handled as missing data, were encountered in only 2 of 23 patients, and comprised only $2 \%$ of all segments analyzed for time-to-peak strain.

The patient's hemodynamic parameters were similar during both studies. The intrinsic heart rhythm during both studies was unchanged for all patients. The mean heart rate was $69 \pm 14$ beats per minute during echocardiography and $71 \pm 11$ beats per minute during EAM $(P=0.33)$. The mean QRS duration was $156 \pm 16$ ms during echocardiography and $154 \pm 15$ ms during $\operatorname{EAM}(P=0.17)$.

\section{Relationship between left ventricular electrical activation and peak contraction}

Successful measurements by both coronary venous EAM and speckle-tracking echocardiography allowed analysis of the electrical activation-peak contraction relationship in 23 of 28 patients. An example of the analysis in one patient is shown in Figure 1. In this patient, the CS and three side branches situated on the basal and mid anterior-, lateral- and posterior wall were mapped (Figure 1A). Earliest electrical activation was found in the mid-segment of the anterior inter-ventricular vein and latest electrical activation in the basal-segment of the posterior vein. Figure $1 \mathrm{~B}$ shows the corresponding time-strain curves of the mapped myocardia segments obtained by speckle tracking echocardiography. In figure $1 C$, the average electrica activation times and corresponding peak contraction times of the mapped myocardia segments of this patient are displayed on a bullseye of the heart. Figure 1D shows the regression line between the electrical activation and peak contraction times for this patient. There was a strong correlation between electrical activation and peak contraction times within this patien $\left(R^{2}=0.90\right)$, and the segment of latest electrical activation corresponded with the segment of latest peak contraction.

A strong linear relationship between electrical activation and peak contraction times, as observed in the example shown in Figure 1 , was found in all patients $\left(R^{2}=0.85 \pm 0.09\right.$.

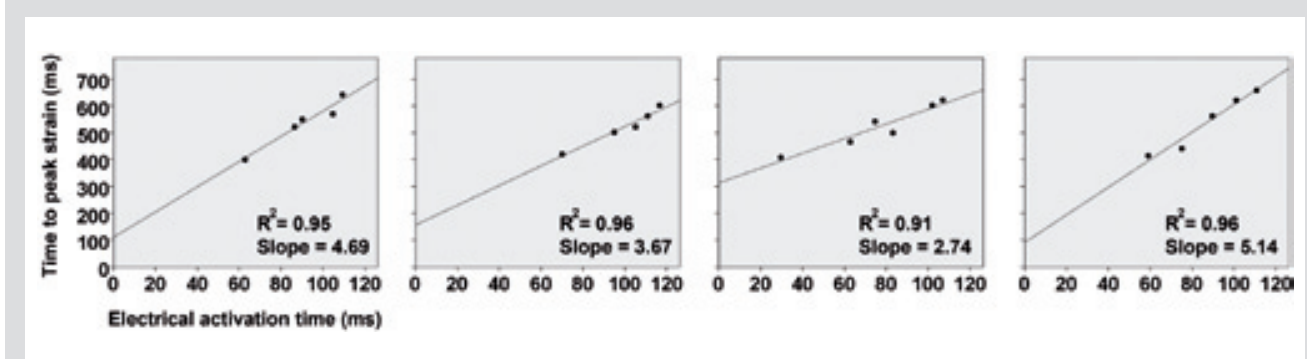

Figure 2. Inter-individual variability in electrical activation-peak contraction relationship. The regression lines between electrical activation and peak contraction times and the points by which these were created are shown for four representative patients. Each point was determined from measuring the electrical activation and peak contraction time of a myocardial segment within a patient. The electrical activation and peak contraction times of 5 myocardial segments (resulting in 5 points) were assessed in 3 of these patients and those of 6 myocardial segments (resulting in 6 points) were assessed in 1 patient. All regression lines exhibited high and positive correlation values $\left(R^{2}\right)$. Yet the slope and hence the magnitude of the electrical activation-peak contraction relationship varied greatly from patient to patient. 
The slope of the regression line between electrical activation and peak contraction times was positive in all patients, indicating that as electrical activation time increases, the peak contraction time increases as well. This implies that the sequence of peak contraction is similar to the electrical activation sequence, also for the non-latest segments. However, the slope and hence the magnitude of this relationship varied greatly between patients (slope of regression line $=4.05$ \pm 3.23 , Figure 2). Also, the slope of the regression line was above unity in all but one patient indicating that regional differences in timing of peak contraction were generally greater than those of electrical activation. Subgroup analysis showed no difference in the strength of the electro-mechanical relationship between patients with ischemic vs. non-ischemic LV dysfunction patients with LBBB vs. IVCD, or patients with sinus rhythm vs. atrial fibrillation (Table 2).

\section{Table 2. Subgroup analysis of the strength of the electro-mechanical relationship}

\begin{tabular}{|l|l|l|}
\hline Patient subgroups & $\mathrm{R}^{2}$ & $\mathrm{P}$ \\
\hline Ischemic- vs. non-ischemic LV dysfunction & $0.88 \pm 0.09$ vs $0.84 \pm 0.09$ & 0.29 \\
\hline LBBB vs IVCD & $0.86 \pm 0.10$ vs $0.84 \pm 0.08$ & 0.69 \\
\hline SR vs AF & $0.87 \pm 0.05$ vs $0.85 \pm 0.09$ & 0.70 \\
\hline
\end{tabular}

$\angle B B B$, left bundle-branch block; IVCD, non-specific intra-ventricular conduction delay; $S R$, sinus rhythm; AF, atrial fibrillation $R^{2}$, Pearson's correlation coefficient computed between the electrical activation and peak contraction times observed for each patient; $P, p$-value.

Figure 3 shows the spatial distribution of the electrically latest activated and lates contracting segments in all patients. The segment of latest electrical activation was located anteriorly in 11 (basal, $n=10 ; \mathrm{mid}, n=1$ ), laterally in 8 (basal, $n=5 ; \mathrm{mid}, n=3$ ), and posteriorly in 4 (all basal). The segment of latest peak contraction was located anteriorly in 11 (all basal), laterally in 8 (basal, $n=5 ; \mathrm{mid}, n=3$ ), and posteriorly in 4 (all basal). The myocardial segment with the largest electrical activation time also had the largest peak contraction time in 19 of 23 patients (83\%). In the other 4 patients, the myocardial segments of latest electrical activation and latest peak contraction were adjacent, which was defined as located directly next to each other on either the apical-basal axis (RAO view) or the short axis projection (LAO view), including touching diagonally.

\section{Discussion}

In the present study we investigated the relationship between the timing of regional LV electrical activation and peak contraction in dyssynchronous heart failure patients undergoing CRT implantation. We demonstrated a strong positive correlation between electrical activation and peak contraction times measured at potential LV pacing regions accessible via the coronary veins in all patients. However, the magnitude of the relationship between electrical activation and peak contraction times varied greatly between patients. The myocardial segments of latest electrical activation and latest peak contraction corresponded in $83 \%$ of patients. Our data indicate that a strategy of determining the latest activated LV region based on speckletracking strain patterns is equivalent to that based on intra-cardiac measurements of electrical activation.

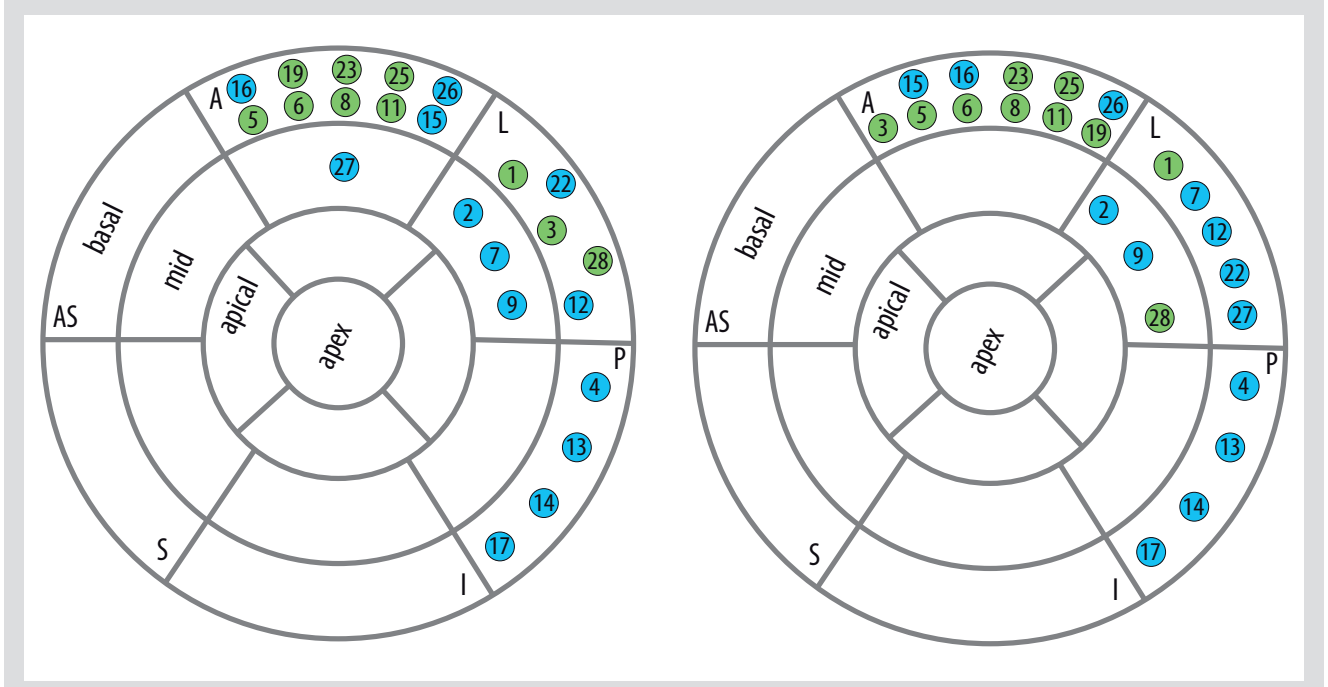

Figure 3. Spatial distribution of the electrically latest activated (left) and latest contracting segments (right) in the 23 patients with successful measurements by both coronary venous EAM and speckle-tracking echocardiography. Each circled number represents a patient with IBBB patients represented in blue and IVCD patients in green. The segment with the largest electric activation time also had the largest peak contraction time in 19 of 23 patients (83\%). In 4 patients (Nos. 3, 7, 27, and 28), the segments of latest electrical activation and latest peak contraction were adjacent. A, anterior; P, posterior; I, inferior; L, lateral; S, septal; $A$, anteroseptal.

\section{Relationship between timing of electrical activation and peak contraction}

A number of animal studies have previously studied the relation between the sequence of LV electrical activation and contraction using a combination of electrical mapping techniques and strain measurements. These studies were conducted in healthy spontaneously activated or paced canine hearts and focused on the relation between timing of electrical activation and time-to-onset of contraction, rather than peak contraction. A strong linear relation between timing of electrical activation and onset of contraction was found in these studies. In addition mechanical delay was shown to be larger than electrical delay. ${ }^{4,6}, 17,18$ While time-to-onset of contraction may be a better surrogate for mechanical activation than time-to-peak contrac tion, in practice, the identification of the first subtle onset of contraction can be cumbersome. Therefore, most clinical studies employed time-to-peak contraction., ${ }^{3,19}$

The findings of the present study are consistent with the results of a recent study by Suever et al., ${ }^{10}$ who investigated the relation between electrical and mechanical delay times measured at potential pacing locations within the coronary veins. In this study, the mechanical contraction times were computed using cross correlation of radial displacement curves from high temporal resolution cine cardiac magnetic resonance images, while electrical activation times were derived from intra-procedural local electrograms obtained using the LV lead. Similar to our findings, they found a strong correlation between electrical and mechanical delay times within each patient. Additionally, the electrically latest activated region corresponded with the latest contracting region in $91 \%$ of patients. 
Our results are also in line with a very recent study by Kroon et al. ${ }^{20}$ who used NOGA mapping derived electrograms and local strain derived from the motion of the NOGA cathete to investigate the relation between the timing of LV electrical activation and peak shortening in 10 CRT candidates. In this study, an excellent correlation was found between local electrical activation and peak shortening times in 8 of 10 patients.

However, our findings are in contrast to the results of a previous study that had a similar design as ours. In that study by Fujiwara et al., the electrically latest activated region as determined by coronary venous EAM matched with the latest contracting region as determined by speckle-tracking radial strain analysis in only $18 \%$ of patients, ${ }^{9}$ whereas we found that the regions of latest electrical activation and latest peak contraction corresponded in $83 \%$ of patients. An important methodological difference between our study and the study by Fujiwara et al. is the use of different types of strain measurements (radial vs. longitudinal). The Longitudinal strain measurements that were used in the present study have been shown to be more feasible and reproducible than radial strain measures. ${ }^{21,22}$ Also, in contrast to Fujiwara et al., we only measured peak contraction times of LV regions accessible via the coronary veins. In doing so we neglected the data on mechanical activation of the septum, because this part of the LV wall is not accessible from the CS and, most importantly, is unlikely to be activated late in LBBB-like conduction abnormalities. It was previously shown in computer simulations that septum strain patterns can be complicated and multiphasic, and can sometimes show a relatively late peak in systole, even in $\mathrm{LBBB},{ }^{23}$ which may lead to erroneously finding the latest peak contraction in the septum.

In the present study, the latest activated region was located on the anterior wall in 11 of 28 patients. This observation may be explained by the fact that seven of these patients did not have a typical LBBB morphology on ECG, and that the remaining four had an ischemic etiology of heart failure with myocardial scarring. In patients with non-ischemic LV dysfunction and $\mathrm{BBB}$, the latest activated region is typically located on the lateral or posterolateral wall. ${ }^{24} \mathrm{In}$ contrast, the LV activation pattern in patients with non-LBBB QRS morphology or patients with ischemic LV dysfunction has been shown to be more variable. ${ }^{25,26}$

\section{Inter-individual variability in electrical activation-peak contraction relationship}

In the present study, we found a strong linear relationship between timing of electrica activation and peak contraction within each patient. In addition, the relationship was positive in each patient, indicating that as electrical activation time increases, peak contraction time increases as well. However, the slope of the best fit line between electrical activation and peak contraction times was $4.06 \pm 3.23$, which indicates that the electrical activation-peak contraction relationship varied greatly between patients and that timing differences of myocardial contraction were greater than those of electrical activation. The differences in the electrical activation-peak contraction relation between hearts may be caused by inter-individual differences in local myocardial tissue properties, such as viability, contractility and stiffness of the myocardium..$^{20}$ The "amplification" of dyssynchrony when using mechanical measures is likely explained by the fact that peak contraction occurs much later in the cardiac cycle and the fact that early activated regions show a very early peak contraction whereas late activated regions are initially pre-stretched and subsequently show a more pronounced and prolonged contraction. ${ }^{4,5,23}$ In computer models of LBBB, the more pronounced mechanical rather than electrical delay has been attributed to the higher mechanical load that needs to be overcome by late activated regions, which causes onset of contraction to occur relatively late.5

\section{Clinical implications}

In the present study, we demonstrated that there is a strong correlation between timing of electrical activation and peak contraction and that the regions of latest electrical activation and latest peak contraction largely correspond within CRT patients. These findings suggest that current targeted LV lead placement strategies which are based on either direct intra-cardiac measurements of electrical activation or speckle-tracking strain echocardiography will most likely target the same myocardial region and as such can be regarded as equivalent. In this respect, the present study can be regarded as a validation of the speckle-tracking approach. This validation is not trivial, because echocardiographic measures of mechanical dyssynchrony have recently been questioned with respect to their ability to predict CRT response.7,8 Proposed explanations for these disappointing results have been that time-to-peak contraction may depend on other factors than electrical activation time alone and that there is a high variability in the way echocardiographic dyssynchrony parameters are acquired and analyzed. However, most of the problems faced with echocardiographic measures of mechanical dyssynchrony relate to difficulties in determining contraction time of the early-activated septum with its complicated, multi-phasic contraction patterns. In current practice, the LV lead is placed epicardially via the coronary veins, which only allow access to the LV free wall segments. Therefore, assessment of mechanical activation of the septum is not as important as that of the LV free wall for guiding LV lead placement. Limiting the assessment of time-to-peak contraction to the LV free wall avoids most of the problems faced during echocardiographic assessment of mechanical dyssynchrony. In daily clinical practice, speckle tracking time-to-peak contraction analysis of the LV free wall segments could be performed prior to CRT implantation during a separate pre-operative assessment which takes only a matter of minutes. This information can then be provided to the implanter during CRT implantation, who can then, after performing invasive coronary venous angiography, use the segmental approach ${ }^{13}$ to identify and match the location of the cardiac veins to the underlying LV myocardial segments and target the LV lead to the segment of latest peak contraction to enhance cardiac synchrony.

\section{Limitations}

The relatively small sample size is a limitation of this study. However, the study was performed on consecutive patients and the study population resembled the typical population of patients with dyssynchronous heart failure referred for CRT.

The small sample size did however preclude any systematic analysis of a relationship between targeting $L V$ lead placement to the latest activation region and clinical response Whether such a LV lead placement strategy actually increases the likelihood of a favourable CRT response needs prospective evaluation in larger and preferably randomized studies.

Epicardial mapping through the coronary veins is limited by coronary venous anatomy. The electrical activation time of some LV free wall segments could therefore not be assessed because they did not contain any veins.

Speckle-tracking echocardiography relies on the availability of echocardiographic images with sufficient quality for reliable assessment of strain patterns. Insufficient image quality and frequent premature ventricular beats hampered reliable assessment of segmental peak contraction times in 5 patients in this study. In these patients, the electrical activation-peak contraction relationship could therefore not be analyzed. 


\section{Conclusion}

The present study demonstrates that there is a strong positive correlation between the timing of LV electrical activation and peak contraction measured at potential LV pacing locations accessible via the coronary veins in typical CRT candidates. Additionally, the regions of latest electrical activation and latest peak contraction largely correspond within CRT patients. These findings suggests that a strategy of determining the latest activated LV region based on speckle-tracking echocardiography is equivalent to that based on intra-cardiac measurements of electrical activation.

\section{References}

. Linde C, Abraham WT, Gold MR, St John Sutton M, Ghio S, Daubert C. Randomized trial of cardiac resynchronization in mildly symptomatic heart failure patients and in asymptomatic patients with left ventricular dysfunction and previous heart failure symptoms. Journal of the American College of Cardiology 2008;52:1834-1843

2. Gold MR, Birgersdotter-Green U, Singh JP, Ellenbogen KA, Yu Y, Meyer TE, Seth M, Tchou PJ. The relationship between ventricular electrical delay and left ventricular remodelling with cardiac resynchronization therapy. European heart journal. 2011;32:2516-2524

3. Khan FZ, Virdee MS, Palmer CR, Pugh PJ, O'Halloran D, Elsik M, Read PA, Begley D, Fynn SP, Dutka DP. Targeted left ventricular lead placement to guide cardiac resynchronization therapy: The target study: A randomized, controlled trial. Journal of the American College of Cardiology. 2012;59:1509-1518

4. Prinzen $\mathrm{FW}$, Augustijn $\mathrm{CH}$, Allessie MA, Arts T, Delhaas T, Reneman RS. The time sequence of electrical and mechanical activation during spontaneous beating and ectopic stimulation. European heart journal. 1992;13:535-543

5. Russell K, Smiseth OA, Gjesdal O, Qvigstad E, Norseng PA, Sjaastad I, Opdahl A, Skulstad H, Edvardsen T, Remme EW. Mechanism of prolonged electromechanical delay in late activated myocardium during lef bundle branch block. American journal of physiology. Heart and circulatory physiology. 2011;301:H2334-2343

6. Wyman BT, Hunter WC, Prinzen FW, McVeigh ER. Mapping propagation of mechanical activation in the paced heart with mri tagging. The American journal of physiology. 1999;276:H881-891

7. Chung ES, Leon AR, Tavazzi L, Sun JP, Nihoyannopoulos P, Merlino J, Abraham WT, Ghio S, Leclercq C, Bax J J, Chung ES, Leon AR, Tavazzi L, Sun JP, Nihoyannopoulos P, Merlino J, Abraham WT, Ghio S, Leclercq C, Bax JJ,
Yu CM, Gorcsan J, 3rd, St John Sutton M, De Sutter J, Murillo J. Results of the predictors of response to crt (prospect) trial. Circulation. 2008;117:2608-2616

8. Ruschitzka F, Abraham WT, Singh JP, Bax JJ, Borer JS, Brugada J, Dickstein K, Ford I, Gorcsan J, 3rd, Gras D, Krum H, Sogaard P, Holzmeister J, Echo CRTSG. Cardiac-resynchronization therapy in heart failure with a narrow qrs complex. The New England journal of medicine. 2013;369:1395-1405

9. Fujiwara R, Yoshida A, Fukuzawa K, Takei A, Kiuchi K, Itoh M, Imamura K, Suzuki A, Nakanishi T, Yamashita S, Matsumoto A, Tanaka H, Hirata KI. Discrepancy between electrical and mechanical dyssynchrony in patients with heart failure and an electrical disturbance. Pacing Clin Electrophysiol. 2013

10. Suever JD, Hartlage GR, Magrath RP, 3rd, Iravanian S, Lloyd MS, Oshinski JN. Relationship between mechanica dyssynchrony and intra-operative electrical delay times in patients undergoing cardiac resynchronization therapy. Journal of cardiovascular magnetic resonance: official journal of the Society for Cardiovascular therapy. Journal of cardiovascic

11. Surawicz B, Childers R, Deal BJ, Gettes LS, Bailey JJ, Gorgels A, Hancock EW, Josephson M, Kligfield P, Kors JA, Macfarlane P, Mason JW, Mirvis DM, Okin P, PahIm O, Rautaharju PM, van Herpen G, Wagner GS, Wellens $\mathrm{H}$ American Heart Association E, Arrhythmias Committee CoCC, American College of Cardiology F, Heart Rhythm S. Aha/accf/hrs recommendations for the standardization and interpretation of the electrocardiogram: Part iii: Intraventricular conduction disturbances: A scientific statement from the american heart association electrocardiography and arrhythmias committee, council on clinical cardiology; the american college of cardiology foundation; and the heart rhythm society: Endorsed by the international society for computerized electrocardiology. Circulation. 2009;119:e235-240

12. Mafi Rad M, Blaauw Y, Dinh T, Pison L, Crijns HJ, Prinzen FW, Vernooy K. Left ventricular lead placement in the latest activated region guided by coronary venous electroanatomic mapping. Europace. 2014

13. Singh JP, Houser S, Heist EK, Ruskin JN. The coronary venous anatomy: A segmental approach to aid cardiac resynchronization therapy. Journal of the American College of Cardiology. 2005;46:68-74

14. Mele D, Agricola E, Galderisi M, Rigo F, Citro R, Dal Monte A, Della Valentina P, Calabrese A, Ferrari R, Study Group of Echocardiography ISoC. Echocardiographic myocardial scar burden predicts response to cardiac resynchronization therapy in ischemic heart failure. Journal of the American Society of Echocardiography: official publication of the American Society of Echocardiography. 2009;22:702-708

15. Hutyra M, Skala T, Kaminek M, Horak D, Kocher M, Tudos Z, Jarkovsky J, Precek J, Taborsky M. Speckle tracking 
echocardiography derived systolic longitudinal strain is better than rest single photon emission tomography perfusion imaging for nonviable myocardium identification. Biomedical papers of the Medical Faculty of the University Palacky, Olomouc, Czechoslovakia. 2013;157:12-21

16. De Boeck BW, Teske AJ, Meine M, Leenders GE, Cramer MJ, Prinzen FW, Doevendans PA. Septal rebound stretch reflects the functional substrate to cardiac resynchronization therapy and predicts volumetric and neurohormonal response. European journal of heart failure. 2009;11:863-871

17. Badke FR, Boinay P, Covell JW. Effects of ventricular pacing on regional left ventricular performance in the dog. The American journal of physiology. 1980;238:H858-867

18. Faris OP, Evans FJ, Ennis DB, Helm PA, Taylor JL, Chesnick AS, Guttman MA, Ozturk C, McVeigh ER. Novel technique for cardiac electromechanical mapping with magnetic resonance imaging tagging and an epicardial electrode sock. Annals of biomedical engineering. 2003;31:430-440

19. Saba S, Marek J, Schwartzman D, Jain S, Adelstein E, White P, Oyenuga OA, Onishi T, Soman P, Gorcsan J, 3rd Echocardiography-guided left ventricular lead placement for cardiac resynchronization therapy: Result of the speckle tracking assisted resynchronization therapy for electrode region trial. Circulation. Hear failure. 2013;6:427-434

20. Kroon W, Lumens J, Potse M, Suerder D, Klersy C, Regoli F, Murzilli R, Moccetti T, Delhaas T, Krause R, Prinzen FW, Auricchio A. In-vivo electro-mechanical assessment of heart failure patients with prolonged grs duration. Heart rhythm: the official journal of the Heart Rhythm Society. 2015;In press

21. Miyazaki C, Redfield MM, Powell BD, Lin GM, Herges RM, Hodge DO, Olson LJ, Hayes DL, Espinosa RE, Rea RF, Bruce CJ, Nelson SM, Miller FA, Oh JK. Dyssynchrony indices to predict response to cardiac resynchronization therapy: A comprehensive prospective single-center study. Circulation. Heart failure. 2010;3:565-573

22. Cheng S, Larson MG, McCabe EL, Osypiuk E, Lehman BT, Stanchev P, Aragam J, Benjamin EJ, Solomon SD, Vasan RS. Reproducibility of speckle-tracking-based strain measures of left ventricular function in a community-based study. Journal of the American Society of Echocardiography: official publication of the American Society of Echocardiography. 2013;26:1258-1266 e1252

23. Lumens J, Leenders GE, Cramer MJ, De Boeck BW, Doevendans PA, Prinzen FW, Delhaas T. Mechanistic evaluation of echocardiographic dyssynchrony indices: Patient data combined with multiscale computer simulations. Circulation. Cardiovascular imaging. 2012;5:491-499

24. Auricchio A, Fantoni C, Regoli F, Carbucicchio C, Goette A, Geller C, Kloss M, Klein H. Characterization of left ventricular activation in patients with heart failure and left bundle-branch block. Circulation 2004;109:1133-1139

25. Ploux S, Lumens J, Whinnett Z, Montaudon M, Strom M, Ramanathan C, Derval N, Zemmoura A, Denis A, De Guillebon M, Shah A, Hocini M, Jais P, Ritter P, Haissaguerre M, Wilkoff BL, Bordachar P. Noninvasive electrocardiographic mapping to improve patient selection for cardiac resynchronization therapy: Beyond qrs duration and left bundle branch block morphology. Journal of the American College of Cardiology. 2013;61:2435-2443

26. Eschalier R, Ploux S, Ritter P, Haissaguerre M, Ellenbogen KA, Bordachar P. Nonspecific intraventricular conduction delay: Definitions, prognosis, and implications for cardiac resynchronization therapy. Heart rhythm: the official journal of the Heart Rhythm Society. 2015;12:1071-1079 


\section{Identifying delayed left}

ventricular lateral wall activation in patients with non-specific intra-ventricular conduction delay using coronary venous electroanatomic mapping

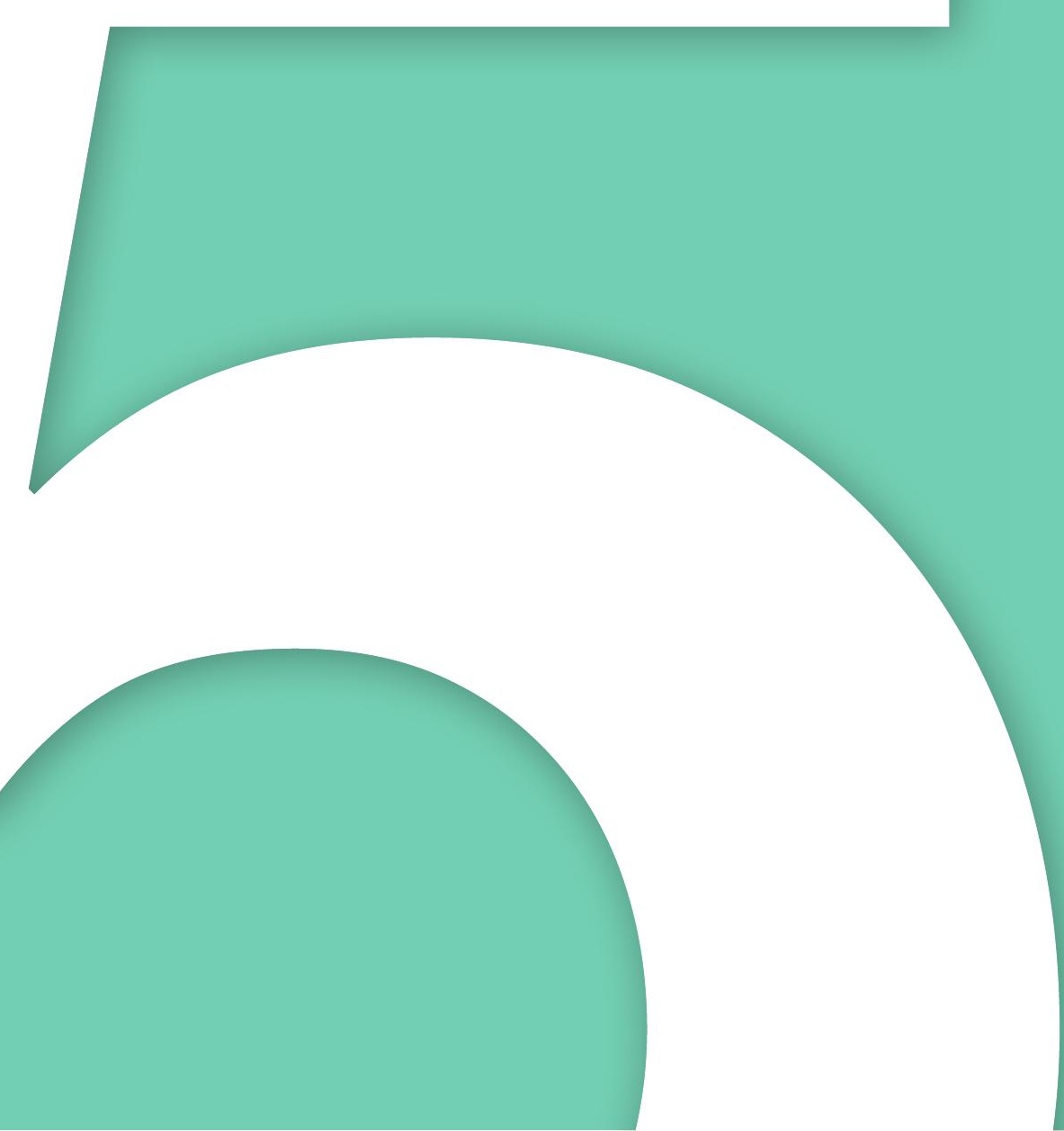

Masih Mafi Rad*, Antonius M. W. van Stipdonk*, Justin G.L.M. Luermans, Harry J. Crijns, Frits W. Prinzen, Kevin Vernooy

*Authors contributed equally to this manuscript

Neth Heart J. 2016 Jan;24(1):58-65 


\section{Abstract}

Aim: Delayed left ventricular (LV) lateral wall (LVLW) activation is considered the electrical substrate that characterizes patients suitable for cardiac resynchronization therapy (CRT). Although typically associated with left bundle-branch block, delayed LVLW activation may also be present in patients with non-specific intra-ventricular conduction delay (IVCD). We assessed LVLW activation in a cohort of CRT candidates with IVCD using coronary venous electroanatomic mapping (EAM), and investigated whether baseline QRS characteristics on the ECG can identify delayed LVLW activation in this group of patients.

Methods: Twenty-three consecutive CRT candidates with IVCD underwent intraprocedural coronary venous EAM using EnSite NavX. Electrical activation time (AT) was measured in ms from QRS onset and expressed as percentage of QRS duration. LVLW activation was considered delayed if maximal AT measured at the LVLW (LVLW-AT) exceeded $75 \%$ of QRS duration. QRS morphology, -duration, -fragmentation, -axis deviation, and left anterior/posterior fascicular block were assessed on baseline ECGs.

Results: Delayed LVLW activation occurred in 12 of 23 patients [maximal LVLW-AT = $133 \pm 20 \mathrm{~ms}(83 \pm 5 \%)$ of QRS duration)]. In these patients, the latest activated region was consistently located on the basal lateral wall. QRS duration and prevalence of QRS fragmentation, left/right axis deviation, and left anterior/posterior fascicular block did not differ between patients with and without delayed LVLW activation.

Conclusion: Coronary venous EAM can be used at the time of CRT implantation to determine the presence of delayed LVLW activation in patients with IVCD. QRS characteristics on the ECG seem unable to identify delayed LVLW activation in this subgroup of patients.

\section{Introduction}

The supposed mechanism of the benefit of cardiac resynchronization therapy (CRT) is that delayed activation of the left ventricular (LV) lateral wall (LVLW) causes mechanical dysfunction which can be reverted by paced pre-excitation of this delayed LV region. Left bundle-branch block (LBBB) is typically associated with early septal activation and delayed activation of the LVLW. ${ }^{1-3}$ Non-specific intra-ventricular conduction delay (IVCD), on the other hand, is considered a more heterogeneous group of conduction disorders exhibiting a more variable pattern of ventricular electrical activation. ${ }^{3}$ This may explain why, in contrast to patients with LBBB, patients with IVCD show a variable response to CRT. ${ }^{4}$ The reduced benefit of CRT observed in this subgroup of patients has led international guidelines to assign a lower level of recommendation to CRT in patients with IVCD. ${ }^{5}$ However, recent studies have suggested that CRT may be beneficial in a subset of IVCD patients with evidence of LV activation delay. ${ }^{6-9}$ Recently, we introduced coronary venous electroanatomic mapping (EAM) as a tool to assess LV electrical activation at the time of CRT implantation in patients with LBBB. ${ }^{10}$

The objectives of the present study were (1) to investigate whether coronary venous EAM can be used at the time of CRT implantation to determine the presence of delayed LVLW activation in patients with IVCD, and (2) to investigate whether QRS characteristics on the ECG, other than QRS morphology, can identify delayed LVLW activation as determined by coronary venous EAM in this subgroup patients.

\section{Methods}

\section{Study population}

Twenty-three consecutive patients referred for CRT device implantation, with LV ejection fraction (LVEF) $<35 \%$, New York Heart Association (NYHA) functional class II, III or ambulatory IV, and IVCD with QRS duration $\geq 120 \mathrm{~ms}$ were enrolled. Non-specific intra-ventricular conduction delay was defined as a QRS duration $\geq 120 \mathrm{~ms}$ without typical features of $\mathrm{LBBB}$ or right bundlebranch block (RBBB), according to accepted criteria. ${ }^{11}$ The study protocol was approved by the Institutional Review Board.

\section{Electroanatomic mapping}

Coronary venous 3D EAM was performed at the time of CRT implantation as described previously. ${ }^{10}$ In brief, prior to LV lead placement, a 0.014 inch guidewire (Vision Wire, Biotronik SE \& Co.KG), which permits unipolar sensing and pacing, was inserted into the coronary sinus (CS) and connected to an EnSite NavX system (St Jude Medical). The guidewire was manipulated to all CS branches located on the inferolateral or anterolateral LV wall as defined by the American Heart Association (AHA) 17-segment heart model, ${ }^{12}$ creating an anatomic map along with determining local electrical activation time (AT) during intrinsic ventricular activation. Local AT was measured in ms from QRS onset on surface ECG and expressed as percentage of total QRS duration. Activation of the LVLW was considered delayed if maximal AT measured at the LVLW (maximal LVLW-AT) exceeded 75\% of total QRS duration. This definition was chosen because epicardial mapping via the coronary veins is limited by coronary venous anatomy, which means that some areas cannot be mapped because they do not contain any veins. Therefore the latest activated LV region can only be identified using coronary venous mapping by relating the electrical activation time of the anatomical region to its timepoint within the QRS complex. We believe that an electrical activation time exceeding $75 \%$ of QRS duration is a reasonable definition for delayed LVLW activation, especially since previous studies have shown that 
positioning of the LV lead over a region of the heart with an electrical delay of just over $50 \%$ of total QRS duration is associated with superior CRT outcome. After the mapping procedure, the LV lead was positioned in or as close as possible to the region of maximal electrical delay based on current evidence and recommendations. ${ }^{13,14}$

\section{ECG assessment}

Twelve-lead ECGs were assessed by 2 experienced clinicians blinded to patient data and mapping results. Any disagreement was reviewed together before achieving consensus. QRS duration was assessed in the lead with the widest QRS. The QRS axis was derived from the automatically computed value on the ECG. Left (LAD) and right axis deviation (RAD), as well as the presence of left anterior (LAFB) and posterior fascicular block (LPFB) were defined according to AHA/ACC/HRS criteria, ${ }_{11}^{11}$ excluding the criterion of QRS duration $<120$ ms because of coexisting IVCD. QRS fragmentation was defined according to Das et al. ${ }_{15}^{15}>2$ notches in at least 2 contiguous leads, or multiple notches in the $\mathrm{R}$ wave, or $>2$ notches in the nadir of the $\mathrm{S}$ wave. The region of notching was classified as anterior when observed in leads V1-5, inferior when observed in II, III, aVF and lateral when observed in leads I, aVL, V6.

\section{Statistical analysis}

Continuous variables are expressed as mean \pm standard deviation and were compared using Mann-Whitney $\mathrm{U}$ test. Categorical variables are expressed as observed numbers and percentage values, and were compared using Fisher's exact test. Statistical significance was accepted at the $95 \%$ confidence interval $(C I)(P<0.05)$. Statistical analysis was performed using SPSS version 22.0 (SPSS Inc.) software.

\section{Results}

Patient characteristics

Tweny-three patients with IVCD referred for CRT implantation were included in this study The patient characteristics are presented in Table 1

\section{Table 1. Patient characteristics $(n=23)$}

\begin{tabular}{|l|l|}
\hline Variable & value \\
\hline Men & $16(64)$ \\
\hline Age & $72 \pm 10$ \\
\hline Ischemic aetiology & $18(72)$ \\
\hline NYHA class & \\
\hline II & $15(60)$ \\
\hline III & $9(36)$ \\
\hline IV & $1(4)$ \\
\hline LVEF (\%) & $29 \pm 5$ \\
\hline QRS duration (ms) & $158 \pm 23$ \\
\hline
\end{tabular}

Values are in means \pm standard deviations or numbers (percentage values). NYHA, New York Heart Association; LVEF, left ventricular ejection fraction.

\section{Results of electroanatomic mapping}

Coronary venous EAM was accomplished without complications in all patients. A mean number of $2.8 \pm 0.7 \mathrm{CS}$ branches were mapped during the procedure, of which $1.9 \pm 0.5$ were located on the LVLW. Three-dimensional electrical activation maps were generated from $79 \pm 18$ unique anatomic points. Mapping time was $18 \pm 5$ minutes, fluoroscopy time during the entire

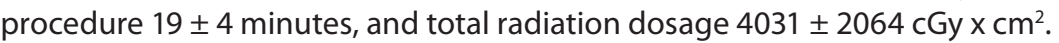

Delayed LVLW activation, defined as maximal LVLW-AT exceeding $75 \%$ of total QRS duration occurred in 12 of 23 (52\%) patients. In Table 2, LVLW-AT data are presented for patients with and without delayed LVLW activation. In patients with delayed LVLW activation, maxima LVLW-AT was $133 \pm 20 \mathrm{~ms}$ ( $83 \pm 5 \%$ of QRS duration) and ranged from 103 to $181 \mathrm{~ms}$ ( $75 \%$ - 93\% of QRS duration). In patients without delayed LVLW activation, maximal LVLW-AT was $100 \pm 19 \mathrm{~ms}$ ( $64 \pm 9 \%$ of QRS duration) and ranged from 69 to $138 \mathrm{~ms}$ ( $45-74 \%$ of QRS duration). The number of lateral veins that were mapped did not differ between patients with and without delayed LVLW activation $(P=0.92)$. Also, baseline characteristics did not differ between the two groups. In patients with delayed LVLW activation, the most delayed lateral region was more frequently located on the "basal" lateral wall than in patients without delayed LVLW activation $(P=0.03)$.

\begin{tabular}{|c|c|c|c|}
\hline Variable & $\begin{array}{l}\text { Delayed LV } \\
\text { activation }(n=12)\end{array}$ & $\begin{array}{l}\text { No delayed LV } \\
\text { activation }(n=11)\end{array}$ & $P$ \\
\hline Maximal LVLW-AT (ms) & $133 \pm 20$ & $100 \pm 19$ & \\
\hline Maximal LVLW-AT (\% of QRS) & $83 \pm 5$ & $64 \pm 9$ & \\
\hline \multicolumn{4}{|l|}{ Region of maximal LVLW-AT } \\
\hline Basal anterolateral & $7(58.3)$ & $2(18.2)$ & 0.09 \\
\hline Basal inferolateral & $4(33.3)$ & $3(27.3)$ & 1.00 \\
\hline Mid anterolateral & $1(8.3)$ & $4(36.4)$ & 0.16 \\
\hline Mid inferolateral & 0 & $2(18.2)$ & 0.22 \\
\hline
\end{tabular}

Values are in means \pm standard deviations or numbers (percentage values). LVLW-AT, left ventricular lateral wall activation time.

Figure 1 shows examples of coronary venous EAMs of 2 patients with and without delayed LVLW activation. In the example shown in panel A, the CS and three side branches located on the anterior, inferior and inferolateral wall were mapped. Delayed activation [139 ms ( $80 \%$ of QRS duration)] was found in the basal region of the inferolateral vein. In the example shown in panel $\mathrm{B}$, coronary veins on both the anterolateral and inferolateral wall were mapped, but delayed activation could not be measured in either vein. 


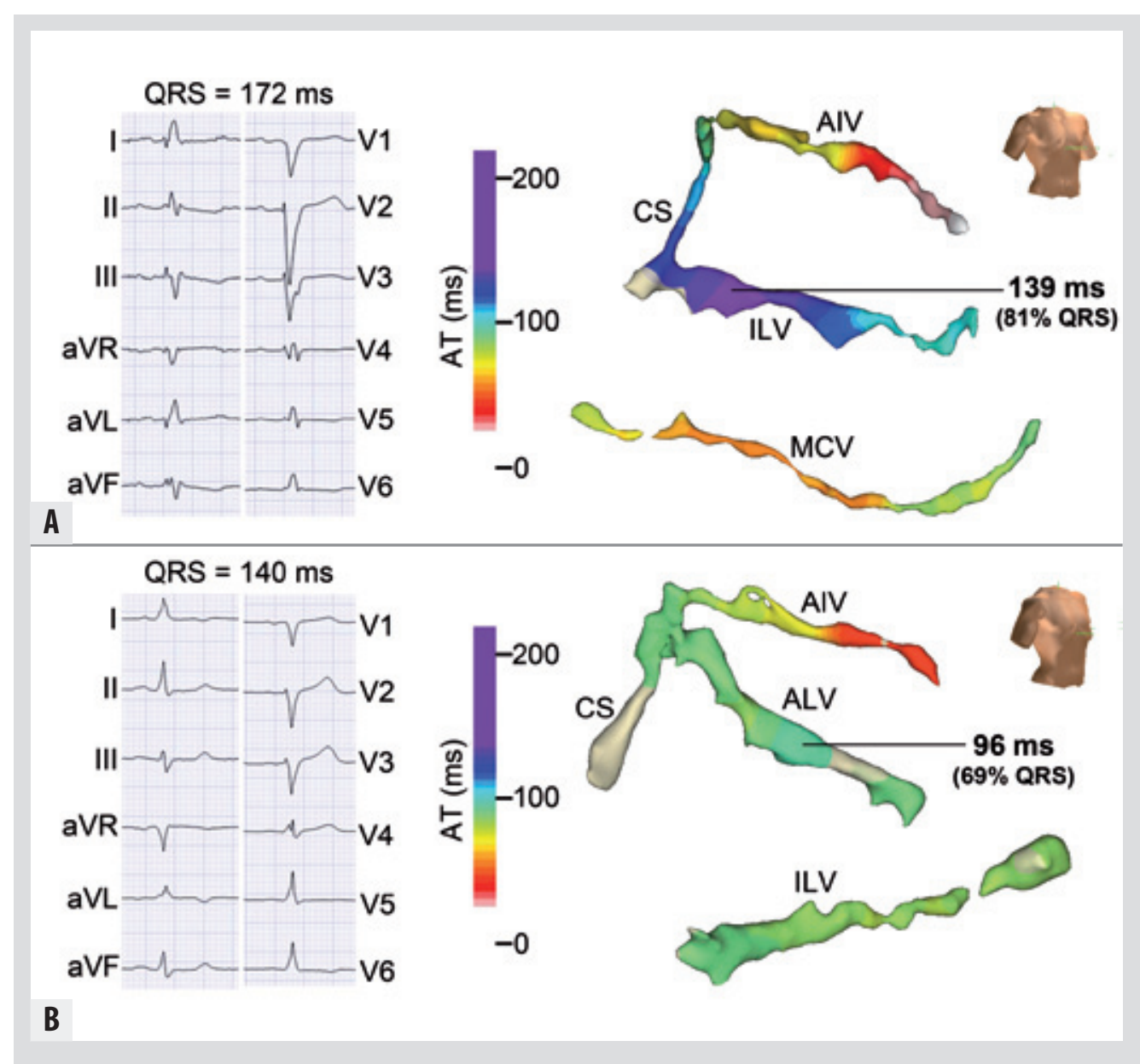

Figure 1. Coronary venous EAM of a patient with (A) and without (B) delayed LVLW activation together with the corresponding 12 lead ECGs (left). Local electrical activation time was measured in ms from QRS onset and projected on the maps using colour coding. Earliest activation is presented in white and red and latest activation in blue and purple. Grey indicates regions mapped too sparsely to fill data. AT, electrical activation time; AIV, anterior inter-ventricular vein; MCV, mid cardiac vein, IVV, inferolateral vein; ALV, anterolateral vein; $C S$. coronary sinus.

\section{ECG parameters in patients with and without delayed LVLW activation}

The ECG characteristics of patients with and without delayed LVLW activation are presented in Table 3. QRS duration did not differ between patients with and without delayed LVLW activation. Neither was there a difference in the prevalence of LAD, RAD, LAFB, LPFB or QRS fragmentation between patients with and without delayed LVLW activation. There was also no difference in the distribution of the regions with QRS fragmentation between the two groups.
Table 3. ECG parameters in patients with and without delayed activation of the LV

\section{lateral wall}

\begin{tabular}{l|l|l|l}
\hline Variable & $\begin{array}{l}\text { Delayed LVLW } \\
\text { activation }(n=12)\end{array}$ & $\begin{array}{l}\text { No delayed LVLW } \\
\text { activation }(n=11)\end{array}$ & P \\
\hline QRS duration (ms) & $159 \pm 19$ & $157 \pm 27$ & 0.46 \\
\hline Left axis deviation & $5(46)$ & $6(55)$ & 1.00 \\
\hline Right axis deviation & $1(9)$ & 0 & 1.00 \\
\hline Left anterior fascicular block & $4(36)$ & $6(55)$ & 0.67 \\
\hline Left posterior fascicular block & $1(9)$ & 0 & 1.00 \\
\hline QRS fragmentation & $7(64)$ & $5(46)$ & 0.67 \\
\hline Region of QRS fragmentation & & & \\
\hline Anterior & $2(18)$ & $2(17)$ & 1.00 \\
\hline Inferior & $4(33)$ & $3(27)$ & 1.00 \\
\hline Lateral & $5(42)$ & $2(18)$ & 0.37
\end{tabular}

Values are in means \pm standard deviations or numbers (percentage values). LVLW, left ventricular lateral wall.

\section{Discussion}

Delayed activation of the LVLW is considered the electrical substrate underlying LV dysfunction amenable to CRT, and may be present in patients without LBBB QRS morphology. ${ }^{6}, 16$ The present study demonstrates that coronary venous EAM can be used at the time of CRT implantation to determine the presence of delayed LVLW activation and specify the latest activated region in CRT candidates with IVCD. Delayed LVLW activation was found in approximately half of the patients. In patients with delayed activation, the location of the latest activated region was practically confined to the "basal" lateral wall, whereas patients without delayed activation showed a more heterogeneous distribution of the latest activated region on the LVLW. Baseline 12-lead ECG QRS characteristics were not able to identify the presence of delayed LVLW activation as determined by coronary venous EAM.

\section{Delayed LVLW activation in IVCD patients.}

The present study demonstrates that coronary venous EAM can be used at the time of CRT implantation to identify IVCD patients with delayed LVLW activation.

Detailed 3D LV mapping in patients with IVCD has so far been limited to a single case series recently published by Ploux et al. ${ }^{6}$ The authors characterized LV epicardial electrical activation of 15 IVCD patients referred for CRT implantation using non-invasive 3D electrocardiographic imaging (ECGi) and found significant LV activation delay in $3(20 \%)$ of these patients. Additionally, the presence of LV activation delay in IVCD patients was shown to be associated with clinical response to CRT. Several other studies have also suggested that CRT may be beneficial in subset of non-LBBB patients with evidence of LV activation delay. ${ }^{9}, 17,18$

\section{Latest activated region}

In patients with delayed LVLW activation, the region of latest activation was similar to that observed in previous mapping studies of patients with LBBB. ${ }^{2,3,6,19}$ This observation suggests 
the presence of a conduction disturbance at a similar level of that observed in patients with LBBB despite the absence of a typical LBBB morphology on surface ECG. On the other hand, in patients without delayed LVLW activation, the location of the latest activated region was more heterogeneous, which suggests that QRS widening in these patients may have a differen underlying etiology such as LV hypertrophy, LV enlargement, myocardial fibrosis or conduction disturbances located more distally than the usual sites at the bundle branches. ${ }^{3}$ These findings correspond with the results of a recent study by Eschalier et al. who characterized a subset of patients with IVCD that had ventricular conduction properties similar to that of LBBB patients, but did not display typical LBBB characteristics on the 12-lead ECG.

\section{Diagnostic performance of ECG parameters for delayed LVLW activation}

Patient selection in CRT has been primarily based on a wide QRS complex. ${ }^{5}$ Yet in the present study we found that a larger QRS duration was not associated with delayed LVLW activation in patients with IVCD. This may be explained by the fact that QRS duration is merely a surface depiction of biventricular depolarization time, sensitive to conduction delay in either the left or right ventricle.

With respect to the frontal QRS axis, neither left nor right axis deviation was associated with delayed LVLW activation in the present study. Especially the lack of delayed LVLW activation in patients with left axis deviation was remarkable, as this is considered a sign of LV involvement in conduction delay. A possible explanation for this finding is that in heart failure patients, axis deviation may often be the result of a change in the anatomical position of the heart due to for instance LV dilatation, rather than an actual change in the vector of electrical conduction ${ }^{21,22}$ Although even more specific for left ventricular conduction delay, in this study neither anterio nor posterior fascicular block was associated with the presence of delayed LVLW activation.

Given the fact that the presence of myocardial scar and ischemic cardiomyopathy in more broader sense have been shown to reduce the likelihood of a favorable response to CRT, ${ }^{23-25}$ we hypothesized that ECG markers of myocardial scarring/fibrosis have an inverse relationship with delayed LVLW activation. Various ECG parameters have been related to the presence or extent of myocardial scarring. ${ }^{26}$ Yet the majority of these parameters have not been validated in patients with ventricular conduction disorders. QRS fragmentation has previously been shown to indicate the presence of myocardial scarring and to predict worse outcome in patients with conduction disorders. 15,27 However, in the present study a significant relationship between QRS fragmentation and delayed LVLW was not found. These results are in line with the findings of two earlier studies that found no relation between the presence of QRS fragmentation and echocardiographic response to CRT. ${ }^{28,29}$

\section{Limitations}

The present study demonstrates the presence of delayed LVLW activation in approximately $50 \%$ of IVCD patients. Admittedly, the study lacks data on acute hemodynamic response and long-term clinical outcome. Whether delayed LVLW activation is also associated with CRT response in this group of patients needs to be confirmed in subsequent, larger and long-term follow up studies.

The small sample size of this study precludes extrapolating the results in our cohort of IVCD patients to larger populations. Nevertheless, the study population was large enough to demonstrate the feasibility of coronary venous EAM to determine the presence of delayed LVLW activation in CRT candidates with IVCD.

\section{Conclusion}

Coronary venous EAM can be used at the time of CRT implantation to identify IVCD patients with delayed LVLW activation, who are more likely to benefit from CRT. Baseline QRS characteristics on the ECG seem unable to identify delayed LVLW activation in this subgroup of patients. 


\section{References}

1. Sweeney MO, van Bommel RJ, Schalij MJ, Borleffs CJ, Hellkamp AS and Bax JJ. Analysis of ventricular activatio using surface electrocardiography to predict left ventricular reverse volumetric remodeling during cardiac resynchronization therapy. Circulation. 2010;121:626-34.

2. Auricchio A, Fantoni C, Regoli F, Carbucicchio C, Goette A, Geller C, Kloss M and Klein H. Characterization of left ventricular activation in patients with heart failure and left bundle-branch block. Circulation 2004;109:1133-9.

3. Eschalier R, Ploux S, Lumens J, Whinnett Z, Varma N, Meillet V, Ritter P, Jais P, Haissaguerre M and Bordachar $P$. Detailed analysis of ventricular activation sequences during right ventricular apical pacing and left bundle branch block and the potential implications for cardiac resynchronization therapy. Heart rhythm: the officia journal of the Heart Rhythm Society. 2015;12:137-43.

4. Sipahi I, Chou JC, Hyden M, Rowland DY, Simon DI and Fang JC. Effect of QRS morphology on clinical event reduction with cardiac resynchronization therapy: meta-analysis of randomized controlled trials. American heart journal. 2012;163:260-7 e3.

5. Authors/Task Force M, Brignole M, Auricchio A, Baron-Esquivias G, Bordachar P, Boriani G, Breithardt OA, Cleland J, Deharo JC, Delgado V, Elliott PM, Gorenek B, Israel CW, Leclercq C, Linde C, Mont L, Padeletti Sutton R, Vardas PE, Guidelines ESCCFP, Zamorano JL, Achenbach S, Baumgartner H, Bax JJ, Bueno H, Dean V Deaton C, Erol C, Fagard R, Ferrari R, Hasdai D, Hoes AW, Kirchhof P, Knuuti J, Kolh P, Lancellotti P, Linhart A, Nihoyannopoulos P, Piepoli MF, Ponikowski P, Sirnes PA, Tamargo JL, Tendera M, Torbicki A, Wijns W, Windecker S, Document R, Kirchhof P, Blomstrom-Lundqvist C, Badano LP, Aliyev F, Bansch D, Baumgartner $\mathrm{H}$ Bsata W, Buser P, Charron P, Daubert JC, Dobreanu D, Faerestrand S, Hasdai D, Hoes AW, Le Heuzey JY, Mavrakis H, McDonagh T, Merino JL, Nawar MM, Nielsen JC, Pieske B, Poposka L, Ruschitzka F, Tendera M Van Gelder IC and Wilson CM. 2013 ESC Guidelines on cardiac pacing and cardiac resynchronization therapy: The Task Force on cardiac pacing and resynchronization therapy of the European Society of Cardiology (ESC). Developed in collaboration with the European Heart Rhythm Association (EHRA). European heart journal. 2013;34:2281-329

6. Ploux S, Lumens J, Whinnett Z, Montaudon M, Strom M, Ramanathan C, Derval N, Zemmoura A, Denis A, De Guillebon M, Shah A, Hocini M, Jais P, Ritter P, Haissaguerre M, Wilkoff BL and Bordachar P. Noninvasive electrocardiographic mapping to improve patient selection for cardiac resynchronization therapy: beyond QRS duration and left bundle branch block morphology. Journal of the American College of Cardiology. 2013;61:2435-43.

7. Chandra R, Zolty R and Palma E. A left hemiblock improves cardiac resynchronization therapy outcomes in patients with a right bundle branch block. Clin Cardiol. 2010;33:89-93.

8. Hara H, Oyenuga OA, Tanaka H, Adelstein EC, Onishi T, McNamara DM, Schwartzman D, Saba S and Gorcsan J, 3rd. The relationship of QRS morphology and mechanical dyssynchrony to long-term outcome following cardiac resynchronization therapy. European heart journal. 2012;33:2680-91.

. Kandala J, Upadhyay GA, Altman RK, Parks KA, Orencole M, Mela T, Kevin Heist E and Singh JP. QR morphology, left ventricular lead location, and clinical outcome in patients receiving cardiac resynchronization therapy. European heart journal. 2013;34:2252-62.

10. Mafi Rad M, Blaauw Y, Dinh T, Pison L, Crijns HJ, Prinzen FW and Vernooy K. Left ventricular lead placemen in the latest activated region guided by coronary venous electroanatomic mapping. Europace: European pacing, arrhythmias, and cardiac electrophysiology: journal of the working groups on cardiac pacing arrhythmias, and cardiac cellular electrophysiology of the European Society of Cardiology. 2015;17:84-93.

11. Surawicz B, Childers R, Deal BJ, Gettes LS, Bailey JJ, Gorgels A, Hancock EW, Josephson M, Kligfield P, Kors JA, Macfarlane P, Mason JW, Mirvis DM, Okin P, PahIm O, Rautaharju PM, van Herpen G, Wagner GS, Wellens H, American Heart Association E, Arrhythmias Committee CoCC, American College of Cardiology F and Heart Rhythm S. AHA/ACCF/HRS recommendations for the standardization and interpretation of the electrocardiogram: part III: intraventricular conduction disturbances: a scientific statement from the American
Heart Association Electrocardiography and Arrhythmias Committee, Council on Clinical Cardiology; the American College of Cardiology Foundation; and the Heart Rhythm Society: endorsed by the Internationa Society for Computerized Electrocardiology. Circulation. 2009;119:e235-40.

12. Cerqueira MD, Weissman NJ, Dilsizian V, Jacobs AK, Kaul S, Laskey WK, Pennell DJ, Rumberger JA, Ryan T, Verani MS, American Heart Association Writing Group on Myocardial $S$ and Registration for Cardiac Standardized myocardial segmentation and nomenclature for tomographic imaging of the heart. A statement for healthcare professionals from the Cardiac Imaging Committee of the Council on Clinica Cardiology of the American Heart Association. Journal of nuclear cardiology: official publication of the American Society of Nuclear Cardiology. 2002;9:240-5.

13. Gold MR, Birgersdotter-Green U, Singh JP, Ellenbogen KA, Yu Y, Meyer TE, Seth M and Tchou PJ. The relationship between ventricular electrical delay and left ventricular remodelling with cardiac resynchronization therapy. European heart journal. 2011;32:2516-24.

14. Khan FZ, Virdee MS, Palmer CR, Pugh PJ, O'Halloran D, Elsik M, Read PA, Begley D, Fynn SP and Dutka DP. Targeted left ventricular lead placement to guide cardiac resynchronization therapy: the TARGET study: a randomized, controlled trial. Journal of the American College of Cardiology. 2012;59:1509-18.

15. Das MK, Suradi H, Maskoun W, Michael MA, Shen C, Peng J, Dandamudi G and Mahenthiran J. Fragmented wide QRS on a 12-lead ECG: a sign of myocardial scar and poor prognosis. Circulation Arrhythmia and electrophysiology. 2008;1:258-68.

16. Varma N. Left ventricular conduction delays and relation to QRS configuration in patients with left ventricular dysfunction. The American journal of cardiology. 2009;103:1578-85.

17. Chandra R, Zolty R and Palma E. A left hemiblock improves cardiac resynchronization therapy outcomes in patients with a right bundle branch block. Clinical cardiology. 2010;33:89-93.

18. Hara H, Oyenuga OA, Tanaka H, Adelstein EC, Onishi T, McNamara DM, Schwartzman D, Saba S and Gorcsan $\rfloor$ 3rd. The relationship of QRS morphology and mechanical dyssynchrony to long-term outcome following cardiac resynchronization therapy. European heart journal. 2012;33:2680-91.

19. Fantoni C, Kawabata M, Massaro R, Regoli F, Raffa S, Arora V, Salerno-Uriarte JA, Klein HU and Auricchio A. Right and left ventricular activation sequence in patients with heart failure and right bundle branch block: a detailed analysis using three-dimensional non- fluoroscopic electroanatomic mapping system. Journa of cardiovascular electrophysiology. 2005;16:112-9; discussion 120-1.

20. Eschalier R, Ploux S, Ritter P, Haissaguerre M, Ellenbogen KA and Bordachar P. Nonspecific intraventricular conduction delay: Definitions, prognosis, and implications for cardiac resynchronization therapy. Heart rhythm: the official journal of the Heart Rhythm Society. 2015.

21. Dougherty JD. The relation of the frontal QRS axis to the anatomic position of the heart. Journal of electrocardiology. 1970;3:267-84.

22. Nguyên UC, Potse M, Regoli F, Caputo ML, Conte G, Murzilli R, Muzzarelli S, Moccetti T, Caiani EG, Prinzen FW, Krause $R$ and Auricchio A. An in-silico analysis of the effect of heart position and orientation on the ECG morphology and vectorcardiogram parameters in patients with heart failure and intraventricular conduction defects. Journal of electrocardiology.

23. Bleeker GB, Schalij MJ, Van Der Wall EE and Bax JJ. Postero-lateral scar tissue resulting in non-response to cardiac resynchronization therapy. Journal of cardiovascular electrophysiology. 2006;17:899-901.

24. Ypenburg C, Roes SD, Bleeker GB, Kaandorp TA, de Roos A, Schalij MJ, van der Wall EE and Bax JJ. Effect of total scar burden on contrast-enhanced magnetic resonance imaging on response to cardiac resynchronization therapy. The American journal of cardiology. 2007;99:657-60.

25. Delgado V, van Bommel RJ, Bertini M, Borleffs CJ, Marsan NA, Arnold CT, Nucifora G, van de Veire NR, Ypenburg C, Boersma E, Holman ER, Schalij MJ and Bax JJ. Relative merits of left ventricular dyssynchrony, left ventricular lead position, and myocardial scar to predict long-term survival of ischemic heart failure patients undergoing cardiac resynchronization therapy. Circulation. 2011;123:70-8.

26. Michael MA, El Masry H, Khan BR and Das MK. Electrocardiographic signs of remote myocardial infarction. Progress in cardiovascular diseases. 2007;50:198-208. 
27. Pietrasik $G$ and Zareba W. QRS fragmentation: diagnostic and prognostic significance. Cardiology journal. 2012;19:114-21.

28. Rickard J, Zardkoohi O, Popovic Z, Verhaert D, Sraow D, Baranowski B, Martin DO, Grimm RA, Chung MK, Tchou P, Lindsay BA and Wilkoff BL. QRS fragmentation is not associated with poor response to cardiac resynchronization therapy. Annals of noninvasive electrocardiology: the official journal of the International Society for Holter and Noninvasive Electrocardiology, Inc. 2011;16:165-71.

29. Pan W, Su Y, Zhu W, Shu X and Ge J. Notched QRS complex in lateral leads as a novel predictor of response to cardiac resynchronization therapy. Annals of noninvasive electrocardiology: the official journal of the International Society for Holter and Noninvasive Electrocardiology, Inc. 2013;18:181-7. 


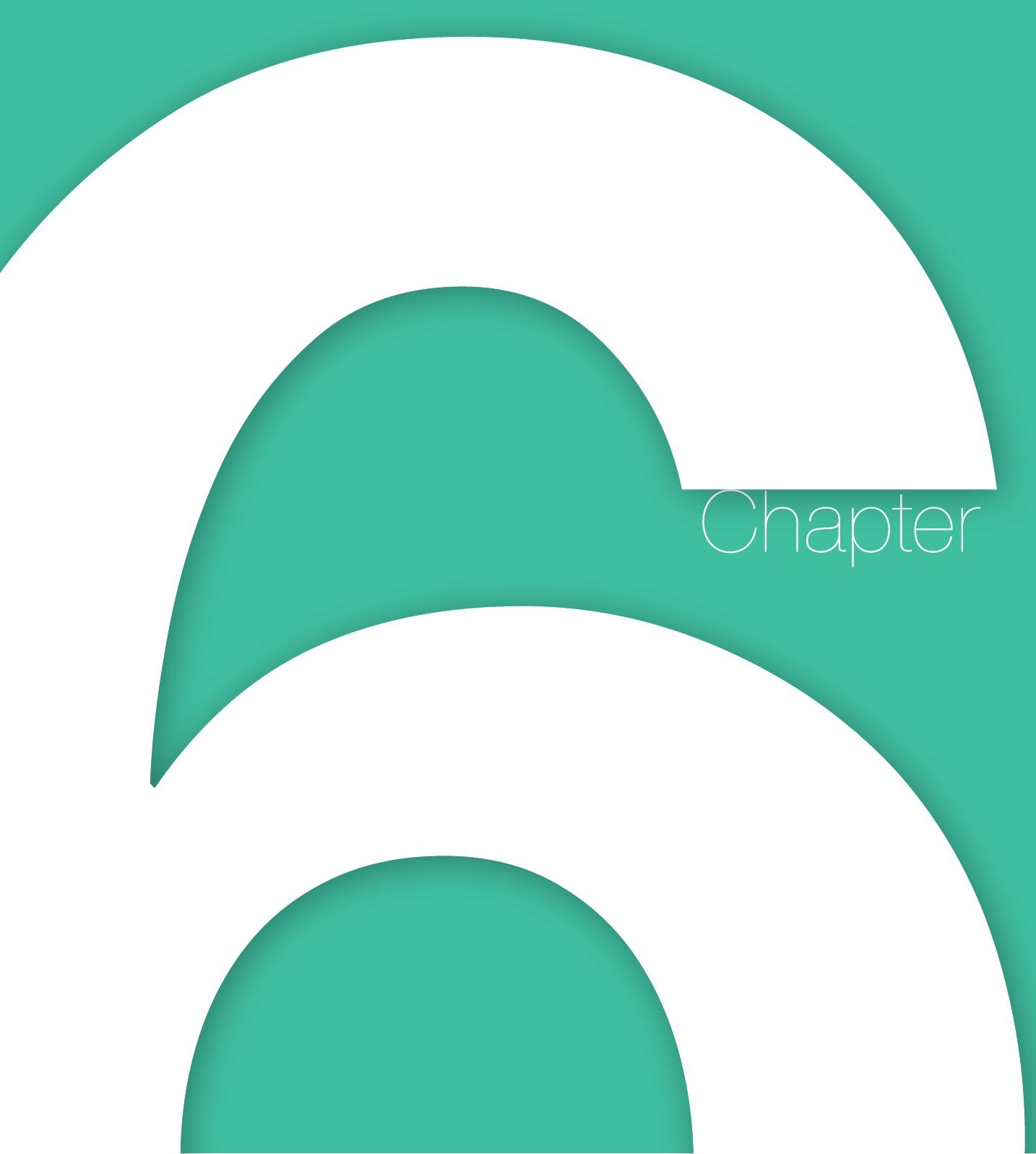

Vectorcardiographic QRS area identifies delayed left ventricular lateral wall activation determined by electroanatomic mapping in candidates for cardiac resynchronization therapy

Masih Mafi Rad, Gilbert W.M. Wijntjens, Elien B. Engels, Yuri Blaauw, Justin G.L.M. Luermans, Laurent Pison, Harry J. Crijns, Frits W. Prinzen, Kevin Vernooy 


\section{Abstract}

Aim: Delayed left ventricular (LV) lateral wall (LVLW) activation is considered the electrical substrate underlying $L V$ dysfunction amenable to cardiac resynchronization therapy (CRT). The purpose of this study was to assess LVLW activation in CRT candidates using coronary venous electroanatomic mapping (EAM) and to investigate whether the QRS area $\left(\mathrm{QRS}_{\text {AREA }}\right.$ ) on the vectorcardiogram (VCG) can identify delayed LVLW activation.

Methods: Fifty-one consecutive CRT candidates (29 left bundle-branch block [LBBB], 15 intra-ventricular conduction delay [IVCD], 7 right bundle-branch block [RBBB]) underwent intraprocedural coronary venous EAM using EnSite NavX. VCGs were constructed from preprocedural digital 12-lead ECGs using the Kors method. QRS ${ }_{A B E A}$ was assessed and compared to QRS duration and 5 different LBBB definitions.

Results: Delayed LVLW activation (activation time $>75 \%$ of QRS duration) occurred in 38 of 51 patients (29/29 LBBB, 8/15 IVCD, 1/7 RBBB). QRS ${ }_{\text {AREA }}$ was larger in patients with than in patients without delayed LVLW activation (108 \pm 42 vs. $51 \pm 27 \mu \mathrm{Vs}, \mathrm{P}<0.001)$ and identified delayed LVLW activation better than QRS duration (area under the curve 0.89 [95\% confidence interval $0.79-0.99$ ] vs. 0.49 [95\% confidence interval $0.33-0.65]$ ]). $\mathrm{QRS}_{\text {AREA }}>69 \mu \mathrm{Vs}$ diagnosed delayed LVLW activation with a higher sum of sensitivity $(87 \%)$ and specificity $(92 \%)$ than any of the LBBB definitions. Of the different LBBB definitions, the European Society of Cardiology textbook definition performed best with sensitivity of $76 \%$ and specificity of $100 \%$.

Conclusions: Coronary venous EAM can be used during CRT implantation to determine

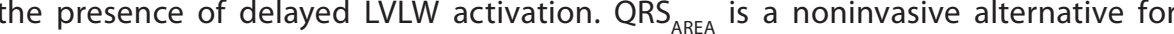
intracardiac measurements of electrical activation, which identifies delayed LVLW activation better than QRS duration and LBBB morphology.

\section{Introduction}

Despite compelling evidence of the benefits of cardiac resynchronization therapy (CRT), the issue remains that a substantial proportion of apparently suitable patients fail to show a favorable response.' The supposed mechanism of CRT is that delayed activation of the left ventricular (LV) lateral wall (LVLW) causes mechanical dysfunction, which is remediable by paced pre-excitation of this delayed LV region. ${ }^{2}$ Currently, the primary marker for delayed ventricular electrical activation is QRS duration. Yet, QRS duration is a reflection of total ventricular activation and therefore is not a reliable marker of $L V$ activation. A left bundle-branch block (LBBB) morphology has been recognized as a potentially better indicator of delayed LVLW activation. However, current LBBB definitions differ between European and American recommendation $3^{3,4}$ and between clinical trials that investigated LBBB as a predictor of CRT effectiveness. ${ }^{5,6}$ This complicates a uniform diagnosis. In addition, patients with right bundle-branch block (RBBB) or nonspecific intraventricular conduction delay (IVCD) may have occult LVLW activation delay that still is amenable to resynchronization therapy.

Recently, the QRS area (QRS ) on the vectorcardiogram (VCG) was shown to predict CRT response better than QRS duration and conventionally defined LBBB morphology. ${ }^{8}$ Therefore, we hypothesized that the VCG, which contains 3-dimensional information of electrical forces within the heart, provides better indicators for delayed LVLW activation. In the present study, we investigated whether the VCG contains information about LVLW activation by comparing VCG measurements with data from coronary venous electroanatomic mapping (EAM). We recently introduced coronary venous EAM as a tool to assess LV electrical activation during CRT implantation?

The objectives of the present study were (1) to assess LVLW electrical activation in a cohor of LBBB and non-LBBB CRT candidates using coronary venous EAM, (2) to investigate whether the VCG can identify delayed LVLW activation as determined by coronary venous EAM, and (3) to compare the diagnostic performance of the VCG for delayed LVLW activation with that of QRS duration and various frequently used LBBB definitions.

\section{Methods}

\section{Study population}

Fifty-one consecutive patients enrolled for CRT with a class I/lla indication according to European Society of Cardiology (ESC) guidelines ${ }^{10}$ were included. The Institutional Review Board approved the study protocol.

\section{Electroanatomic mapping}

Coronary venous EAM was performed intraprocedurally as described previously. ${ }^{9}$ In brief, before LV lead placement, a guidewire (Vision Wire, Biotronik SE \& Co.KG) that permits unipolar sensing and pacing, was inserted into the coronary sinus (CS) and connected to EnSite NavX (St. Jude Medical). The guidewire was manipulated to all CS branches located on the inferolateral or anterolateral LV wall, creating an anatomic map along with determining local electrical activation time (AT). RBBB patients underwent additional right ventricular (RV) endocardial mapping with a quadripolar diagnostic electrophysiology catheter (St. Jude Medical). Local AT was measured in ms from QRS onset and expressed as percentage of QRS duration. LVLW activation was considered delayed if maximal AT measured at the LVLW (maxLVLW-AT) exceeded $75 \%$ of QRS duration. ${ }^{9}$ 


\section{Vectorcardiography}

Vectorcardiograms were synthesized from preprocedural standard 12-lead ECGs as described previously." In brief, 12-lead ECGs were recorded digitally, analyzed semi-automatically using custom made software (MATLAB R2010b, Math Works), and converted to VCGs using the Kors method. ${ }^{12} \mathrm{~A}$ VCG consists of three orthogonal leads $X, Y$ and $Z$, which together form a 3D vector loop (Figure 1). The maximum QRS and T vector were defined, and their direction in space was calculated. The 3D angle between the maximum QRS and T vector was described as QRS-T angle. The magnitude of the maximum QRS vector was expressed as QRS vector

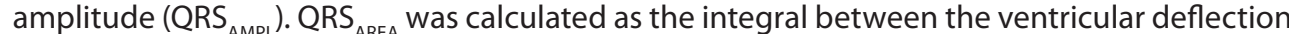
curve and the baseline from QRS beginning to end in leads $X, Y$, and $Z$.

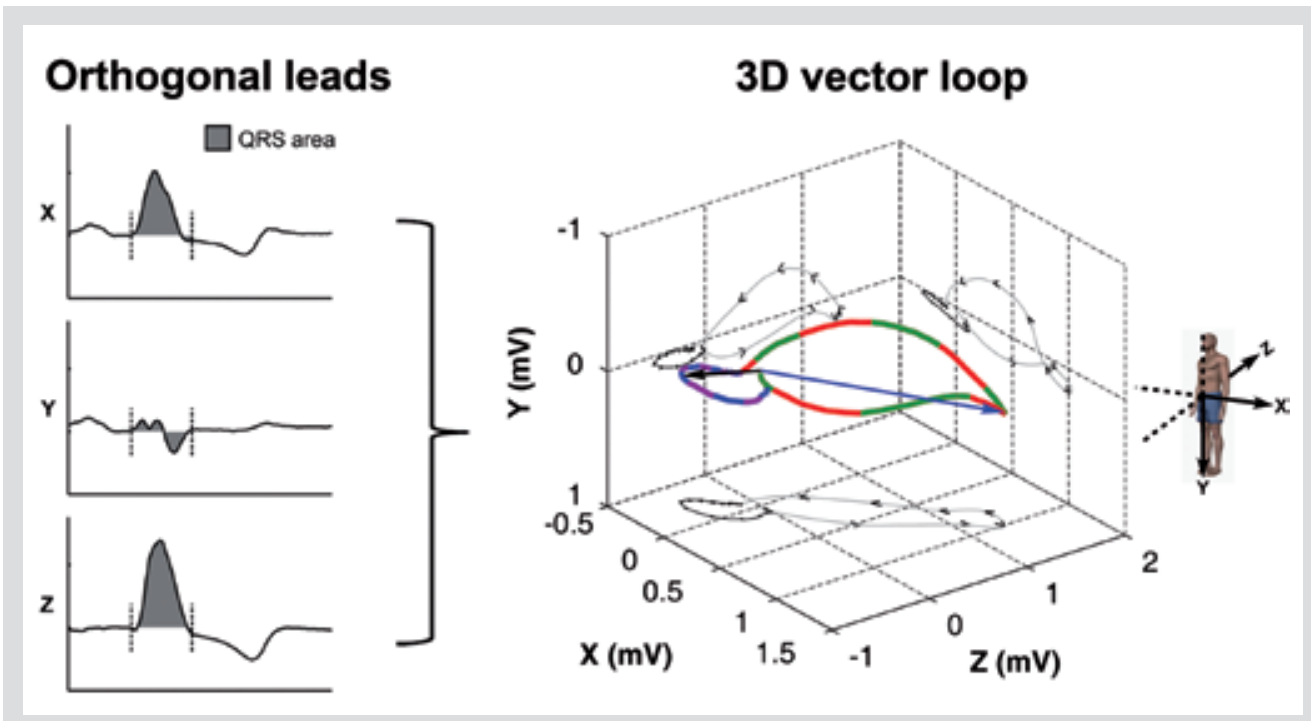

Figure 1. Vectorcardiogram consisting of three orthogonal leads $X, Y$ and Z (left), which together form a $3 D$ vector loop (right). The green/red loop represents the QRS vector loop and the blue/purple loop the T vector loop. Blue arrow represents the maximal QRS vector, and black arrow the maximal T vector. QRS ${ }_{\text {AREA }}$ is calculated using the integral between the ventricular deflection curve and the baseline from QRS beginning to end in leads $X, Y$, and $Z$.

\section{Assessment of QRS duration and morphology}

QRS duration and morphology were assessed on preprocedural 12-lead ECGs. LBBB was defined according to five different definitions:

- ESC Textbook of Cardiovascular Medicine ${ }^{4}$ (LBBB_ESCT): QRS duration $\geq 120 \mathrm{~ms}, \mathrm{QS} / \mathrm{rS}$ in leads V1 and V2, broad notched $\mathrm{R}$ wave in leads $\mathrm{I}, \mathrm{aVL}, \mathrm{V} 5$, and V6, absent q-wave in leads I, $\mathrm{aVL}, \mathrm{V} 5$, and $\mathrm{V} 6$.

- American Heart Association (LBBB_AHA): QRS duration $\geq 120 \mathrm{~ms}$, R-peak time $\geq 60 \mathrm{~ms}$ in leads $\mathrm{V} 5$ and $\mathrm{V} 6$ but normal in leads $\mathrm{V} 1, \mathrm{~V} 2$ and $\mathrm{V} 3$ when small initial $r$-waves can be discerned in these leads, broad notched/slurred $\mathrm{R}$ wave in leads $\mathrm{l}, \mathrm{VVL}, \mathrm{V} 5$ and V6, occasional RS pattern in V5 and V6, absent q wave in leads I, V5 and V6.

- MADIT-CRT trial ${ }^{6}$ (LBBB_MADIT): QRS duration $\geq 130 \mathrm{~ms}, \mathrm{QS} / \mathrm{rS}$ in lead V1, broad R wave in leads I, aVL, V5 or V6, absent q waves in leads V5 and V6.
- REVERSE trial $5^{5}$ (LBBB REVERSE): QRS duration $\geq 120 \mathrm{~ms}$, QS/rS in lead $\mathrm{V} 1$, broad $\mathrm{R}$ waves in lead I, aVL, V5, or V6, absent q-waves in lead V5 and V6.

- Strauss et al. ${ }^{13}$ (LBBB_Strauss): QRS duration $\geq 130 \mathrm{~ms}$ for women and $\geq 140 \mathrm{~ms}$ for men, QS/rS in leads V1 and V2, mid-QRS notching/slurring in $\geq 2$ contiguous leads of $\mathrm{l}$, aVL, V1, V2, V5 and V6.

\section{Statistical analysis}

Continuous variables are expressed as mean \pm standard deviation and categorical variables as number and percentage. Continuous variables were compared using Mann-Whitney $\mathrm{U}$ test and categorical variables using Fisher exact test. The performance of electrical parameters for identifying delayed LVLW activation was evaluated using receiver operating characteristic (ROC) curve analysis. Continuous variables were dichotomized for comparison with discrete variables by computing cutoff values with maximal sum of sensitivity and specificity. Subsequently, sensitivity, specificity, positive predictive value, and negative predictive value for delayed LVLW activation were calculated for all parameters. Statistical significance was accepted at the $95 \%$ confidence interval. Statistical analysis was performed using SPSS version 20.0 (SPSS Inc.).

\section{Results}

Patient characteristics

Fifty-one consecutive patients referred for CRT implantation for a class I/lla indication according to $\mathrm{ESC}$ guidelines ${ }^{10}$ were included. Patient characteristics are given in Table 1.

\section{Electroanatomic mapping}

Coronary venous EAM was accomplished in all patients without complications. In 39 patients, a CS branch on both the anterolateral and inferolateral LV wall was mapped. In 12 patients, coronary venography revealed a single anterolateral or inferolateral vein, which could be successfully mapped. The 3D electrical activation maps were generated from $69 \pm 28$ unique anatomic points. Mapping time was $19 \pm 6$ minutes, total fluoroscopy time $21 \pm 4$ minutes, and total radiation dosage $4132 \pm 2057 \mathrm{cGy} \times \mathrm{cm}^{2}$.

QRS duration and LVLW-AT data for the entire study cohort and per QRS morphology classified according to ESCT criteria are given in Table 2. Delayed LVLW activation occurred in 38 of 51 patients. In patients with delayed LVLW activation, maxLVLW-AT was $131+15 \mathrm{~ms}$ ( $84 \pm 6 \%$ of QRS duration) and ranged from 103 to $169 \mathrm{~ms}$ (75-96\% of QRS duration). QRS duration did not differ between different QRS morphologies. However, maxLVLW-AT was significantly larger in LBBB patients than in IVCD and RBBB patients. Delayed LVLW activation occurred in all 29 LBBB patients (EAM example in Figure 2A), 8 of 15 IVCD patients, and 1 of 7 RBBB patients. Figures $2 B$ and $2 \mathrm{C}$ show EAMs of 2 IVCD patients, and Figures $2 \mathrm{D}$ and $2 \mathrm{E}$ show EAMs of 2 RBBB patients with and without delayed LVLW activation. As can be seen on the ECG in Figure 2E, the RBBB patient with delayed LVLW activation did not have a typical RBBB and showed a leftward axis deviation suggestive of left anterior hemiblock, which most probably was the cause of LV conduction delay in this patient. In contrast, all of the RBBB patients without delayed LVLW activation showed a classic RBBB QRS morphology without leftward axis deviation (example in Figure 2D). In the IVCD group, however, we found no difference in the prevalence of leftward axis deviation between patients with and without delayed LVLW activation (38\% vs. 43\%, respectively, $\mathrm{P}=1$ ). In RBBB patients, total RV activation time was larger than maxLVLW-AT $(111 \pm 21 \mathrm{~ms}[69 \pm 10 \%$ of $\mathrm{QRS}$ duration] vs, $85 \pm 21 \mathrm{~ms}$ [53 $\pm 13 \%$ of $\mathrm{QRS}$ duration], $\mathrm{P}=0.02$ ). 


\section{Table 1. Patient characteristics $(n=51)$}

\begin{tabular}{|l|l|}
\hline Characteristics & Value \\
\hline Age, years & $72 \pm 9$ \\
\hline Male gender & $33(65)$ \\
\hline Ischemic heart disease & $31(61)$ \\
\hline NYHA functional class & \\
\hline II & $26(51)$ \\
\hline III & $25(49)$ \\
\hline Echocardiography characteristics & \\
\hline LV ejection fraction $(\%)$ & $27 \pm 4$ \\
\hline LV end-diastolic diameter $(\mathrm{mm})$ & $61 \pm 6$ \\
\hline LV end-systolic diameter $(\mathrm{mm})$ & $52 \pm 8$ \\
\hline LV end-diastolic volume $(\mathrm{mL})$ & $157 \pm 33$ \\
\hline LV end-systolic volume $(\mathrm{mL})$ & $114 \pm 26$ \\
\hline ECG characteristics & \\
\hline LBBB* & $29(57)$ \\
\hline RBBB & $7(14)$ \\
\hline IVCD & $15(29)$ \\
\hline QRS duration (ms) & $157 \pm 13$ \\
\hline Intrinsic rhythm & \\
\hline Sinus rhythm & $39(76)$ \\
\hline Atrial fibrillation & $12(24)$ \\
\hline Treatment & \\
\hline Diuretics & $39(76)$ \\
\hline ACE-i/ARB & $46(90)$ \\
\hline Beta-blockers & $45(88)$ \\
\hline Spironolactone & $26(51)$ \\
\hline Nitrates & $13(25)$ \\
\hline Digoxin & $7(14)$ \\
\hline Amiodarone & $7(14)$ \\
\hline
\end{tabular}

Values are mean \pm standard deviations or no. (\%).

ACE-I, angiotensin converting enzyme inhibitor; ARB, angiotensin receptor blocker; LBBB, left bundle-branch block;

$\mathrm{LV}$, left ventricle; $\mathrm{RBBB}$, right bundle-branch block; IVCD, intraventricular conduction delay;

${ }^{*} \mathrm{LBBB}$ according to the ESC Textbook of Cardiovascular Medicine definition. ${ }^{4}$
Table 2. QRS duration and LVLW activation timing

\begin{tabular}{|l|l|l|l|l|}
\hline Data & All patients $(n=51)$ & LBBB $^{*}(n=29)$ & IVCD $(n=15)$ & RBBB $(n=7)$ \\
\hline QRS duration $(\mathrm{ms})$ & $157 \pm 13$ & $158 \pm 16$ & $155 \pm 7$ & $159 \pm 7$ \\
\hline maxLVLW-AT $(\mathrm{ms})$ & $119 \pm 28$ & $133 \pm 15 \dagger$ & $107 \pm 30 \neq$ & $85 \pm 21$ \\
\hline $\begin{array}{l}\text { maxLVLW-AT } \\
\text { (\% of QRS duration) }\end{array}$ & $76 \pm 16$ & $86 \pm 5 \dagger$ & $72 \pm 24 \neq$ & $53 \pm 13$ \\
$\begin{array}{l}\text { maxLVLW-AT }>75 \% \text { of } \\
\text { QRS duration }\end{array}$ & $38(75)$ & $29(100)$ & $8(53)$ & $1(14)$ \\
\hline
\end{tabular}

QRS duration

Values are mean \pm standard deviations or no (\%).

IVCD, intraventricular conduction delay; LBBB, left bundle-branch block; maxLVLW-AT,

maximal left ventricular lateral wall activation time; $\mathrm{RBBB}$, right bundle-branch block.

${ }^{*} \mathrm{LBBB}$ according to the ESC Textbook of Cardiovascular Medicine definition. ${ }^{4}$

$P<0.01$ versus IVCD and $R B B B$.

$\neq P<0.05$ versus $R B B B$.

\section{VCG parameters in patients with and those without delayed LVLW activation}

The values of different VCG parameters in patients with and those without delayed LVLW activation are given in Table 3. The frontal and sagittal QRS vector angles and the QRS-T angle did not differ between patients with and those without delayed LVLW activation. However, the transverse QRS vector angle, $\mathrm{QRS}_{\text {AMP }}$ and $\mathrm{QRS}_{\mathrm{AREA}}$ were significantly larger in patients with than in patients without delayed LVLW activation. The difference between the 2 groups was most pronounced for QRS $_{\text {AMPL }}$ and QRS $_{\text {AREA }}$.

\section{Table 3. VCG values in patients with and without delayed LVLW activation}

\begin{tabular}{|l|l|l|l|}
\hline Parameter & $\begin{array}{l}\text { Delayed LVLW } \\
\text { activation }(n=38)\end{array}$ & $\begin{array}{l}\text { No delayed LVLW } \\
\text { activation }(n=13)\end{array}$ & P value \\
\hline QRS vector angle, frontal $\left(^{\circ}\right)$ & $3 \pm 77$ & $-31 \pm 71$ & NS \\
\hline QRS vector angle, transverse $\left(^{\circ}\right)$ & $-64 \pm 55$ & $-17 \pm 84$ & 0.03 \\
\hline QRS vector angle, sagittal $\left(^{\circ}\right)$ & $-5 \pm 49$ & $12 \pm 90$ & NS \\
\hline QRS-T angle $\left({ }^{\circ}\right)$ & $160 \pm 20$ & $135 \pm 46$ & NS \\
\hline QRS $_{\text {AMPL }}(m V)$ & $1.6 \pm 0.5$ & $1.0 \pm 0.4$ & $<0.001$ \\
\hline QRS $_{\text {AREA }}(\mu \mathrm{VS})$ & $108 \pm 42$ & $51 \pm 27$ & $<0.001$ \\
\hline
\end{tabular}

Values are given as mean \pm standard deviations.

LVLW, left ventricular lateral wall; $\mathrm{QRS}_{\mathrm{AMPL}^{\prime}}, \mathrm{QRS}$ amplitude; $\mathrm{QRS}{\mathrm{AREA^{ \prime }}} \mathrm{QRS}$ area; NS, non-significant.

Diagnostic performance of ECG and VCG parameters for delayed LVLW activation

Figure 3 displays ROC curves, showing the abilities of QRS duration, $\mathrm{QRS}_{\text {AMPL }}$ and $\mathrm{QRS}_{\text {AREA }}$ to identify delayed LVLW activation. QRS duration performed poorly with an area under the

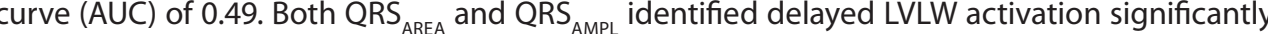
better than QRS duration. QRS ${ }_{\text {AREA }}$ performed best with an AUC of 0.89 . At a cutoff value of $69 \mu \mathrm{Vs}$, 


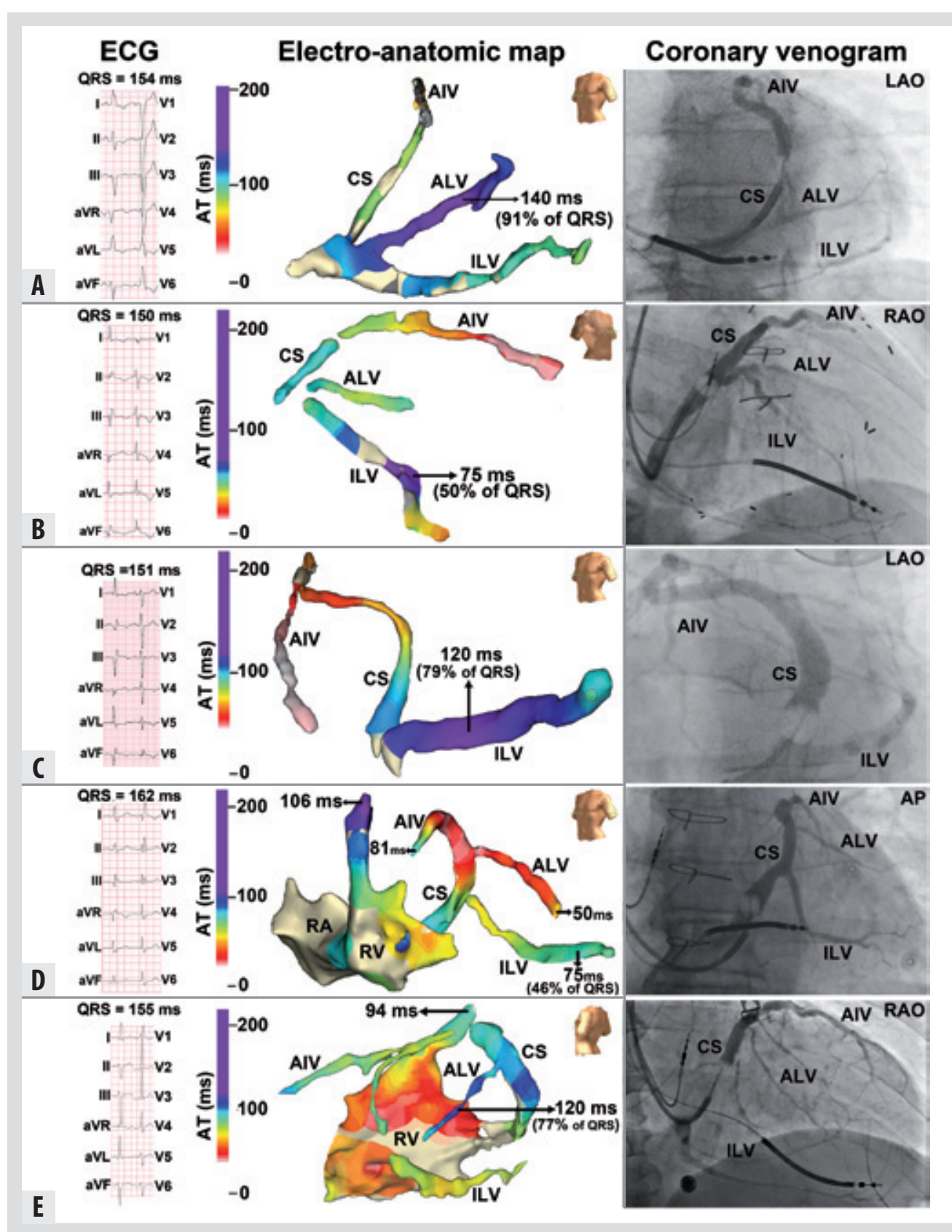

Figure 2. Coronary venous EAM of (A) an LBBB patient demonstrating delayed activation of the LV anterolateral wall, (B) an IVCD patient demonstrating absence of delayed LV lateral wall activation, (C) an IVCD patient demonstrating delayed activation of the LV inferolateral wall, (D) a RBBB patient demonstrating absence of delayed LV lateral wall activation and a longer activation time of the RV than the LV lateral wall, and (E) a RBBB patient with a potential left anterior hemiblock, demonstrating delayed activation of the LV anterolateral wall. AIV, anterior inter-ventricular vein; ALV, anterolateral vein; ILV, inferolateral vein; CS, coronary sinus; $\mathrm{AT}$, electrical activation time; AP, antero-posterior; L/RA0, left/right anterior oblique; $\mathrm{RA}$, right atrium; $\mathrm{RV}$, right ventricle.

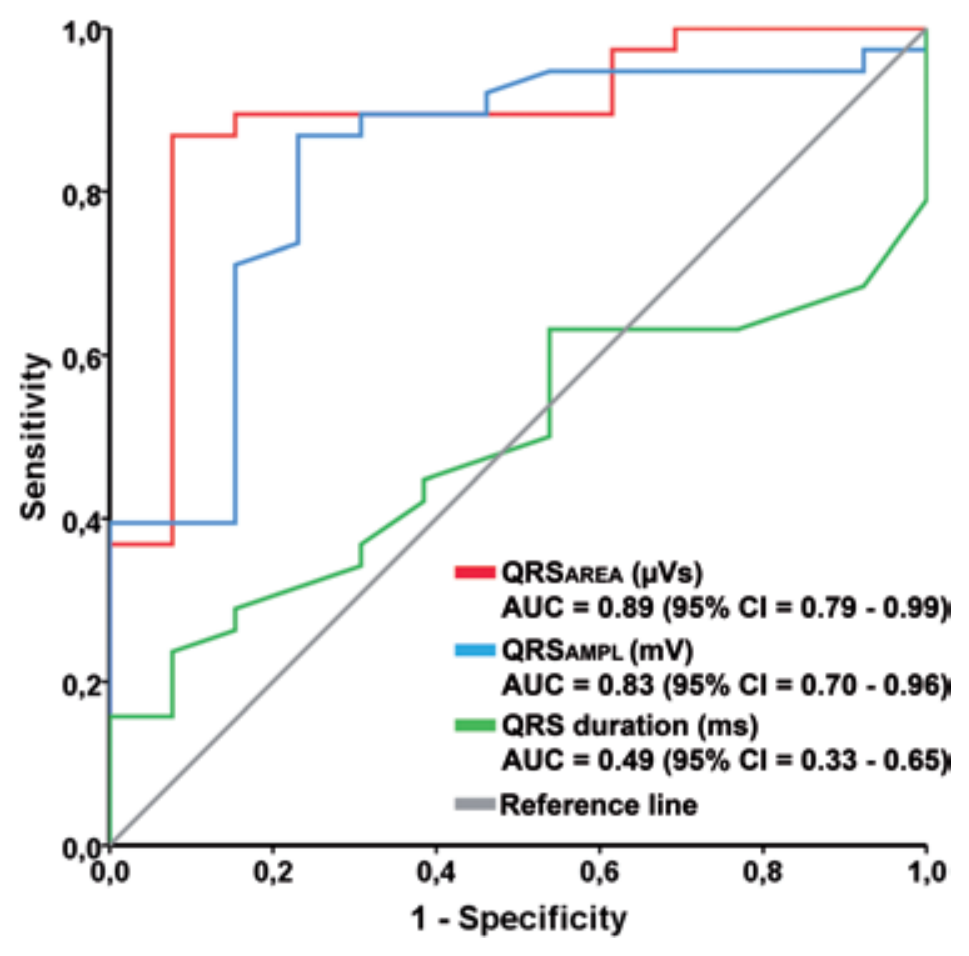

Figure 3. Receiver operating characteristic curves for QRS duration, QRS ${ }_{\text {AMP' }}$, and QRS ${ }_{\text {AREA }}$. The area under the curve (AUC) signifies the performance of each parameter for identifying delayed left ventricular lateral wall activation and is given for each parameter with the $95 \%$ confidence interval (CI).

QRS identified delayed LVLW with the best combined sensitivity and specificity of $87 \%$ and $92 \%$, respectively. The LV end-diastolic volume did not differ between patients with a QRS $_{\text {AREA }}$ above and below the cutoff value of $69 \mu \mathrm{Vs}(177 \pm 40 \mathrm{vs} 187 \pm 45 \mathrm{ml}$, respectively, $\mathrm{P}=0.29)$. $\mathrm{QRS}_{\text {AREA }}$ diagnosed delayed LVLW activation with a higher sum of sensitivity and specificity than any of the LBBB definitions (Table 4). The LBBB_REVERSE and LBBB_MADIT definition had the highest sensitivity of all LBBB definitions ( $82 \%$ and $79 \%$, respectively), but relatively low specificity (54\% for both). The LBBB ESCT and LBBB AHA definitions had the highest specificity ( $100 \%$ and $92 \%$, respectively) but only moderate-to-low sensitivity ( $76 \%$ and $50 \%$, respectively). Moderate sensitivity and specificity (68\% and 77\%, respectively) was found for the LBBB_Strauss definition. Figure 4A shows QRS $_{\text {AREA }}$ plotted as a function of maxLVLW-AT for the entire study cohort, illustrating the excellent diagnostic performance of QRS $_{\text {AREA }}$ for delayed LVLW activation. Using the cutoff value of $69 \mu \mathrm{Vs}$ correctly identified 33 of 38 patients with and 12 of 13 patients without delayed LVLW activation. Figures 4B-F of figure 4 display the same plot but with LBBB diagnosed according to a different definition in each panel, illustrating the difference in QRS morphology classification caused by disparity in LBBB definitions. 
Table 4. Diagnostic performance of QRS $_{\text {AREA }}$ and different LBBB definitions

\section{for delayed LVLW activation}

\begin{tabular}{|l|l|l|l|l|}
\hline & Sensitivity (\%) & Specificity (\%) & PPV (\%) & NPV (\%) \\
\hline QRS $_{\text {AREA }}>69 \mu \mathrm{V} s$ & 87 & 92 & 97 & 71 \\
\hline LBBB_ESCT & 76 & 100 & 100 & 59 \\
\hline LBBB_AHA & 50 & 92 & 95 & 39 \\
\hline LBBB_MADIT & 79 & 54 & 83 & 47 \\
\hline LBBB_REVERSE & 82 & 54 & 84 & 50 \\
\hline LBBB_Strauss & 68 & 77 & 90 & 45
\end{tabular}

AHA, American Heart Association; ESCT, European Society of Cardiology Textbook; LBBB, left bundle-branch block;

LVLW, left ventricular lateral wall; PPV, positive predictive value; NPV, negative predictive value.

\section{Discussion}

Delayed activation of the LVLW causing mechanical dyssynchrony is considered the mechanism underlying LV dysfunction that may be improved through CRT. In the present study, we assessed LVLW activation timing in CRT candidates using intraprocedural coronary venous EAM. Delayed LVLW activation was found in all LBBB patients, approximately half the IVCD patients, and 1of 7 RBBB patients. The VCG parameter QRS $_{\text {AREA }}$ identified delayed LVLW activation better than QRS duration or LBBB morphology according to 5 different definitions. Compared to LBBB morphology, $\mathrm{QRS}_{\text {AREA }}$ had the additional advantage of being objectively quantifiable as a continuous parameter.

\section{Delayed LVLW activation in LBBB and non-LBBB patients}

The finding that delayed LVLW activation occurred in all LBBB patients is in line with previous mapping studies ${ }^{14}$ and consistent with the results of a study by Varma who demonstrated late LV inferolateral wall activation (>100 ms) in 87\% of LBBB patients with QRS duration of 120-150 ms and in $100 \%$ of LBBB patients with a QRS duration of $>150$ ms.

In the present study, delayed LVLW activation occurred in approximately half the IVCD patients and in 1 of 7 RBBB patients. Data on LV electrical activation in non-LBBB patients are limited. Fantoni et al. performed extensive measurements of $\mathrm{RV}$ and $\mathrm{LV}$ endocardial electrical activation in 6 heart failure patients with RBBB and demonstrated the presence of LV activation delays equivalent to those found in LBBB in 4 of these patients. ${ }^{15}$ Notably, the QRS morphology in these 4 patients showed a specific ECG pattern, previously defined as RBBB masking LBBB ${ }^{16}$, which is characterized by broad, slurred, sometimes notched $R$ waves in leads I and $\mathrm{AVL}$, together with leftward axis deviation. In the present study, we observed a somewhat simila ECG pattern in the RBBB patient with delayed LVLW activation, whereas the other RBBB patients without delayed LVLW activation exhibited a more classic RBBB pattern. In the study by Varma, late LV inferolateral wall activation occurred in 45\% of RBBB patients. ${ }^{7}$ However, characteristic differences in QRS morphology between RBBB patients with and those without late activation were not reported. Ploux et al. characterized LV epicardial electrical activation of 15 CRT candidates with IVCD using noninvasive 3D ECG imaging (ECGi) and found significant activation delay in $3(20 \%)$ of these patients.
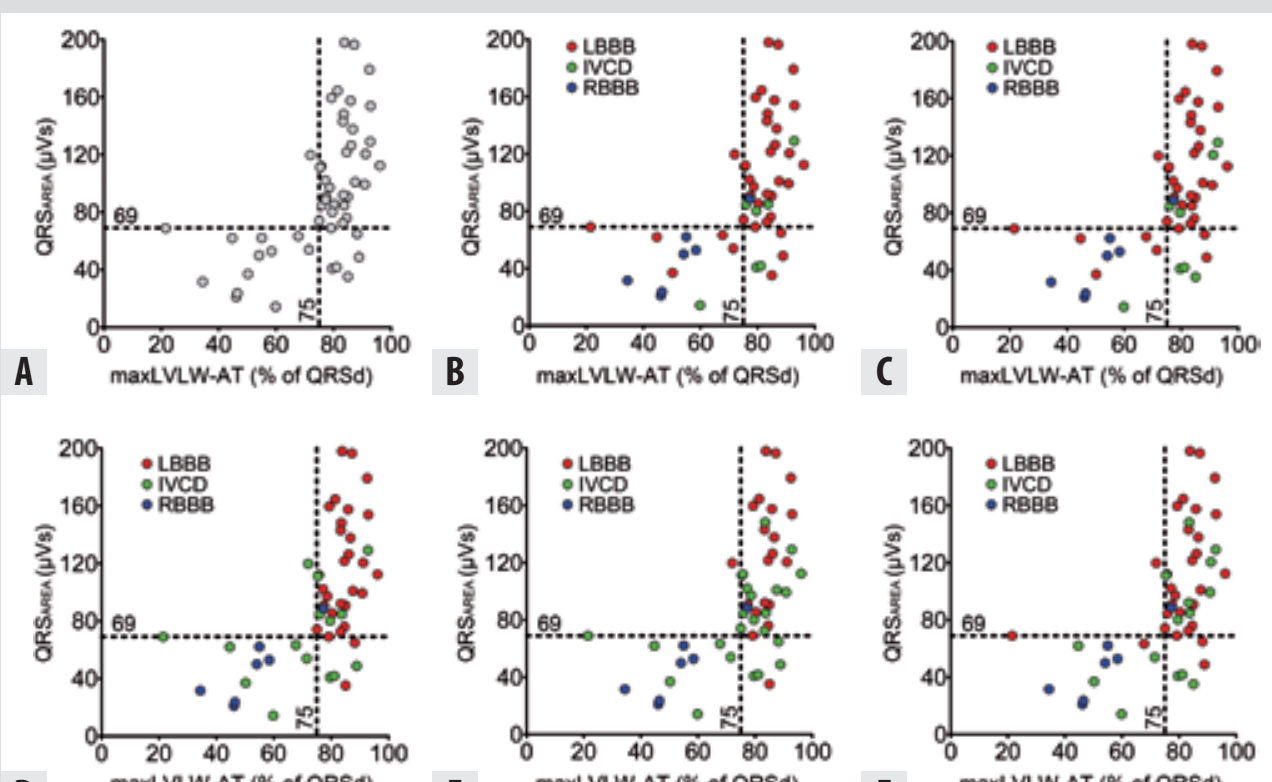

E

XLVLW-AT (\% of QRSA)

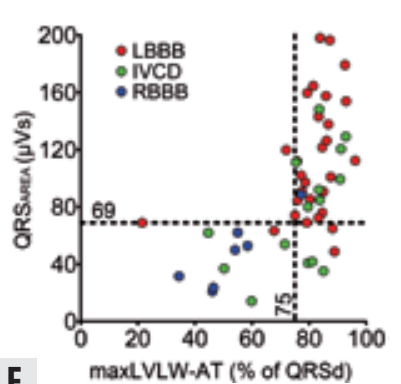

Figure 4. (A) QRS AREA $_{\text {p }}$ plotted as function of maximal left ventricular lateral wall activation time (maxLVLW-AT) expressed as \% of QRS duration (QRSd) for the entire study cohort. Each dot represents a patient. (B-F)Same plot as A, but with left bundle-branch block (LBBB) diagnosed according to the definition provided by the REVERSE5(B). MADIT-CRT trial ${ }^{6}(C)$, ESC Textbook of Cardiovascular Medicine ${ }^{4}(\mathrm{D})$, $\mathrm{AHA}^{3}(\mathrm{E})$, and Strauss et al. ${ }^{13}(\mathrm{~F})$. IVCD, intraventricular conduction delay; $\mathrm{RBBB}$, right bundle-branch block.

Several studies have suggested that CRT may be beneficial in a subset of non-LBBB patients with evidence of LV activation delay. ${ }^{17-19}$ The present study demonstrates that intra-cardiac measurements of electrical activation such as performed by coronary venous EAM or by electrical mapping with the LV lead, may be particularly useful to identify non-LBBB patients with an electrical substrate for CRT. The ECGi technique has been proposed as a noninvasive alternative to characterize the electrical substrate of patients before CRT implantation. ${ }^{17}$ ECGi provides a detailed $3 \mathrm{D}$ view of epicardial electrical activation. However, the technique requires a multielectrode vest combined with a computed tomography scan, which precludes widespread application of this approach in clinical practice.

\section{QRS $_{\text {AREA }}$ identifies delayed LVLW activation}

The present study demonstrates the potential of a relatively easy and noninvasive approach to identify patients with an electrical substrate for CRT using the QRS $_{\text {AREA }}$ on the VCG. We demonstrated that a $\mathrm{QRS}_{\text {AREA }}>69 \mu \mathrm{Vs}$ accurately identifies delayed LVLW activation in CRT candidates. In the present study, all patients with a QRS $>69 \mu$ Vs had a maxLVLW-AT $>100$ ms and $>70 \%$ of QRS duration. Positioning the LV lead over an area of the heart with an electrical activation time $>95 \mathrm{~ms}$ or $>50 \%$ of QRS duration has previously been shown to provide superior CRT outcome. ${ }^{20,21}$

Van Deursen et al. recently demonstrated that a large $\mathrm{QRS}_{\text {AREA }}$ is associated with highe odds of long-term volumetric CRT response. ${ }^{8}$ It was hypothesized that strong unopposed electrical forces generated within the heart, are the underlying mechanism of a large QRS $_{\text {AREA }}$ 
In a previous study, the average $\mathrm{QRS}_{\text {AREA }}$ in normal adult hearts was found to be $34 \mu \mathrm{Vs}^{22}$ a value of approximately one-third of that associated with $\mathrm{LBBB}^{8}$ and half of that associated with delayed LVLW activation in the present study.

$\mathrm{QRS}_{\text {AREA }}$ has been shown to be smaller in patients with heart failure of ischemic etiology, which may be explained by the presence of non-conducting fibrotic tissue. ${ }^{8}$ In the present study, five patients had a $\mathrm{QRS}_{\text {AREA }}<69 \mu \mathrm{V}$ s despite evidence of delayed LVLW activation during EAM. Four of these patients had a previous myocardial infarction which may partly explain the small QRS ${ }_{\text {AREA }}$ despite the presence of delayed LVLW activation. This observation suggests that QRS $_{\text {AREA }}$ is not only useful to determine whether there is an electrical substrate for CRT but that it also may reflect the presence of determinants known to reduce the chance of CRT benefit, such as an ischemic etiology of heart failure.

In the present study, one patient had QRS AREA $>69 \mu$ Vs without evidence of delayed LVLW activation during EAM. In this patient, coronary venography revealed only a single anterolateral vein, which could be successfully mapped. The constraints imposed by coronary venous anatomy during mapping may explain the absence of delayed LVLW activation in this particular case.

\section{QRS $_{\text {AREA }}$ compared to QRS duration and LBBB morphology}

In the present study, QRS duration performed poorly in identifying delayed LVLW activation. This may be explained by the fact that QRS duration is merely a surface depiction of biventricular depolarization time, sensitive to conduction delay in either the left or right ventricle.

LBBB according to any of the definitions identified delayed LVLW activation better than QRS duration. However, the LBBB_MADIT and LBBB_REVERSE definitions had a relatively low specificity for delayed LVLW activation. As a result, a significant proportion of patients that lacked delayed LVLW activation were not identified as such. Recently, Strauss et al. suggested that QRS notching/slurring should be present for the diagnosis of LBBB. ${ }^{13}$ The lack of requirement for QRS notching/slurring in the LBBB_MADIT and LBBB_REVERSE definitions may have included patients in whom QRS widening was caused by LV hypertrophy, LV enlargement or incomplete LBBB. ${ }^{23}$ The LBBB_ESCT and LBBB_AHA definitions included QRS notching/slurring and as a result had a high specificity for delayed LVLW activation. In addition, these definitions appeared to be more accurate for diagnosing delayed LVLW activation than the LBBB_Strauss definition which may be explained by the requirement of QRS notching/slurring in at least 4 leads, whereas the LBBB Strauss definition requires QRS notching/slurring in only 2 or more contiguous leads. However, the high specificity of the LBBB_ESCT and LBBB_AHA definitions came at the expense of their sensitivity. In particular, the LBBB_AHA definition, which is the strictest definition of all, had a relatively low sensitivity. As a result, a significant proportion of patients that had delayed LVLW activation were not identified as such. The LBBB_ESCT definition provided the best compromise between sensitivity and specificity of all LBBB definitions.

However, in the present study, we demonstrated that the diagnostic performance of even the best LBBB definition for delayed LVLW activation was inferior to having QRS $_{\text {AREA }}>69 \mu \mathrm{Vs}$. In addition, QRS $_{\text {AREA }}$ had the advantage of being an objective continuous measurement, which is not subject to different definitions or subjective interpretations of QRS notching/slurring.

\section{Clinical implications}

The present study demonstrates that coronary venous EAM can be used during CRT implantation to identify patients with an electrical substrate for CRT.

Vectorcardiograms are usually recorded using a dedicated 3D VCG system, but they may also be synthesized from standard 12-lead ECGs as performed in the present study. In fact, most commercially available ECG machines have algorithms to construct VCGs using the inverse Dower or Kors regression transformation.12,22 From this, the QRS ${ }_{\text {AREA }}$ can be automatically computed. The simple and noninvasive analysis provided by the VCG combined with the excellent diagnostic performance of QRS ${ }_{\text {APEA }}$ for delayed LVLW activation indicates that this technique can be easily applied in clinical practice to identify appropriate CRT candidates before CRT implantation.

The present study also emphasizes the importance of including the presence of QRS notching/slurring as described by the ESC textbook and AHA into the criteria for diagnosing LBBB. In this respect, the present study may be regarded as a validation study for LBBB definition that are currently frequently used.

\section{Study limitation}

The present study demonstrates that QRS $_{\text {AREA }}$ identifies delayed LVLW activation in CRT candidates. Admittedly, the study lacks long-term clinical follow-up. Whether delayed LVLW activation is also associated with CRT response needs to be confirmed in subsequent, larger and long-term follow-up studies.

Epicardial mapping through the coronary veins is limited by coronary venous anatomy, which means that some areas cannot be mapped because they do not contain any veins.

Data on local myocardial wall thickness and scar derived from cardiac magnetic resonance were not available in the present study. Therefore, we could not assess the contribution of transmural conduction delay to LVLW activation time. The effect of CRT may differ between patients in whom delayed LVLW activation is primarily caused by transmural conduction abnormalities (due to hypertrophy or scar) and those in which the main part of activation delay occurs in the conduction system of the heart.

We used an adapted version of the Kors method to calculate VCGs from standard 12-lead ECGs, which is an estimation of the gold standard Frank VCG. However, previous studies have demonstrated that the Kors method shows the best resemblance to the Frank VCG, ${ }^{24}$ and the method recently has also been validated for use in CRT patients. ${ }^{25}$

\section{Conclusion}

Coronary venous EAM can be used at the time of CRT implantation to determine the presence of delayed LVLW activation, an electrical substrate amenable to resynchronization therapy. This approach seems particularly useful for identifying non-LBBB patients with an electrical substrate for CRT. QRS ${ }_{\text {AREA }}$ derived from the VCG is a noninvasive alternative for intra-cardiac measurements of electrical activation, which identifies delayed LVLW activation better than QRS duration and LBBB morphology. This parameter can be easily applied in daily clinical practice to identify appropriate CRT candidates before CRT implantation. The ESC textbook LBBB definition appears superior to other frequently used LBBB definitions for identifying delayed LVLW activation. 


\section{References}

1. Daubert JC, Saxon L, Adamson PB, et al.2012 EHRA/HRS expert consensus statement on cardiac resynchronization therapy in heart failure: implant and follow-up recommendations and management.Heart rhythm: the official journal of the Heart Rhythm Society Sep 2012;9:1524-1576.

2. Vernooy K, Cornelussen RN, Verbeek XA, Vanagt WY, van Hunnik A, Kuiper M, Arts T, Crijns HJ, Prinze FW.Cardiac resynchronization therapy cures dyssynchronopathy in canine left bundle-branch block hearts.European heart journal Sep 2007;28:2148-2155.

3. Surawicz B, Childers R, Deal BJ, et al.AHA/ACCF/HRS recommendations for the standardization and interpretation of the electrocardiogram: part III: intraventricular conduction disturbances: a scientific statement from the American Heart Association Electrocardiography and Arrhythmias Committee, Council on Clinica Cardiology; the American College of Cardiology Foundation; and the Heart Rhythm Society: endorsed by the International Society for Computerized Electrocardiology. Circulation Mar 17 2009;119:e235-240.

4. Cosio FG.The Electrocardiogram.In: Camm AJ, editor The ESC Textbook of Cardiovascular Medicine 2009;2nd ed. UK: Oxford University Press; 2009.

5. Gold MR, Thebault C, Linde C, Abraham WT, Gerritse B, Ghio S, St John Sutton M, Daubert JC.Effect of QRS duration and morphology on cardiac resynchronization therapy outcomes in mild heart failure: results from the Resynchronization Reverses Remodeling in Systolic Left Ventricular Dysfunction (REVERSE) study. Circulation Aug 14 2012;126:822-829.

6. Zareba W, Klein H, Cygankiewicz I, et al.Effectiveness of Cardiac Resynchronization Therapy by QRS Morphology in the Multicenter Automatic Defibrillator Implantation Trial-Cardiac Resynchronization Therapy (MADIT-CRT).Circulation Mar 15 2011;123:1061-1072.

7. Varma N.Left ventricular conduction delays and relation to QRS configuration in patients with left ventricular dysfunction.The American journal of cardiology Jun 1 2009;103:1578-1585.

8. van Deursen CJ, Vernooy K, Dudink E, Bergfeldt L, Crijns HJ, Prinzen FW, Wecke L.Vectorcardiographic QRS area as a novel predictor of response to cardiac resynchronization therapy.Journal of electrocardiology Oct 242014

9. Mafi Rad M, Blaauw Y, Dinh T, Pison L, Crijns HJ, Prinzen FW, Vernooy K.Left ventricular lead placement in the latest activated region guided by coronary venous electroanatomic mapping.Europace Sep 32014.

10. Authors/Task Force M, Brignole M, Auricchio A, et al.2013 ESC Guidelines on cardiac pacing and cardiac resynchronization therapy: The Task Force on cardiac pacing and resynchronization therapy of the European Society of Cardiology (ESC). Developed in collaboration with the European Heart Rhythm Association (EHRA).European heart journal Aug 2013;34:2281-2329.

11. Engels EB, Vegh EM, CJ VAND, Vernooy K, Singh JP, Prinzen FW.T-Wave Area Predicts Response to Cardiac Resynchronization Therapy in Patients with Left Bundle Branch Block.Journal of cardiovascular electrophysiology Sep 172014

12. Kors JA, van Herpen $G$, Sittig $A C$, van Bemmel JH.Reconstruction of the Frank vectorcardiogram from standard electrocardiographic leads: diagnostic comparison of different methods.European heart journa Dec 1990;11:1083-1092.

13. Strauss DG, Selvester RH, Wagner GS.Defining left bundle branch block in the era of cardiac resynchronization therapy.The American journal of cardiology Mar 15 2011;107:927-934.

14. Auricchio A, Fantoni C, Regoli F, Carbucicchio C, Goette A, Geller C, Kloss M, Klein H.Characterization of left ventricular activation in patients with heart failure and left bundle-branch block.Circulation Mar 9 2004;109:1133-1139.

15. Fantoni C, Kawabata M, Massaro R, Regoli F, Raffa S, Arora V, Salerno-Uriarte JA, Klein HU, Auricchio A.Right and left ventricular activation sequence in patients with heart failure and right bundle branch block: detailed analysis using three-dimensional non-fluoroscopic electroanatomic mapping system.Journal o cardiovascular electrophysiology Feb 2005;16:112-119; discussion 120-111.

16. Richman JL, Wolff L.Left bundle branch block masquerading as right bundle branch block.American heart journal Mar 1954;47:383-393.
17. Ploux S, Lumens J, Whinnett Z, et al.Noninvasive electrocardiographic mapping to improve patien selection for cardiac resynchronization therapy: beyond QRS duration and left bundle branch block morphology.Journal of the American College of Cardiology Jun 18 2013;61:2435-2443.

18. Chandra R, Zolty R, Palma E.A left hemiblock improves cardiac resynchronization therapy outcomes in patients with a right bundle branch block.Clin Cardiol Feb 2010;33:89-93.

19. Kandala J, Upadhyay GA, Altman RK, Parks KA, Orencole M, Mela T, Kevin Heist E, Singh JP.QRS morphology, left ventricular lead location, and clinical outcome in patients receiving cardiac resynchronization therapy. European heart journal Apr 92013

20. Gold MR, Birgersdotter-Green U, Singh JP, Ellenbogen KA, Yu Y, Meyer TE, Seth M, Tchou PJ.The relationship between ventricular electrical delay and left ventricular remodelling with cardiac resynchronization therapy.European heart journal Oct 2011;32:2516-2524.

21. Singh JP, Fan D, Heist EK, Alabiad CR, Taub C, Reddy V, Mansour M, Picard MH, Ruskin JN, Mela T.Left ventricular lead electrical delay predicts response to cardiac resynchronization therapy.Heart rhythm: the official journal of the Heart Rhythm Society Nov 2006;3:1285-1292.

22. Edenbrandt L, Pahlm O.Vectorcardiogram synthesized from a 12-lead ECG: superiority of the inverse Dower matrix.Journal of electrocardiology Nov 1988;21:361-367.

23. Bacharova L, Szathmary V, Mateasik A.Electrocardiographic patterns of left bundle-branch block caused by intraventricular conduction impairment in working myocardium: a model study.Journal of electrocardiology Nov-Dec 2011;44:768-778.

24. Schreurs CA, Algra AM, Man SC, Cannegieter SC, van der Wall EE, Schalij MJ, Kors JA, Swenne CA.The spatia QRS-T angle in the Frank vectorcardiogram: accuracy of estimates derived from the 12-lead electrocardiogram.Journal of electrocardiology Jul-Aug 2010;43:294-301.

25. Engels EB, Alshehri S, van Deursen CJ, Wecke L, Vernooy K, Prinzen FW.The synthesized vectorcardiogram resembles the measured vectorcardiogram in patients with dyssynchronous heart failure.Journal of electrocardiology Apr 82015 


\section{Feasibility and acute hemodynamic effect of left ventricular septal pacing by transvenous approach through the interventricular septum}




\section{Abstract}

Aim: Left ventricular septal (LVS) pacing reduces ventricular dyssynchrony and improves cardiac function relative to right ventricular apex (RVA) pacing in animals. We aimed to establish permanent placement of an LVS pacing lead in patients using a transvenous approach through the interventricular septum.

Methods: Ten patients with sinus node dysfunction scheduled for dual-chamber pacemaker implantation were prospectively enrolled. A custom pacing lead with extended helix was introduced via the left subclavian vein and, after positioning against the right ventricular septum (RVS) using a preshaped guiding catheter, driven through the interventricular septum to the LVS. The acute hemodynamic effect of RVA RVS and LVS pacing was evaluated by invasive LVdP/dtmax measurements.

Results: The lead was successfully delivered to the LVS in all patients. Procedure time and fluoroscopy time shortened with experience. QRS duration was shorter during LVS pacing $(144 \pm 20 \mathrm{~ms})$ than during RVA ( $172 \pm 33 \mathrm{~ms}, \mathrm{P}=0.02 \mathrm{vs}$. LVS) and RVS pacing (165 $\pm 17 \mathrm{~ms}, \mathrm{P}=0.004 \mathrm{vs}$. LVS). RVA and RVS pacing reduced LVdP/dtmax compared with baseline atrial pacing $(-7.1 \pm 4.1 \%$ and $-6.9 \pm 4.3 \%$, respectively), whereas LVS pacing maintained LVdP/dtmax at baseline level $(1.0 \pm 4.3 \%, P=0.001$ vs. RVA and RVS). R-wave amplitude and pacing threshold were $12.2 \pm 6.7 \mathrm{mV}$ and $0.5 \pm 0.2 \mathrm{~V}$ at implant and remained stable during 6-months follow-up without lead-related complications.

Conclusion: Permanent placement of an LVS pacing lead by transvenous approach through the interventricular septum is feasible in patients. LVS pacing preserves acute left ventricular pump function. This new pacing method could serve as an alternative and hemodynamically preferable approach for antibradycardia pacing.

\section{Introduction}

Cardiac pacing is the only effective treatment for symptomatic bradycardia that is caused by sinus node dysfunction (SND) or atrioventricular (AV) block. The right ventricular apex (RVA) has become the preferred site for ventricular lead placement because it is easily accessible for implantation and yields chronically stable lead positions and stimulation thresholds. In general, RVA pacing is well tolerated and effective. However, there is increasing evidence that the dyssynchronous left ventricular (LV) electrical activation and contraction, induced by RVA pacing, has detrimental effects on LV structure and function, which is associated with increased risk of cardiac morbidity and mortality. ${ }^{1-3}$ New pacemaker algorithms have minimized the percentage of undesirable ventricular pacing in patients with SND and patients with implantable cardioverter-defibrillators. ${ }^{4-6}$ However, in many patients, continuous ventricular pacing is unavoidable because of unreliable or absent AV conduction. In recognition of this, interest has also been focused on alternative ventricular pacing sites to preserve LV pump function. Alternative pacing sites within the right ventricle (RV) such as the RV septum (RVS) or RV outflow tract, have been intensively studied but show mixed results.-9 Studies in animals have shown that pacing at the LV septum (LVS) yields LV pump function closely approximating that during normal ventricular conduction and significantly better than that during RVS pacing. ${ }^{10,11}$ In the animal experiments, the LVS lead was permanently placed by introducing a custom pacing lead with extended helix transvenously into the RV and driving it from the RV side through the interventricular septum (IVS) to the LVS."1 This was shown to be a feasible and safe procedure, and leads remained mechanically and electrically stable during 4 months follow-up in the otherwise healthy and active canines. The objectives of this study were (1) to perform a first-inman study, investigating the feasibility of permanently implanting an LVS lead in patients using a transvenous approach through the interventricular septum; and (2) to compare the acute hemodynamic effect of LVS pacing with that of RVS pacing and conventional RVA pacing.

\section{Methods}

\section{Study population}

We prospectively enrolled patients with a pacemaker indication for symptomatic SND, who were thus not ventricular pacing dependent and, therefore, considered at relatively low risk of adverse events in case of lead failure. Exclusion criteria were second- or third-degree AV block history of septal myocardial infarction, IVS wall thickness $>10 \mathrm{~mm}$ on echocardiography, permanent atrial fibrillation, or severe aortic valve stenosis. The study protocol was approved by the Institutional Review Board, and all patients gave written informed consent to participate in the study.

\section{Ventricular pacing lead}

A custom 4.15-Fr bipolar, fixed-screw, steroid-eluting ventricular pacing lead (Model 09066; Medtronic Inc., Minneapolis, MN) was used, which was exclusively delivered for this study. The lead Model 09066 is a modification of the market-released Select Secure model 3830 (Medtronic Inc.) with an extended helix (Figure 1A). Instead of the short 1.8-mm helix of the Model 3830, the Model 09066 has been fitted with a longer 4-mm helix to provide better lead fixation and a higher pull-through force for deeper penetration into the IVS. The helix is partially coated with a thin nonconductive polyurethane layer to have an electrically active portion of only the distal $1.27 \mathrm{~mm}$, which serves as electrode. The helix-ring distance is $5 \mathrm{~mm}$. However, the electrical tip-ring spacing is $\approx 8 \mathrm{~mm}$ due to the nonconductive coating on the proxima 


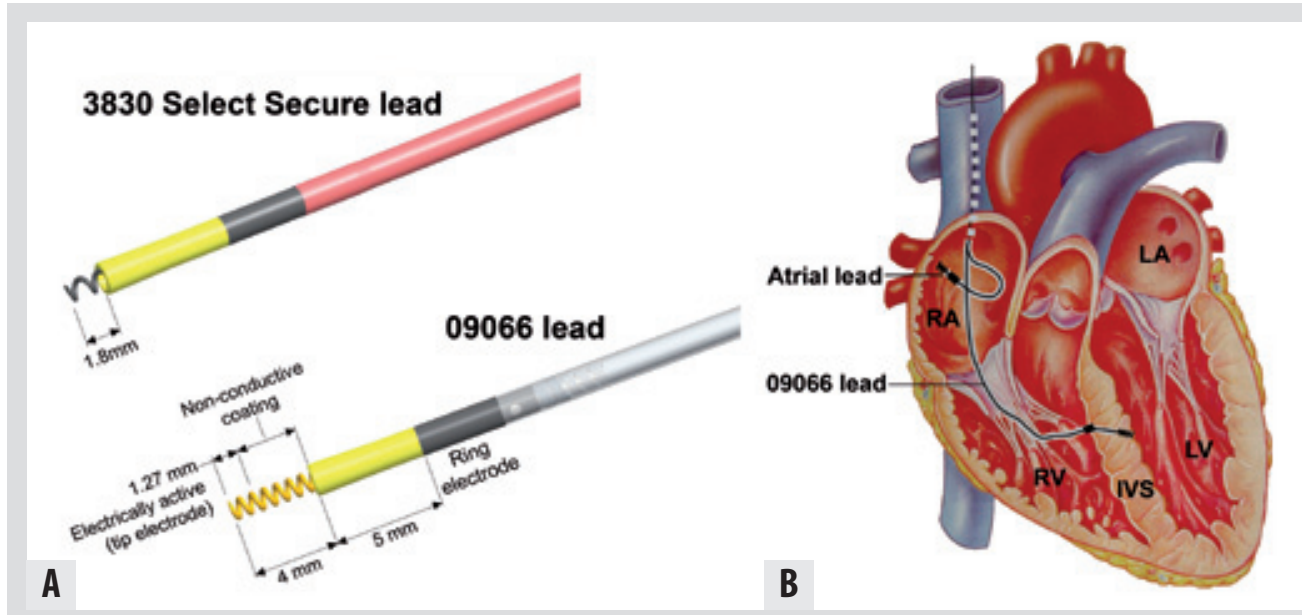

Figure 1. (A) Lead design of the lead Model 09066. The lead is a modification of the market-released Select Secure Model 3830 with an extended helix. The lead has been fitted with a 4-mm helix instead of the standard 1.8-mm helix of the Model 3830. The helix is partially insulated to have an electrically active portion of only the distal $1.27 \mathrm{~mm}$. (B) Schematic representation of lead positioning. The lead Model 09066 is introduced transvenously into the right ventricle (RV), and after positioning against the RV septum, driven through the interventricular septum (IVS) with the screw-in tip until the left ventricular (LV) septum is reached, without perforating the IVS. The ring stimulates the RV side and the tip, the LV side of the IVS. RA, right atrium; LA, left atrium.

part of the helix. The lead is introduced transvenously into the RV, and after positioning against the RVS, driven through the IVS with the screw-in tip until the LVS is reached, without perforating the IVS (Figure 1B).

\section{Implantation procedure}

Figure 2 illustrates the different steps performed during the implantation procedure. Two venous accesses were obtained by left cephalic vein cutdown or left subclavian vein puncture. A standard atrial bipolar active fixation pacing lead was positioned in the right atrial appendage according to routine clinical practice (Figure 2A). A Certus Pressure Wire (St Jude Medical Systems

Legend of Figure 2. Images of the implantation procedure. The atrial lead is positioned in the right atrial (RA) appendage and a Certus Pressure Wire is positioned in the left ventricle (LV) for acute hemodynamic measurements (A) A right ventricular (RV) angiogram is performed in right anterior oblique (RAO; A) and left anterior oblique (LAO; B). The custom left ventricular septal (LVS) pacing lead is positioned perpendicularly against the interventricular septum (IVS) using a preshaped guiding catheter (C). The tip of the lead is positioned as close to the middle of the IVS as possible by using fluoroscopy in both RAO (C) and LAO (D) with reference to the corresponding RV angiogram (A and B). Intracardiac echocardiography ultrasound catheter (ICE) is used to verify the position of the lead tip on the IVS achieved using fluoroscopy before screwing the lead into the IVS (E). The intracardiac echocardiogram shows the RV in a long axis view that parallels the septum with the lead tip located at mid-level between the apex and base and the anterior and posterior border of the RV. (F), A schematic representation of the intra-cardiac echocardiogram. After proper positioning of the LVS lead on the IVS, the lead is screwed through to the left side of the IVS. (G), The tip of the lead resting perpendicularly against the IVS (indicated by the dashed yellow line) before screwing the lead in. While rotating the lead, repeated hand injections of contrast medium through the guiding catheter against the IVS are used to assess the penetration depth (H and I). The part of the lead tip that protrudes into the IVS is not covered by contrast medium. Based on beforehand knowledge of the lead tip dimensions and the patient's IVS wall thickness, this provides an estimation of penetration depth in the IVS. TV, tricuspid valve; $\mathrm{AO}$, aorta; $\mathrm{PA}$, pulmonary artery.

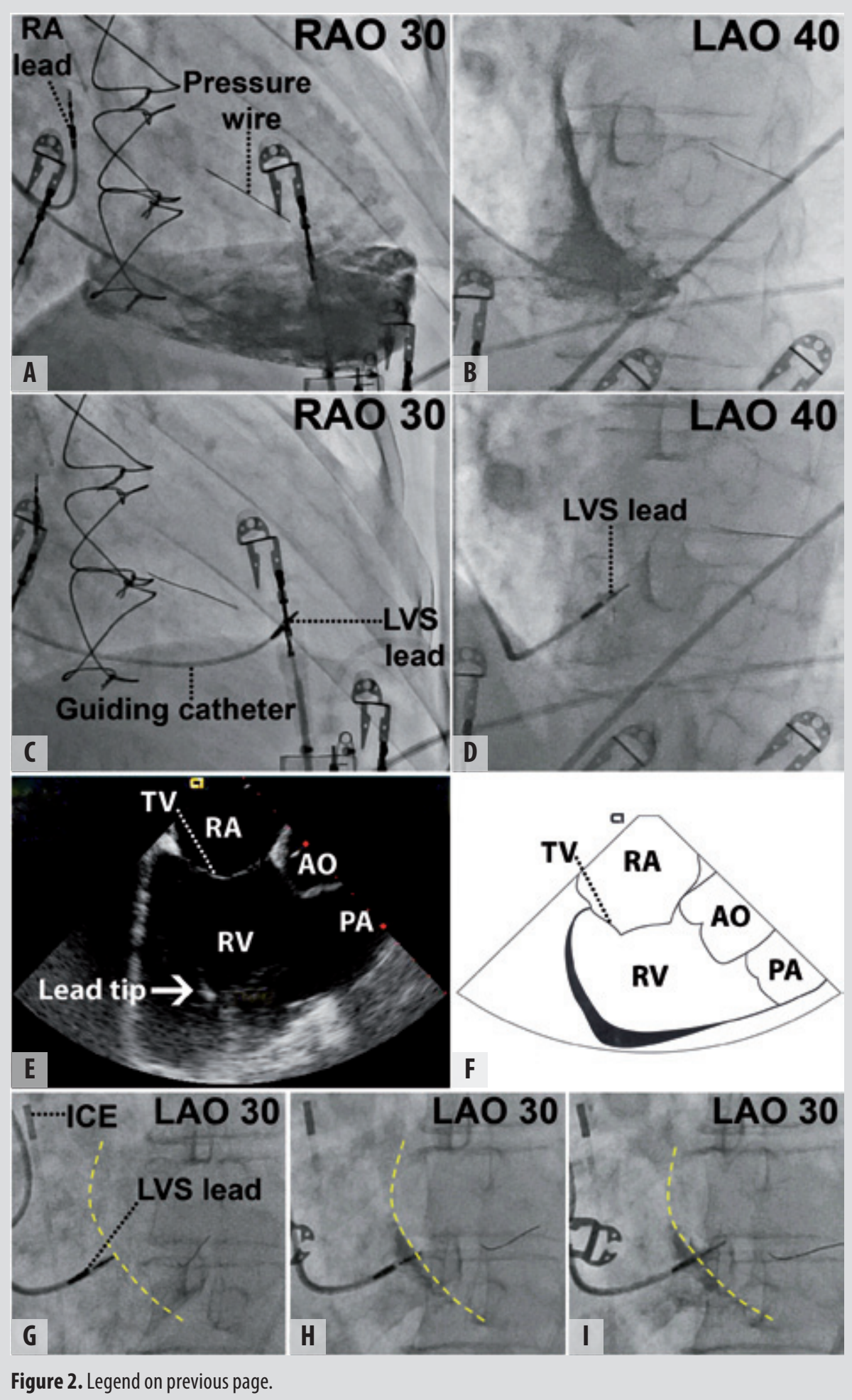

LV septal pacing via the interventricular septum 
AB, Uppsala, Sweden) was positioned in the LV for acute hemodynamic measurements (see below). The Certus wire was introduced via a left femoral arterial puncture and positioned in the LV by the retrograde aortic approach using a 4-Fr multipurpose catheter. Subsequently, the multipurpose catheter was withdrawn into the aorta leaving the soft tip of the pressure wire in a stable position in the LV cavity (Figure 2A). An RV angiogram was made in right anterior oblique (RAO; Figure $2 \mathrm{~A}$ ) and left anterior oblique (LAO; figure $2 \mathrm{~B}$ ) view to visualize the IVS borders using a 6-Fr pigtail catheter introduced into the RV via the second venous access. The pigtail catheter was replaced with a quadripolar diagnostic electrophysiology catheter that was positioned in the RVA for temporary pacing. Next, the acute hemodynamic effect of RVA pacing was evaluated. Subsequently, the electrophysiology catheter was removed, and the custom ventricular pacing lead was introduced into the RV using a 7-Fr preshaped guiding catheter (Model C315-S10; Medtronic Inc.; Figure 2C). The specific shape of the C315-S10 catheter allows straightforward positioning of the catheter tip perpendicularly against the IVS. During lead placement, the implanter repeatedly alternated between RAO (Figure $2 \mathrm{C}$ ) and LAO (Figure 2D) view to position the tip of the lead as close to the middle of the IVS as possible while using the RV angiogram in RAO (Figure 2A) and LAO (Figure 2B) as a reference. Hereby, the RAO view was used to direct the lead to halfway between apex and base, whereas the LAO view was used to position the lead halfway between the anterior and posterior septal borders. An 8-Fr ACUSON AcuNav diagnostic ultrasound catheter (Siemens Medical Solutions USA, Inc.) was introduced via a right femoral venous puncture and advanced to the right atrium for intra-cardiac echocardiography (ICE). ICE was used to verify the position of the lead tip on the IVS achieved using fluoroscopy before screwing the lead into the IVS (Figure $2 \mathrm{E}$ and $2 \mathrm{~F}$ ). Subsequently, the pacing electrode was screwed through the IVS until the LVS was reached, without perforating the IVS. While rotating the lead, the implanter repeatedly assessed the penetration depth in the IVS by injecting small amounts of contrast medium through the guiding catheter against the IVS under fluoroscopy in LAO (figure $2 \mathrm{G}$ and 2I). Because the contrast medium is restrained by the IVS, the part of the lead tip that protrudes into the IVS is not covered by contrast medium. In combination with beforehand knowledge of the lead tip dimensions and the patient's IVS wall thickness (preprocedurally assessed by echocardiography), this provided an estimation of penetration depth in the IVS. In addition, pacing was repeatedly performed from the tip electrode while advancing the helix through the IVS to assess changes in paced ORS morphology that indicated that the left side of the IVS had been reached. Pacing thresholds and impedances were measured to ensure that the helix did not protrude in the LV cavity. Subsequently, acute hemodynamic measurements were performed as described below. All patients received a dual-chamber pacemaker. The pacemaker was programmed to AAI with DDD (AV-sequential pacing) backup.

\section{Acute hemodynamic measurements}

The acute hemodynamic effect of RVA pacing (with the temporary electrophysiology catheter) RVS pacing (unipolar pacing from the ring of the custom lead) and LVS pacing (unipolar pacing from the tip of the custom lead) was evaluated by invasive measurement of LVdP/dtmax using the Certus Pressure Wire and PhysioMon software (St Jude Medical Systems AB). All pacing was performed at 10 beats per minute above intrinsic sinus rate. For each ventricular site, LVdP/ $\mathrm{dtmax}$ was measured during AV sequential pacing (DDD mode) with a paced AV delay $60 \mathrm{~ms}$ shorter than intrinsic activation to ensure full ventricular capture. Baseline LVdP/dtmax measurements were performed during atrial pacing (AAl mode) before and after each DDD measurement. A waiting period of at least 30 seconds was respected after each measurement to allow for hemodynamic stabilization. During each measurement LVdP/dtmax was measured and averaged over an interval of 20 seconds. The acute hemodynamic effect of pacing at each ventricular site was calculated as the relative change in LVdP/dtmax compared with the average of the two adjacent baseline AAI measurements.

Follow-up

R-wave amplitude, pacing thresholds, and impedances were recorded immediately after implantation; the day after implantation; as well as 10 days, 1 month, 3 months, and 6 month after the implantation.

\section{Statistical analysis}

Continuous variables are expressed as mean \pm standard deviation (SD). Categorical variables are expressed as observed number and percentage values. Means of continuous variable were compared among pacing conditions using repeated measures ANOVA with Bonferron multiple comparisons procedure applied to pairwise comparisons. A P value $<0.05$ was used to denote statistically significant differences. Statistical analysis was performed using SPSS version 20.0 (SPSS Inc.) software.

\section{Results}

Ten patients (mean age, $72 \pm 10$ years; 5 men) were included in the study. The baseline characteristics of the patients are shown in Table 1. All patients were in sinus rhythm, had normal QRS duration on standard 12-lead ECG, and had a normal LV ejection fraction a echocardiographic evaluation. Mean IVS thickness assessed by echocardiography was $9 \pm 1 \mathrm{~mm}$.

\section{Table 1. Patient characteristics}

\begin{tabular}{|l|l|l|l|l|l|l|l|l|}
\hline No. & Age & Gender & $\begin{array}{l}\text { Pacing } \\
\text { indication }\end{array}$ & $\begin{array}{l}\text { Intrinsic } \\
\text { rhythm }\end{array}$ & $\begin{array}{l}\text { QRS } \\
\text { duration } \\
(\mathrm{ms})\end{array}$ & LVEF (\%) & $\begin{array}{l}\text { LVEDD } \\
(\mathrm{mm})\end{array}$ & $\begin{array}{l}\text { IVS } \\
\text { thickness } \\
(\mathrm{mm})\end{array}$ \\
\hline 1 & 73 & $\mathrm{M}$ & SND & SR & 90 & 62 & 55 & 8 \\
\hline 2 & 80 & $\mathrm{~F}$ & SND & SR & 92 & 65 & 48 & 9 \\
\hline 3 & 85 & $\mathrm{~F}$ & SND & SR & 84 & 66 & 42 & 9 \\
\hline 4 & 62 & $\mathrm{M}$ & SND & SR & 90 & 54 & 53 & 10 \\
\hline 5 & 62 & $\mathrm{M}$ & SND & SR & 92 & 50 & 64 & 10 \\
\hline 6 & 53 & $\mathrm{M}$ & SND & SR & 98 & 61 & 63 & 10 \\
\hline 7 & 77 & $\mathrm{~F}$ & SND & SR & 80 & 60 & 47 & 8 \\
\hline 8 & 74 & $\mathrm{~F}$ & SND & SR & 88 & 52 & 45 & 9 \\
\hline 9 & 81 & M & SND & SR & 94 & 54 & 50 & 10 \\
\hline 10 & 70 & $\mathrm{~F}$ & SND & SR & 96 & 65 & 48 & 7 \\
\hline Mean \pm SD & $72 \pm 10$ & & & & $90 \pm 5$ & $59 \pm 6$ & $52 \pm 7$ & $9 \pm 1$ \\
\hline
\end{tabular}

M, male; F, female; SND, sinus node dysfunction; SR, sinus rhythm; LVEF, left ventricular ejection fraction; LVEDD, left ventricular end-diastolic diameter; IVS, interventricular septum. 


\section{Implantation}

All patients underwent a successful implantation of an LVS lead through the IVS in a single procedure. In 8 of 10 patients, a lead position at the midlevel of the LVS (halfway between the apex and base) was achieved (Table 2). In patients 2 and 7, the lead was positioned in a more apical and basal region of the LVS, respectively. The mean time required to implant the LVS lead was $29 \pm 24$ minutes (limits 9-90 minutes) and the mean fluoroscopy time during the entire procedure was $20 \pm 9$ minutes (limits 10-44 minutes) with a clear trend of shortening times with increasing experience (Table 2). During implantation of the last two patients, the implanter felt safe enough with the procedure to accomplish implantation of the LVS lead without guidance by ICE.

\section{Lead stability and complications}

There were no clinically significant changes in pacing threshold, R-wave amplitude, or impedance of the LVS lead between implantation and the day after implantation, as well as at 10-days, 1- month, 3-month, and 6-month follow-up. Mean pacing threshold, R-wave amplitude, and impedance at implant were $0.5 \pm 0.2 \mathrm{~V}, 12.2 \pm 6.7 \mathrm{mV}$, and $715 \pm 83 \mathrm{ohms}$, respectively. At 6-month follow-up, mean pacing threshold, $R$-wave amplitude and impedance were $0.9 \pm 0.3 \mathrm{~V}$ $16.0 \pm 8.7 \mathrm{mV}$, and $550 \pm 55 \mathrm{ohms}$, respectively.

No periprocedural complications related to the LVS lead were observed. None of the patients developed ventricular conduction disturbances during the procedure. During 6-month follow-up, none of the patients showed signs of dislodgement of the LVS lead, loss of capture, prolongation of the paced or intrinsic QRS duration, or infections associated with the implantation procedure.

\section{ECG characteristics}

Figure 3 shows the ECG from patient 2 (Table 1) during intrinsic activation, RVA, RVS, and LVS pacing. During RVA and RVS pacing, a left bundle-branch block-like QRS morphology was observed, and QRS duration was considerably prolonged relative to intrinsic activation. During LVS pacing, a right bundle-branch block-like QRS morphology was observed in the precordial leads and QRS duration was considerably less prolonged than during RVS and RVA pacing. For the entire study cohort, QRS duration during intrinsic activation was $90 \pm 5 \mathrm{~ms}$. During RVA and RVS pacing, ORS duration was almost twice as long as during intrinsic activation (RVA pacing, $172 \pm 33 \mathrm{~ms}$ [P = 0.004 vs. intrinsic activation]; RVS pacing, $165 \pm 17 \mathrm{~ms},[\mathrm{P}<0.001$ vs. intrinsic activation]). QRS duration during LVS pacing was $144 \pm 20 \mathrm{~ms}$, which was prolonged compared with intrinsic activation $(P=0.002)$, yet significantly shorter than during RVA pacing $(\mathrm{P}=0.02)$ and RVS pacing $(\mathrm{P}=0.004)$

\section{Acute hemodynamic measurements}

The LVdP/dtmax measurements were successfully obtained in all patients without complications. Figure 4 shows the acute change in LV dP/dtmax during RVA, RVS and LVS pacing relative to baseline atrial pacing for the entire study cohort, as well as the individual hemodynamic responses to pacing at the different ventricular sites. RVA and RVS pacing reduced LVdP/dtmax as compared with baseline atrial pacing by $7.1 \pm 4.1 \%$ and $6.9 \pm 3.4 \%$, respectively, whereas LVS pacing maintained LVdP/dtmax at baseline level ( $1.0 \pm 4.3 \% ; P=0.001$ vs. RVA and RVS). This acute hemodynamic benefit of LVS pacing over RVA and RVS pacing was observed in al patients (Figure 4).
Table 2. Implantation procedure details

\begin{tabular}{|c|c|c|c|c|c|c|c|c|}
\hline ż & 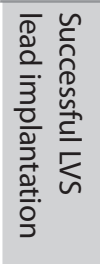 & 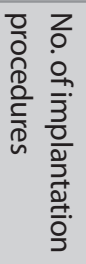 & 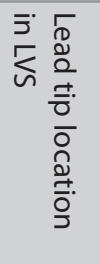 & 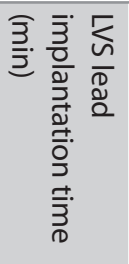 & 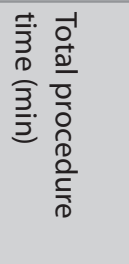 & 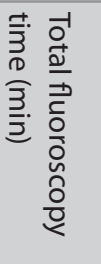 & 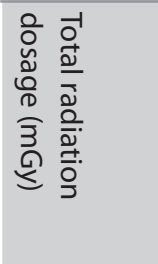 & 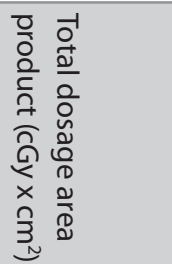 \\
\hline 1 & Yes & 1 & mid & 90 & 237 & 44 & 1700 & 14911 \\
\hline 2 & Yes & 1 & apical & 33 & 204 & 21 & 400 & 6435 \\
\hline 3 & Yes & 1 & mid & 47 & 135 & 14 & 300 & 3953 \\
\hline 4 & Yes & 1 & mid & 30 & 158 & 25 & 447 & 3692 \\
\hline 5 & Yes & 1 & mid & 23 & 103 & 19 & 147 & 1435 \\
\hline 6 & Yes & 1 & mid & 19 & 103 & 14 & 333 & 4102 \\
\hline 7 & Yes & 1 & basal & 18 & 125 & 17 & 56 & 975 \\
\hline 8 & Yes & 1 & mid & 9 & 115 & 16 & 117 & 1888 \\
\hline 9 & Yes & 1 & mid & 11 & 93 & 22 & 287 & 3482 \\
\hline 10 & Yes & 1 & mid & 12 & 83 & 10 & 26 & 418 \\
\hline \multicolumn{4}{|c|}{ Mean \pm SD } & $29 \pm 24$ & $136 \pm 50$ & $20 \pm 9$ & $381 \pm 485$ & $4129 \pm 4193$ \\
\hline
\end{tabular}

LVS, left ventricular septum.

\section{Discussion}

The present study demonstrates that permanent implantation of a pacing lead with extended helix in the LVS using a transvenous approach through the IVS is feasible and safe, at least in this small group of patients. Compared with RVA and RVS pacing, LVS pacing reduces electrical dyssynchrony and preserves acute LV pump function. Electrical and mechanical lead properties remain stable during 6-month of follow-up.

\section{Feasibility of LVS pacing}

The feasibility of LVS pacing using a transvenous approach through the IVS has previously only been demonstrated in animal experimental studies. Grosfeld et al. were the first to demonstrate implantation of a custom pacing lead with a long insulated screw in the LVS through the IVS in six goats. ${ }^{2}$ In a later study, Mills et al. achieved permanent and stable LVS pacing over a period of 16 weeks in eight adult mongrel dogs using a custom pacing lead with extended helix, similar to the one used in the present study. ${ }^{11}$

The present study translates the results of these preclinical studies into clinical practice by demonstrating that this form of LVS pacing is also feasible in patients. Implantation of an LVS lead was successfully accomplished in all patients in a single procedure. There were no short- or long-term lead-related complications. Pacing thresholds and sensing characteristics were within an adequate range and in keeping with that during RVA pacing, and the leads remained electrically and mechanically stable during 6-month follow-up. Because it is a nove implantation technique, procedure time and total fluoroscopy time were relatively long during the first implantations. However, both procedure time and fluoroscopy time steeply 


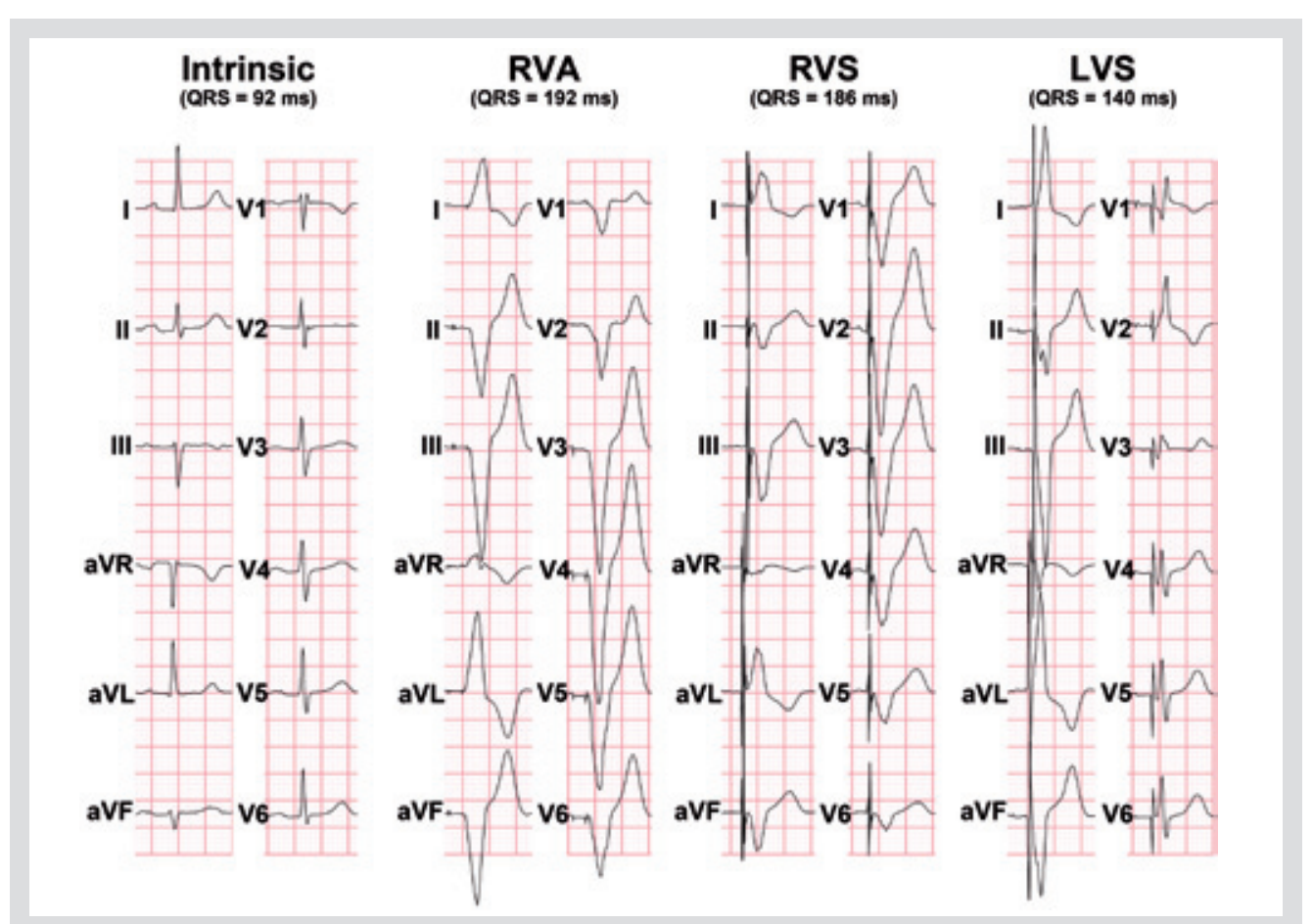

Figure 3. Twelve-lead ECG from patient 2 (Table 1) during intrinsic activation, right ventricular apex (RVA), right ventricular septal (RVS) and left ventricular septal (LVS) pacing. During RVA and RVS pacing a left bundle-branch block-like QRS morphology was observed. During LVS pacing, a right bundle-branch block-like QRS morphology was observed in the precordial leads. RVA and RVS pacing considerably prolonged QRS duration relative to intrinsic activation. QRS duration during LVS pacing was prolonged compared with intrinsic activation, yet considerably shorter than during RVA and RVS pacing.

declined with increasing experience. The study protocol initially involved ICE as an additional visualization tool to increase the safety of the procedure. However, the experience gained throughout the study allowed omission of ICE during the last two procedures without compromising safety, thereby increasing feasibility of the implantation procedure in clinical practice. Furthermore, implantation of the LVS lead could be accomplished using a commercially available preshaped guiding catheter, making the procedure applicable in any implanting center with access to the relevant instruments.

\section{LVS pacing versus RVA and RVS pacing}

The finding that RVA pacing induces electrical dyssynchrony and impairs acute hemodynamic function is well known from literature. ${ }^{1,13}$ Subanalyses of different clinical trials have shown that a higher RVA pacing burden is associated with heart failure worsening, atrial fibrillation and death. $2,14,15$

In the present study, RVS pacing did not show a better ventricular electrical activation pattern or an acute hemodynamic benefit compared with RVA pacing. The RVS has been suggested as an alternative pacing site, but comparative studies have found conflicting results. Small acute hemodynamic studies generally show a tendency toward an advantage of RVS over RVA pacing. However, three randomized trials comparing RVS with RVA pacing in

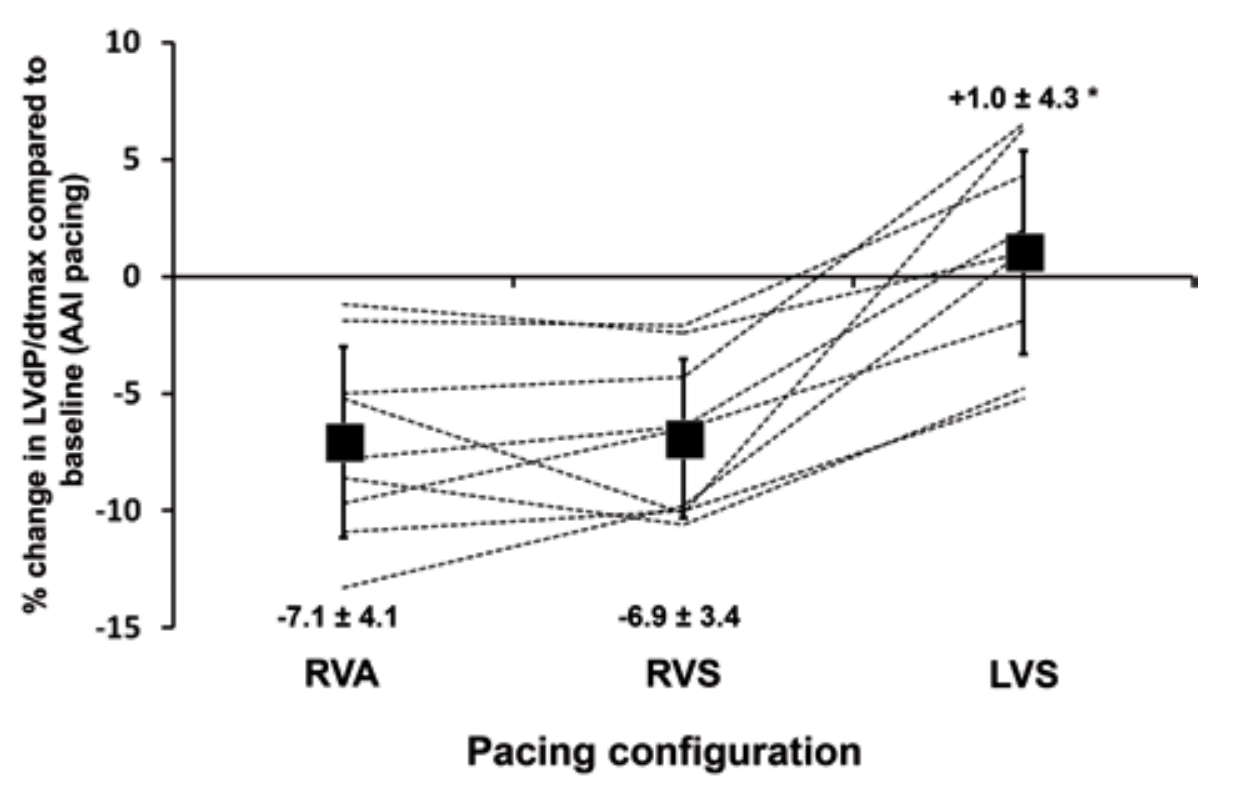

Figure 4. Acute change in left ventricular (LV)dP/dtmax (mean \pm SD) during pacing at different ventricular sites relative to baseline atrial pacing. Dashed lines represent individual hemodynamic responses to pacing at different ventricular sites. RVA, right ventricular apex; RVS, right ventricular septum; LVS, left ventricular septum. ${ }^{*} P=0.001$ vs. RVA and RVS.

patients with congestive heart failure and chronic atrial fibrillation and patients with total AV block showed no differences in LV ejection fraction, quality of life, exercise capacity, and brain natriuretic peptide levels at long-term follow-up. ${ }^{8,16,17}$

Previous acute hemodynamic studies in dogs with normal ventricular conduction have demonstrated that pacing at the LVS maintains LV systolic and diastolic function at sinus rhythm level, whereas LV function is depressed during RVA and RVS pacing.10, 11 The data from the present study extrapolate these preclinical findings on the beneficial hemodynamic effect of LVS pacing to the human population. In the animal studies, electrical activation mapping and MRI tagging showed that the superior hemodynamic effect of LVS pacing is related to the more physiological sequence of LV electrical activation and contraction, resulting in less LV electric and mechanical dyssynchrony."1 In the present study, reduction in electric dyssynchrony was reflected by the shorter QRS duration during LVS pacing compared with RVA and RVS pacing. During normal ventricular conduction, electric activation of the working myocardium starts at the LV septal endocardium, which may explain why pacing at or near this site maintains a closer to normal electric activation as well as mechanical synchrony and coordination. Activation of the RV wall has been shown to remain moderately delayed during LVS pacing, which may explain why in the present study QRS duration during LVS pacing, although shorter compared with RVA and RVS pacing, was still prolonged compared with intrinsic ventricular activation. A remarkable finding of the present study is the large difference in QRS duration and hemodynamic effect between pacing at the RV and LV side of the IVS despite the fact that these sites were not more $>1 \mathrm{~cm}$ apart. These observations are consistent 
with earlier observations in animals and patients $s^{11,18}$ and have been related to a significan delay in transseptal conduction during RVS pacing which causes considerably later LV mechanical activation and peak contraction of the LV lateral wall, thereby inducing both inter- and intraventricular asynchrony.

Another pacing site that is capable of preserving native ventricular activation is the His bundle. Similar to our observations in LVS pacing, His bundle pacing in patients has been shown to result in less inter- and intraventricular dyssynchrony ${ }^{19}$ and better hemodynamic performance than RVA pacing. ${ }^{20-22}$ Permanent His bundle pacing has been achieved in patient with $\mathrm{SND}_{1}{ }^{23}$ in patients with atrial fibrillation post-AV nodal ablation, ${ }^{19}$ and in patients with $\mathrm{AV}$ block. ${ }^{24}$ Although the various studies have demonstrated beneficial effects of this alternative pacing site, at present, His bundle pacing is not recommended in patients requiring permanent cardiac pacing because of technical challenges during lead positioning and concerns about lead stability and threshold. ${ }^{25}$

Currently, the most common way to reverse or prevent pacing-induced dyssynchrony is the application of biventricular pacing. An upgrade of RVA pacing to biventricular pacing in patients with permanent AV block, severe symptoms of heart failure, and depressed LV ejection fraction is likely to improve their symptoms and cardiac function and reduce hospitalization. ${ }^{26-29}$ In addition, several small randomized trials have suggested that patients with a conventional indication for antibradycardia pacing with moderate to severe LV dysfunction might benefit from de novo biventricular pacing compared with RV pacing in terms of LV function and remodeling, hospitalization, heart failure symptoms, and quality of life. ${ }^{30-32}$ However, biventricular pacing also has drawbacks, such as the more complex and time-consuming implantation procedure, ${ }^{33}$ the higher rate of complications, failed implantations, and loss of pacing associated with a coronary sinus lead with the consequent need fo reoperation, ${ }^{33-36}$ the shorter battery life of biventricular devices and the additional costs.

The excellent feasibility of permanently implanting an LVS pacing lead through the IVS in combination with the acute hemodynamic benefit of LVS pacing as demonstrated in the present study suggests that this pacing technique could serve as an alternative for a biventricula upgrade or primary implantation of a biventricular system in patients with a conventiona indication for antibradycardia pacing.

\section{Limitations}

As with any implanted lead, possible future complications, such as lead fracture or lead infection, may necessitate lead extraction. Extraction of a deep septal lead could potentially pose the risk of creating a ventricular septal defect, and temporary protrusion of the extraction sheath in the LV cavity could potentially create risk of systemic embolization. The present study lacks data on the magnitude of these potential risks of a possible LVS lead extraction.

During implantation, protrusion of the LV septal lead into the LV cavity was avoided by repeated injection of small amounts of contrast medium through the guiding catheter and by repeated assessment of pacing thresholds (see Methods). In the present study, no protrusion into the LV cavity was observed, guaranteeing integrity of the LV endocardia surface. In case of protrusion, the lead should be withdrawn a few millimeters to its final position. This would leave a small wound at the LV endocardium, which is likely to be healed soon, but the exact amount and nature of the final damage are not known.

The sample size of this study was small, though can be considered sufficient to make an initial statement about the feasibility of permanently implanting a pacing lead in the LVS through the IVS. Although the procedure was also safe in this small group, a larger study is required to ultimately show safety of large-scale use of the LVS lead.

Because this is a novel pacing technique with unknown success rate and complications, the study was conducted in patients with SND, a group that is generally not ventricular pacing dependent and, therefore, considered at relatively low risk of adverse events in case of lead failure.

The different shape of the ring and tip electrode of the pacing lead may have flawed the comparison between RVS and LVS pacing. Yet, we chose to test these sites in this way to minimize the time interval between the hemodynamic measurements during RVS and LVS pacing, and thus the variability between these measurements.

The findings of this study clearly require further clinical validation in larger and prospective studies. These studies should also indicate whether the acute hemodynamic benefit of LVS pacing, as demonstrated in the present study, translates into preservation of LV pump function on the longer term.

\section{Conclusion}

This study demonstrates that permanent placement of a pacing lead in the LVS using a transvenous approach through the IVS is feasible and safe, at least in this small group of patients. Compared with RVA and RVS pacing, LVS pacing reduces electric dyssynchrony and preserves acute LV pump function. The LVS lead remains electrically and mechanically stable during 6-month follow-up. The clinical benefit of this pacing method needs prospective evaluation. The results of this study suggest that LVS pacing could serve as a better alternative for RVA pacing in patients with a conventional indication for antibradycardia pacing, while lacking some of the disadvantages of biventricular pacing. 


\section{References}

. Tops LF, Schalij MJ, Holman ER, van Erven L, van der Wall EE, Bax JJ. Right ventricular pacing can induce ventricular dyssynchrony in patients with atrial fibrillation after atrioventricular node ablation. J Am Coll Cardiol. 2006;48:1642-1648.

2. Sweeney MO, Hellkamp AS, Ellenbogen KA, Greenspon AJ, Freedman RA, Lee KL, Lamas GA. Adverse effect of ventricular pacing on heart failure and atrial fibrillation among patients with normal baseline grs duration in a clinical trial of pacemaker therapy for sinus node dysfunction. Circulation. 2003;107:2932-2937.

3. Wilkoff BL, Cook JR, Epstein AE, Greene HL, Hallstrom AP, Hsia H, Kutalek SP, Sharma A. Dual-chamber pacing or ventricular backup pacing in patients with an implantable defibrillator: The dual chamber and vvi implantable defibrillator (david) trial. JAMA. 2002;288:3115-3123.

4. Savoure A, Frohlig G, Galley D, Defaye P, Reuter S, Mabo P, Sadoul N, Amblard A, Limousin M, Anselme F. A new dual-chamber pacing mode to minimize ventricular pacing. Pacing Clin Electrophysiol. 2005;28Suppl 1:543-46.

5. Sweeney MO, Bank AJ, Nsah E, Koullick M, Zeng QC, Hettrick D, Sheldon T, Lamas GA. Minimizing ventricular pacing to reduce atrial fibrillation in sinus-node disease. N Engl J Med. 2007;357:1000-1008.

6. Sweeney MO, Shea JB, Fox V, Adler S, Nelson L, Mullen TJ, Belk P, Casavant D, Sheldon T. Randomized pilot study of a new atrial-based minimal ventricular pacing mode in dual-chamber implantable cardioverter-defibrillators. Heart Rhythm. 2004;1:160-167.

7. de Cock CC, Giudici MC, Twisk JW. Comparison of the haemodynamic effects of right ventricular outflow-tract pacing with right ventricular apex pacing: A quantitative review. Europace. 2003;5:275-278.

8. Kaye GC, Linker NJ, Marwick TH, Pollock L, Graham L, Pouliot E, Poloniecki J, Gammage M. Effect of right ventricular pacing lead site on left ventricular function in patients with high-grade atrioventricular block: Results of the protect-pace study. Eur Heart J. 2015;36:856-862.

9. Tse HF, Yu C, Wong KK, Tsang V, Leung YL, Ho WY, Lau CP. Functional abnormalities in patients with permanent right ventricular pacing: The effect of sites of electrical stimulation. J Am Coll Cardiol. 2002;40:1451-1458.

10. Peschar M, de Swart H, Michels KJ, Reneman RS, Prinzen FW. Left ventricular septal and apex pacing for optimal pump function in canine hearts. J Am Coll Cardiol. 2003;41:1218-1226.

11. Mills RW, Cornelussen RN, Mulligan LJ, Strik M, Rademakers LM, Skadsberg ND, van Hunnik A, Kuiper M, Lampert A, Delhaas T, Prinzen FW. Left ventricular septal and left ventricular apical pacing chronically maintain cardiac contractile coordination, pump function and efficiency. Circ Arrhythm Electrophysiol. 2009;2:571-579.

12. Grosfeld MJ, Res JC, Vos DH, de Boer TJ, Bos HJ. Testing a new mechanism for left interventricular septal pacing: The transseptal route; a feasibility and safety study. Europace. 2002;4:439-444.

13. Lieberman R, Padeletti L, Schreuder J, Jackson K, Michelucci A, Colella A, Eastman W, Valsecchi S, Hettrick DA. Ventricular pacing lead location alters systemic hemodynamics and left ventricular function in patients with and without reduced ejection fraction. J Am Coll Cardiol. 2006;48:1634-1641.

14. Sharma AD, Rizo-Patron C, Hallstrom AP, O'Neill GP, Rothbart S, Martins JB, Roelke M, Steinberg JS, Greene HL. Percent right ventricular pacing predicts outcomes in the david trial. Heart Rhythm. 2005;2:830-834.

15. Steinberg JS, Fischer A, Wang P, Schuger C, Daubert J, McNitt S, Andrews M, Brown M, Hall WJ, Zareba W, Moss AJ. The clinical implications of cumulative right ventricular pacing in the multicenter automatic defibrillator trial ii. J Cardiovasc Electrophysiol. 2005;16:359-365.

16. Stambler BS, Ellenbogen K, Zhang X, Porter TR, Xie F, Malik R, Small R, Burke M, Kaplan A, Nair L, Belz M, Fuenzalida C, Gold M, Love C, Sharma A, Silverman R, Sogade F, Van Natta B, Wilkoff BL. Right ventricula outflow versus apical pacing in pacemaker patients with congestive heart failure and atrial fibrillation. J Cardiovasc Electrophysiol. 2003;14:1180-1186.
17. Kypta A, Steinwender C, Kammler J, Leisch F, Hofmann R. Long-term outcomes in patients with atrioventricular block undergoing septal ventricular lead implantation compared with standard apical pacing. Europace. 2008;10:574-579

18. Prinzen FW, Auricchio A. Is echocardiographic assessment of dyssynchrony useful to select candidates for cardiac resynchronization therapy? Echocardiography is not useful before cardiac resynchronization therapy if qrs duration is available. Circ Cardiovasc Imaging. 2008;1:70-77; discussion 78.

19. Occhetta E, Bortnik M, Magnani A, Francalacci G, Piccinino C, Plebani L, Marino P. Prevention of ventricular desynchronization by permanent para-hisian pacing after atrioventricular node ablation in chronic atria fibrillation: A crossover, blinded, randomized study versus apical right ventricular pacing. J Am Coll Cardiol. 2006; $47: 1938-1945$.

20. Hirao K, Otomo K, Wang X, Beckman KJ, McClelland JH, Widman L, Gonzalez MD, Arruda M, Nakagawa H Lazzara R, Jackman WM. Para-hisian pacing. A new method for differentiating retrograde conduction over an accessory av pathway from conduction over the av node. Circulation. 1996;94:1027-1035.

21. Deshmukh P, Casavant DA, Romanyshyn M, Anderson K. Permanent, direct his-bundle pacing: A novel approach to cardiac pacing in patients with normal his-purkinje activation. Circulation. 2000;101:869-877.

22. Zanon F, Bacchiega E, Rampin L, Aggio S, Baracca E, Pastore G, Marotta T, Corbucci G, Roncon L, Rubello D, Prinzen FW. Direct his bundle pacing preserves coronary perfusion compared with right ventricular apical pacing: A prospective, cross-over mid-term study. Europace. 2008;10:580-587.

23. Catanzariti D, Maines M, Cemin C, Broso G, Marotta T, Vergara G. Permanent direct his bundle pacing does not induce ventricular dyssynchrony unlike conventional right ventricular apical pacing. An intrapatient acute comparison study. J Interv Card Electrophysiol. 2006;16:81-92.

24. Feasibility and electrocardiographic findings. J Interv Card Electrophysiol. 2011;31:255-262.

25. Epstein AE, DiMarco JP, Ellenbogen KA, Estes NA, 3rd, Freedman RA, Gettes LS, Gillinov AM, Gregoratos $G$ Hammill SC, Hayes DL, Hlatky MA, Newby LK, Page RL, Schoenfeld MH, Silka MJ, Stevenson LW, Sweeney MO, Smith SC, Jr., Jacobs AK, Adams CD, Anderson JL, Buller CE, Creager MA, Ettinger SM, Faxon DP, Halperin JL, Hiratzka LF, Hunt SA, Krumholz HM, Kushner FG, Lytle BW, Nishimura RA, Ornato JP, Riegel B, Tarkington LG, Yancy CW. Acc/aha/hrs 2008 guidelines for device-based therapy of cardiac rhythm abnormalities: A report of the american college of cardiology/american heart association task force on practice guidelines (writing committee to revise the acc/aha/naspe 2002 guideline update for implantation of cardiac pacemakers and antiarrhythmia devices) developed in collaboration with the american association for thoracic surgery and society of thoracic surgeons. J Am Coll Cardiol. 2008;51:e1-62.

26. Leclercq C, Cazeau S, Lellouche D, Fossati F, Anselme F, Davy JM, Sadoul N, Klug D, Mollo L, Daubert JC. Upgrading from single chamber right ventricular to biventricular pacing in permanently paced patients with worsening heart failure: The rd-chf study. Pacing Clin Electrophysiol. 2007;30 Suppl 1:S23-30.

27. Delnoy PP, Ottervanger JP, Vos DH, Elvan A, Misier AR, Beukema WP, Steendijk P, van Hemel NM. Upgrading to biventricular pacing guided by pressure-volume loop analysis during implantation. J Cardiovas Electrophysiol. 2011;22:677-683.

28. Baker CM, Christopher TJ, Smith PF, Langberg JJ, Delurgio DB, Leon AR. Addition of a left ventricular lead to conventional pacing systems in patients with congestive heart failure: Feasibility, safety, and early results in 60 consecutive patients. Pacing Clin Electrophysiol. 2002;25:1166-1171.

29. Leon AR, Greenberg JM, Kanuru N, Baker CM, Mera FV, Smith AL, Langberg JJ, DeLurgio DB. Cardiac resynchronization in patients with congestive heart failure and chronic atrial fibrillation: Effect of upgrading to biventricular pacing after chronic right ventricular pacing. J Am Coll Cardiol. 2002;39:1258-1263.

30. Curtis $A B$. Biventricular pacing for atrioventricular block and systolic dysfunction. N Engl J Med. 2013;369:579.

31. Kindermann M, Hennen B, Jung J, Geisel J, Bohm M, Frohlig G. Biventricular versus conventional right ventricular stimulation for patients with standard pacing indication and left ventricular dysfunction: The homburg biventricular pacing evaluation (hobipace). J Am Coll Cardiol. 2006;47:1927-1937. 
32. Martinelli Filho M, de Siqueira SF, Costa R, Greco OT, Moreira LF, D'Avila A, Heist EK. Conventional versus biventricular pacing in heart failure and bradyarrhythmia: The combat study. J Card Fail. 2010;16:293-300.

33. Curtis AB, Worley SJ, Adamson PB, Chung ES, Niazi I, Sherfesee L, Shinn T, Sutton MS, Biventricular versus Right Ventricular Pacing in Heart Failure Patients with Atrioventricular Block Trial I. Biventricular pacing for atrioventricular block and systolic dysfunction. N Engl J Med. 2013;368:1585-1593.

34. Bulava A, LukI J. Single-centre experience with coronary sinus lead stability and long-term pacing parameters, Europace. 2007;9:523-527.

35. Biff M, Boriani G. Phrenic stimulation management in crt patients: Are we there yet? Curr Opin Cardio 2011;26:12-16.

36. Biffi M, Moschini C, Bertini M, Saporito D, Ziacchi M, Diemberger I, Valzania C, Domenichini G, Cervi E, Martignani C, Sangiorgi D, Branzi A, Boriani G. Phrenic stimulation: A challenge for cardiac resynchronization therapy. Circ Arrhythm Electrophysiol. 2009;2:402-410. 


\section{Evaluation of left ventricular endocardial cardiac resynchronization therapy in a non-responder with ventricular arrhythmias}

Masih Mafi Rad, Yuri Blaauw, Luuk Debie, Hans-Peter BrunnerLa Rocca, Kevin Vernooy 


\section{Abstract}

Approximately one-third of patients treated with cardiac resynchronization therapy do not derive any detectable benefit. In these patients, acute invasive hemodynamic evaluation can be used for therapy optimization. This report describes the use of systematic invasive hemodynamic measurements for clinical decision making in a patient who experienced severe ventricular arrhythmias and clinical deterioration following a biventricular upgrade.

\section{Introduction}

Cardiac resynchronization therapy (CRT) has been established as an effective treatment fo heart failure patients with severe left ventricular (LV) systolic impairment and electrica dyssynchrony.' Unfortunately, a significant proportion of apparently suitable patients fail to benefit. ${ }^{2}$ In this subset of patients, acute invasive hemodynamic evaluation can be used to optimize CRT with alternative LV pacing sites or atrio-ventricular (AV) and inter-ventricular pacing delays. ${ }^{3,4}$ We describe a patient who experienced severe ventricular arrhythmias and clinical deterioration following upgrade to a biventricular (BiV) system. CRT was discontinued based on the outcome of invasive hemodynamic measurements.

\section{Case report}

A 65-year-old male patient with non-ischemic dilated cardiomyopathy, left ventricular ejection fraction of $20 \%$, intraventricular conduction delay with a QRS duration of $148 \mathrm{~ms}$, and New York Heart Association class 3 was scheduled for upgrade of an implantable cardioverter defibrillator (ICD) to a cardiac resynchronization therapy - defibrillation (CRT-D) system. The ICD had previously been implanted for primary prevention. Echocardiography prior to the BiV upgrade demonstrated myocardial scarring of the LV lateral wall and showed no evidence of mechanical dyssynchrony. Unfavorable coronary venous anatomy required epicardial LV lead placement in the lateral position via minimal lateral thoracotomy. Four weeks later, the patient was admitted with multiple ICD discharges due to incessant ventricular tachycardia (VT) (Figure 1).

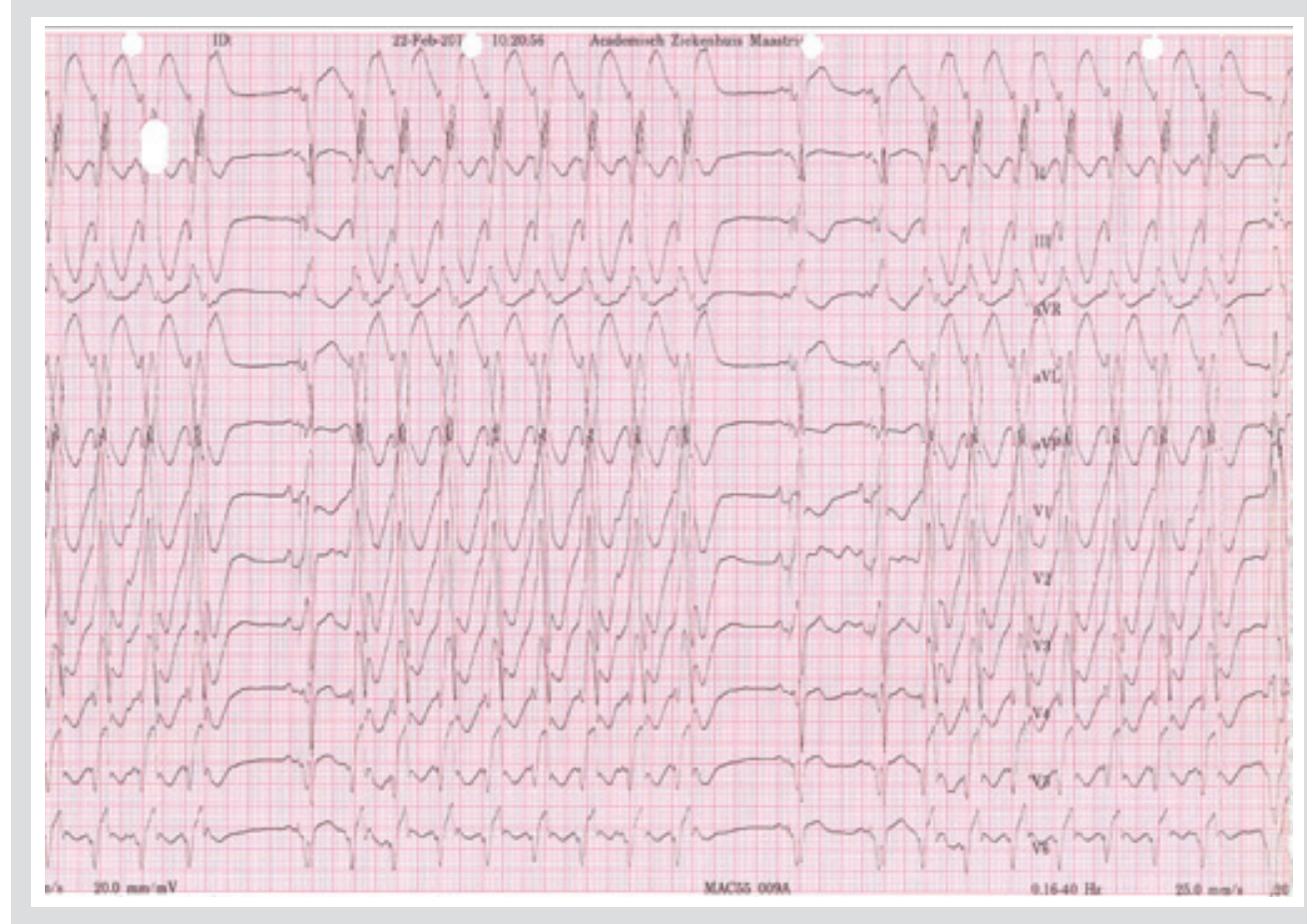

Figure 1. Incessant VT, 4 weeks after onset of BiV pacing. 
He was sedated and Amiodarone was initiated, whereupon VT recurrences were no longe observed. In the following months his clinical condition deteriorated despite continuation of BiV pacing.

An invasive hemodynamic pacing study was performed to evaluate the hemodynamic effect of conventional BiV pacing and to explore whether LV endocardial pacing could effectuate hemodynamic improvement. For this purpose, a temporary pacing electrode and a RADI pressure wire were positioned within the LV cavity, another temporary pacing electrode was placed in the right atrium (Figure 2). The RADI wire allowed determination of maximal rate of $\mathrm{LV}$ pressure rise (LVdP/dtmax) as a measure of $\mathrm{LV}$ function. ${ }^{3}$ The pacing protocol consisted of a baseline without ventricular pacing (atrial pacing) alternated with AV-sequential BiV, LV and right ventricular (RV) pacing using the implanted system and LV endocardial pacing using the temporary LV pacing electrode. To exclude hemodynamic variability induced by spontaneous changes in heart rate, pacing was performed at 10 beats per minute above intrinsic heart rate. Average LVdP/dtmax was measured during 10 seconds of pacing for each pacing configuration.

Neither LV, RV or BiV pacing with the implanted system nor LV endocardial pacing at different sites improved LVdP/dtmax as compared to baseline (Figure 3). Furthermore, the number of premature ventricular complexes (PVCs) increased upon LV stimulation. This was confirmed by 24 hour Holter monitoring, which demonstrated 40.000 PVCs during BiV pacing vs. 4000 PVCs when ventricular pacing was programmed off (Figure 4). Considering the unfavourable hemodynamic and pro-arrhythmic effects of LV pacing, placement of a permanent endocardial LV lead was not performed and the ICD was programmed to ventricular pacing off (AAI-DDD mode). Our patient was scheduled for left ventricular assist device placement.

\section{Discussion}

Patient selection plays an important role in CRT response. According to the ESC heart failure guidelines available at the time of device implantation, our patient had a class I indication for CRT. ${ }^{5}$ However, based on the most recent guidelines, he may not have been an "ideal" candidate due to the absence of a typical left bundle-branch block.' This is supported by the outcome of the acute hemodynamic measurements. Although a definite relationship between acute LVdP/dtmax increase and long-term clinical response needs to be confirmed, our findings suggest that acute invasive hemodynamic testing could help to guide the decision on whether or not to implant a CRT device in cases where there is less consensus for a clinical benefit.

The presence of myocardial scar at the area targeted by the LV lead is an important determinant of CRT response. ${ }^{6}$ Lead position optimization in the coronary sinus is usually limited by side branch anatomy. A surgical

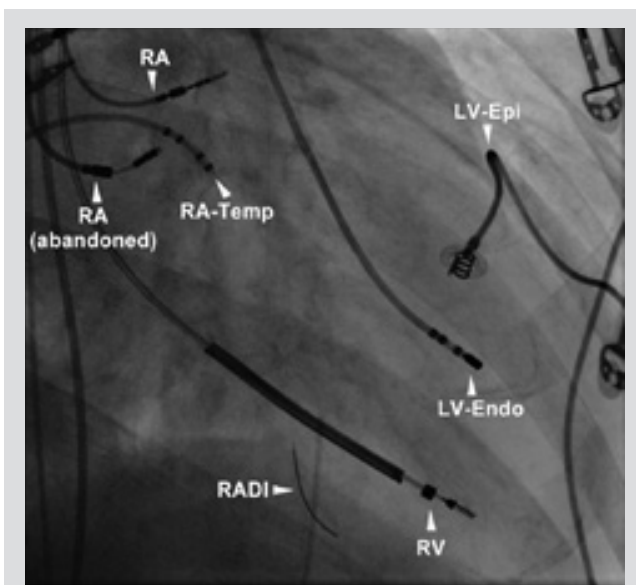

Figure 2. X-ray detail of the invasive hemodynamic pacing study setup. The right atrial (RA), right ventricular (RV) and LV epicardial (LV-Epi) lead of the implanted system are shown, together with the temporary right atrial (RA-Temp) and LV endocardial electrode (LV-Endo). The RADI pressure wire is located in the LV cavity.

\section{LVdP/dt max measurements}

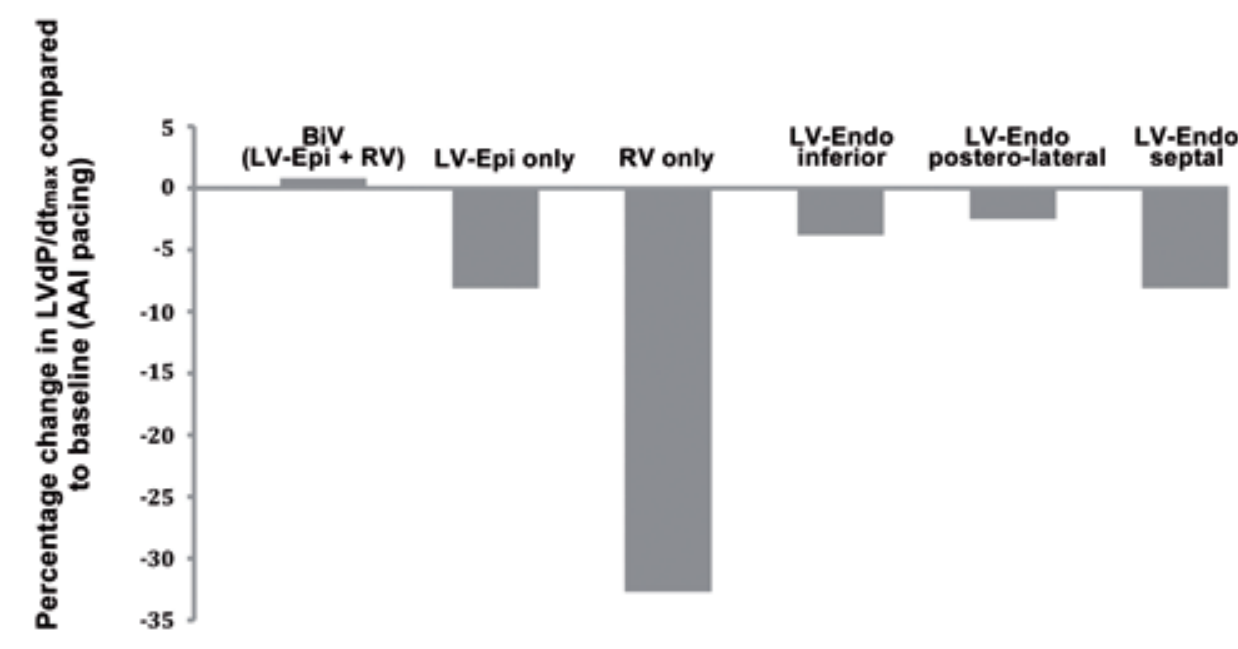

Pacing mode

Figure 3. Percentage change in LVdP/dtmax compared to baseline (AAl pacing) during AV-sequential BiV, LV and RV only pacing using the implanted system and LV endocardial pacing at different sites using the temporary LV endocardial electrode. Epi, epicardial; Endo, endocardial.

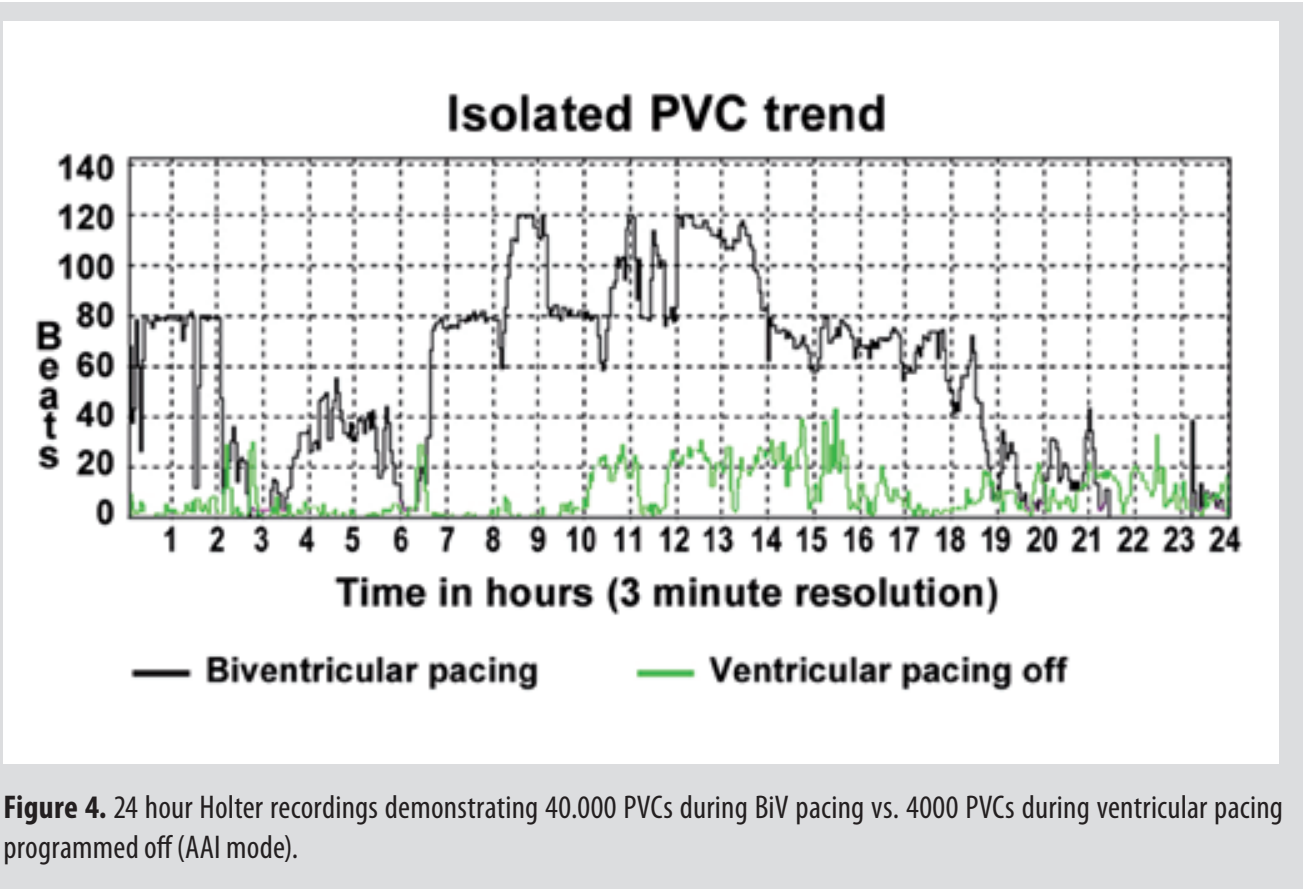


epicardial LV lead implantation may then be preferred. Our patient had extensive scarring of the LV lateral wall which limited the possibility of placing an epicardial LV lead outside the scar region. Recently, LV endocardial pacing has been suggested as a potentially better alternative to the epicardial approach.' This method allows more liberty in lead positioning, which can help to avoid pacing in infarcted areas. However, the risk of thrombo-embolic complications is unknown and requires further investigation. Although the potential of acute LVdP/ dtmax measurements to predict long-term outcome needs to be confirmed, our findings suggest that acute hemodynamic testing of LV endocardial pacing in a temporary setup may help to identify the optimal pacing site and may also prevent implantation of a potentially profitless endocardial LV lead with a yet unknown risk of hazardous complications.

In a small percentage of patients, CRT may potentiate ventricular tachyarrhythmias. ${ }^{8}$ The exact mechanisms of proarrhythmia remain largely unclear but our findings suggest that pacing in the region of myocardial scar may facilitate its development. This conception is supported by the morphology of the VT which suggested a lateral exit site close to the LV epicardial pacing lead. A suggested underlying mechanism is a potential increase in local myocardial oxygen demand by pacing, precipitating ischemia in the peri-infarct zone and making it vulnerable to re-entry. ${ }^{8,9}$ The currently available evidence is however too limited to develop strategies for stratifying patients at risk for proarrhythmia in the setting of CRT.

\section{Conclusion}

This case report illustrates the potential contribution of acute invasive hemodynamic evaluation to clinical decision making in CRT. Acute hemodynamic testing may also be considered as a step-up approach to justify implantation of an LV endocardial lead and to guide lead positioning optimization. Finally, this case underlines the importance of considering the possibility of CRT related proarrhythmia, whenever CRT treated patients develop new ventricular tachyarrhythmia's.

\section{References}

McMurray JJ, Adamopoulos S, Anker SD, Auricchio A, Bohm M, Dickstein K, Falk V, Filippatos G, Fonseca C, Gomez-Sanchez MA, Jaarsma T, Kober L, Lip GY, Maggioni AP, Parkhomenko A, Pieske BM, Popescu BA, Ronnevik PK, Rutten FH, Schwitter J, Seferovic P, Stepinska J, Trindade PT, Voors AA, Zannad F, Zeiher A, Bax JJ, Baumgartner H, Ceconi C, Dean V, Deaton C, Fagard R, Funck-Brentano C, Hasdai D, Hoes A, Kirchhof P, Knuuti J, Kolh P, McDonagh T, Moulin C, Reiner Z, Sechtem U, Sirnes PA, Tendera M, Torbicki A, Vahanian A Windecker S, Bon et LA, Avraamides P, Ben Lamin HA, Brignole M, Coca A, Cowburn P, Dargie H, Elliott $P$, Flachskampf FA, Guida GF, Hardman S, lung B, Merkely B, Mueller C, Nanas JN, Nielsen OW, Orn S, Parissis JT and Ponikowski P. ESC guidelines for the diagnosis and treatment of acute and chronic heart failure 2012 The Task Force for the Diagnosis and Treatment of Acute and Chronic Heart Failure 2012 of the European Society of Cardiology. Developed in collaboration with the Heart Failure Association (HFA) of the ESC. European journal of heart failure. 2012;14:803-69.

2. Daubert JC, Saxon L, Adamson PB, Auricchio A, Berger RD, Beshai JF, Breithard O, Brignole M, Cleland $J_{\text {, }}$ Delurgio DB, Dickstein K, Exner DV, Gold M, Grimm RA, Hayes DL, Israel C, Leclercq C, Linde C, Lindenfeld J, Merkely B, Mont L, Murgatroyd F, Prinzen F, Saba SF, Shinbane JS, Singh J, Tang AS, Vardas PE, Wilkoff BL and Zamorano JL. 2012 EHRA/HRS expert consensus statement on cardiac resynchronization therapy in heart failure: implant and follow-up recommendations and management. Heart rhythm: the official journal of the Heart Rhythm Society. 2012;9:1524-76.

3. van Gelder BM, Bracke FA, Meijer A, Lakerveld LJ and Pijls NH. Effect of optimizing the VV interval on left ventricular contractility in cardiac resynchronization therapy. The American journal of cardiology. 2004;93:1500-3.

4. Bracke FA, Houthuizen P, Rahel BM and van Gelder BM. Left ventricular endocardial pacing improves the clinical efficacy in a non-responder to cardiac resynchronization therapy: role of acute haemodynamic testing. Europace. 2010;12:1032-4.

5. Dickstein K, Vardas PE, Auricchio A, Daubert JC, Linde C, McMurray J, Ponikowski P, Priori SG, Sutton R and van Veldhuisen DJ. 2010 focused update of ESC Guidelines on device therapy in heart failure: an update of the 2008 ESC Guidelines for the diagnosis and treatment of acute and chronic heart failure and the 2007 ESC Guidelines for cardiac and resynchronization therapy. Developed with the special contribution of the Heart Failure Association and the European Heart Rhythm Association. European journal of heart failure. 2010;12:1143-53.

6. Ypenburg C, Schalij MJ, Bleeker GB, Steendijk P, Boersma E, Dibbets-Schneider P, Stokkel MP, van der Wall EE and Bax J. Impact of viability and scar tissue on response to cardiac resynchronization therapy in ischaemic heart failure patients. European heart journal. 2007;28:33-41.

7. van Gelder BM, Scheffer MG, Meijer A and Bracke FA. Transseptal endocardial left ventricular pacing: an alternative technique for coronary sinus lead placement in cardiac resynchronization therapy. Heart rhythm the official journal of the Heart Rhythm Society. 2007;4:454-60.

8. Shukla G, Chaudhry GM, Orlov M, Hoffmeister P and Haffajee C. Potential proarrhythmic effect of biventricular pacing: fact or myth? Heart rhythm: the official journal of the Heart Rhythm Society. 2005;2:951-6.

9. Garrigue S, Reuter S, Efimov IR, Mazgalev TN, Jais P, Haissaguerre M and Clementy J. Optical mapping technique applied to biventricular pacing: potential mechanisms of ventricular arrhythmias occurrence. Pacing and clinical electrophysiology: PACE. 2003;26:197-205. 
The role of acute invasive hemodynamic measurements in cardiac resynchronization therapy: looping towards prediction of long-term response and therapy optimization

Masih Mafi Rad, Yuri Blaauw, Frits W. Prinzen, Kevin Vernooy

Eur J Heart Fail. 2013 Mar;15(3):247-9

Editorial on 'Prediction of long-term outcome of cardiac resynchronization therapy by acute pressure-volume loop measurements', by G.J. de Roest et al. Eur J Heart Fail. 2013 Mar;15(3):299-307 
Cardiac resynchronization therapy (CRT) has been established as an effective treatment strategy for heart failure patients with severe left ventricular (LV) systolic impairment and electrical dyssynchrony.' Despite the striking effectiveness of CRT in improving echocardiographic and clinical outcomes as well as prognosis, the issue remains that a substantial proportion of apparently suitable patients fails to benefit. ${ }^{2}$ Efforts to increase response rate have mainly focused on improving patient selection and optimizing therapy delivery by better lead positioning and device programming. However, criteria for electrical and mechanical dyssynchrony are thus far of limited value in improving patient selection. ${ }^{3,4}$ In addition, the best strategy to optimize lead positioning and atrio-ventricular (AV) and inter-ventricular (VV) delay remains to be established. In clinical practice, echocardiographic techniques assessing stroke volume or mitral inflow patterns are the most widely employed for CRT optimization. However, these techniques are subject to large measurement errors and intra- and interobserver variability.

A potentially more accurate technique is invasive measurement of acute hemodynamic response to CRT, which has been used in several studies to determine the optimal LV lead position and optimize device programming. 5,6 The rationale behind this approach is that CRT acutely improves LV contractility and that this translates into beneficial effects in the longer term. The most widely used invasive hemodynamic parameter is the maximum rate of LV pressure rise (LVdP/dtmax). However, evidence for a strong relation between invasively measured acute $\mathrm{LVdP} / \mathrm{dtmax}$ increase and long-term outcome is conflicting. A recent study by Duckett et al. demonstrated a strong relationship between the magnitude of increase in LVdP/dtmax and reverse remodeling, as well as improvement in functional status.? However, these results are not supported by several other studies. Stellbrink et al. demonstrated that an acute LVdP/dtmax increase did not predict reverse remodeling. ${ }^{8}$ More recently, two larger studies comprising a total of 353 patients found no relation between acute change in LVdP/dtmax and cardiac morbidity or survival., 10

A few studies have assessed CRT response using LV pressure-volume (PV) loop measurements. ${ }^{11}$ The study by de Roest et al. in this issue of the European Journal of Heart Failure ${ }^{12}$ is the first to investigate the relationship between acute hemodynamic response, assessed as an increase in LV stroke work (SW), and long-term response to CRT. This group optimized the position of the right ventricular and LV lead using LV SW measurements. A clear association was demonstrated between acute LV SW increase and reverse remodeling (defined as a $>15 \%$ decrease in end-systolic volume [ESV]) after 6 months of CRT). An acute increase in LV SW of $>20 \%$ predicted reverse remodeling with a sensitivity of $90 \%$ and a specificity of $75 \%$. In contrast, a predictive value of LVdP/dtmax for long-term response to CRT was not observed. The authors should be complemented for this innovative and carefully conducted study. Although the small sample size as well as the absence of a control group are obvious limitations for extrapolation to larger populations and require confirmation in large multicentre randomized trials, these results highlight the potential of invasively measured LV SW to guide lead placement and improve CRT response rates.

At present, it is unclear which hemodynamic index is the best predictor for long-term response. However, the accumulating evidence against a relationship between acute change in LVdP/dtmax and long-term outcome combined with the recent positive findings on LV SW by de Roest et al. indicate that the latter might be a stronger predictor of pump function improvement. From a theoretical perspective, this may be explained by the fact that LVdP/dtmax reflects only a short period of the cardiac systole, while LV SW comprises the full systolic phase and incorporates both LV pressure and volume changes. 
Measurements of LV SW require the acquisition of PV loops using a conductance catheter that is positioned in the LV cavity. Unfortunately, this method has some limitations. Acquisition of reliable volume signals using a conductance catheter is challenging, especially in dilated and dyssynchronous hearts. de Roest et al. calculated LV SW as the area of the PV loop. Their Figure 2 shows that these loops contain certain specific artefacts, such as the "tail" on the lower right side of the loop. In the calculation this is neglected in both the responders and the non-responders. Other publications show even more complicated loops ${ }^{13}$, and this is also ou experience in dogs with LBBB and in CRT patients. ${ }^{14}$ One possible explanation of such artefacts could be mitral valve regurgitation, as suggested by de Roest et al. Another possible explanation relates to limitations of the conductance technique that assumes the catheter to be in the middle of a perfectly cylindrical cavity and that all ventricular walls move towards the catheter to a similar extent during systole. In practice, positioning of the catheter through the aortic valve causes the catheter to be close to the septum, a wall that is known to show very abnormal motion in dyssynchronous hearts. In order to show the effect of abnormal wall motion on the volume signal, we inserted a conductance catheter into a rubber balloon filled with saline. When moving the closed balloon around the catheter, a significant volume change was detected (see Figure 1). Based on these observations, we think that the absolute volumetric changes measured by PV loops in dyssynchronous hearts should be interpreted with care, and so should the values of LV SW calculated from the loop area. This idea is also supported by the finding of de Roest et al. that the mean increase in SW ( 50\%) is considerably larger than the product of stroke volume necessarily useless, we just propose to avoid the term SW in this respect. An elegant alternative analysis has been published by Lieberman et al. These investigators calculated cycle efficiency from conductance measurements using the formula cycle efficiency $=S W /(\Delta L V$ pressure $x \Delta L V$ volume), in other words the ratio of the area of the generated loop to that of the externa rectangle ("ideal loop"). Indeed, cycle efficiency was highest during LV and biventricular pacing. ${ }^{13}$ These observations suggest that the high sensitivity of PV loops to predict CRT response may relate to a measurement artefact that, fortunately, is sensitive to dyssynchrony. Therefore, a preferable way to express the changes in PV-loops may be cycle efficiency, rather than SW. This being said, one still has to consider that additional limitations of the conductance technique are its lower accuracy in dilated hearts with low ejection fractions, the need for time-consuming calibration, and the larger size and higher costs of the conductance catheters compared with the pressure wires used for LVdP/dtmax measurements.

Considering the substantial clinical and economical implications of CRT non-response, the potential of acute PV loop measurements to improve response rate may compensate for the technical challenges and higher costs associated with the conductance technique. Theoretically, a number of approaches employing PV loop measurements could be applied to achieve a higher rate of favorable response. The measurements could be performed to improve patient selection. An interesting aspect of the protocol used by de Roest et al. is that the hemodynamic measurements were performed during a separate procedure, preceding the implantation of the CRT device. The strong predictive power of the PV loop measurements, shown in this study, could allow a strategy in which CRT would be denied to patients who do not show a significant PV loop response. This approach may have important additional value in subsets of patients in whom there is less consensus for a clinical benefit, i.e. patients with right bundlebranch block, intraventricular conduction delay, or narrow QRS. PV loop measurements could also be performed to optimize the LV lead position, which has been shown to improve response to CRT. This approach may particularly benefit patients with ischemic cardiomyopathy, in whom implantation of the LV lead at areas with myocardial scar has been shown to reduce CRT effectiveness..$^{15}$ de Roest et al. performed PV loop-guided lead position optimization and observed a considerably higher response rate compared with those reported in the literature. Unlike the lower response rates in patients with ischemic compared with non-ischemic cardiomoypathy reported in large randomized CRT trials, they found comparable numbers of responders in both subgroups. PV loop measurements could also be used to optimize AV and $\mathrm{VV}$ delays. Although the role of $\mathrm{AV}$ and $\mathrm{V} V$ optimization in improving long-term outcomes in CRT remains unclear, optimizing these timing intervals has been shown to have acute hemodynamic benefits. The results of de Roest et al. indicate that acute PV loop benefit translates into long-term improvement, suggesting the potential role of PV loop-guided AV and VV delay optimization to maximize therapy benefit and increase response rates in CRT. Finally, a systematic invasive hemodynamic evaluation using acute PV loop measurements may be applied in CRT non-responders to determine whether the treatment can be optimized with alternative LV stimulation sites or adjusted $\mathrm{AV}$ and $\mathrm{VV}$ pacing delays.

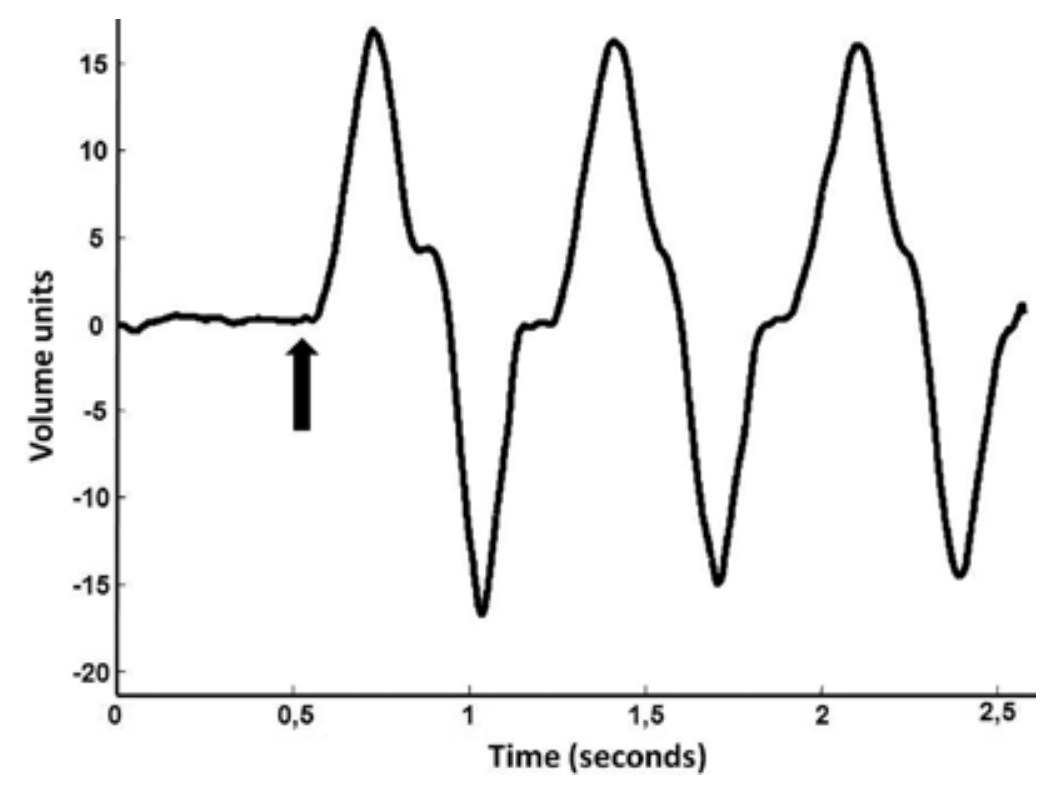

Figure 1. Volume signal obtained from a fixed conductance catheter positioned in a closed saline-filled rubber balloon The arrow indicates the onset of manual balloon movement. Motion of the balloon wall relative to the fixed catheter resulted in detection of significant volume changes, even though actual balloon volume remained unchanged. 


\section{References}

1. McMurray JJ, Adamopoulos S, Anker SD, Auricchio A, Bohm M, Dickstein K, Falk V, Filippatos G, Fonseca C, Gomez-Sanchez MA, Jaarsma T, Kober L, Lip GY, Maggioni AP, Parkhomenko A, Pieske BM, Popescu BA, Ronnevik PK, Rutten FH, Schwitter J, Seferovic P, Stepinska J, Trindade PT, Voors AA, Zannad F, Zeiher A, Bax JJ, Baumgartner H, Ceconi C, Dean V, Deaton C, Fagard R, Funck-Brentano C, Hasdai D, Hoes A, Kirchhof P, Knuuti J, Kolh P, McDonagh T, Moulin C, Reiner Z, Sechtem U, Sirnes PA, Tendera M, Torbicki A, Vahanian A, Windecker S, Bonet LA, Avraamides P, Ben Lamin HA, Brignole M, Coca A, Cowburn P, Dargie H, Elliott $P$, Flachskampf FA, Guida GF, Hardman S, lung B, Merkely B, Mueller C, Nanas JN, Nielsen OW, Orn S, Parissis J and Ponikowski P. ESC guidelines for the diagnosis and treatment of acute and chronic heart failure 2012: The Task Force for the Diagnosis and Treatment of Acute and Chronic Heart Failure 2012 of the European Society of Cardiology. Developed in collaboration with the Heart Failure Association (HFA) of the ESC. European journal of heart failure. 2012;14:803-69.

2. Daubert JC, Saxon L, Adamson PB, Auricchio A, Berger RD, Beshai JF, Breithard O, Brignole M, Cleland J, Delurgio DB, Dickstein K, Exner DV, Gold M, Grimm RA, Hayes DL, Israel C, Leclercq C, Linde C, Lindenfeld Merkely B, Mont L, Murgatroyd F, Prinzen F, Saba SF, Shinbane JS, Singh J, Tang AS, Vardas PE, Wilkoff BL and Zamorano JL. $2012 \mathrm{EHRA} / \mathrm{HRS}$ expert consensus statement on cardiac resynchronization therapy in heart failure: implant and follow-up recommendations and management. Heart rhythm: the official journal of the Heart Rhythm Society. 2012;9:1524-76.

3. Hawkins NM, Petrie MC, MacDonald MR, Hogg KJ and McMurray JJ. Selecting patients for cardiac resynchronization therapy: electrical or mechanical dyssynchrony? European heart journal. 2006;27:1270-81.

4. Chung ES, Leon AR, Tavazzi L, Sun JP, Nihoyannopoulos P, Merlino J, Abraham WT, Ghio S, Leclercq C, Bax JJ, Yu CM, Gorcsan J, 3rd, St John Sutton M, De Sutter J and Murillo J. Results of the Predictors of Response to CRT (PROSPECT) trial. Circulation. 2008;117:2608-16.

5. Derval N, Steendijk P, Gula LJ, Deplagne A, Laborderie J, Sacher F, Knecht S, Wright M, Nault I, Ploux S, Ritter P, Bordachar P, Lafitte S, Reant P, Klein GJ, Narayan SM, Garrigue S, Hocini M, Haissaguerre M, Clementy J and Jais P. Optimizing hemodynamics in heart failure patients by systematic screening of left ventricular pacing sites: the lateral left ventricular wall and the coronary sinus are rarely the best sites. Journal of the American College of Cardiology. 2010;55:566-75.

6. Auricchio A, Stellbrink C, Block M, Sack S, Vogt J, Bakker P, Klein H, Kramer A, Ding J, Salo R, Tockman B, Pochet $T$ and Spinelli J. Effect of pacing chamber and atrioventricular delay on acute systolic function of paced patients with congestive heart failure. The Pacing Therapies for Congestive Heart Failure Study Group. The Guidant Congestive Heart Failure Research Group. Circulation. 1999;99:2993-3001.

7. Duckett SG, Ginks M, Shetty AK, Bostock J, Gill JS, Hamid S, Kapetanakis S, Cunliffe E, Razavi R, Carr-White 6 and Rinaldi CA. Invasive acute hemodynamic response to guide left ventricular lead implantation predicts undergoing cardiac resynchronization therapy. Journal of the American College of Cardiology. 2011;58:1128-36.

8. Stellbrink C, Breithardt OA, Franke A, Sack S, Bakker P, Auricchio A, Pochet T, Salo R, Kramer A and Spinelli J. Impact of cardiac resynchronization therapy using hemodynamically optimized pacing on left ventricular remodeling in patients with congestive heart failure and ventricular conduction disturbances. Journal of the American College of Cardiology. 2001;38:1957-65.

9. Suzuki H, Shimano M, Yoshida Y, Inden Y, Muramatsu T, Tsuji Y, Tsuboi N, Hirayama H, Shibata R and Murohara T. Maximum Derivative of Left Ventricular Pressure Predicts Cardiac Mortality After Cardiac Resynchronization Therapy. Clinical cardiology. 2010.

10. Bogaard MD, Houthuizen P, Bracke FA, Doevendans PA, Prinzen FW, Meine M and van Gelder BM. Baseline left ventricular $\mathrm{dP} / \mathrm{dtmax}$ rather than the acute improvement in $\mathrm{dP} / \mathrm{dtmax}$ predicts clinical outcome in patients with cardiac resynchronization therapy. European journal of heart failure. 2011;13:1126-32.

11. Delnoy PP, Ottervanger JP, Luttikhuis HO, Vos DH, Elvan A, Ramdat Misier AR, Beukema WP, Steendijk P and van Hemel NM. Pressure-volume loop analysis during implantation of biventricular pacemaker/cardiac resynchronization therapy device to optimize right and left ventricular pacing sites. European hear journal. 2009;30:797-804.

12. de Roest GJ, Allaart CP, Kleijn SA, Delnoy PP, Wu L, Hendriks ML, Bronzwaer JG, van Rossum AC and de CockCC. Prediction of long-term outcome of cardiac resynchronization therapy by acute pressure-volume loop measurements. European journal of heart failure. 2012.

13. Lieberman R, Padeletti L, Schreuder J, Jackson K, Michelucci A, Colella A, Eastman W, Valsecchi S and Hettrick DA. Ventricular pacing lead location alters systemic hemodynamics and left ventricular function in patients with and without reduced ejection fraction. Journal of the American College of Cardiology. 2006;48:1634-41.

14. Dekker AL, Phelps B, Dijkman B, van der Nagel T, van der Veen FH, Geskes GG and Maessen JG. Epicardia left ventricular lead placement for cardiac resynchronization therapy: optimal pace site selection with pressure-volume loops. The Journal of thoracic and cardiovascular surgery. 2004;127:1641-7.

15. Ypenburg C, Schalij MJ, Bleeker GB, Steendijk P, Boersma E, Dibbets-Schneider P, Stokkel MP, van der Wall EE and Bax J. Impact of viability and scar tissue on response to cardiac resynchronization therapy in ischaem heart failure patients. European heart journal. 2007;28:33-41. 


\section{Introduction}

The general aims of the research presented in this thesis were three-fold:

1. To optimize targeted left ventricular (LV) lead placement for cardiac resynchronization therapy (CRT).

2. To improve identification of patients with an appropriate electrical substrate for CRT.

3. To investigate the feasibility of a novel method of ventricular lead placement for antibrady-

cardia pacing therapy that targets an alternative ventricular pacing site, which may prevent pacing-induced dyssynchrony and the adverse effects associated with this condition.

Aims 1 and 2 were achieved by using a novel method of epicardial mapping via the coronary veins at the time of CRT implantation to evaluate the LV electrical activation (chapter 2-6). In addition, data obtained from coronary venous electroanatomic mapping were used to demonstrate the potential of a relatively easy and non-invasive approach to identify patients with an electrical substrate for CRT using the area of the QRS complex ( $\mathrm{QRS}_{\text {AREA }}$ ) on the vectorcardiogram (VCG) (chapter 6), and to validate the use of speckle-tracking based time-to-peak strain measures of mechanical activation to guide LV lead placement (chapter 4).

Aim 3 was achieved by performing a first-in-man study demonstrating the feasibility of permanently implanting an LV septal lead in patients using a transvenous approach through the interventricular septum

The main findings from the research presented in this thesis were:

- Coronary venous electroanatomic can be used at the time of CRT implantation to identify patients with an electrical substrate for CRT and guide LV lead placement to the latest activated region.

- Right ventricular apex pacing significantly alters the pattern of LV electrical activation in CRT patients with LBBB, and shifts the latest activated region in a substantial proportion of these patients. This may have potential implications for the optimal pacing site.

- There is a strong positive correlation between the timing of LV electrical activation and peak contraction in candidates for CRT, which suggests that a strategy of LV lead targeting based on speckle-tracking based time-to-peak strain measures of mechanical activation is equivalent to that based on intra-cardiac measurements of electrical activation.

- QRS $_{\text {APEA }}$ derived from the VCG provides a non-invasively acquired parameter that identifies the electrical substrate for CRT better than the conventional electrical markers QRS duration and LBBB morphology.

- Permanent placement of an LV septal lead using a transvenous approach through the interventricular septum is feasible and safe in patients. This new pacing method is hemodynamically preferable to conventional RV apex pacing and could serve as an alternative for biventricular pacing in patients with a conventional indication for antibradycardia pacing.

In this general discussion, these results are put in broader perspective. The first part of this chapter discusses improvement of patient selection in CRT by better identification of patients with an appropriate electrical substrate. For this purpose, a survey of the literature is provided discussing the limitations of conventional electrical markers of dyssynchrony to identify patients likely to benefit from CRT, the insights that have been gained in the electrical substrate for CRT from electroanatomic mapping studies, and the use of these insights in order to deliver better electrocardiographic markers of CRT response. The second part of the chapter concerns the role of electroanatomic mapping in optimization of LV lead placement for CRT, and the third part discusses the prevention of pacing-induced dyssynchrony by alternative site pacing 


\section{Why QRS duration should be replaced by better measures of electrical} activation to improve patient selection
for cardiac resynchronization therapy

\section{Based on:}

Masih Mafi Rad, Elien B. Engels, Antonius M.W. van Stipdonk, Kevin Vernooy, Frits W. Prinzen.

Why QRS duration should be replaced by better measures of electrical activation to improve patient selection for cardiac resynchronization therapy.

J Cardiovasc TransI Res. 2016 May 26. [Epub ahead of print]

\section{Introduction}

Cardiac resynchronization therapy (CRT) is an effective therapy for patients with a decreased left ventricular ejection fraction (LVEF) in combination with a ventricular conduction delay, especially due to left bundle branch block (LBBB). CRT creates a more coordinated and efficient contraction of the heart, improves LV systolic function and quality of life, and reduces heart failure (HF) symptoms, hospitalizations and mortality. ${ }^{1,2}$

Nevertheless, there is still an incomplete understanding of the mechanism of the therapy and unsatisfying selection of patients. On the one hand, a significant portion (30-50\%) of patients that are implanted according to current guidelines ${ }^{3,4}$ benefit little from this therapy whereas $\sim 20 \%$ of patients show complete normalization of LVEF. ${ }^{5}$ Possible explanations for this huge range of benefit are variation in substrate that is amenable to resynchronization, inadequate device settings, suboptimal medical treatment, arrhythmias, and variable lead position. ${ }^{6}$

The most important selection criteria in current CRT implantation guidelines are derived from the electrocardiogram (ECG): QRS duration and morphology., ${ }^{3,7}$ Here we review the strengths and weaknesses of these ECG markers in the light of the current knowledge on the underlying electrical substrate and mechanism of action of CRT and discuss potentially better ECG-based biomarkers for selection of CRT candidates.

\section{The role of the 12-lead ECG in the selection of CRT candidates}

The clinical application of CRT began in 1994 when the first cases of atrio-biventricular pacemaker implantations in patients with severe congestive $\mathrm{HF}$ were described., 9 The surface ECG in these patients often showed a prolonged PR interval and a widened QRS complex due to ventricular conduction disturbances.

The first randomized crossover trial investigating the clinical efficacy of CRT was the MUltisite StImulation in Cardiomyopathy (MUSTIC) study. ${ }^{10}$ This trial in patients with chronic severe HF (New York Heart Association (NYHA) III), reduced LVEF $(<35 \%)$ and a broad QRS complex (>150ms), showed that biventricular (BiV) pacing improved the 6-min walking distance, peak oxygen uptake, quality of life score, and NYHA class. The multi-center insync randomized clinical evaluation (MIRACLE) study confirmed these results in patients with a QRS duration $\geq 130 \mathrm{~ms} \mathrm{~s}^{2,1}$ This study also showed a clear reduction in LV volumes, reduced HF hospitalization, and better survival. Similar results were shown by the COMPANION'2 and the CARE-HF' trials, which included patients with QRS duration $\geq 120 \mathrm{~ms}$ and NYHA class III-IV.

These favourable and consistent results led to the recommendation of CRT in patients in NYHA class III-IV despite optimal medical treatment, with a reduced LVEF $(<35 \%)$, in sinus rhythm, and a wide QRS complex ( $\geq 120 \mathrm{~ms})^{13}$

Subsequent trials investigated the effect of CRT in less symptomatic patients (the resynchronization reverses remodelling in systolic left ventricular dysfunction (REVERSE), ${ }^{14}$ multicenter automatic defibrillator implantation trial (MADIT)-CRT, ${ }^{15}$ and resynchronization/ defibrillation for ambulatory heart failure trial (RAFT) trial ${ }^{16}$ ). Again, LV function improved, and both all-cause mortality and non-fatal HF events improved. However, subgroup analyses of these three trials demonstrated that these effects were predominantly confined to patients with a QRS duration $\geq 150 \mathrm{~ms}$ (Figure 1). ${ }^{17}$ This evidence resulted in the addition of a class I indication to CRT for patients presenting with NYHA class II, a reduced LVEF, and a QRS duration $>150 \mathrm{~ms}$, in the 2010 guidelines. $^{18}$ 


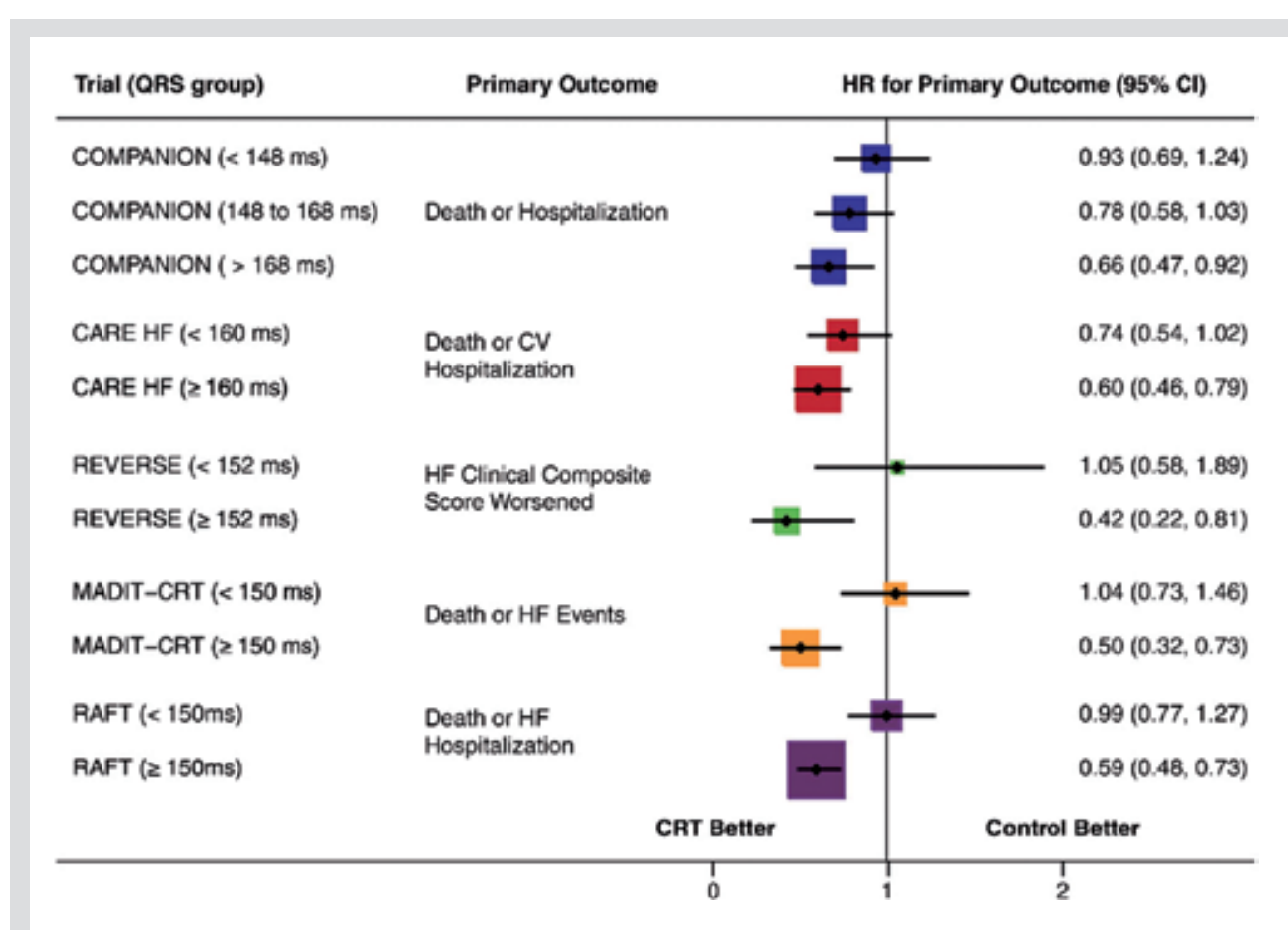

Figure 1. Effect of CRT on composite clinical events in patients with moderately prolonged (QRS duration of 120-150 ms) and severely prolonged QRS duration (>150 ms) (reprinted from ${ }^{17}$ ).

Even though most studies show an increased response rate after CRT in patients with a severely prolonged QRS duration, these studies used the fairly crude division of the cohorts in patients with a QRS duration < and >150 ms. However, the best cutoff value for QRS duration is unclear.

More recently, attention has shifted from QRS duration to QRS morphology. Small singlecentre studies ${ }^{19,20}$ and sub-analyses of the MADIT-CRT, ${ }^{21}$ REVERSE, ${ }^{22}$ and RAFT ${ }^{16}$ study showed that patients with a LBBB morphology benefit most from CRT. In contrast, patients with right bundle-branch block (RBBB) or intra-ventricular conduction delays (IVCD) had no benefit or even a worse outcome from CRT (Figure 2). These observations led to the adaptation of the guidelines in 2012/2013, including LBBB as the primary ECG criterion and QRS duration >150 ms only if a non-LBBB morphology is present. ${ }^{3,4}$

Interesting and important however, is that the definition of complete LBBB from the 12-lead ECG varies between European and American guidelines and between large clinical trial ${ }^{21,22}$ or studies $^{23}$ that investigated LBBB as a predictor of CRT effectiveness. The refinement of LBBB morphology with the presence of notching or slurring appears to significantly improve the prediction of CRT response and clinical outcome, at least in small single-center studies. ${ }^{20,24}$

While QRS morphology is now one of the primary indicators for CRT, a recent meta-analysis, combining data from CARE-HF, MIRACLE, MIRACLE ICD, REVERSE, and RAFT showed that QRS duration is a more powerful predictor of CRT outcomes (mortality and morbidity) than QRS morphology. ${ }^{25}$ This conclusion is in contrast to several reports derived from some of the individual

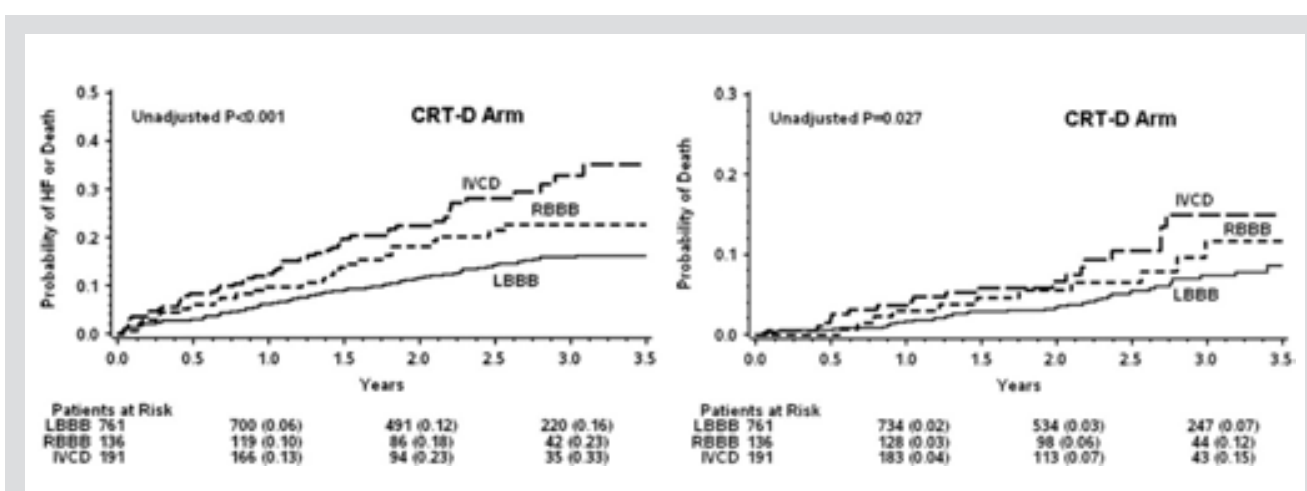

Figure 2. Cumulative probability of HF event or death (left) and of deat h alone (right) according to QRS morphology in the CRT with defibrillator (CRT-D) arm of the MADIT-CRT (adjusted from ${ }^{21}$ ).

trials and to a meta-analysis of the MADIT-CRT, RAFT, and REVERSE study (Figure 1). ${ }^{26}$ One possible explanation for this discrepancy is the use of "liberal" LBBB criteria. In that case, it is likely that QRS duration provides additional information. Indeed, when using "liberal" LBBB criteria the non-LBBB patients tended to have a lower QRS duration than the LBBB patients, ${ }^{21}$ but this difference could not be observed when stricter LBBB criteria were used. ${ }^{20}$ Furthermore, in the studies where strict LBBB criteria as defined by Strauss et al..$^{23}$ were used, QRS duration was not a predictor of response while LBBB was. ${ }^{20,27}$

In conclusion, currently it is not clear whether QRS duration or morphology should be preferred as primary marker for selection of CRT patients. QRS duration may not be specific, but LBBB criteria may be too complex and/or user dependent. In order to come to a possible solution, it may be worthwhile to go back to the basic physiology of dyssynchronous $\mathrm{HF}$ and the mechanisms of CRT.

\section{Electrophysiological evaluation of the electrical substrate for CRT}

Delayed electrical activation of the LV is considered the underlying substrate of LV dysfunction in patients with systolic dysfunction and a conduction delay, mainly due to $L B B B .{ }^{28} C R T$ aims to correct the underlying electrical substrate by paced pre-excitation of late depolarized and contracting LV regions, thereby restoring synchronous ventricular electrical activation and contraction. ${ }^{28}$ Experimental studies have confirmed that in hearts with delayed LV activation due to $\mathrm{LBBB}$, LV only or BiV pacing creates a more synchronous contraction pattern, which is accompanied by marked hemodynamic improvement. ${ }^{28,29}$ The clinical importance of LV activation delay has become evident in studies showing that a greater delay in time from onset of the QRS complex to the local intrinsic activation at the LV stimulation site (Q-LV) is associated with a greater likelihood of benefit from CRT. Singh et al. measured Q-LV intra-procedurally as a percentage of the baseline QRS interval in 71 patients undergoing CRT device implantation. ${ }^{30}$ A longer Q-LV was related to superior acute LV hemodynamic improvement, whereas a reduced Q-LV ( $<50 \%$ of QRS duration) was related to a worse clinical outcome..$^{30} \mathrm{~A}$ secondary analysis of the prospective multi-center SMART-AV trial showed that patients with a Q-LV >95 ms show significantly improved odds of reverse remodeling and quality of life response. ${ }^{3}$ Conversely, experimental studies and computer simulations have shown that pacing induced 
pre-excitation in a heart without significant electrical delay (narrow QRS complex) widens the QRS complex and consequently worsens LV pump function. ${ }^{32-34}$ The clinical significance of these findings has become evident in the results of the recent EchoCRT trial. ${ }^{35}$ This was a randomized trial that evaluated the effect of CRT in patients with a narrow QRS complex ( $<130 \mathrm{~ms}$ ) and evidence of mechanical dyssynchrony. The trial was prematurely stopped because the CRT group did not derive any detectable clinical benefit and even showed a significant increase in mortality compared to the control group. ${ }^{35}$

All the aforementioned data support the notion that an electrical substrate, consisting of an sufficient amount of LV activation delay, needs to be present for CRT to be efficient. LBBB is considered the hallmark conduction disturbance that is associated with delayed LV activation. In canine hearts where proximal ablation of the left bundle-branch was performed, electrica mapping showed that earliest electrical activation occurs inside the right ventricle and that the electrical wave front then slowly propagates through the interventricular septum toward the lateral wall of the LV. ${ }^{36}$ Induction of LBBB in healthy canine hearts leads to electrical and mechanical dyssynchrony that in turn causes loss of LV pump function and ventricular remodeling. ${ }^{37}$ In these hearts, CRT largely reverses functional and structural abnormalities. ${ }^{28}$ The key clinical investigation to detect and evaluate the extent of $L V$ activation delay remain the surface ECG. However, identifying true LBBB on the ECG is not as straightforward as one might presume. As discussed earlier, numerous dissimilarities in ECG criteria for the diagnosis of LBBB between different definitions complicate a uniform diagnosis.

The most accurate way to evaluate the cardiac electrical activation sequence in patients is by invasive mapping using conventional point-by-point technique or three-dimensional electroanatomical reconstruction contact (CARTO, NOGA) or non-contact (EnSite) mapping Studies that performed endocardial mapping in patients with heart failure and LBBB according to conventional ECG criteria have shown that the sequence of LV endocardial activation in these patients is heterogeneous. ${ }^{38-41}$ The activation wave front originating from the right ventricle was shown to cause LV endocardial breakthrough in different septal regions. ${ }^{39,40}$ In some patients, breakthrough occurred in the vicinity of the conduction system in the mid-septa region, which suggests activation by slow conduction through the left bundle-branch, in others, LV endocardial activation occurred as a result of right-to-left transseptal spread of activation. ${ }^{\circ}$ A characteristic finding in true LBBB patients also seems to be a long (>40 ms) transseptal conduction time. ${ }^{42}$

Endocardial non-contact mapping has also identified two different patterns of electrical wave front propagation in the LV of these patients. The first entity, observed in approximately two thirds of patients, is characterized by a U-shaped pattern of activation that turns around the LV apex and inferior wall in order to activate the lateral wall, $39,41,43$ which is similar to the activation pattern that has been observed during endocardial non-contact mapping in canine hearts where proximal ablation of the left bundle-branch has been performed. ${ }^{44}$ The second entity is characterized by homogeneous propagation of electrical activation throughout the left ventricle. ${ }^{41,43}$ The varying conduction patterns observed in these mapping studies could be explained by variations in left bundle-branch anatomy ${ }^{45}$ and the location of the block, but also by the fact that cellular uncoupling as a consequence of LV hypertrophy or fibrosis can give rise to a wide QRS complex with morphological features that meet conventional ECG criteria for $L B B B .46,47$

In contrast to $L B B B, R B B B$ is typically associated with delayed RV activation, but not delayed $V$ activation. However, in some RBBB patients, the QRS morphology differs significantly from the characteristic RBBB pattern. These patients show a specific electrocardiographic pattern previously defined as RBBB masking $L B B B, 48,49$ which is characterized by precordial lead findings consistent with RBBB and limb lead findings consistent with LBBB. Extensive measurements of both RV and LV endocardial electrical activation in heart failure patients with RBBB using CARTO 3D contact mapping showed that patients with RBBB masking LBBB have concomitant LV activation delay similar to that found in LBBB. ${ }^{50}$

Although the aforementioned mapping techniques provide accurate characterization of cardiac electrical activation, the application of these techniques in clinical practice is timeconsuming, cumbersome, and not without risk. Measuring the Q-LV as described above provides a relatively simple manner of assessing the extent of $L V$ activation delay. However, this technique provides limited information on LV electrical activation because usually measurements are only performed at the anatomically targeted region. The novel technique of intra-procedura coronary venous electroanatomic mapping described in this thesis provides a middle ground between complete mapping and single Q-LV measurements. In chapter 6 of this thesis, we used this technique to assess the LV electrical activation in a cohort of 51 CRT candidates. ${ }^{5}$ Significant LV activation delay (>75\% of QRS duration) was found in 38 of 51 patients. QRS duration was shown to perform poorly in identifying delayed LV activation (area under the curve $=0.49$ ). Twenty-nine of the 51 patients had LBBB according to specific ECG criteria which included broad, notched or slurred R waves in leads I, aVL, V5 and V6, an occasional RS pattern in leads V5 and V6 attributed to displaced transition of the QRS complex, and absent q waves in lead I, V5 and V6 (in the absence of a large anterior-apical infarction). As described earlie, this refined LBBB definition, which includes the presence of QRS notching and slurring, has previously been shown to significantly improve the predictive value of $L B B B$ QRS morphology for CRT response. ${ }^{52}$ Of the remaining 22 patients, 7 met ECG criteria for RBBB and 15 met neither criteria for LBBB nor RBBB and were classified as IVCD. QRS duration did not differ between different QRS morphologies. However, LV activation time was significantly larger in LBBB patients as compared to RBBB and IVCD patients. Significant LV activation delay was found in all patients diagnosed with LBBB according to specific ECG criteria, but also in 8 of 15 patients with IVCD an even in 1 of 7 patients with RBBB. The findings of this mapping study indicate that (1) a prolonged QRS duration by itself is not a reliable marker of delayed LV activation. Thus, patient selection based on QRS duration alone will most likely include a substantial number of patients without the appropriate electrical substrate to benefit from CRT, and (2) the refined LBBB definition, which includes QRS notching and slurring, is highly specific for delayed LV activation, but lacks sufficient sensitivity. As a consequence, a substantial number of patients that have delayed LV activation are not identified as such, and in these patients, CRT may be withheld erroneously.

Instead, our technique of coronary venous electroanatomic mapping can be used at the time of CRT implantation for a more precise characterization of the electrical substrate at only minor prolongation of procedure time $(\sim 20 \mathrm{~min}))^{51,53}$ However, ideally the decision whether or not to implant a CRT device is made in advance. In this respect, electrocardiographic imaging (ECGi) provides an entirely non-invasive alternative. ${ }^{54}$ ECGi provides high-resolution non-invasive electrical mapping of the epicardial electrical activation. The technique acquires electrica data from more than 200 body surface electrodes using a multi-electrode vest. Epicardial anatomy and body-surface electrode positions are registered simultaneously by a thoracic computed tomography scan. The body-surface electrical data and the anatomical data are then processed with algorithms to construct epicardial depolarization and repolarization patterns, using a single heartbeat. ${ }^{54}$ In this way, detailed information on LV electrical activation can be readily obtained prior to CRT implantation, which may be used to guide the decision on 


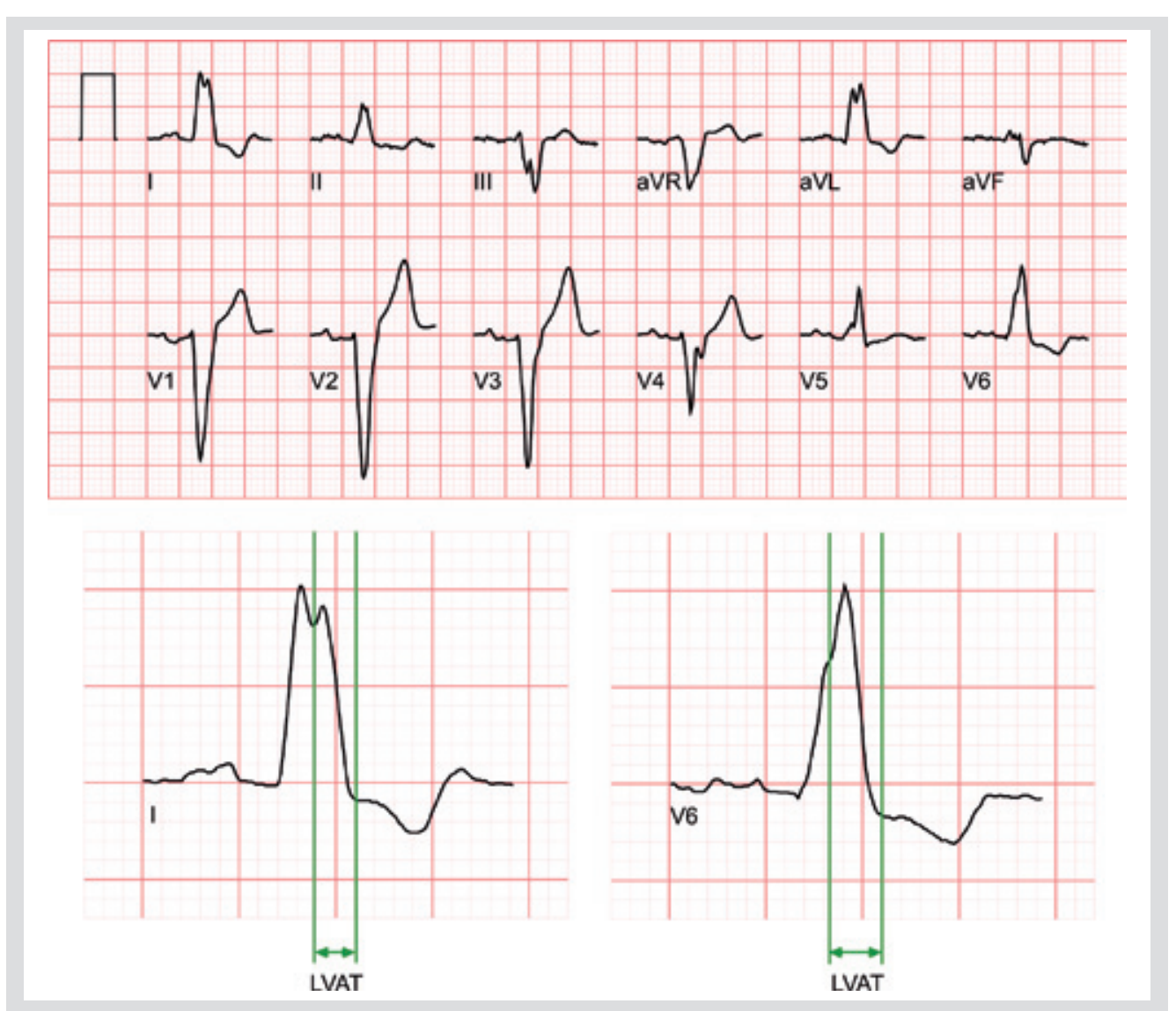

Figure 3. Example of a left ventricular activation time (LVAT) measurement. LVATmax is measured as the time difference between the first notch after $40 \mathrm{~ms}$ of QRS onset and the end of the QRS.

whether or not to implant a CRT device. However, the requirement for a multi-electrode vest in combination with a computed tomography scan may preclude widespread application of this technique in clinical practice.

\section{Better electrocardiographic identification of the electrical substrate:}

New ECG parameters

The demand for easy and widely applicable non-invasive techniques that can be used to accurately characterize the electrical substrate in CRT candidates has renewed the interest in finding additional/alternative electrocardiographic markers of dyssynchrony. Sweeney et al. carefully analyzed standard 12-lead ECGs of 202 CRT candidates with LBBB according to specific ECG criteria that included QRS notching/slurring and identified new measurements that predict volumetric CRT response..$^{19}$ The time difference between the first notch after $40 \mathrm{~ms}$ of QRS onset and the end of the QRS on the baseline ECG was indicated as the LV activation time (LVATmax, Figure 3). A longer LVATmax was shown to be predictive for CRT response $(\mathrm{OR}[\mathrm{Cl}]=1.30[1.11-1.52]$ for each $10 \mathrm{~ms}$ increase up to $125 \mathrm{~ms}$ ). In addition, the Selvester QRS score for LBBB was used to quantify LV scar extent. A higher Selvester score was negatively associated with reverse remodeling $(\mathrm{OR}[\mathrm{Cl}]=$ $0.49[0.27-0.88]$ for each 1-point increase from 0 to $4 ; 0.92[0.83-1.01]$ for each 1-point increase $>4))^{19}$

Recently, the value of the vectorcardiogram (VCG) for characterizing the electrical substrate and predicting CRT response has been explored. The VCG contains 3D information of the electrica forces within the heart, which might provide more valuable information than the 1D ECG. It was hypothesized that large electrical dyssynchrony, amenable to CRT, would lead to large unopposed electrical forces during ventricular depolarization and that the size of these forces may be well represented by the area of the QRS complex on the VCG $\left(\mathrm{QRS}_{\text {AREA }}\right)$. Van Deursen et al. assessed QRS $_{\text {AREA }}$ in 81 consecutive CRT candidates and showed that a large QRS $_{\text {AREA }}$ was associated with higher odds of long-term volumetric CRT response. Moreover, $\mathrm{QRS}_{\text {ARA }}$ predicted CRT response better than QRS duration and conventionally defined LBBB and as least as good as the most refined LBBB definition. ${ }^{24}$

The notion that $\mathrm{QRS}_{\text {AREA }}$ represents the extent of unopposed electrical forces is supported by the observation that $\mathrm{QRS}_{\text {AREA }}$ is larger in patients with $\mathrm{LBBB}$ as compared to patients with IVCD and that QRSarea is smaller in ischemic than in non-ischemic patients. ${ }^{24}$ Further support comes from observations in the aforementioned study described in chapter 6 of this thesis. In this study, VCGs were constructed from pre-procedural standard 12-lead ECGs for all patients using an adapted Kors algorithm. A large QRS AREA $(>69 \mu \mathrm{Vs})$ on the VCG was shown to be highly predictive of delayed LV lateral wall activation as determined by coronary venous mapping. On the other hand, QRS has been shown to be smaller in patients with heart failure of ischemic etiology, which may be explained by the presence of non-conductive fibrotic tissue. ${ }^{24}$ Taken together, these observations suggest that QRS $_{A B E A}$ is not only useful to determine the extent of electrical dyssynchrony, but that it may also reflect the presence of determinants known to reduce the chance of CRT benefit, such as an ischemic etiology of heart failure. These considerations might explain the power of QRS $_{\text {AREA }}$ for prediction of CRT response, but more research is required to better understand all determinants of $\mathrm{QRS}_{\mathrm{ARE}}$

Interestingly, two studies showed that VCG-derived measures of repolarization predict CRT response even better than QRS $_{\text {AREA }}$. Engels et al. assessed the T-wave area from VCGs of 244 CRT recipients (VCG examples shown in Figure 4C and 4D). The VCG-derived T-wave area was shown to predict echocardiographic CRT response better than $\mathrm{QRS}_{\text {AREA }}{ }^{55} \mathrm{In}$ a larger cohort consisting of 335 CRT recipients in which the primary endpoint was the composite of HF hospitalization, heart transplantation, left ventricular assist device implantation, or death during a 3-year follow-up period, the predictive power of T-wave area for CRT response was found to be primarily evident in the group of patients with LBBB (Figure 4E and 4F). ${ }^{56} \mathrm{~A}$ large T-wave area in LBBB patients was associated with less HF hospitalizations and a higher chance of survival. ${ }^{56}$ The size of the T-wave area is a reflection of the extent of unopposed electrical forces during the repolarization phase. The T-wave area is partially determined by the size of the QRS but other factors such as changes in $\mathrm{K}^{+}$and $\mathrm{Ca}^{2+}$ ion channel expression might also play a role. In this study, a large T-wave area was primarily caused by a larger amplitude and not so much by a longer JT-interval. Further research is needed to investigate which other factors are exactly reflected in the T-wave area.

A limitation of all these studies regarding QRS $_{\text {AREA }}$ is that relatively small sample sizes were used. Furthermore, the studies related to the prediction of CRT response using the QRS $_{\text {AREA }}$ were all retrospective. Therefore, these results need to be validated in a larger prospective study.

The great practical benefit of $\mathrm{QRS}_{\text {AREA }}$ and T-wave area is that these parameters are measured in an objective manner and quantified as continuous variables, as opposed to LBBB which is a dichotomous measurement that is subject to the use of different definitions and subjective 


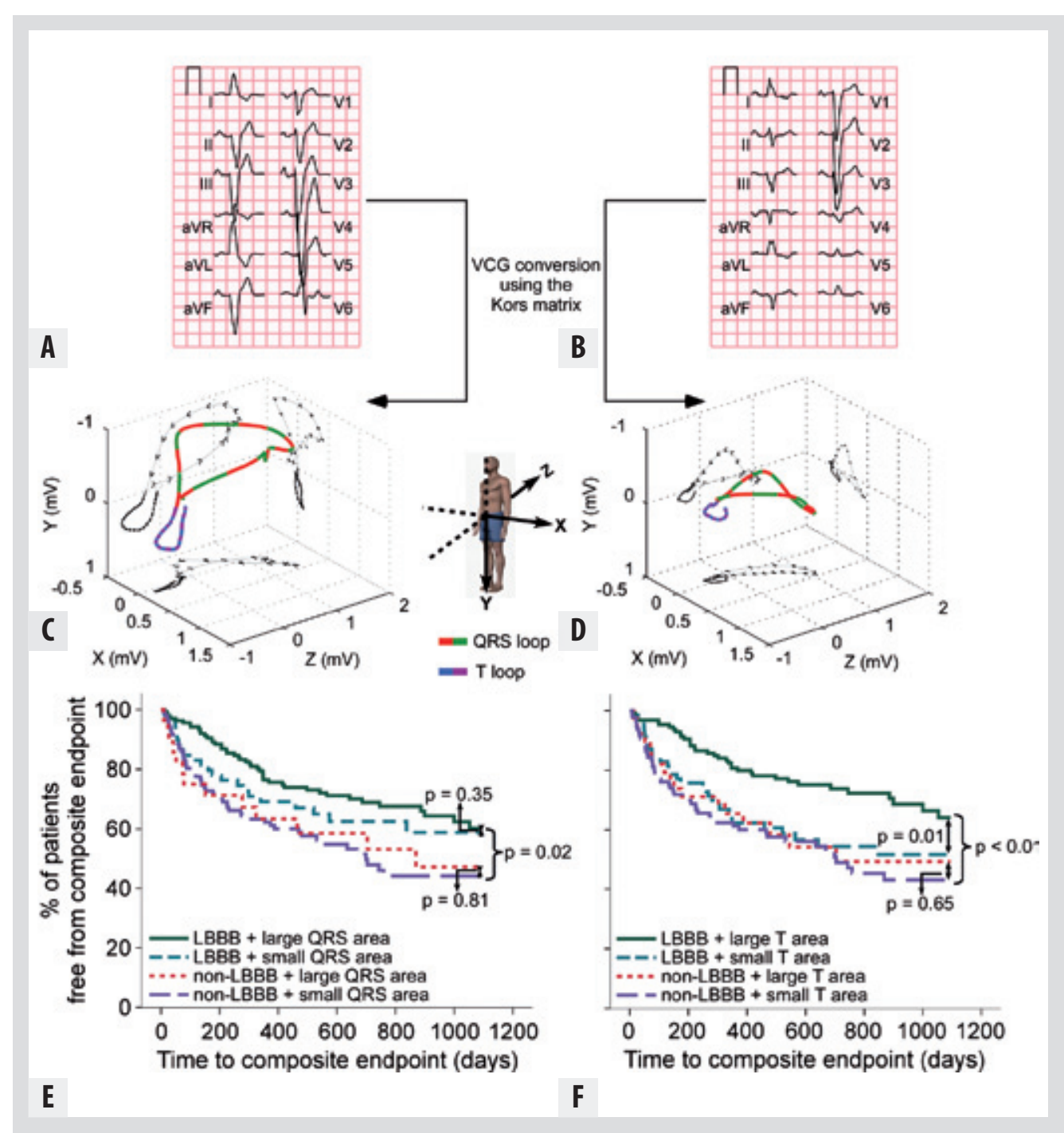

Figure 4. Typical example of VCGs constructed from standard 12-lead ECGs for a patient with a large (A and C)) and a patient with a small ( $B$ and D) T-wave area, despite being both classified as having LBBB. Panels $E$ and $F$ show Kaplan-Meier estimates of the probability free from the composite endpoint HTLD (HF hospitalization, heart transplantation, LVAD implantation, death) after 3 years of (RT. Large QRS or T area are values $\geq$ median value and small QRS or T area are values < median value. (Adapted from ${ }^{55,56}$ )

interpretations of QRS notching/slurring, as illustrated in the study described in chapter 6 of this thesis. Another practical feature of $\mathrm{QRS}_{\mathrm{AREA}}$ and T-wave area is that they can easily be derived from the standard 12-lead ECG. Most commercially available ECG machines have algorithms to construct VCGs from standard 12-lead ECGs using the inverse Dower or Kors' regression transformation. ${ }^{57,58}$ These VCGs provide a good resemblance of the gold standard Frank VCG and have recently also been validated for use in patients with dyssynchronous heart failure. ${ }^{59}$
The non-invasive and simple nature of VCG analysis combined with the excellent predictive power of $\mathrm{QRS}_{\text {AREA }}$ and T-wave area for CRT response indicates that these parameters can be easily applied in clinical practice to identify appropriate candidates for CRT, thereby potentially improving response to this therapy.

\section{Conclusion}

Based on the evidence provided in this thesis (chapter 6) that $\mathrm{QRS}_{\text {AREA }}$ reflects LV activation delay, the primary electrical substrate for CRT, and on the better prediction of CRT response by QRS as compared to QRS duration, we propose to include QRS $_{A R E A}$ in the guidelines as a selection criterion for CRT implantation. The possibly even better prediction of CRT response by using the T-wave rather than the QRS complex requires further investigation. 


\section{Optimization of left ventricular lead}

\section{placement for cardiac resynchronization}

\section{therapy: Role of electroanatomic}

\section{mapping}

\section{Coronary venous electroanatomic mapping as compared to other} mapping techniques

The novel method of coronary venous electroanatomic mapping (EAM) described in this thesis (chapter 2-6) allowed for detailed collection of data on the sequence of left ventricular (LV) electrical activation during cardiac resynchronization therapy (CRT) device implantation. This information could subsequently be used to target the LV lead to the latest activated region. An important finding of coronary venous mapping in chapter 2 was that in most patients with more than one target vein on the lateral wall, maximal electrical delay was found in another vein than the anatomically targeted vein. This shows that the anatomical (empirical) site of first choice often does not correspond with the site of latest activation, thereby illustrating the additional value of mapping-guided LV lead placement as compared to the conventional anatomical approach for optimization of LV lead positioning.

Previous investigators used three-dimensional (3D) contact or non-contact LV endocardial mapping techniques to characterize the LV activation pattern..$^{39-41,43,60}$ Yet, these techniques require the insertion of mapping catheters or multi-electrode arrays into the LV cavity, which is cumbersome, time-consuming and not without risk. In addition, LV endocardial mapping provides no information on the electrical activation of the epicardium, which is the region where the LV lead is usually positioned in clinical practice.

Recently, 3D electrocardiographic imaging (ECGi) has been introduced as a non-invasive alternative that provides a detailed reconstruction of the epicardial electrical activation prio to CRT implantation ${ }^{54,61}$ In this way, detailed information on LV epicardial electrical activation can be readily obtained without increasing the invasiveness of the implantation procedure or prolonging procedure time. However, so far, coronary venous anatomy has not been integrated in these ECGi activation maps. Thus identifying the region of latest activation using ECGi does not necessarily allow positioning of the LV lead in this region because a suitable target vein with acceptable pacing parameters may not be found overlying the desired LV area. In contrast, direct mapping within the coronary veins as we performed in this thesis provides information on timing of electrical activation in anatomical regions where the LV pacing electrode can most likely also be positioned.

Other investigators did not perform full electroanatomic mapping of the coronary vein in favor of a simpler approach where the electrical delay at potential LV pacing sites is determined by measuring the time from QRS onset to the locally sensed LV lead electrogram (Q-LV). 30, 31, 62-64 This approach, although easier and less time consuming, does have its disadvantages. For instance, the latest activated region may be missed, because other potential LV pacing sites are usually not tested when electrical delay at the anatomically (empirically) targeted LV region is deemed late enough. Besides, Q-LV measurements are usually performed after final LV lead implantation. If the measured electrical delay is deemed unsatisfactory, the LV lead may have to be relocated to an alternative target vein, which can be a cumbersome venture with extended procedure and fluoroscopy time. In contrast, our method of coronary venous EAM provides detailed information on electrical activation timing of all potential LV pacing sites prior to LV lead placement. The LV lead can then be targeted to the latest activated region in a single approach, thus reducing placement attempts at unsuitable sites. Moreover, in comparison with other invasive mapping techniques, this can be achieved at only minor prolongation of procedure time and without increasing the invasiveness of the implantation procedure by performing mapping with the same guide wire over which the LV lead is subsequently advanced. 
However, the practical benefits of our mapping approach and the potential profit it yields in terms of CRT outcome have to be weighed against the additional costs. In the current thesis, the clinical value of this lead placement strategy was not evaluated by long-term follow-up data. The impact of coronary venous mapping-guided LV lead placement on CRT outcome and the cost-effectiveness of this approach require further investigation.

\section{Mapping-guided LV lead placement: which patients will benefit most?} The additional value of mapping-guided LV lead placement will most likely depend on the type of conduction disorder and aetiology of LV dysfunction. In patients with non-ischemic LV dysfunction and LBBB, the latest activated region is typically located on the lateral or posterolatera wall..$^{39,65}$ Furthermore, the area from where LV pacing is effective in these patients, the so-called sweet spot, has been shown to be quite large. ${ }^{66} \mathrm{LV}$ sites yielding $>70 \%$ of maximal acute hemodynamic improvement were found to cover approximately $43 \%$ of the LV free wall, indicating that in non-ischemic failing hearts with LBBB, optimal CRT can be achieved by pacing over a fairly broad area of the LV. ${ }^{6}$ In these patients, mapping-guided LV lead placement may therefore provide only little profit in terms of CRT outcome and may not be cost-effective. In contrast the optimal pacing site in patients with non-LBBB QRS morphology or patients with ischemi LV dysfunction appears to be more restricted and to vary significantly. ${ }^{67-71}$ Thus, the sweet spot for pacing the LV in these patients is most likely both smaller and more variable. Studies have shown that these groups of patients show reduced response to CRT.22,68,72-74 Mapping-guided LV lead placement may therefore be especially of value in these groups of patients, both in terms of CRT outcome and cost-effectiveness. Support for this notion comes from a recent study by Kandala et al. who demonstrated that patients with non-LBBB conduction in whom the LV lead was positioned in a region with significant electrical delay (Q-LV >50 \% of QRS duration) had less heart failure hospitalizations and an improved composite outcome of all-cause mortality, heart failure hospitalization, LV assist-device implantation, and cardiac transplantation at 3 years. ${ }^{63}$ The benefit of mapping for optimizing LV lead placement in these patients comes on top of the benefit it provides with regard to patient selection by determining whether these patients have an electrical substrate amenable to CRT at all, as already discussed in part one of this general discussion.

\section{Optimizing the right ventricular lead position by electroanatomic}

\section{mapping}

Even though the latest activated region of the LV can be identified using electrical mapping techniques, it is common for the implanter not to find a suitable target vein with acceptable pacing parameters overlying the region of interest. In contrast to the limited number of suitable

Legend of Figure 1. Preprocedural 3D CE-CMR segmentation using CAAS-MRV 3.4 software (Pie Medical Imaging BV, Maastricht, the Netherlands) and intraprocedural integration with coronary venous electroanatomic map to guide LV lead placement to the region with maximal electrical delay free of scar in a patient with ischemic cardiomyopathy. CE-CMR showed a large basa to apical inferior to inferolateral scar. Coronary venous angiography revealed 2 target veins situated on the anterolateral and inferolateral wall. Maximal electrical delay was found in the mid segment of the anterolateral vein during coronary venous electroanatomic mapping. The LV lead was successfully positioned in the latest activated region and the electroanatomic map and 3D CE-CMR segmentation were integrated to verify positioning of the LV lead outside the region of scar. CS, coronary sinus; RV, right ventricle; LV-epi, left ventricular epicard; LV-endo, left ventricular endocard; AIV, anterior interventricular vein; ALV, anterolateral vein; ILV, inferolateral vein.
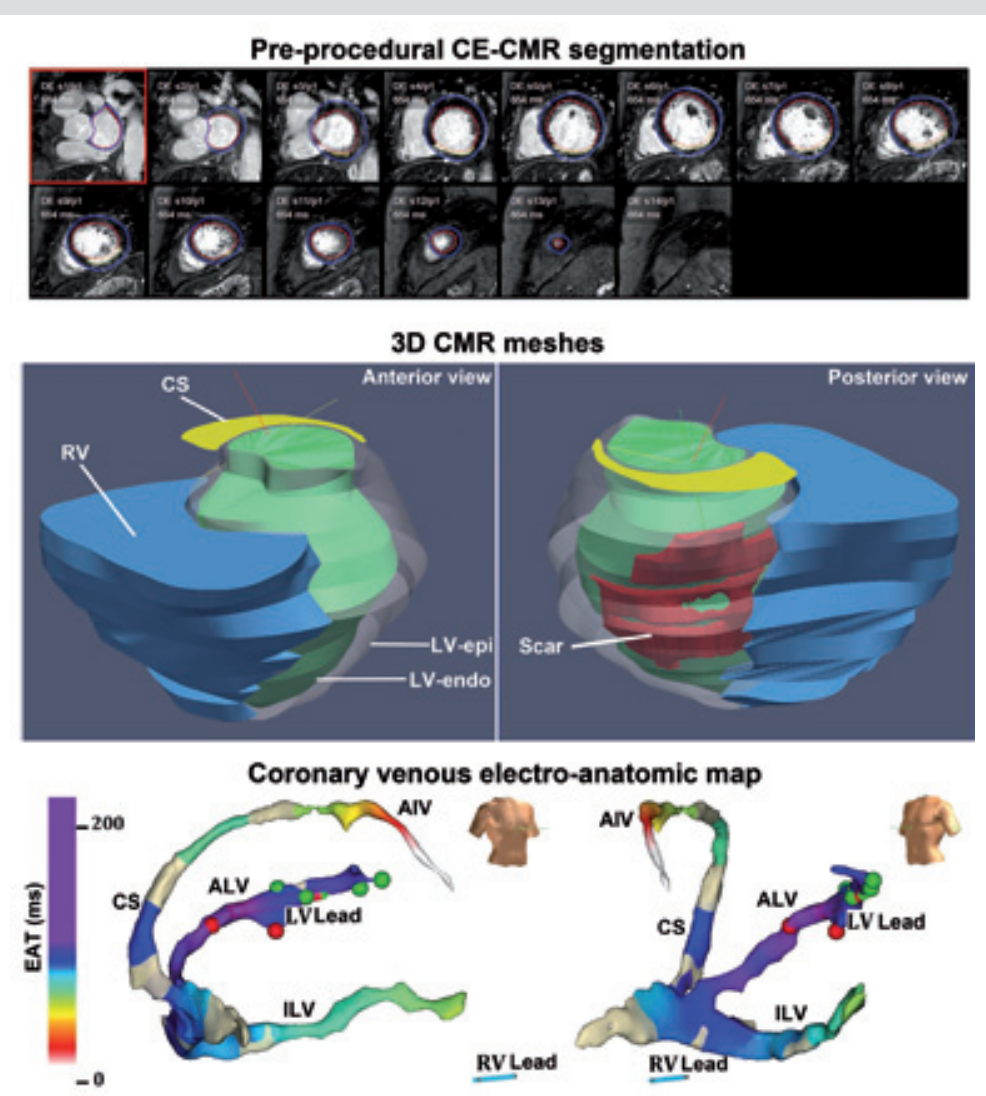

Intra-procedural Integration of electro-anatomic map and CMR mesh

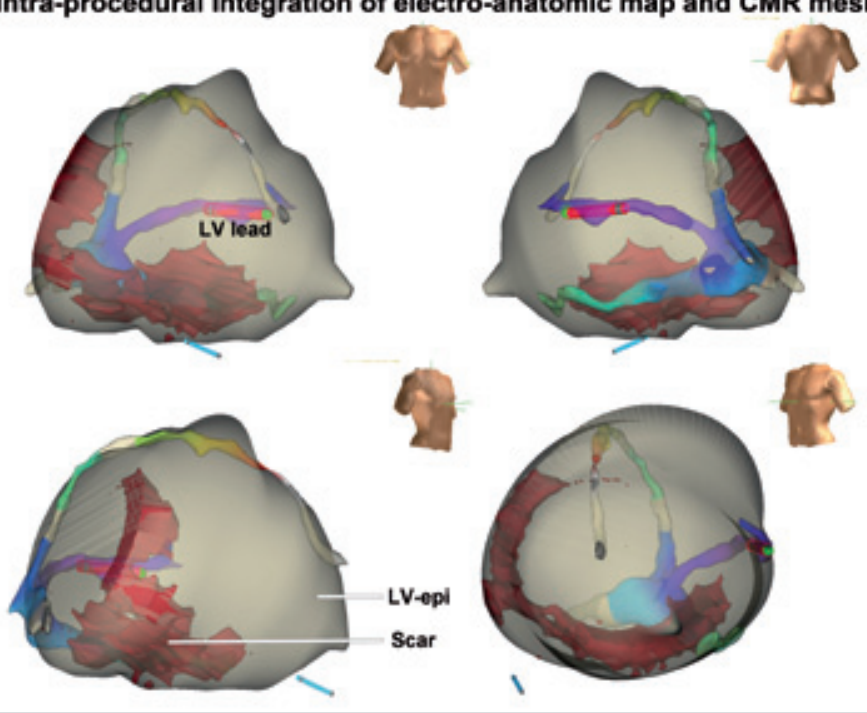

Figure 1. Legend on previous page. 
LV pacing sites due to constraints of coronary venous anatomy, RV pacing can typically be performed over a large region of the RV. Recently, Singh et al. proposed to select an RV pacing site complementary to the chosen LV site to compensate for a suboptimal LV lead position. This would involve initial placement of the LV lead at the most suitable anatomical site. Subsequently, the RV endocardial surface is tested with the RV lead to maximize electrical separation of the leads by either RV pacing and sensing the electrical delay at the LV lead position, or by LV pacing and sensing the electrical delay at the RV lead position. ${ }^{75}$ Kiuchi et al. demonstrated acute hemodynamic benefit of this so-called "dial in" strategy in thirteen consecutive CRT candidates. LV leads were positioned according to the conventional anatomical approach (anterolateral in 1, lateral in 9, and posterolateral in 3). Subsequently, a detailed electroanatomic map of the RV septum was generated during LV pacing to identify the most delayed activated region. Compared to conventional biventricular pacing at the RV apex, biventricular pacing at the most delayed site induced a significantly greater increase in LVdP/dtmax and pulse pressure relative to baseline. ${ }^{76}$ The results of this study suggest that mapping-guided RV lead placement may improve the degree of cardiac resynchronization and that this can be obtained across a broad range of LV pacing sites.

\section{Future directions: Scar integration}

While the position of the LV lead with respect to the latest activated region is a factor that can influence CRT response, the proximity of the LV lead to an area with myocardial scar is considered an important factor as well. Several studies, using different imaging modalities, including myocardial contrast echocardiography, single photon emission computed tomography and contrast enhanced cardiac magnetic resonance (CE-CMR) have shown that implantation of the LV lead at an area with myocardial scar may reduce the effectiveness of CRT.67,77-79 Thus pacing at the site with maximal electrical delay, while avoiding a region of scar is desired. Electroanatomic mapping may help to However, a precise scar description cannot be guaranteed by electroanatomic data. ${ }^{82,83} \mathrm{CE}-\mathrm{CM}$ is considered the gold standard for myocardial scar delineation and has also been shown to identify non-transmural scars and infarct grey zones not detected by electroanatomic voltage mapping according to currently used voltage criteria.$^{83}$ Integrating information obtained from CE-CMR regarding myocardial scar with data on electrical delay and venous anatomy obtained from coronary venous EAM may give a better representation of the pacing possibilities within a patient and help to further optimize LV lead positioning. Hence, we are currently developing a strategy of preprocedural 3D scar segmentation from CE-CMR images and intraprocedura integration of these segmentations with the coronary venous EAM obtained in real-time to guide LV lead placement. Figure 1 shows preliminary results of the procedure in a patient with ischemic cardiomyopathy. Integrating these techniques also allows us to investigate whether voltages and other electrogram characteristics during coronary venous EAM can distinguish scar from viable myocardium. Since CE-CMR may not always be available in clinical practice, such knowledge may still help to avoid pacing in scarred regions. 


\section{Prevention of pacing-induced dyssynchrony by alternative}

\section{site pacing}

Left ventricular septal pacing through the interventricular septum: a new, feasible, safe and hemodynamically preferable approach for anti-bradycardia pacing

In the study described in chapter 7 of this thesis we translated the results of previous canine experiment ${ }^{84}$ into clinical practice by demonstrating the feasibility and safety of permanently implanting a left ventricular (LV) septal lead using a trans-interventricular septal approach in a cohort of 10 patients. The implantation of the custom ventricular pacing lead with extended helix in the LV septum was accomplished in all patients in a single procedure. Procedure and fluoroscopy time steeply declined with increasing experience to values comparable to those during lead implantation at the conventional RV apex site. In addition, implantation was accomplished with a commercially available pre-shaped quiding catheter, making the procedure applicable in any center with access to the relevant instruments. Pacing and sensing threshold where within an adequate range and in keeping with that during RVA pacing and the leads remained electrically and mechanically stable during long-term follow-up without lead-related complications.

Similar to pre-clinical findings on the beneficial effects of LV septal pacing, ${ }^{84,85}$ our study showed that LV septal pacing induced less electrical dyssynchrony and preserved acute LV pump function, compared to RV apex and RV septal pacing. The underlying mechanism of the more natural activation pattern during LV septal pacing may be that pacing is performed at or near the normal breakout site during physiological impulse conduction, namely the LV septal endocardium.

The excellent feasibility of the trans-interventricular septal lead implantation approach in combination with the electrical and hemodynamic benefit of LV septal pacing shown in this thesis suggest that this new pacing method could serve as a better alternative for RV apex pacing in patients with a conventional indication for antibradycardia pacing. Admittedly, the findings of our study require further clinical validation in larger and prospective, long-term follow-up studies.

\section{LV septal pacing as compared to other alternative pacing sites and}

\section{biventricular pacing}

Small acute hemodynamic studies in patients generally showed a tendency towards a benefit of RV septal over RV apex pacing. ${ }^{86}$ However, three randomized trials comparing RV septal with RV apex pacing have shown no differences in LV pump function or clinical status. ${ }^{87-89}$ In our study, RV septal pacing showed no advantage over RV apex pacing in terms of electrical activation or hemodynamic performance. A remarkable finding was the large difference in QRS duration and acute hemodynamic effect between RV septal and LV septal pacing despite the fact that these sites were no more than $1 \mathrm{~cm}$ apart. Both findings are consistent with observations in animals and have been related to a significant delay in transseptal conduction which causes considerable later LV mechanical activation and peak contraction of the LV lateral wall during RV septal pacing, thereby inducing both inter- and intra-ventricular dyssynchrony. A similar but reverse dyssynchrony is to be expected during LV septal pacing, but several animal and human studies showed that earliertV activation and contraction is to be preferred over RV pre-excitation 90.92

A potentially even better and more physiological activation pattern can be achieved using His bundle pacing. Indeed, several studies have shown that His bundle pacing results in less dyssynchrony and better hemodynamic performance than RV apex pacing. ${ }^{93-96}$ Severa investigators have achieved permanent His bundle pacing in patients, ${ }^{97,98}$ and recently it was shown in a double-blind randomized cross-over study that His pacing preserves LV ejection 
fraction and mechanical synchrony as compared to RV septal pacing at long-term follow-up in patients with AV block. ${ }^{99}$ Yet, despite its beneficial effects, His bundle pacing is not recommended in patients requiring permanent cardiac pacing because of technical challenges during lead positioning and concerns about lead stability and threshold..$^{100}$

Several studies have suggested that an upgrade of RV apex pacing to biventricular pacing ${ }^{101-104}$ or de novo implantation of a biventricular device ${ }^{105-107}$ in patients with AV block and reduced ejection fraction reverses or prevents pacing-induced dyssynchrony and further deterioration of cardiac function. Accordingly, this has been included in current international guidelines. Yet, the benefit of biventricular pacing has to be weighed against the more complex and timeconsuming procedure, the higher rate of complications, failed implantations and loss of pacing associated with a coronary sinus (CS) lead with the consequent need for re-operation, ${ }^{108-110}$ the shorter battery life and the additional costs. Our data suggest that LV septal pacing could serve as an easier, less complication- and failure-sensitive and more cost-effective alternative for biventricular pacing to prevent or reverse pacing induced-dyssynchrony in patients requiring pacing because of symptomatic bradycardia. Yet, this requires further investigation in preferably large randomized controlled trials that directly compare these two pacing methods with regard to long-term effect on LV pump function, clinical outcome with particular focus on complication- and re-operation rates, and cost-effectiveness.

Possible role of LV septal pacing in cardiac resynchronization therapy

Another possible application of LV septal pacing might be cardiac resynchronization therapy Another possible application of LV septal pacing might be cardiac resynchronization therapy
(CRT). In CRT, most commonly, a pacing electrode is inserted into a CS branch on the LV epicardial lateral wall. However, introduction of the lead into the tortuous CS is often difficult and time-consuming, and failure to access the CS occurs in 5-10\% of patients. ${ }^{111}, 112$ In addition problems encountered during positioning and fixation of the lead in the coronary vein, such as lead dislodgment, ${ }^{112}$ phrenic nerve stimulation ${ }^{113-115}$ or elevated pacing thresholds, ${ }^{108}$ account for suboptimal or loss of CRT in a substantial number of patients, which may require re-operation during follow-up.

In canine hearts with normal ventricular conduction, LV septal pacing reduced dyssynchrony and improved LV pump function as compared to conventional RV pacing, but interestingly, also performed at least as good as conventional biventricular pacing. Recent unpublished data from our group show that pacing at the LV septum, alone or in combination with RV pacing also decreases electrical dyssynchrony (Figure 1) and accordingly improves LV systolic function to a similar degree as conventional biventricular pacing in canine hearts with left bundle-branch block (LBBB) and in CRT candidates.[Rademakers et al. unpublished]

These findings may be explained because a considerable part of the electrical dyssynchrony in LBBB hearts originates from the delay in conduction across the interventricular septum. ${ }^{42,116}$ Therefore, LV septal pacing can reduce inter-ventricular dyssnynchrony considerably. In addition pacing at or near the LV septal endocardium also takes advantage of the more rapid conduction in the inner $(\sim 1 \mathrm{~mm})$ layer of the ventricular wall as compared to the other layers of the working myocardium, ${ }^{117-119}$ which allows quick spread of the electrical impulse from the septum to the lateral wall, thereby reducing intra-ventricular dyssynchrony.

From this point of view, LV septal pacing fits in the more general concept of LV endocardia pacing for CRT. Studies in canine hearts with LBBB and in CRT candidates have previously shown that the use of an LV endocardial pacing electrode increases the efficacy of CRT owing to the more physiological activation achieved by LV endocardial pacing as compared to conventional

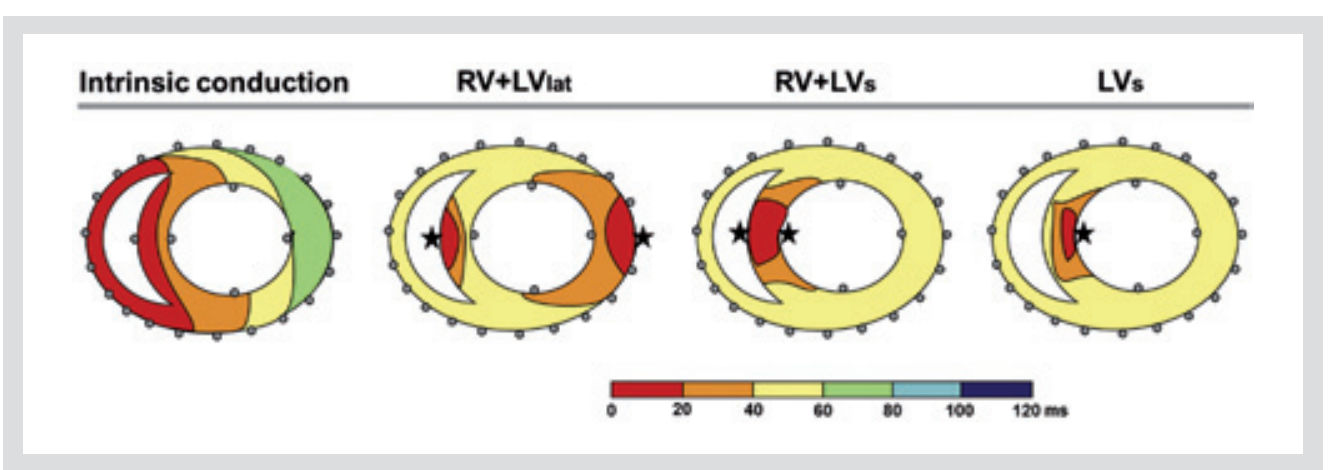

Figure 1. Reconstruction of the electrical activation times of the RV and LV of a canine heart at mid ventricular level during BBBB (intrinsic conduction), simultaneous RV septal and LV epicardial lateral wall pacing (RV + LVlat), simultaneous RV septa and LV septal pacing (RV + LVs), and LV septal pacing alone (LVs). Electrical activation times as measured by 108 epicardial and 5 endocardial electrodes were interpolated and plotted on a model of the ventricles. Dots represent electrodes and stars active pacing sites. LV septal pacing alone, or in combination with RV septal pacing decreased electrical dyssynchrony to a similar degree as conventional biventricular pacing. (Adapted with permission from Rademakers et al. unpublished)

epicardial LV pacing. ${ }^{19-122}$ In patients, chronic LV endocardial pacing has been achieved using a trans-atrial septal approach. ${ }^{123}$ However, this approach has an enhanced risk of thrombo-embolic complications due to the contact of the lead with the LV cavity which requires anti-coagulant therapy.

Theoretically, pacing into the Purkinje system, such as performed during direct His-bundle pacing, would be an even more physiological approach to treat a bundle-branch block. Previously, Narula reported that he could abolish the electrocardiographic signs of LBBB in 25 patients by distal His-bundle pacing, thereby curing the conduction disease. ${ }^{24}$ However, as mentioned in the previous section, chronic implantation of a lead into the His bundle remains a technically challenging procedure.

The above mentioned beneficial effects of LV septal pacing in dyssynchronous hearts and the promising results of permanent LV septal lead implantation via the trans-interventricular septal route demonstrated in the current thesis suggest that LV septal pacing could become an equal alternative for biventricular pacing that avoids the difficult access route through the CS. This approach would also allow CRT to be performed using a single ventricular lead in combination with a simpler 2-chamber pacemaker, thereby reducing the complication rate as well as implantation costs and prolonging battery life.

In conclusion, if clinical experience with LV septal pacing turns out to be positive, the results of our study may have a practice-changing impact on future pacing therapy. The LV septum may become the universal pacing site, being preferred for antibradycardia pacing as well as CRT. 


\section{References}

1. Cleland JG, Daubert JC, Erdmann E, Freemantle N, Gras D, Kappenberger L, Tavazzi L, Cardiac ResynchronizationHeart Failure Study I. The effect of cardiac resynchronization on morbidity and mortality in heart failure. The New England journal of medicine. 2005;352:1539-1549

2. Abraham WT, Fisher WG, Smith AL, Delurgio DB, Leon AR, Loh E, Kocovic DZ, Packer M, Clavell AL, Hayes DL, Ellestad M, Trupp RJ, Underwood J, Pickering F, Truex C, McAtee P, Messenger J, Evaluation MSGMIRC. Cardia resynchronization in chronic heart failure. The New England journal of medicine. 2002;346:1845-1853

3. Authors/Task Force M, Brignole M, Auricchio A, Baron-Esquivias G, Bordachar P, Boriani G, Breithardt OA, Cleland J, Deharo JC, Delgado V, Elliott PM, Gorenek B, Israel CW, Leclercq C, Linde C, Mont L, Padeletti L, Sutton R, Vardas PE, Guidelines ESCCfP, Zamorano JL, Achenbach S, Baumgartner H, Bax JJ, Bueno H, Dean V, Deaton C, Erol C, Fagard R, Ferrari R, Hasdai D, Hoes AW, Kirchhof P, Knuuti J, Kolh P, Lancellotti P, Linhart A Nihoyannopoulos P, Piepoli MF, Ponikowski P, Sirnes PA, Tamargo JL, Tendera M, Torbicki A, Wijns W, Windecker S, Document R, Kirchhof P, Blomstrom-Lundqvist C, Badano LP, Aliyev F, Bansch D, Baumgartner $H$, Bsata W, Buser P, Charron P, Daubert JC, Dobreanu D, Faerestrand S, Hasdai D, Hoes AW, Le Heuzey JY, Mavrakis H, McDonagh T, Merino JL, Nawar MM, Nielsen JC, Pieske B, Poposka L, Ruschitzka F, Tendera M, Van Gelder IC, Wilson CM. 2013 esc guidelines on cardiac pacing and cardiac resynchronization therapy: The task force on cardiac pacing and resynchronization therapy of the european society of cardiology (esc). Developed in collaboration with the european heart rhythm association (ehra). European heart journal. 2013;34:2281-2329

4. Tracy CM, Epstein AE, Darbar D, Dimarco JP, Dunbar SB, Estes NA, $3^{\text {rd }}$, Ferguson TB, Jr., Hammill SC, Karasik PE, Link MS, Marine JE, Schoenfeld MH, Shanker AJ, Silka MJ, Stevenson LW, Stevenson WG, Varosy PD. 2012 accf/aha/hrs focused update of the 2008 guidelines for device-based therapy of cardiac rhythm abnormalities: A report of the american college of cardiology foundation/american heart association task force on practice guidelines. Heart rhythm: the official journal of the Heart Rhythm Society. 2012;9:1737-1753

5. European Heart Rhythm A, European Society of C, Heart Rhythm S, Heart Failure Society of A, American Society of E, American Heart A, European Association of E, Heart Failure A, Daubert JC, Saxon L, Adamson PB, Auricchio A, Berger RD, Beshai JF, Breithard O, Brignole M, Cleland J, Delurgio DB, Dickstein K, Exner DV, Gold M, Grimm RA, Hayes DL, Israel C, Leclercq C, Linde C, Lindenfeld J, Merkely B, Mont L, Murgatroyd F, Prinzen F, Saba SF, Shinbane JS, Singh J, Tang AS, Vardas PE, Wilkoff BL, Zamorano JL. 2012 ehra/hrs expert consensus statement on cardiac resynchronization therapy in heart failure: Implant and follow-up recommendations and management. Heart rhythm: the official journal of the Heart Rhythm Society 2012;9:1524-1576

6. Mullens W, Grimm RA, Verga T, Dresing T, Starling RC, Wilkoff BL, Tang WH. Insights from a cardiac resynchronization optimization clinic as part of a heart failure disease management program. Journal of the American College of Cardiology. 2009:53:765-773

7. Priori SG, Blomstrom-Lundqvist C, Mazzanti A, Blom N, Borggrefe M, Camm J, Elliott PM, Fitzsimons D, Hatala R, Hindricks G, Kirchhof P, Kjeldsen K, Kuck KH, Hernandez-Madrid A, Nikolaou N, Norekval TM, Spaulding C, Van Veldhuisen DJ. 2015 esc guidelines for the management of patients with ventricular arrhythmias and the prevention of sudden cardiac death: The task force for the management of patients with ventricular arrhythmias and the prevention of sudden cardiac death of the european society of cardiology (esc). Endorsed by: Association for european paediatric and congenital cardiology (aepc). European heart journal. 2015;36:2793-2867

8. Cazeau S, Ritter P, Bakdach S, Lazarus A, Limousin M, Henao L, Mundler O, Daubert JC, Mugica J. Four chamber pacing in dilated cardiomyopathy. Pacing and clinical electrophysiology: PACE. 1994;17:1974-1979

9. Bakker PF, Meijburg HW, de Vries JW, Mower MM, Thomas AC, Hull ML, Robles De Medina EO, Bredee JJ. Biventricular pacing in end-stage heart failure improves functional capacity and left ventricular function. Journal of interventional cardiac electrophysiology: an international journal of arhythmias and pacing 2000:4:395-404

10. Linde C, Leclercq C, Rex S, Garrigue S, Lavergne T, Cazeau S, McKenna W, Fitzgerald M, Deharo JC, Alonso C,
Walker S, Braunschweig F, Bailleul C, Daubert JC. Long-term benefits of biventricular pacing in congestive heart failure: Results from the multisite stimulation in cardiomyopathy (mustic) study. Journal of the American College of Cardiology. 2002;40:111-118

11. Sutton MG, Plappert T, Hilpisch KE, Abraham WT, Hayes DL, Chinchoy E. Sustained reverse left ventricular structural remodeling with cardiac resynchronization at one year is a function of etiology: Quantitative doppler echocardiographic evidence from the multicenter insync randomized clinical evaluation (miracle). Circulation. 2006;113:266-272

12. Bristow MR, Saxon LA, Boehmer J, Krueger S, Kass DA, De Marco T, Carson P, DiCarlo L, DeMets D, White BG DeVries DW, Feldman AM, Comparison of Medical Therapy P, Defibrillation in Heart Failure I Cardiac-resynchronization therapy with or without an implantable defibrillator in advanced chronic heart failure. The New England journal of medicine. 2004;350:2140-2150

13. Vardas PE, Auricchio A, Blanc JJ, Daubert JC, Drexler H, Ector H, Gasparini M, Linde C, Morgado FB, Oto A, Sutton R, Trusz-Gluza M, European Society of C, European Heart Rhythm A. Guidelines for cardiac pacing and cardiac resynchronization therapy. The task force for cardiac pacing and cardiac resynchronization therapy of the european society of cardiology. Developed in collaboration with the european heart rhythm association. Europace: European pacing, arrhythmias, and cardiac electrophysiology: journal of the working groups on cardiac pacing, arrhythmias, and cardiac cellular electrophysiology of the European Society of Cardiology. 2007;9:959-998

14. Linde C, Abraham WT, Gold MR, St John Sutton M, Ghio S, Daubert C, Group RS. Randomized trial of cardiac resynchronization in mildly symptomatic heart failure patients and in asymptomatic patients with left ventricular dysfunction and previous heart failure symptoms. Journal of the American College of Cardiology. 2008;52:1834-1843

15. Moss AJ, Hall WJ, Cannom DS, Klein H, Brown MW, Daubert JP, Estes NA, 3rd, Foster E, Greenberg H, Higgins SL, Pfeffer MA, Solomon SD, Wilber D, Zareba W, Investigators M-CT. Cardiac-resynchronization therapy for the prevention of heart-failure events. The New England journal of medicine. 2009;361:1329-1338

16. Tang AS, Wells GA, Talajic M, Arnold MO, Sheldon R, Connolly S, Hohnloser SH, Nichol G, Birnie DH, Sapp JL, Yee R, Healey JS, Rouleau JL, Resynchronization-Defibrillation for Ambulatory Heart Failure Trial I. Cardiacresynchronization therapy for mild-to-moderate heart failure. The New England journal of medicine. 2010;363:2385-2395

17. Bryant AR, Wilton SB, Lai MP, Exner DV. Association between qrs duration and outcome with cardiac resynchronization therapy: A systematic review and meta-analysis. Journal of electrocardiology. 2013;46:147-155

18. Dickstein K, Vardas PE, Auricchio A, Daubert JC, Linde C, McMurray J, Ponikowski P, Priori SG, Sutton R, van Veldhuisen DJ, Guidelines ESCCFP. 2010 focused update of esc guidelines on device therapy in heart failure: An update of the 2008 esc guidelines for the diagnosis and treatment of acute and chronic heart failure An update of the 2008 esc guidelines for the diagnosis and treatment of acute and chronic heart failure
and the 2007 esc guidelines for cardiac and resynchronization therapy. Developed with the special and the 2007 esc guidelines for cardiac and resynchronization therapy. Developed with the specia
contribution of the heart failure association and the european heart rhythm association. Europace: European contribution of the heart failure association and the european heart rhythm association. Europace: European arrhythmias, and cardiac cellular electrophysiology of the European Society of Cardiology. 2010:12:1526-1536

19. Sweeney MO, van Bommel RJ, Schalij MJ, Borleffs CJ, Hellkamp AS, Bax JJ. Analysis of ventricular activation using surface electrocardiography to predict left ventricular reverse volumetric remodeling during cardiac resynchronization therapy. Circulation. 2010;121:626-634

20. Tian Y, Zhang P, Li X, Gao Y, Zhu T, Wang L, Li D, Wang J, Yuan C, Guo J. True complete left bundle branch block morphology strongly predicts good response to cardiac resynchronization therapy. Europace: European pacing, arrhythmias, and cardiac electrophysiology: journal of the working groups on cardiac pacing arrhythmias, and cardiac cellular electrophysiology of the European Society of Cardiology. 2013;15:1499-1506

21. Zareba W, Klein H, Cygankiewicz I, Hall WJ, MCNitt S, Brown M, Cannom D, Daubert JP, Eldar M, Gold MR Goldberger JJ, Goldenberg I, Lichstein E, Pitschner H, Rashtian M, Solomon S, Viskin S, Wang P, Moss AJ, MADIT-CRTI. Effectiveness of cardiac resynchronization therapy by qrs morphology in the multicenter 
automatic defibrillator implantation trial-cardiac resynchronization therapy (madit-crt). Circulation. 2011;123:1061-1072

22. Gold MR, Thebault C, Linde C, Abraham WT, Gerritse B, Ghio S, St John Sutton M, Daubert JC. Effect of qrs duration and morphology on cardiac resynchronization therapy outcomes in mild heart failure: Results from the resynchronization reverses remodeling in systolic left ventricular dysfunction (reverse) study. Circulation. 2012;126:822-829

23. Strauss DG, Selvester RH, Wagner GS. Defining left bundle branch block in the era of cardiac resynchronization therapy. Am J Cardiol. 2011;107:927-934

24. van Deursen CJ, Vernooy K, Dudink E, Bergfeldt L, Crijns HJ, Prinzen FW, Wecke L. Vectorcardiographic qrs area as a novel predictor of response to cardiac resynchronization therapy. Journal of electrocardiology. 2015;48:45-52

25. Cleland JG, Abraham WT, Linde C, Gold MR, Young JB, Claude Daubert J, Sherfesee L, Wells GA, Tang AS. An individual patient meta-analysis of five randomized trials assessing the effects of cardiac resynchronization therapy on morbidity and mortality in patients with symptomatic heart failure. European heart journal. 2013;34:3547-3556

26. Zusterzeel R, Selzman KA, Sanders WE, Canos DA, O'Callaghan KM, Carpenter JL, Pina IL, Strauss DG. Cardiac resynchronization therapy in women: Us food and drug administration meta-analysis of patient-level data. JAMA internal medicine. 2014;174:1340-1348

27. Mascioli G, Padeletti L, Sassone B, Zecchin M, Lucca E, Sacchi S, Boggian G, Tondo AL, Belvito C, Bakhtadze $\mathrm{N}$, Borrelli A, Sinagra G. Electrocardiographic criteria of true left bundle branch block: A simple sign to predict a better clinical and instrumental response to crt. Pacing and clinical electrophysiology: PACE. 2012;35:927-934

28. Vernooy K, Cornelussen RN, Verbeek XA, Vanagt WY, van Hunnik A, Kuiper M, Arts T, Crijns HJ, Prinzen FW. Cardiac resynchronization therapy cures dyssynchronopathy in canine left bundle-branch block hearts. European heart journal. 2007;28:2148-2155

29. Liu L, Tockman B, Girouard S, Pastore J, Walcott G, KenKnight B, Spinelli J. Left ventricular resynchronization therapy in a canine model of left bundle branch block. American journal of physiology. Heart and circulatory physiology. 2002;282:H2238-2244

30. Singh JP, Fan D, Heist EK, Alabiad CR, Taub C, Reddy V, Mansour M, Picard MH, Ruskin JN, Mela T. Left ventricula lead electrical delay predicts response to cardiac resynchronization therapy. Heart rhythm: the officia journal of the Heart Rhythm Society. 2006;3:1285-1292

31. Gold MR, Birgersdotter-Green U, Singh JP, Ellenbogen KA, Yu Y, Meyer TE, Seth M, Tchou PJ. The relationship between ventricular electrical delay and left ventricular remodelling with cardiac resynchronization therapy. European heart journal. 2011;32:2516-2524

32. van Oosterhout MF, Prinzen FW, Arts T, Schreuder JJ, Vanagt WY, Cleutjens JP, Reneman RS. Asynchronou electrical activation induces asymmetrical hypertrophy of the left ventricular wall. Circulation. 1998;98:588-595

33. Wyman BT, Hunter WC, Prinzen FW, Faris OP, McVeigh ER. Effects of single- and biventricular pacing on temporal and spatial dynamics of ventricular contraction. American journal of physiology. Heart and circulatory physiology. 2002;282:H372-379

34. Lumens J, Delhaas T, Kirn B, Arts T. Three-wall segment (triseg) model describing mechanics and hemodynamics of ventricular interaction. Annals of biomedical engineering. 2009;37:2234-2255

35. Ruschitzka F, Abraham WT, Singh JP, Bax JJ, Borer JS, Brugada J, Dickstein K, Ford I, Gorcsan J, 3rd, Gras D, Krum H, Sogaard P, Holzmeister J, Echo CRTSG. Cardiac-resynchronization therapy in heart failure with narrow qrs complex. The New England journal of medicine. 2013;369:1395-1405

36. Strik M, van Middendorp LB, Vernooy K. Animal models of dyssynchrony. Journal of cardiovascular translational research. 2012;5:135-145

37. Vernooy K, Verbeek XA, Peschar M, Crijns HJ, Arts T, Cornelussen RN, Prinzen FW. Left bundle branch block induces ventricular remodelling and functional septal hypoperfusion. European heart journal. 2005;26:91-98
38. Vassallo JA, Cassidy DM, Marchlinski FE, Buxton AE, Waxman HL, Doherty JU, Josephson ME. Endocardial activation of left bundle branch block. Circulation. 1984;69:914-923

39. Auricchio A, Fantoni C, Regoli F, Carbucicchio C, Goette A, Geller C, Kloss M, Klein H. Characterization of left ventricular activation in patients with heart failure and left bundle-branch block. Circulation. 2004:109:1133-1139

40. Rodriguez LM, Timmermans C, Nabar A, Beatty G, Wellens HJ. Variable patterns of septal activation in patients with left bundle branch block and heart failure. Journal of cardiovascular electrophysiology. 2003;14:135-141

41. Fung JW, Yu CM, Yip G, Zhang Y, Chan H, Kum CC, Sanderson JE. Variable left ventricular activation pattern in patients with heart failure and left bundle branch block. Heart. 2004;90:17-19

42. Prinzen FW, Auricchio A. Is echocardiographic assessment of dyssynchrony useful to select candidates for cardiac resynchronization therapy? Echocardiography is not useful before cardiac resynchronization therap if qrs duration is available. Circulation. Cardiovascular imaging. 2008;1:70-77; discussion 78

43. Fung JW, Chan JY, Yip GW, Chan HC, Chan WW, Zhang Q, Yu CM. Effect of left ventricular endocardial activation pattern on echocardiographic and clinical response to cardiac resynchronization therapy. Heart. 2007;93:432-437

44. Strik M, Ploux S, Vernooy K, Prinzen FW. Cardiac resynchronization therapy: Refocus on the electrical substrate. Circ J. 2011;75:1297-1304

45. Demoulin JC, Kulbertus HE. Histopathological examination of concept of left hemiblock. British heart journal. 1972;34:807-814

46. Bacharova L, Mateasik A, Krause R, Prinzen FW, Auricchio A, Potse M. The effect of reduced intercellular coupling on electrocardiographic signs of left ventricular hypertrophy. Journal of electrocardiology. 2011;44:571-576

47. Bacharova L, Szathmary V, Mateasik A. Electrocardiographic patterns of left bundle-branch block caused by intraventricular conduction impairment in working myocardium: A model study. Journal of electrocardiology. 2011;44:768-778

48. Unger PN, Lesser ME, Kugel VH, Lev M. The concept of masquerading bundle-branch block; an electrocardiographic-pathologic correlation. Circulation. 1958;17:397-409

49. Richman JL, Wolff L. Left bundle branch block masquerading as right bundle branch block. American heart journal. 1954;47:383-393

50. Fantoni C, Kawabata M, Massaro R, Regoli F, Raffa S, Arora V, Salerno-Uriarte JA, Klein HU, Auricchio A. Righ and left ventricular activation sequence in patients with heart failure and right bundle branch block: $A$ detailed analysis using three-dimensional non-fluoroscopic electroanatomic mapping system. Journal of cardiovascular electrophysiology. 2005;16:112-119; discussion 120-111

51. Mafi Rad M, Wijntjens GW, Engels EB, Blaauw Y, Luermans JG, Pison L, Crijns HJ, Prinzen FW, Vernooy K. Vectorcardiographic qrs area identifies delayed left ventricular lateral wall activation determined by electroanatomic mapping in candidates for cardiac resynchronization therapy. Heart rhythm: the officia journal of the Heart Rhythm Society. 2015

52. van Deursen CJ, Blaauw Y, Witjens MI, Debie L, Wecke L, Crijns HJ, Prinzen FW, Vernooy K. The value of the 12-lead ecg for evaluation and optimization of cardiac resynchronization therapy in daily clinical practice. Journal of electrocardiology. 2014;47:202-211

53. van Stipdonk AM, Rad MM, Luermans JG, Crijns HJ, Prinzen FW, Vernooy K. Identifying delayed left ventricular lateral wall activation in patients with non-specific intraventricular conduction delay using coronary venous electroanatomical mapping. Netherlands heart journal: monthly journal of the Netherlands Society of Cardiology and the Netherlands Heart Foundation. 2016;24:58-65

54. Ramanathan C, Ghanem RN, Jia P, Ryu K, Rudy Y. Noninvasive electrocardiographic imaging for cardiac electrophysiology and arrhythmia. Nature medicine. 2004;10:422-428

55. Engels EB, Vegh EM, CJ VAND, Vernooy K, Singh JP, Prinzen FW. T-wave area predicts response to cardia 
resynchronization therapy in patients with left bundle branch block. Journal of cardiovascular electrophysiology. 2014

56. Vegh EM, Engels EB, van Deursen CJ, Merkely B, Vernooy K, Singh JP, Prinzen FW. T-wave area as biomarker of clinical response to cardiac resynchronization therapy. Europace. 2015

57. Kors JA, van Herpen G, Sittig AC, van Bemmel JH. Reconstruction of the frank vectorcardiogram from standard electrocardiographic leads: Diagnostic comparison of different methods. European heart journal. 1990;11:1083-1092

58. Edenbrandt L, Pahlm O. Vectorcardiogram synthesized from a 12-lead ecg: Superiority of the inverse dowe matrix. Journal of electrocardiology. 1988;21:361-367

59. Engels EB, Alshehri S, van Deursen CJ, Wecke L, Vernooy K, Prinzen FW. The synthesized vectorcardiogram resembles the measured vectorcardiogram in patients with dyssynchronous heart failure. Journal of electrocardiology. 2015

60. Lambiase PD, Rinaldi A, Hauck J, Mobb M, Elliott D, Mohammad S, Gill JS, Bucknall CA. Non-contact left ventricular endocardial mapping in cardiac resynchronisation therapy. Heart. 2004;90:44-51

61. Ramanathan C, Jia P, Ghanem R, Ryu K, Rudy Y. Activation and repolarization of the normal human heart under complete physiological conditions. Proceedings of the National Academy of Sciences of the United States of America. 2006;103:6309-6314

62. Gold MR, Leman RB, Wold N, Sturdivant JL, Yu Y. The effect of left ventricular electrical delay on the acute hemodynamic response with cardiac resynchronization therapy. Journal of cardiovascular electrophysiology. 2014;25:624-630

63. Kandala J, Upadhyay GA, Altman RK, Parks KA, Orencole M, Mela T, Kevin Heist E, Singh JP. Qrs morphology, left ventricular lead location, and clinical outcome in patients receiving cardiac resynchronization therapy. European heart journal. 2013;34:2252-2262

64. Zanon F, Baracca E, Pastore G, Fraccaro C, Roncon L, Aggio S, Noventa F, Mazza A, Prinzen F. Determination of the longest intrapatient left ventricular electrical delay may predict acute hemodynamic improvemen in patients after cardiac resynchronization therapy. Circ Arrhythm Electrophysiol. 2014;7:377-383

65. Ansalone G, Giannantoni P, Ricci R, Trambaiolo P, Fedele F, Santini M. Doppler myocardial imaging to evaluate the effectiveness of pacing sites in patients receiving biventricular pacing. Journal of the American College of Cardiology. 2002;39:489-499

66. Helm RH, Byrne M, Helm PA, Daya SK, Osman NF, Tunin R, Halperin HR, Berger RD, Kass DA, Lardo AC. Threedimensional mapping of optimal left ventricular pacing site for cardiac resynchronization. Circulation. 2007;115:953-961

67. Ypenburg C, Schalij MJ, Bleeker GB, Steendijk P, Boersma E, Dibbets-Schneider P, Stokkel MP, van der Wall $\mathrm{EE}, \mathrm{Bax} \mathrm{JJ}$. Impact of viability and scar tissue on response to cardiac resynchronization therapy in ischaemic heart failure patients. European heart journal. 2007;28:33-41

68. White JA, Yee R, Yuan X, Krahn A, Skanes A, Parker M, Klein G, Drangova M. Delayed enhancement magnetic resonance imaging predicts response to cardiac resynchronization therapy in patients with intraventricular dyssynchrony. Journal of the American College of Cardiology. 2006;48:1953-1960

69. Bleeker GB, Kaandorp TA, Lamb HJ, Boersma E, Steendijk P, de Roos A, van der Wall EE, Schalij MJ, Bax Jر. Effect of posterolateral scar tissue on clinical and echocardiographic improvement after cardiac resynchronization therapy. Circulation. 2006;113:969-976

70. Arzola-Castaner D, Taub C, Kevin Heist E, Fan D, Haelewyn K, Mela T, Picard MH, Ruskin JN, Singh JP. Left ventricular lead proximity to an akinetic segment and impact on outcome of cardiac resynchronization therapy. Journal of cardiovascular electrophysiology. 2006;17:623-627

71. Ploux S, Lumens J, Whinnett Z, Montaudon M, Strom M, Ramanathan C, Derval N, Zemmoura A, Denis A, De Guillebon M, Shah A, Hocini M, Jais P, Ritter P, Haissaguerre M, Wilkoff BL, Bordachar P. Noninvasive electrocardiographic mapping to improve patient selection for cardiac resynchronization therapy: Beyond qrs duration and left bundle branch block morphology. Journal of the American College of Cardiology. 2013;61:2435-2443
72. Zareba W, Klein H, Cygankiewicz I, Hall WJ, McNitt S, Brown M, Cannom D, Daubert JP, Eldar M, Gold MR Goldberger JJ, Goldenberg I, Lichstein E, Pitschner H, Rashtian M, Solomon S, Viskin S, Wang P, Moss A Investigators $\mathrm{M}$-C. Effectiveness of cardiac resynchronization therapy by qrs morphology in the multicenter automatic defibrillator implantation trial-cardiac resynchronization therapy (madit-crt). Circulation. 2011;123:1061-1072

73. Chalil S, Foley PW, Muyhaldeen SA, Patel KC, Yousef ZR, Smith RE, Frenneaux MP, Leyva F. Late gadolinium enhancement-cardiovascular magnetic resonance as a predictor of response to cardiac resynchronization therapy in patients with ischaemic cardiomyopathy. Europace. 2007;9:1031-1037

74. Mullens W, Grimm RA, Verga T, Dresing T, Starling RC, Wilkoff BL, Tang WH. Insights from a cardiac resynchronization optimization clinic as part of a heart failure disease management program. Journal of the American College of Cardiology. 2009;53:765-773

75. Singh JP, Heist EK, Ruskin JN, Harthorne JW. "Dialing-in" cardiac resynchronization therapy: Overcoming constraints of the coronary venous anatomy. Journal of interventional cardiac electrophysiology: an international journal of arrhythmias and pacing. 2006;17:51-58

76. Kiuchi K, Yoshida A, Fukuzawa K, Takano T, Kanda G, Takami K, Hirata K. Identification of the right ventricular pacing site for cardiac resynchronization therapy (crt) guided by electroanatomical mapping (carto). Circ J. 2007;71:1599-1605

77. Chalil S, Stegemann B, Muhyaldeen SA, Khadjooi K, Foley PW, Smith RE, Leyva F. Effect of posterolateral left ventricular scar on mortality and morbidity following cardiac resynchronization therapy. Pacing Clin Electrophysiol. 2007;30:1201-1209

78. Hummel JP, Lindner JR, Belcik JT, Ferguson JD, Mangrum JM, Bergin JD, Haines DE, Lake DE, DiMarco JP, Mounsey JP. Extent of myocardial viability predicts response to biventricular pacing in ischemic cardiomyopathy. Heart rhythm: the official journal of the Heart Rhythm Society. 2005;2:1211-1217

79. Leyva F, Foley PW, Chalil S, Ratib K, Smith RE, Prinzen F, Auricchio A. Cardiac resynchronization therap guided by late gadolinium-enhancement cardiovascular magnetic resonance. Journal of cardiovascular magnetic resonance: official journal of the Society for Cardiovascular Magnetic Resonance. 2011;13:29

80. Soejima K, Suzuki M, Maisel WH, Brunckhorst CB, Delacretaz E, Blier L, Tung S, Khan H, Stevenson WG. Catheter ablation in patients with multiple and unstable ventricular tachycardias after myocardial infarction: Shor ablation lines guided by reentry circuit isthmuses and sinus rhythm mapping. Circulation. 2001;104:664-669

81. Marchlinski FE, Callans DJ, Gottlieb CD, Zado E. Linear ablation lesions for control of unmappable ventricular tachycardia in patients with ischemic and nonischemic cardiomyopathy. Circulation. 2000;101:1288-1296

82. Codreanu A, Odille F, Aliot E, Marie PY, Magnin-Poull I, Andronache M, Mandry D, Djaballah W, Regent D, Felblinger J, de Chillou C. Electroanatomic characterization of post-infarct scars comparison with 3-dimensional myocardial scar reconstruction based on magnetic resonance imaging. Journal of the American College of Cardiology. 2008;52:839-842

83. Wijnmaalen AP, van der Geest RJ, van Huls van Taxis CF, Siebelink HM, Kroft LJ, Bax JJ, Reiber JH, Schalij M Zeppenfeld K. Head-to-head comparison of contrast-enhanced magnetic resonance imaging and electroanatomical voltage mapping to assess post-infarct scar characteristics in patients with ventricular tachycardias: Real-time image integration and reversed registration. European heart journal. 2011;32:104-114

84. Mills RW, Cornelussen RN, Mulligan LJ, Strik M, Rademakers LM, Skadsberg ND, van Hunnik A, Kuiper M Lampert A, Delhaas T, Prinzen FW. Left ventricular septal and left ventricular apical pacing chronically maintain cardiac contractile coordination, pump function and efficiency. Circ Arrhythm Electrophysiol. 2009;2:571-579

85. Peschar M, de Swart H, Michels KJ, Reneman RS, Prinzen FW. Left ventricular septal and apex pacing for optimal pump function in canine hearts. Journal of the American College of Cardiology. 2003:41:1218-1226

86. de Cock CC, Giudici MC, Twisk JW. Comparison of the haemodynamic effects of right ventricular outflow-tract pacing with right ventricular apex pacing: A quantitative review. Europace. 2003;5:275-278

87. Kaye GC, Linker NJ, Marwick TH, Pollock L, Graham L, Pouliot E, Poloniecki J, Gammage M. Effect of right 
ventricular pacing lead site on left ventricular function in patients with high-grade atrioventricular block: Results of the protect-pace study. European heart journal. 2015;36:856-862

88. Kypta A, Steinwender C, Kammler J, Leisch F, Hofmann R. Long-term outcomes in patients with atrioventricular block undergoing septal ventricular lead implantation compared with standard apical pacing. Europace. 2008;10:574-579

89. Stambler BS, Ellenbogen K, Zhang X, Porter TR, Xie F, Malik R, Small R, Burke M, Kaplan A, Nair L, Belz M Fuenzalida C, Gold M, Love C, Sharma A, Silverman R, Sogade F, Van Natta B, Wilkoff BL. Right ventricular outflow versus apical pacing in pacemaker patients with congestive heart failure and atrial fibrillation. Journal of cardiovascular electrophysiology. 2003;14:1180-1186

90. Prinzen FW, Peschar M. Relation between the pacing induced sequence of activation and left ventricular pump function in animals. Pacing Clin Electrophysiol. 2002;25:484-498

91. van Geldorp IE, Delhaas T, Gebauer RA, Frias P, Tomaske M, Friedberg MK, Tisma-Dupanovic S, Elders J, Fruh A, Gabbarini F, Kubus P, Illikova V, Tsao S, Blank AC, Hiippala A, Sluysmans T, Karpawich P, Clur SA, Ganame X, Collins KK, Dann G, Thambo JB, Trigo C, Nagel B, Papagiannis J, Rackowitz A, Marek J, Nurnberg JH, Vanagt WY, Prinzen FW, Janousek J, Working Group for Cardiac D, Electrophysiology of the Association for European Paediatric C. Impact of the permanent ventricular pacing site on left ventricular function in children: A retrospective multicentre survey. Heart. 2011;97:2051-2055

92. Janousek J, van Geldorp IE, Krupickova S, Rosenthal E, Nugent K, Tomaske M, Fruh A, Elders J, Hiippala A, Kerst G, Gebauer RA, Kubus P, Frias P, Gabbarini F, Clur SA, Nagel B, Ganame J, Papagiannis J, Marek J, TismaDupanovic S, Tsao S, Nurnberg JH, Wren C, Friedberg M, de Guillebon M, Volaufova J, Prinzen FW, Delhaas Working Group for Cardiac D, Electrophysiology of the Association for European Pediatric C. Permanent cardiac pacing in children: Choosing the optimal pacing site: A multicenter study. Circulation. 2013;127:613-623

93. Deshmukh P, Casavant DA, Romanyshyn M, Anderson K. Permanent, direct his-bundle pacing: A nove approach to cardiac pacing in patients with normal his-purkinje activation. Circulation. 2000;101:869-877

94. Hirao K, Otomo K, Wang X, Beckman KJ, McClelland JH, Widman L, Gonzalez MD, Arruda M, Nakagawa H, Lazzara R, Jackman WM. Para-hisian pacing. A new method for differentiating retrograde conduction over an accessory av pathway from conduction over the av node. Circulation. 1996;94:1027-1035

95. Occhetta E, Bortnik M, Magnani A, Francalacci G, Piccinino C, Plebani L, Marino P. Prevention of ventricular desynchronization by permanent para-hisian pacing after atrioventricular node ablation in chronic atrial fibrillation: A crossover, blinded, randomized study versus apical right ventricular pacing. Journal of the American College of Cardiology. 2006;47:1938-1945

96. Zanon F, Bacchiega E, Rampin L, Aggio S, Baracca E, Pastore G, Marotta T, Corbucci G, Roncon L, Rubello D, Prinzen FW. Direct his bundle pacing preserves coronary perfusion compared with right ventricular apical pacing: A prospective, cross-over mid-term study. Europace. 2008;10:580-587

97. Catanzariti D, Maines M, Cemin C, Broso G, Marotta T, Vergara G. Permanent direct his bundle pacing does not induce ventricular dyssynchrony unlike conventional right ventricular apical pacing. An intrapatien acute comparison study. Journal of interventional cardiac electrophysiology: an international journal of arrhythmias and pacing. 2006;16:81-92

98. Kronborg MB, Mortensen PT, Gerdes JC, Jensen HK, Nielsen JC. His and para-his pacing in av block: Feasibility and electrocardiographic findings. Journal of interventional cardiac electrophysiology: an internationa journal of arrhythmias and pacing. 2011;31:255-262

99. Kronborg MB, Mortensen PT, Poulsen SH, Gerdes JC, Jensen HK, Nielsen JC. His or para-his pacing preserve left ventricular function in atrioventricular block: A double-blind, randomized, crossover study. Europace. 2014;16:1189-1196

100.Epstein AE, DiMarco JP, Ellenbogen KA, Estes NA, 3rd, Freedman RA, Gettes LS, Gillinov AM, Gregoratos G, Hammill SC, Hayes DL, Hlatky MA, Newby LK, Page RL, Schoenfeld MH, Silka MJ, Stevenson LW, Sweeney MO Smith SC, Jr., Jacobs AK, Adams CD, Anderson JL, Buller CE, Creager MA, Ettinger SM, Faxon DP, Halperin JL, Hiratzka LF, Hunt SA, Krumholz HM, Kushner FG, Lytle BW, Nishimura RA, Ornato JP, Riegel B, Tarkington LC,
Yancy CW. Acc/aha/hrs 2008 guidelines for device-based therapy of cardiac rhythm abnormalities: A report of the american college of cardiology/american heart association task force on practice guidelines (writin committee to revise the acc/aha/naspe 2002 guideline update for implantation of cardiac pacemakers and antiarrhythmia devices) developed in collaboration with the american association for thoracic surgery and society of thoracic surgeons. Journal of the American College of Cardiology. 2008;51:e1-62

101. Baker CM, Christopher TJ, Smith PF, Langberg JJ, Delurgio DB, Leon AR. Addition of a left ventricular lead to conventional pacing systems in patients with congestive heart failure: Feasibility, safety, and early results in 60 consecutive patients. Pacing Clin Electrophysiol. 2002;25:1166-1171

102.Delnoy PP, Ottervanger JP, Vos DH, Elvan A, Misier AR, Beukema WP, Steendijk P, van Hemel NM. Upgrading to biventricular pacing guided by pressure-volume loop analysis during implantation. Journal of cardiovascular electrophysiology. 2011;22:677-683

03.Leclerca C, Cazeau S, Lellouche D, Fossati F, Anselme F, Davy JM, Sadoul N, Klug D, Mollo L, Daubert JC. Upgrading from single chamber right ventricular to biventricular pacing in permanently paced patients with worsening heart failure: The rd-chf study. Pacing Clin Electrophysiol. 2007;30 Suppl 1:S23-30

104.Leon AR, Greenberg JM, Kanuru N, Baker CM, Mera FV, Smith AL, Langberg JJ, DeLurgio DB. Cardiac resynchronization in patients with congestive heart failure and chronic atrial fibrillation: Effect of upgrading to biventricular pacing after chronic right ventricular pacing. Journal of the American College of Cardiology. 2002;39:1258-1263

105.Kindermann M, Hennen B, Jung J, Geisel J, Bohm M, Frohlig G. Biventricular versus conventional right ventricular stimulation for patients with standard pacing indication and left ventricular dysfunction: The homburg biventricular pacing evaluation (hobipace). Journal of the American College of Cardiology. 2006;47:1927-1937

106.Martinelli Filho M, de Siqueira SF, Costa R, Greco OT, Moreira LF, D'Avila A, Heist EK. Conventional versus biventricular pacing in heart failure and bradyarrhythmia: The combat study. J Card Fail. 2010;16:293-300

107. Curtis AB. Biventricular pacing for atrioventricular block and systolic dysfunction. The New England journa of medicine. 2013;369:579

108.Bulava A, LukI J. Single-centre experience with coronary sinus lead stability and long-term pacing parameters. Europace. 2007;9:523-527

109. Biff M, Boriani G. Phrenic stimulation management in crt patients: Are we there yet? Current opinion in cardiology. 2011;26:12-16

110. Biffi M, Moschini C, Bertini M, Saporito D, Ziacchi M, Diemberger I, Valzania C, Domenichini G, Cervi E, Martignani C, Sangiorgi D, Branzi A, Boriani G. Phrenic stimulation: A challenge for cardiac resynchronization therapy. Circ Arrhythm Electrophysiol. 2009;2:402-410

111. McAlister FA, Ezekowitz J, Hooton N, Vandermeer B, Spooner C, Dryden DM, Page RL, Hlatky MA, Rowe BH. Cardiac resynchronization therapy for patients with left ventricular systolic dysfunction: A systematic review. Jama. 2007;297:2502-2514

112. McAlister FA, Ezekowitz JA, Wiebe N, Rowe B, Spooner C, Crumley E, Hartling L, Klassen T, Abraham W. Systematic review: Cardiac resynchronization in patients with symptomatic heart failure. Annals of interna medicine. 2004:141:381-390

113. Gold MR, Auricchio A, Hummel JD, Giudici MC, Ding J, Tockman B, Spinelli J. Comparison of stimulation sites within left ventricular veins on the acute hemodynamic effects of cardiac resynchronization therapy. Heart rhythm: the official journal of the Heart Rhythm Society. 2005;2:376-381

114. Biffi M, Moschini C, Bertini M, Saporito D, Ziacchi M, Diemberger I, Valzania C, Domenichini G, Cervi E, Martignani C, Sangiorgi D, Branzi A, Boriani G. Phrenic stimulation: A challenge for cardiac resynchronization therapy. Circ Arrhythm Electrophysiol. 2009;2:402-410

115. Seifert M, Schau T, Moeller V, Neuss M, Meyhoefer J, Butter C. Influence of pacing configurations, body mass index, and position of coronary sinus lead on frequency of phrenic nerve stimulation and pacing thresholds under cardiac resynchronization therapy. Europace. 2010;12:961-967 
116. Strik M, van Deursen CJ, van Middendorp LB, van Hunnik A, Kuiper M, Auricchio A, Prinzen FW. Transseptal conduction as an important determinant for cardiac resynchronization therapy, as revealed by extensive electrical mapping in the dyssynchronous canine heart. Circ Arrhythm Electrophysiol. 2013;6:682-689

117. Frazier DW, Krassowska W, Chen PS, Wolf PD, Danieley ND, Smith WM, Ideker RE. Transmural activations and stimulus potentials in three-dimensional anisotropic canine myocardium. Circulation research. 1988;63:135-146

118. Myerburg RJ, Gelband H, Nilsson K, Castellanos A, Morales AR, Bassett AL. The role of canine superficial ventricular muscle fibers in endocardial impulse distribution. Circulation research. 1978;42:27-35

119. van Deursen C, van Geldorp IE, Rademakers LM, van Hunnik A, Kuiper M, Klersy C, Auricchio A, Prinzen FW. Left ventricular endocardial pacing improves resynchronization therapy in canine left bundle-branch hearts. Circ Arrhythm Electrophysiol. 2009;2:580-587

120. Bracke FA, Houthuizen P, Rahel BM, van Gelder BM. Left ventricular endocardial pacing improves the clinical efficacy in a non-responder to cardiac resynchronization therapy: Role of acute haemodynamic testing. Europace. 2010;12:1032-1034

121. Garrigue S, Jais P, Espil G, Labeque JN, Hocini M, Shah DC, Haissaguerre M, Clementy J. Comparison of chronic biventricular pacing between epicardial and endocardial left ventricular stimulation using doppler tissue imaging in patients with heart failure. The American journal of cardiology. 2001;88:858-862

122. Ginks MR, Shetty AK, Lambiase PD, Duckett SG, Bostock J, Peacock JL, Rhode KS, Bucknall C, Gill J, Taggart P, Leclercq C, Carr-White GS, Razavi R, Rinaldi CA. Benefits of endocardial and multisite pacing are dependen on the type of left ventricular electric activation pattern and presence of ischemic heart disease: Insights from electroanatomic mapping. Circ Arrhythm Electrophysiol. 2012;5:889-897

123.van Gelder BM, Scheffer MG, Meijer A, Bracke FA. Transseptal endocardial left ventricular pacing: An alternative technique for coronary sinus lead placement in cardiac resynchronization therapy. Heart rhythm: the officia journal of the Heart Rhythm Society. 2007;4:454-460

24. Narula OS. Longitudinal dissociation in the his bundle. Bundle branch block due to asynchronous conduction within the his bundle in man. Circulation. 1977;56:996-1006 
Appendix

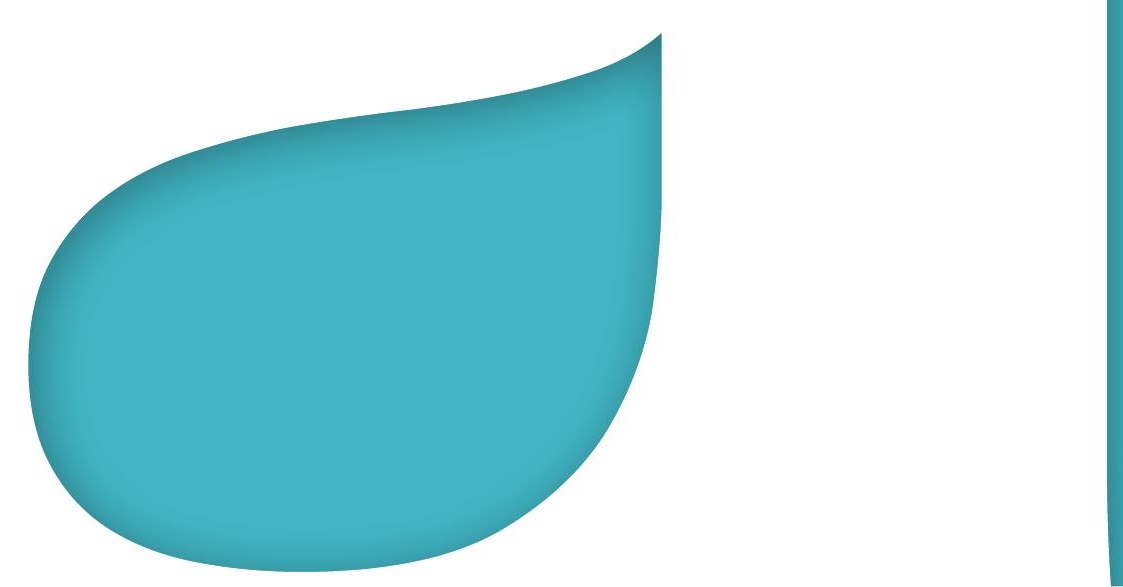




\section{Summary}

Under normal conditions, electrical activation of the chambers of the heart occurs very fast and nearly synchronous. This synchronous activation is considered of utmost importance to maintain coordinate ventricular contraction and normal cardiac pump function. In the presence of conduction abnormalities such as left bundle-branch block (LBBB) or during right ventricular (RV) pacing, left ventricular (LV) activation occurs slower and in a dyssynchronous manner. Intrinsic or pacing-induced dyssynchrony impairs LV pump function and, on the long run is associated with adverse structural changes and increased risk of heart failure and cardiac mortality. In the past decade and a half, cardiac resynchronization therapy (CRT) has emerged as a successful treatment for symptomatic heart failure patients with impaired LV systolic function and electrical dyssynchrony due to LBBB. The positive impact of CRT on LV pump function is attributed to the restoration of synchronous ventricular electrical activation by simultaneous biventricular pacing. However, up to half of CRT-treated patients do not show clinical and/or echocardiographic signs of response. The response rate of CRT may be improved by better identification of patients who have an appropriate electrical substrate for CRT and by optimizing therapy delivery by targeting LV lead placement to the latest activated region. In patients requiring continuous ventricular pacing because of symptomatic bradycardia, pacing at alternative ventricular sites rather than the standard site at the RV apex may produce less pacing-induced ventricular dyssynchrony and preserve LV pump function. In this respect, previous animal studies have shown that pacing at the LV septum yields LV pump function closely approximating that during normal ventricular conduction. However, a suitable method for application of LV septal pacing in clinical practice remains to be established.

The general background and introduction to the studies presented in this thesis are provided in chapter $\mathbf{1}$. The general aims of the research presented in chapter 1 are:

1) To optimize targeted LV lead placement for CRT.

2) To improve identification of patients with an appropriate electrical substrate for CRT.

3) To perform a first-in man study investigating the feasibility of a novel method of ventricular lead placement for anti-bradycardia pacing therapy that targets the LV septum.

An increasing literature supports the practice of placing the LV lead in the latest activated region as a means of maximizing CRT efficacy. Conventional LV lead placement strategy involves an anatomic approach, targeting a coronary venous branch on the lateral or posterolateral wall which is based on the contention that most patients eligible for CRT have LBBB, where the wall which is based on the contention that most patients eligible for CRT have LBBB, where the
lateral or posterolateral wall is typically the latest activated region. However, studies have shown considerable inter-individual differences in activation patterns between LBBB patients. Also, a significant percentage of CRT candidates do not have LBBB. Moving away from a one size-fits-all strategy towards a more patient-tailored approach of LV lead placement may thus improve therapy delivery and increase the rate of CRT response. In the study described in chapter $\mathbf{2}$ we developed a novel method of LV epicardial mapping via the coronary veins, which utilizes a commercially available electroanatomic mapping system in combination with a mapping guide wire, to evaluate the LV electrical activation pattern of CRT candidates. The study activated region. In addition, this was achieved without increasing the invasiveness of the implantation procedure and at only minor prolongation of procedure time.

In chapter $\mathbf{3}$ we used the novel method of coronary venous EAM to investigate the difference in LV electrical activation sequence between LBBB and RV apex pacing and the 
potential implications thereof for LV lead placement. Current targeted LV lead placement strategy is directed at the latest activated region during intrinsic activation. However, in daily clinical practice the CRT device is most commonly programmed to (almost) simultaneous RV and LV pacing (i.e. biventricular pacing) without fusion with intrinsic ventricular activation Although LBBB and RV apex pacing have similar QRS morphologies on the surface ECG, suggesting that the conditions are electrically equivalent, their activation patterns may be quite different, which may have implications for the choice of the optimal pacing site. To investigate this we assessed the LV electrical activation pattern of CRT candidates during both intrinsic LBBB and RV apex pacing using coronary venous EAM. The study showed that RV apex pacing significantly alters the pattern of LV electrical activation in CRT candidates with LBBB, and shifts the latest activated region in a half of these patients. These findings, added to results of a previous study showing a similar discordance in the mechanical activation pattern between LBBB and RV apex pacing, urge for reconsideration of the current practice of LV lead targeting for CRT.

Current LV lead targeting strategies are based on targeting either the region of latest electrical activation or the segment of latest peak contraction. Which of these regions to target is currently a matter of debate. In chapter $\mathbf{4}$, we investigated whether these LV lead targeting strategies are comparable by performing a within-patient comparison of the timing of LV electrical activation obtained from coronary venous EAM and the timing of LV peak contraction derived from speckle-tracking echocardiography in CRT candidates. The analysis showed that there is a strong positive correlation between the timing of LV electrical activation and peak contraction and that the regions of latest electrical activation and latest peak contraction largely correspond in CRT candidates. These findings suggests that a strategy of LV lead targeting based on speckle-tracking time-to-peak strain measures of mechanical activation is equivalent to that based on intra-cardiac measurements of electrical activation. The results of this study can be regarded as a validation of the strain-based approach to guide LV lead placement.

It is becoming increasingly clear that an appropriate electrical substrate, consisting of a sufficient amount of $L V$ activation delay, needs to be present in order for CRT to be effective. At present, the key clinical markers to detect and evaluate the extent of LV activation delay remain the QRS duration and morphology on the surface electrocardiogram (ECG). Yet, QRS duration appears insufficiently accurate whereas the classification of QRS morphology (LBBB or not) is operator dependant. In chapter $\mathbf{5}$ and $\mathbf{6}$, we demonstrate that coronary venous EAM can be used at the time of CRT implantation to determine the presence of delayed LV latera wall activation, the primary electrical substrate for CRT. This technique represents a middle ground between invasive mapping methods and the standard ECG. Ideally, characterization of the electrical substrate is performed before the start of the implantation procedure in order to guide the decision on whether or not to implant a CRT device. We hypothesized that QRS characteristics other than QRS duration and morphology may be able to identify delayed LV lateral wall activation. In chapter 5, we investigated this by comparing ECG measurements with data from coronary venous EAM in a cohort of patients with nonspecific intraventricular conduction delay. The analysis showed that baseline QRS characteristics were unable to identify delayed LV lateral wall activation in this subgroup of patients. Recently, the value of the vectorcardiogram (VCG) for predicting CRT response has been explored. The VCG contains three-dimensional information of the electrical forces within heart, which led us to hypothesize that this technique may provide better indicators for delayed LV lateral wall activation than the one-dimensional ECG. In chapter 6, we investigated this by comparing VCG measurements with data obtained from coronary venous $E A M$ in a cohort of $\angle B B B$ and non- $L B B B$ patients. We found that the area of the QRS complex derived from the VCG (QRS $\left.{ }_{\text {AREA }}\right)$ accurately identifies the electrical substrate for CRT, performing better than the conventional electrical markers QRS duration and LBBB morphology. QRS ${ }_{\text {AREA }}$ has the additional practical advantage that this parameter is measured in an objective manner and quantified as a continuous variable, as opposed to LBBB which is a dichotomous measurement that is subject to the use of different definitions and subjective interpretations. Another practical feature of $\mathrm{QRS}_{\text {AREA }}$ is that it can easily be derived from the standard 12-lead ECG because most commercially available ECG machines have algorithms to construct VCGs from standard 12-lead ECGs. The non-invasive and simple nature of VCG analysis combined with the evidence provided in this thesis that $\mathrm{QRS}_{\text {}}$ reflects the electrical substrate for CRT indicates that this parameter can be easily applied in clinical practice to identify appropriate candidates for CRT, thereby potentially improving response to this therapy.

Chapter $\mathbf{7}$ describes the first-in-man study on the use of LV septal pacing for antibradycardia treatment, in order to prevent RV pacing-induced dyssynchrony. This idea was based on previous animal studies, showing that LV septal pacing leads to a more physiological sequence of $L V$ electrical activation and contraction. In the animal experiments, permanent and stable implantation of an LV septal lead was achieved by introducing a custom pacing lead with extended helix transvenously into the RV and driving it from the RV side to the LV side of the interventricular septum. In chapter $\mathbf{7}$, the results of the previous animal studies were translated into clinical practice by demonstrating the feasibility and safety of permanently implanting an LV septal lead using a transvenous approach through the interventricular septum in a cohort of 10 patients. Similar to the pre-clinical findings, the study showed that LV septal pacing induces less electrical dyssynchrony and provides hemodynamic benefit as compared to conventional RV apex pacing. The excellent feasibility of the trans-interventricular septal lead implantation approach in combination with the electrical and hemodynamic benefit of LV septal pacing shown in this study suggest that this new pacing method could serve as a better alternative for RV apex pacing in patients with a conventional indication for antibradycardia pacing. In addition, our results suggest that this new pacing method could serve as an easier, less complication- and failure-sensitive and more cost-effective alternative for biventricular pacing to prevent or reverse pacing-induced dyssynchrony in patients requiring pacing because of symptomatic bradycardia. If clinical experience with LV septal pacing turns out to be positive, our results may have a practice-changing impact on future pacing therapy.

Chapter $\mathbf{8}$ and $\mathbf{9}$ of this thesis discuss the potential value of measurements of acute hemodynamic response to CRT for improving patient selection and optimizing CRT delivery by systematic hemodynamic evaluation of potential LV pacing sites and atrio-ventricular and inter-ventricular stimulation intervals.

\section{Conclusions}

- Coronary venous EAM can be used at the time of CRT implantation to characterize the electrica substrate of CRT candidates and to guide LV lead placement to the latest activated region.

- RV apex pacing significantly alters the pattern of LV electrical activation in CRT candidates with LBBB, and shifts the latest activated region in a substantial proportion of these patients. This suggests that LV lead targeting for CRT which is applied by biventricular pacing should be directed at the region latest activated during RV apex pacing rather than the region latest activated during intrinsic activation. 
- Regional LV electrical activation and peak contraction are closely related in candidates for CRT. This suggests that a strategy of determining the latest activated region based on speckle-tracking time-to-peak measures is equivalent to that based on intra-cardiac measurements of electrical activation.

- $\mathrm{QRS}_{\text {APEA }}$ derived from the VCG provides a relatively easy and non-invasively acquired parameter that identifies the electrical substrate for CRT better than the conventional electrical markers QRS duration and LBBB morphology, while having the additional advantage of being objectively quantifiable as a continuous parameter. The simple and non-invasive nature of VCG analysis indicates that QRS $_{\text {AREA }}$ can be easily applied in clinical practice to identify appropriate CRT candidates, thereby potentially improving response to this therapy.

- Permanent placement of an LV septal lead using a transvenous approach through the interventricular septum is feasible and safe in patients. This new pacing method is hemodynamically preferable to conventional RV apex pacing and could serve as an alternative for biventricular pacing to prevent or reverse pacing induced-dyssynchrony in patients requiring continuous pacing because of symptomatic bradycardia. 


\section{Samenvatting}

In een normaal hart zorgt een speciaal geleidingsysteem voor snelle en bijna gelijktijdige elektrische activatie van de rechter en linker hartkamer, waardoor beide hartkamers vrijwel gelijktijdig samentrekken. Dit zorgt voor een optimale pompfunctie van het hart. Bij patiënten met een ziek geleidingssysteem ontstaat een ongecoördineerde samentrekking waardoor de wordt het probleem van ongecoördineerde (niet gelijktijdige) samentrekking van de hartspier tegenwoordig behandeld met Cardiale Resynchronisatie Therapie (CRT). Deze therapie heeft als doel de abnormale impulsgeleiding over de hartkamers te herstellen zodat de pompfunctie van het hart verbetert. Hiervoor wordt een speciale pacemaker geïmplanteerd met pacemakerdraden op de rechter en linker kamer. Het uiteinde (ook wel elektrode genoemd) van elke draad kan een elektrische prikkel afgeven. De pacemaker geeft gelijktijdig elektrische impulsen af aan beide elektroden (ook wel pacen genoemd) waardoor de rechter en de linker kamer weer min of meer gelijktijdig gaan samentrekken. Hierdoor kan de pompfunctie van het har verbeteren. Veel patiënten met hartfalen die behandeld worden met CRT hebben minder klachten van hartfalen, kunnen zich beter inspannen en ervaren een betere kwaliteit van leven. Maar helaas heeft een belangrijk deel van hen (ongeveer een derde) weinig tot geen baat bij deze behandeling. Dit grote aantal vraagt om een verbetering en verdere ontwikkeling van CRT.

De algemene achtergrond en doelstellingen van de studies in dit proefschrift zijn uiteengezet in hoofdstuk 1.

Een van de manieren voor het verbeteren van CRT is door de elektrode van de linker kame draad van de pacemaker op de meest gunstige plek op de linker kamer te leggen. In de huidige dagelijkse klinische praktijk wordt de linker kamer elektrode bij elke patiënt op nagenoeg dezelfde plek op de linker kamer gelegd. De resultaten van recente onderzoeken suggereren echter dat de optimale plek voor de linker kamer elektrode het gebied is dat zonder pacen het laatst de normale elektrische prikkel ontvangt. Doordat het activatiepatroon van de linker kamer behoorlijk kan verschillen tussen patiënten, varieert ook de optimale elektrode positie van patiënt tot patiënt. Dit vraagt om een meer patiënt-specifieke benadering voor het plaatsen van de linker kamer elektrode. Een manier om dit te doen zou kunnen zijn door gebruik te maken van "electroanatomic mapping", een techniek waarmee men het elektrische activatie patroon van het hart 3-dimensionaal in kaart kan brengen. De techniek wordt gewoonlijk door cardiologen gebruikt als hulpmiddel bij de diagnose en behandeling van hartritmestoornissen. In hoofdstuk 2 tonen wij aan hoe electroanatomic mapping ook gebruikt kan worden om tijdens een CRT pacemaker implantatie het laatst geactiveerde gebied van de linker kamer te bepalen en de linker kamer elektrode in het desbetreffende gebied te plaatsen.

Momenteel wordt het laatst geactiveerde gebied bepaald tijdens eigen activatie van de linker kamer. In de dagelijkse klinische praktijk wordt CRT echter meestal toegepast door de rechter en linker kamer gelijktijdig te pacen zonder bijdrage van de eigen activatie. In hoofdstuk 3 laten we met behulp van electroanatomic mapping zien dat pacen van de rechter kamer het activatiepatroon van de linker kamer in belangrijke mate verandert en in de helft van de patiënten het laatst geactiveerde gebied verschuift. In theorie zou dit betekenen dat de linker kamer elektrode eerder geplaatst zou moeten worden in het gebied dat het laatst geactiveerd wordt tijdens rechter kamer pacen en niet in het gebied dat het laatst geactiveerd wordt tijdens eigen activatie van de linker kamer.

Tot op heden is er geen consensus over de methode welke gebruikt dient te worden om het laatst geactiveerde gebied te bepalen. Sommige studies gebruiken elektrische mapping methoden om te meten waar in de linker kamer het elektrische signaal het laatst aankom andere studies bepalen met behulp van echografische beelden van het hart (ook wel 
echocardiografie genoemd) welk deel van de linker kamer het laatst samentrekt, wat minder invasief is. In hoofdstuk 4 laten we zien dat de gebieden in de linker kamer waar het elektrische signaal het laatst aankomt grotendeels overeenkomen met die gebieden die volgens echocardiografie het laatst samentrekken. Deze bevindingen suggereren dat beide methoden gelijkwaardig zijn voor het bepalen van het laatst geactiveerde gebied.

Een andere manier voor het verbeteren van CRT is door díe patiënten te identificeren die een grote kans hebben om beter te worden door deze behandeling. De resultaten van eerdere onderzoeken duiden er op dat patiënten met een vertraagde elektrische activatie van de linker hartkamer de grootste kans hebben om baat te hebben bij CRT. Momenteel is de belangrijkste techniek voor het vaststellen van de aanwezigheid en mate van vertraagde linker kamer activatie nog steeds het standaard hartfilmpje, ook wel electrocardiogram (ECG) genoemd. Echter, de conventionele ECG markers voor vertraagde linker kamer activatie zijn ontoereikend gebleken voor het accuraat identificeren van patiënten met grote kans op baat bij CRT. In hoofdstuk 5 en 6 tonen wij aan dat de boven beschreven electroanatomic mapping methode gebruikt kan worden om de aan-/afwezigheid van vertraagde linker kamer activatie van potentiële CRT kandidaten tijdens de implantatieprocedure te bepalen. Idealiter gebeurt dit uiteraard vóór de implantatie, zodat deze informatie gebruikt kan worden om de beslissing tot het wel of niet implanteren van een CRT pacemaker te sturen. Daarom hebben we in hoofdstuk 6 de mapping data vergeleken met metingen van het vectorcardiogram (VCG). Anders dan het standaard ECG dat 1-dimensionale informatie bevat over de elektrische activatie van het hart, is het VCG een hartfilmpje dat 3-dimensionale informatie bevat over de elektrische krachten in het hart. In hoofdstuk $\mathbf{6}$ tonen wij aan dat VCG metingen vertraagde linker kamer activatie nauwkeurig kunnen identificeren en daarbij beter presteren dan de conventionele ECG markers. Het VCG zou in de dagelijkse klinische praktijk makkelijk kunnen worden toegepast om geschikte CRT kandidaten te identificeren voorafgaand aan de CRT implantatie.

Een ongecoördineerde samentrekking van het hart wordt niet alleen gezien bij patiënten met een ziek geleidingssysteem, maar ook bij patiënten die een standaard pacemaker hebben ontvangen vanwege een te trage hartslag. Bij een standaard pacemaker wordt alleen één pacemakerdraad in de punt (ook wel "apex"genoemd) van de rechter hartkamer geplaatst. Pacen van de apex van de rechter kamer leidt ook tot een ongecoördineerde samentrekking van het hart, waardoor de pompfunctie van het hart afneemt en hartfalen kan ontstaan. Eerder verricht dieronderzoek heeft aangetoond dat het mogelijk is om dergelijke achteruitgang van de pompfunctie van het hart te voorkomen door bij een standaard pacemaker de elektrode van de pacemakerdraad aan de linker kant van het tussenschot van de hartkamers (ook wel "septum"genoemd) te plaatsen in plaats van in de apex van de rechter kamer. Dit werd in het dieronderzoek gedaan door de elektrode van de draad vanuit de rechter kamer door het septum heen te schroeven, tot de linker kant van het septum bereikt was. In hoofdstuk 7 onderzochten wij de haalbaarheid van deze implantatiemethode voor het eerst in patiënten. Permanente implantatie van een pacemaker draad aan de linker kant van het septum bleek haalbaar en veilig in een groep van 10 patiënten. Daarnaast toonden we aan dat pacen van de linker kant van het septum, ten opzichte van de apex van de rechter kamer, een snellere elektrische activatie van het hart geeft en de pompfunctie van het hart behoudt. Onze bevindingen suggereren dat deze nieuwe implantatiemethode zou kunnen dienen als een beter alternatief voor de conventionele methode bij patiënten met een indicatie voor een standaard pacemaker. Als de klinische ervaring met deze nieuwe implantatiemethode positie blijkt, zouden de resultaten van ons onderzoek een praktijk-veranderende invloed kunnen hebben op toekomstige pacemakertherapie.
In hoofdstuk 8 en 9 wordt de potentiele waarde van het meten van acute hemodynamische respons op CRT voor het verbeteren van patiëntselectie en optimalizeren van de toepassing van CRT bediscussieerd.

\section{Conclusies}

- Electroanatomic mapping kan tijdens een CRT pacemaker implantatie gebruikt worden om het elektrische activatiepatroon van de linker kamer in kaart te brengen en de de linker kamer elektrode in het laatst geactiveerde gebied te plaatsen.

- Pacen van de rechter kamer tijdens CRT verandert het activatiepatroon van de linker kamer in belangrijke mate en verschuift het laatst geactiveerde gebied in een aanzienlijk deel van de patiënten. Dit suggereert dat de linker kamer elektrode eerder geplaatst zou moeten worden in het gebied dat het laatst geactiveerd wordt tijdens rechter kamer pacen en nie in het gebied dat het laatst geactiveerd wordt tijdens eigen activatie van de linker kamer.

- De elektrisch laatst geactiveerde gebieden van de linker kamer komen grotendeels overeen met de gebieden die volgens echocardiografie het laatst samentrekken. Dit suggeert dat elektrische mapping methoden en echocardiografie gelijkwaardig zijn voor het bepalen van het laatst geactiveerde gebied.

- Het VCG is een relatief makkelijke en non-invasieve techniek die vertraagde linker kamer activatie beter identificeert dan de conventionele ECG markers. Deze techniek zou in de kandidaten te identificeren voorafgaand aan de CRT implantatie.

- Permanente implantatie van een pacemaker draad door het septum heen aan de linker kant van het septum is haalbaar en veilig in patiënten. Pacen van de linker kant van he septum behoudt de pompfunctie van het hart. Deze nieuwe implantatiemethode zou kunnen dienen als een beter alternatief voor de conventionele methode bij patiënten met een indicatie voor een standaard pacemaker. 
Valorisation

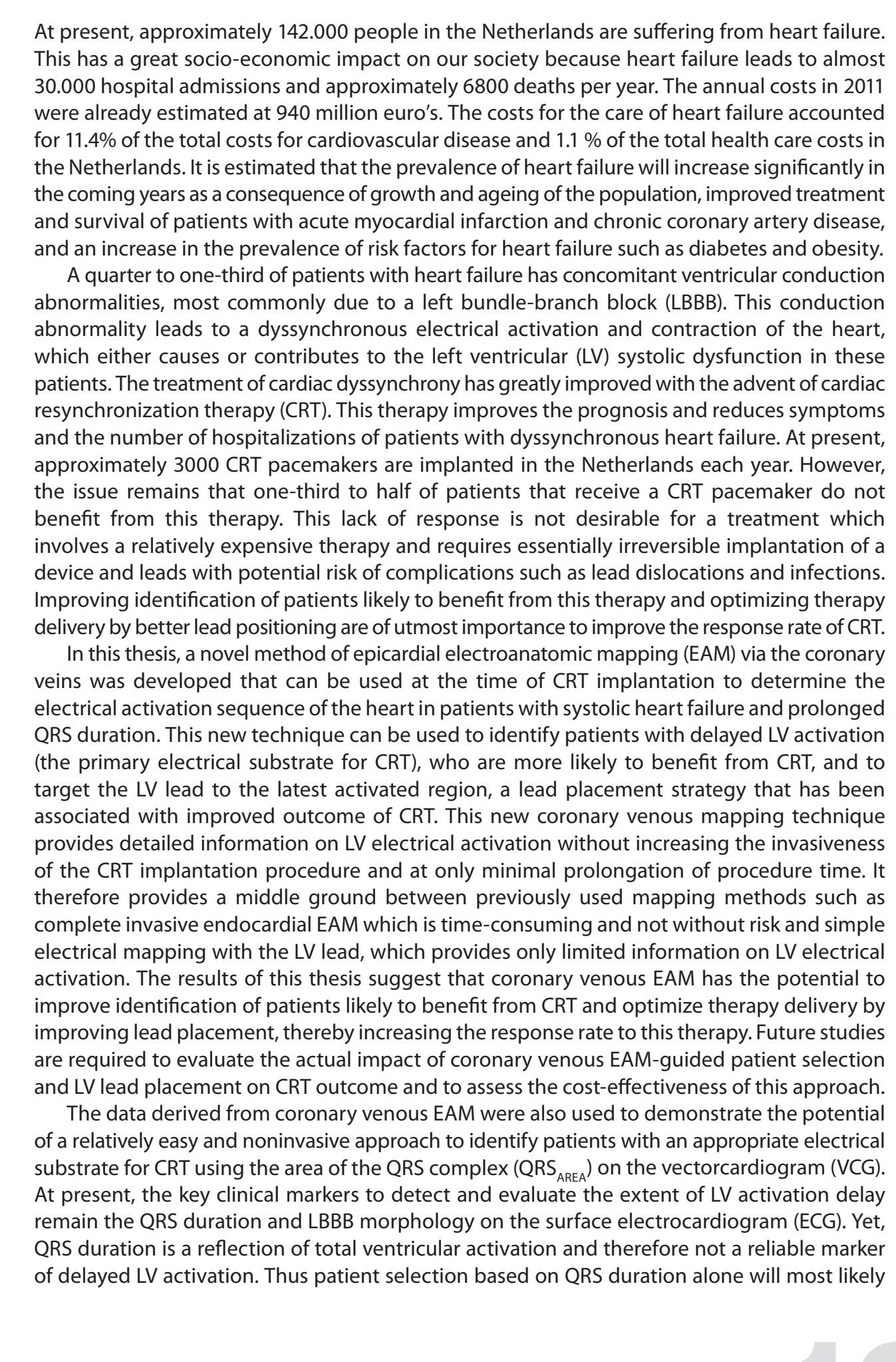


result in a substantial number of patients receiving a CRT device without deriving any detectable benefit. Classification of QRS morphology (LBBB or not) faces the problem of being operator dependent due to the presence of different LBBB definitions in the literature and the subjective interpretation of QRS notching and slurring. In addition, the refined LBBB definition is highly specific for delayed LV activation, but lacks sufficient sensitivity. As a consequence, a substantial number of patients that have delayed LV activation are not identified as such, and in these patients, CRT may be withheld erroneously. The present thesis demonstrates that vectorcardiographic QRS $_{\text {AREA }}$ identifies delayed LV activation better than the conventional electrical markers QRS duration and LBBB morphology. The great practical benefit of QRS ${ }_{\text {AREA }}$ is that this parameter is measured in an objective manner and quantified as a continuous variable, as opposed to LBBB, which is a dichotomous measurement that is subject to the use of different definitions and subjective interpretations. Another practical feature of $\mathrm{QRS}_{\mathrm{AREA}}$ is that it can be easily derived from the standard 12-lead ECG since most commercially available ECG machines have algorithms to construct VCGs from standard 12-lead ECGs. The simple and non-invasive nature of VCG analysis combined with the excellent diagnostic performance of QRS $_{\text {AREA }}$ for delayed LV activation implies that this parameter can be easily used in clinical practice to identify appropriate CRT candidates before CRT implantation. This may potentially improve the response to this therapy and prevent ineffective and costly CRT device implantations with potential risk of complications. In addition, it may allow application of CRT in a substantia number of patients to whom treatment is currently wrongfully denied based on current guideline criteria.

A second topic in this thesis is the prevention of cardiac dyssynchrony, as caused by right ventricular (RV) pacing. Cardiac dyssynchrony is not only observed in patients with conduction disorders but also in patients receiving RV pacing because of symptomatic bradycardia. At present, approximately 8000 patients in the Netherlands are implanted with a pacemaker for anti-bradycardia treatment each year. Especially in patients with pre-existent impaired LV pump function, pacing-induced dyssynchrony can cause further deterioration of pump function and increase the risk of heart failure. Several studies have suggested that an upgrade of RV pacing to biventricular pacing or de novo implantation of a biventricular device in patients with atrio-ventricular block and reduced ejection fraction reverses or prevents pacing-induced dyssynchrony and further deterioration of cardiac function. Yet, the benefit of biventricular pacing comes at the expense of a more complex and time-consuming procedure, a higher rate of complications, failed implantations with the consequent need for re-operation, a shorter battery life and additional costs.

In this thesis, a first-in-man study was performed on the use of LV septal pacing for antibradycardia treatment, in order to prevent RV pacing-induced dyssynchrony. The feasibility of permanently implanting an LV septal lead using a transvenous approach through the interventricular septum has previously only been demonstrated in animal experimental studies. These animal studies showed that LV septal pacing leads to a more physiological sequence of left ventricular electrical activation and contraction. In this thesis, the results of the previous animal studies were translated into clinical practice by demonstrating the feasibility and safety of permanently implanting an LV septal lead using a transvenous approach through the interventricular septum in a cohort of 10 patients. Similar to the pre-clinical findings, the study showed that LV septal pacing induces less electrical dyssynchrony and provides acute hemodynamic benefit as compared to conventional RV apex pacing. These results suggest that this new pacing method could serve as a better alternative for RV apex pacing in patients with a conventional indication for antibradycardia pacing. If clinical experience with the trans-interventricular septal lead placement approach turns out to be positive and if subsequent larger and prospective studies indicate that the acute hemodynamic benefit of LV septal pacing translates into preservation of $L V$ pump function on the longer term, the $L V$ septum may become the preferred site for anti-bradycardia pacing. This may reduce the number of patients that develop heart failure due to pacing-induced dyssynchrony. In addition, the study results suggest that LV septal pacing could serve as an easier, less complication- and failure-sensitive and more cost-effective alternative for biventricular pacing to prevent pacing induced-dyssynchrony in patients requiring pacing because of symptomatic bradycardia.

Another possible application of LV septal pacing might be CRT. Recent research has shown that pacing at the LV septum, also decreases electrical dyssynchrony and accordingly improves LV systolic function to a similar degree as conventional biventricular pacing in canine hearts with LBBB and heart failure patient with LBBB. The beneficial effects of LV septal pacing in dyssynchronous hearts and the promising results of permanent LV septal lead implantation via the trans-interventricular septal route demonstrated in the present thesis suggest that $\mathrm{LV}$ septal pacing could become an equal alternative for biventricular pacing in CRT. Yet, compared with biventricular pacing, this approach would allow CRT to be performed using a single ventricular lead in combination with a simpler 2-chamber pacemaker, thereby reducing the complication rate as well as implantation costs and prolonging battery life. Yet, this requires further investigation in preferably large randomized controlled trials that directly compare LV septal pacing and biventricular pacing with regard to long-term effect on left ventricular pump function, clinical outcome with particular focus on complication- and re-operation rates, and cost-effectiveness.

In conclusion, the research performed in this thesis could lead to improvement of the treatment and prevention of cardiac dyssynchrony. This may reduce death and morbidity due to dyssynchronous heart failure and the health care costs associated with this disease. 


\section{Dankwoord}

Dit proefschrift was nooit tot stand gekomen zonder de inzet en steun van vele anderen. Ik ben iedereen die op welke wijze dan ook heeft bijgedragen aan dit werk, enorm dankbaar.
Om te beginnen wil ik graag mijn promotoren bedanken.

Beste Harry, bedankt dat je mij de gelegenheid hebt gegeven om dit promotieonderzoek te doen. Ik voel me erg bevoorrecht dat ik gedurende dit vier jaar lange promotietraject de tijd en de ruimte heb gekregen om mijn volledige aandacht aan de wetenschap te wijden. Je hebt mij gedurende dit traject veel vrijheid gegeven om mijn eigen wetenschappelijke interesses te volgen en de inhoud van dit proefschrift persoonlijk vorm te geven. Bedankt voor je vertrouwen en steun hierin. Bedankt ook voor de waardevolle overlegmomenten, je kritische blik op mijn manuscripten en dat je het mij mogelijk hebt gemaakt om mijn onderzoeksresultaten op vele congressen te presenteren.

Beste Frits, onze wetenschappelijke paden kruisten zich al vroeg in mijn promotietraject maar pas na circa 2 jaar gingen wij officieel met elkaar samenwerken. Een erg vruchtbare samenwerking zoals nu blijkt. Een betere begeleiding door een promotor kan ik mij haast niet voorstellen. Je was altijd laagdrempelig benaderbaar voor overleg en wist mij tijdens onze wetenschappelijke besprekingen met jouw kennis en ervaring altijd verder te helpen als ik de oplossing niet kon vinden. Jouw suggesties en ideeën zijn van zeer grote waarde geweest oplossing niet kon vinden. Jouw suggesties en ideeën zijn van zeer grote waarde geweest
voor de kwaliteit van de verichte onderzoeken en het proefschrift in zijn geheel. De grote voor de kwaliteit van de verichte onderzoeken en het proefschrift in zijn geheel. De grote waardevol commentaar is bewonderenswaardig en is een aspect van onze samenwerking die proefschrift voor het grootste deel af kunnen krijgen voordat ik aan mijn opleiding cardiologie begon. Graag wil ik deze gelegenheid aangrijpen om je officieel daarvoor te bedanken. Ik kijk met veel plezier terug op de periode waarin wij hebben samengewerkt en hoop dat we de samenwerking op wetenschappelijk gebied in de toekomst kunnen blijven continueren.

Mijn copromotor, Kevin Vernooy, ben ik bijzonder veel dank verschuldigd. Je was aanvankelijk niet mijn copromotor. Maar wat voor mij begon als een interessant gezamenlijk zijproject, groeide uit tot een veel grotere en zeer succesvolle samenwerking die wij denk ik beiden niet van te voren hadden voorzien. Vele mapping- en implantatieprocedures, abstracts, presentaties, congressen en meerdere manuscripten verder is hier dan eindelijk het resultaat van al onze gezamenlijke inspanningen van de afgelopen jaren. Een resultaat waaraan jij een enorme bijdrage hebt geleverd. Gedurende het hele traject ben je direct betrokken geweest bij het bijdrage hebt geleverd. Gedurende het hele traject ben je direct betrokken geweest bij het
verzamelen en analyseren van alle data en de revisie van de manuscripten. Jouw klinische visie en ideeën hebben het onderzoek vormgegeven en naar een hoger niveau getild. Maar jouw bijdrage was niet alleen van inhoudelijke aard. Gedurende mijn hele promotietraject heb ik je ervaren als een zeer toegewijde en betrokken begeleider. Bedankt voor je altijd optimistische woorden op de momenten waar ik het somber inzag. Bedankt ook voor de virtuele deadlines woorden op de momenten waar ik het somber inzag. Bedankt ook voor de virtuele deadlines
die jij mij, maar ook jezelf stelde om de vaart er in te houden. Ik krijg altijd een glimlach op mijn gezicht als ik denk aan de momenten dat je binnenliep om te vragen of het manuscript al af was als we nog geen uur eerder hadden afgesproken om er aan te beginnen ;). Ik heb erg genoten van onze samenwerking en hoop dat we dit in de toekomst kunnen voortzetten op zowe wetenschappelijk als klinisch gebied.

Yuri Blaauw, in eerste instantie mijn copromotor, bedankt voor je begeleiding en sturing in de eerste 2 jaar van mijn promotietraject. Jouw brede wetenschappelijke blik heeft een belangrijke bijdrage geleverd aan de totstandkoming van dit proefschrift. Ik kan me nog goed de momenten 
herinneren dat ik enigzins gefrustreerd luisterde naar het zoveelste nieuwe idee of project waarmee je naar mij toekwam. Achteraf zie ik in dat het juist die brede inzet was die ervoo heeft gezorgd dat ik zo ver ben gekomen. Ik vond het erg jammer dat je na twee jaar naar Grongingen vertrok. Ik had graag langer met je samengewerkt. Ik hoop dat we in de toekomst nog eens op klinisch en/of wetenschappelijk gebied kunnen samenwerken.

Voorzitter en leden van de beoordelingscommissie, Prof. Dr. J.C.A. Hoorntje, Prof. Dr. T. Delhaas, Dr. M. Meine, Prof. Dr. U. Schotten en Prof. Dr. J.L.R.M. Smeets, hartelijk dank voor de kritische beoordeling van mijn proefschrift.

De resultaten beschreven in dit proefschrift waren nooit verkregen zonder de medewerking en expertise van het vaatkamerpersoneel en de pacemakertechnici. lk wil iedereen van het vaatkamerpersoneel en het planbureau van de vaatkamer hartelijk bedanken voor hun hulp in de planning, voorbereiding en uitvoering van alle mapping- en implantatieprocedures. Alle pacemakertechnici, hartelijk dank voor jullie hulp tijdens de metingen op de vaatkamer en het verzamelen van de follow-up data van studiepatiënten.

Peter Bakker en Arjan Bennink van St. Jude Medical, bedankt voor de tijd en moeite die jullie hebben gestoken in het mij wegwijs maken in het EnSite NavX systeem en voor de technische support bij vragen en problemen gedurende de mappingprocedures en daarbuiten.

Jeroen Wassen, Mark Lazeroms en Jean Rutten van Medtronic, bedankt voor jullie hulp bij de voorbereidingen en gedurende de implantatieprocedures voor de LV septum pacing studie.

Debbie Wilkens van Biosense Webster, bedankt voor je hulp bij het bedienen van de intracardiale echo katheter tijdens de implantatieprocedures voor de LV septum pacing studie.

De volgende personen wil ik speciaal bedanken voor hun bijdrage aan specifieke hoofdstukken van dit proefschrift:

Beste Twan, bedankt voor de goede en prettige samenwerking in een voor jou nog relatief nieuw onderwerp. Je frisse en kritische blik hebben een uiterst positieve invloed gehad op het onderzoek. De goede samenwerking komt voor mij uiteraard niet als een verrassing aangezien we elkaar al vrij lang (bijna 15 jaar, ongelofelijk als je er over nadenkt) kennen en ik je in de eerste plaats zie als een goede vriend en pas op de tweede plaats als collega. Je zit nu midden in je eigen promotietraject en ik weet zeker dat daar een prachtig proefschrift uit voort zal komen. Uiteraard hoop ik, net zoals jij dat bij mij hebt gedaan, een bijdrage hieraan te kunnen leveren.

Beste Elien, bedankt voor je expertise en hulp bij de constructie en analyse van de vectorcardiogrammen. Je bent erg kundig in je werk en ik heb veel van je mogen leren. We hebben samen een paar mooie studies opgezet en uitgevoerd en een paar mooie manuscripten geschreven. Je bent een erg prettige collega om mee samen te werken. Heel veel succes met de afronding van je eigen promotieonderzoek en met je verdere carrière in het bedrijfsleven P.S. bedankt dat ik en Saskia gebruik mochten maken van je smokkelkwaliteiten in Londen ;). Beste Jetske, bedankt voor de fijne -nog ongoing- samenwerking. Het stuk is nog niet gepubliceerd maar we komen dichtbij... de laatste loodjes. Je bezit veel kennis en kundigheid en ik heb veel van onze samenwerking geleerd. Heel veel succes met de rest van je carrière.
Beste Gilbert, bedankt voor de prettige en productieve samenwerking tijdens je WESP stage. Je hebt in die relatief korte periode veel en waardevol werk verricht. Heel veel succes met je promotieonderzoek en de rest van je carrière.

Justin Luermans, bedankt voor je bijdrage aan de LV septum pacing studie en je kritische revisie van het manuscript. Daarnaast wil ikje ook graag bedanken voor de uiterst prettige en leerzame manier waarop je mijn polispreekuur tijdens mijn promotietraject hebt gesuperviseerd. Ik heb erg veel van je geleerd en hoop in de toekomst nog meer van je te kunnen leren.

Bij de vakgroep Fysiologie zou ik graag de groep van Frits Prinzen willen bedanken voor hun luisterend oor en kritische bijdrages tijdens de werkbesprekingen.

Mijn promotietijd zou uiteraard niet hetzelfde zijn geweest zonder mijn mede-pomovend Ik denk niet dat ik deze periode, zo goed had kunnen doorstaan zonder jullie. Jullie zorgden voor de nodige afleiding die een mens af en toe nodig heeft om zijn frustaties te verwerken en zijn motivatie, inspiratie en creativiteit weer nieuw leven in te blazen. Al denk ik dat ik jullie misschien vaker deed afleiden dan jullie mij ;). Maar hoe dan ook, wat kijk ik toch met onzettend vee plezier terug op de periode die wij samen hebben doorgebracht.

Bob, het is alweer erg lang geleden dat je mijn achterbuurman was, maar ik ben je niet vergeten. Bedankt voor de gezelligheid in het eerste jaar van mijn promotieonderzoek. PYPD forever jonge ;).

Caroline, bedankt voor de fijne gesprekken en goede adviezen tijdens mijn promotietraject. Je bent een erg prettige collega door je vriendelijke karakter en je altijd rustige en kalme houding. Wij zijn elkaar tijdens de vooropleiding interne geneeskunde in het azM een beetje misgelopen, maar ik hoop dat we elkaar ook in de kliniek weer wat vaker gaan zien.

Casper,lk kijk met veel plezier terug op het jaar dat wij samen onderzoek hebben gedaan De eerste 3 maanden van mijn promotieonderzoek die wij op dezelfde kamer hebben doorgebracht zijn mij altijd bijgebleven. Ondanks het feit dat je het best zwaar had, was je altijd goed gehumeurd. Ik heb erg genoten van je humor en gezelligheid. Ik hoop je gauw weer terug te zien in de kliniek.

Désirée, mijn favoriete ginger ;). Het was absoluut niet mijn bedoeling om je van de kamer te verjagen. Kun je me ooit vergeven? Heel veel succes met je verdere carrière!

Elton, a.k.a Elton John (zo sta je trouwens nog steeds in mijn telefoonlijst), a.k.a Elton Dudnik, a.k.a Eldick. Altijd goed voor een heerlijk potje droge humor, maar ook benaderbaar voor serieuze gesprekken. Wat zal ik die bekvecht battles tussen jou en Jort toch missen. Het was altijd weer genieten. Heel veel succes met de ACWAS en het afronden van je promotie.

Frederique, high society! Jou maak je niet snel gek. Je hebt je mannetje goed gestaan in het hol vol luidruchtige mannetjes. Hoe vaak heb ik je wel niet horen zuchten en zien draaien met je ogen vanwege ons. Mede namens de andere mannelijke kamergenoten, bedankt voor je geduld ;). Heel veel succes met de rest van je promotieonderzoek. 
Ione, het kleine positief geladen iontje, iedereen kent jou en jij kent iedereen. Een groter sociaal netwerk dan dat van jou bestaat denk ik niet, maar dat komt ook niet als een verassing voor wie jou kent. Wat een heerlijke kamergenoot was jij toch, altijd vrolijk, altijd lachen en niet te beroerd om mee te helpen met een kleine prank;). Bedankt voor de leuke tijd zowel op het werk als daarbuiten.

Jort, heerlijke theatrale vent van me! Wat heb ik toch ontzettend genoten van jou en je onzin! Altijd mooie grote verhalen, waar op een of andere manier nooit getuigen bij zijn geweest ; Maar ik blijf geloven in jou Jordan! In de afgelopen jaren heb je je bewezen als een volwaardig lid van de Wolfpack en heb je je certificaat behaald als meesterpranker ;). Ik denk niet dat ik iemand ken met meer kennis en consumptie van gin tonic dan jij. Mocht je huidige promotieonderzoek in de soep lopen, kun je daar nog altijd een proefschrift over schrijven. Maar je bent goed op weg met je onderzoek, dus ik heb er alle vertrouwen in dat het helemaal goed gaat komen. Zet 'm op kerel! En laat je niet gek maken door de midget ;).

Marije, nooit te beroerd voor een lekkere provocatieve droge opmerking. Kon ik altijd van genieten. Bedankt dat ik de eerste 3 maanden op jouw stoel mocht zitten. Vind wel dat je je poetsvrouw iets beter mag betalen voor al dat zware werk. Of was het nou je tuinman? Ik heb in ieder geval een poging tot salarisverhoging voor haar/hem gedaan ;).

Martijn, ik dacht wel eens dat ik het moeilijk had met mijn promotieonderzoek, maar als ik jouw verhalen af en toe hoorde dan hielp dat wel om een beetje te relativeren. Wat veel en waardevol werk heb jij verricht in de afgelopen jaren, alle respect daarvoor. Succes met het afronden van je promotieonderzoek en tot gauw in de kliniek.

Mindy, volgens mij ben je erg druk geweest in het eerste jaar van je promotie want we hebben elkaar maar weinig gezien. Maar goed, dat geldt ook voor mij in mijn laatste jaar. Ik hoor dat je goed op weg bent. Keep up the good work! Heel veel succes met je onderzoek! Tot over een paar jaar in de kliniek.

Ömer, altijd vriendelijk, rustig, kalm en correct. Je heb het vaak zwaar te verduren gehad me ons, vooral met die achterbuurman van je. Bedankt voor je stabiliserende invloed. Heel veel succes met je promotieonderzoek!

Ron, bedankt voor je nuttige adviezen en geruststellende woorden in de eerste paar jaar van mijn promotieonderzoek. Als ervaren mede-onderzoeker heb je mij met deze woorden erg gesteund en gemotiveerd.

Ruud, Je hebt een zeer eigen visie op wetenschappelijk onderzoek en het leven in het algemeen en dat heb ik altijd erg aan jou gerespecteerd. Ik kijk met veel plezier terug op onze krachttrainsessies bij UM sport na het werk en de mooie gesprekken en discussies bij een biertje in het weekend. Helaas zijn we elkaar in de laatjes jaren uit het oog verloren, ik hoop dat daar verandering in kan komen. Stay lean Rudy boy! groeten van Mr. Lean ;).

Sandra, sporty spice! Ik ken denk ik niemand die zo efficient kan werken als jij. Full-time onderzoek, eigen wekelijkse polispreekuur, publiceren aan de lopende band en daarnaast ook nog fitnessinstructrice bij UM sport. En op een of andere manier hield je ook nog vrije tijd over. Respect! Ik voel me nog steeds vereerd dat ik mocht figureren in jouw UM sport fitness filmpje. Bedankt voor de mooie jaren. Groeten aan die mooie kerel van je.

Sema, in het begin hebben ik en Mark je een beetje moeten ontgroenen maar daarna kwam je goed los. Het was een leuke tijd met jou op de kamer. Succes met het afronden van je promotieonderzoek.

Sibel, je bent een erg vriendelijke en aangename collega. Momenteel zit je in de afrondingsfase van je promotieonderzoek en ga je gauw beginnen met je vooropleiding interne geneeskunde in het azM. Ik kijk ernaar uit om met je samen te werken in de kliniek. Heel veel succes met de laatste efforts voor je boekje.

Theo, een fijnere collega kun je je niet wensen. Een goede onderzoeker en een goede clinicus en altijd in voor een gezellig biertje. Ik denk nog vaak met veel plezier terug aan die mooie congressen die we samen beleefd hebben in San Francisco en Boston. Jij bent inmiddels net als ik begonnen met je cardiologie opleiding en in de afrondingsfase van je promotie. Heelveel succes met de laatste loodjes. Ik kijk er naar uit om met je samen te werken in de kliniek.

Yvonne, jij kwam en ik ging. Jammer dat we niet langer samen onderzoek hebben kunnen doen, want ondanks dat we elkaar maar kort kennen is het altijd erg gezellig met jou. Binnenkort maar weer een biertje in Thembi. Heel veel succes met je onderzoek!

Nu had ik tot nu een alfabetische volgorde aangehouden, maar ze zeggen altijd "save the bes for last", dus vandaar Mark, dat je nu pas aan de beurt bent. Tjah! wat kan ik zeggen over degene die ruim 3 jaar mijn buurman is geweest. Ik denk dat onze haat/liefde verhouding moeilijk in woorden uit te drukken is, maar ik zal een poging doen. Ik denk dat de volgende zin het op zich wel goed samenvat: Ik heb overal, echt overal gevraagd, maar niemand, dan ook echt niemand..... (vul zelf maar in ;). Niemand..., behalve ik. Ze zeggen wel eens: degene van wie je het meeste houdt doe je het meeste pijn. Ik zeg altijd, degene die je het meest mag prank je het hardst ;). Markie, wat heb ik in de afgelopen jaren toch ontzettend veel ten koste van jou gelachen. Ik vrees echter dat het tij zich heel binnekort tegen mij gaat keren. Uiteraard ga jij een van mijn paranimfen zijn tijdens de verdediging, daar bestond bij mij na al die mooie jaren geen twijfel over. Bedankt kerel!

Pieter, van de vakgroep cardiothoracale chirurgie, jij bent de ware koning van het relativeren. lk ken denk ik niemand anders die zo kalm en positief kan blijven wanneer hij geconfronteerd wordt met tegenslag. Die eigenschap van jou heb ik altijd als voorbeeld genomen. In de afgelopen jaren zijn we goede vrienden geworden. Je staat altijd klaar om te helpen en je biedt een luisterend oor in moeilijke tijden. Het stelt me erg gerust om te weten dat jij er als een van mijn paranimfen gaat zijn om me te helpen relativeren als we in dat zweethok zitten.

De Silenen, dank ik voor hun vriendschap en de mooie momenten. Ik ben voor altijd met jullie verbonden.

De Wolfpack; Mark, Pieter, Twan, Jort, Stefan, Sammie dank ik voor de broodnodige momenten van ontlading. Ik hoop dat er nog vele zullen volgen! Wie prikt er een datum? 
Aan mijn familie komt speciale dank toe, omdat ik zonder hun liefde en steun nooit zo ver was gekomen:

Lieve Maryam en Mahboobeh, mijn favoriete tweelingnichtjes! Allereerst, bedankt voor het prachtige ontwerp van mijn proefschrift! In mijn dromen had het niet mooier gekund. Jullie zijn werkelijk waar getalenteerd. Ik prijs mij elke dag weer gelukkig met zulke liefdevolle nichten die zo toegewijd zijn aan mij. Vanaf mijn geboorte zijn jullie er altijd voor mij geweest. Bedankt voor al jullie zorgen.

Lieve Shahed, als kinderen speelden we, als pubers maakten we wel eens ruzie, als jongvolwassenen waren we huisgenoten, en ja ook voor jou geldt, het is vaker leuk dan vervelend met jou ;) (beter goed gejat dan slecht bedacht he!). Maar op welke leeftijd dan ook, een ding was voor mij altijd duidelijk. Mijn grote zus staat altijd achter mij. Ik ben trots dat jij mijn zus bent. Weet dat je broertje er altijd voor jou en die kleine schatjes van je zal zijn.

Beste Frank, allereerst bedankt voor alle tijd en moeite die je hebt geïnvesteerd om mij te helpen met het samenstellen van de figuren van het proefschrift. Zonder jou was het nooit gelukt. Een betere schoonbroer kan ik me niet wensen. Je bent een zorgzame en toegewijde partner voor Shahed en je bent een geweldige papa voor Isabel en Emilia (Papa Frank ;) Daarnaast sta je ook altijd voor mij klaar als ik hulp nodig heb. Ik kijk uit naar alle mooie jaren die we samen met de kinderen gaan beleven.

Lieve Petra en Leen, bedankt voor alle hulp en steun in de afgelopen jaren. Jullie warmte en gastvrijheid zorgen er voor dat ik mij altijd heel erg thuis heb gevoeld bij jullie. Jullie staa altijd onvoorwaardelijk klaar voor ons en de kinderen. Niets is te veel, we hoeven het maar te vragen. Het doet mij erg veel plezier om te zien hoe dol Elyse en Ryan zijn op oma en opa en ik kijk heel erg uit naar alle mooie momenten die wij samen met de kinderen zullen beleven.

Lieve mama, lieve papa, is er iets in deze wereld dat jullie niet voor mij over zouden hebben? k denk niet dat het bestaat. Jullie staan altijd onvoorwaardelijk voor mij klaar als ik jullie nodig heb. Bij elk probleem waar ik tegen aan loop weet ik dat ik ten alle tijden op jullie hulp kan rekenen. Jullie hebben alles gedaan om mij de kans te bieden het allerbeste van mijn mogelijkheden te maken. Heel veel dank voor jullie liefdevolle betrokkenheid, hulp, steun en raad gedurende mijn leven. Geen fortuin op deze wereld zou groot genoeg zijn om jullie terug te betalen voor alles wat jullie voor mij hebben gedaan en geen woorden of gebaren zijn moo genoeg om echt te laten zien hoeveel jullie voor mij betekenen.

Vertaling voor papa (Übersetzung für Papa)

Liebe Mama, Lieber Papa! Gibt es irgendetwas auf dieser Welt was ihr nicht für mich geben würdet? Mir fäll jedenfalls nichts ein. Ihr seid immer für mich da egal worum es geht. Welches Problem ich auch habe, weiß ich dass ich jederzeit auf euch zählen kann. Ihr habt alles getan um mir die Chance zu bieten das Allerbeste aus meinen Möglichkeiten zu machen. Vielen lieben Dank für eure liebevolle Zuwendung und Engagement, eure Hilfe und Unterstützung und das ihr mir mit Rat und Tat zur Seite steht in all den Jahren. Kein Geld dieser Welt würde reichen um aufzuwiegen was ihr alles für mich getan habt und keine Worte und Gesten können wirklich ausdrücken wie vie ihr beide mir bedeutet. (Vertaling met dank aan Patricia van den Berg)
Saskia, lieve Sasje, de jaren van mijn promotie zijn geen makkelijke periode geweest voor mij. Het was een lange en hobbelige weg. Jij weet dit als geen ander, omdat je de gehele weg samen met mij bewandeld hebt. Alles waar ik doorheen ben gegaan, ben jij met mij doorheen gegaan k besef dan ook dat deze periode ook voor jou belastend is geweest en ik dank je uit het diepste van mijn hart dat je er door alles heen voor mij bent geweest. Je hebt het met name het laatste jaar niet makkelijk gehad omdat je regelmatig alleen voor de kinderen moest zorgen als ik dienst had of na het werk of in het weekend aan het proefschrift moest werken. Bedankt dat je mij in deze periode zo ontlast hebt, anders was het me nooit gelukt om het proefschrift binnen afzienbare tijd af te krijgen. Ik zal het nooit vergeten. Met Elyse en Ryan heb je mij het grootste geschenk op aarde gegeven. Ik ben zo ontzettend blij dat jij met mij deze twee wondertjes op de wereld hebt gezet en ik kijk er erg naar uit om onze twee wooshies samen met jou groot te brengen.

Lieve lieve Elyse en Ryan, mijn kleine kleine wooshies! Jullie zijn de grootste vreugde in mijn leven! Elke dag opnieuw voel ik mij de gelukkigste persoon op aarde omdat ik papa mag zijn van zo een prachtig meisje en zo een prachtig jongetje. Hoe zwaar mijn dag ook is geweest hoe somber ik ook ben, als ik jullie lachende gezichtjes zie en jullie met open armpjes op mij af zie rennen verdwijnen alle negatieve gevoelens als sneeuw voor de zon en vervullen jullie mijn hart met een intens gevoel van geluk. Ik hou ontzettend veel van jullie en kijk er heel erg naar uit om jullie te zien opgroeien tot twee volwassen wooshies. Ja sorry, voor mij zullen jullie toch altijd klein en schattig blijven vrees ik, hoe oud jullie ook worden :). 


\section{About the Author}

He attended high school at the Regionale Scholengemeenschap in Steenwijk where he obtained his gymnasium diploma in 2002. The same year he moved to Maastricht where he started his medical training at the Faculty of Health Medicine and Life Sciences at Maastricht University. In his final year of medical training he did a clinical internship at the Cardiology department of the Orbis Medical Center in Sittard under the supervision of Dr. D.J.W. van Kraaij. This was followed by a research internship at the department of Cardiology of the University Hospital of Heidelberg under supervision of Prof. Dr. T.J. Dengler. The research focused on the role of tumor necrosis factor proteins in the pathogenesis of atherosclerosis. After graduating as Medical Doctor at Maastricht University in July 2008 he continued his research at the University as Medical Doctor at Maastricht University in July 2008 he continued his research at the University
Hospital of Heidelberg. This work led to the doctoral thesis entitled "Involvement of LIGHT in atherosclerosis and the large scale production of soluble LIGHT receptor TR2 for in vivo application" with which he obtained a Medical Doctor degree at the Medical Faculty of the University of Heidelberg in 2009. From February 2009 until December 2010 he worked as a physician at the Cardiology departments of the Orbis Medical Center in Sittard and the Maastricht University Medical Center. In December 2010 he started a PhD-track focused on cardiac dyssynchrony at the Cardiology department of the Maastricht University Medical Cente under supervision of Prof. Dr. H.J.G.M. Crijns, Prof. Dr. F.W. Prinzen and Dr. K. Vernooy. The results of his research were presented at various national and international congresses and finally resulted in this thesis. On September 1, 2015, he started his Cardiology training at the Maastricht University Medical Center under supervision of Prof. Dr. H.J.G.M. Crijns and Dr. E.C. Cheriex. In the context of this training, he is currently doing his residency in Internal Medicine at the Maastricht University Medical Center under supervision of Prof. Dr. C.D.A. Stehouwer and Prof. Dr. R.P. Koopmans. 


\section{List of publications}

Mafi Rad M, Engels EB, van Stipdonk AMW, Vernooy K, Prinzen FW. Why QRS duration should be replaced by better measures of electrical activation to improve patient selection for cardiac resynchronization therapy. J of Cardiovasc Transl Res. 2016 May 26. [Epub ahead of print]

Mafi Rad M, Luermans JG, Blaauw Y, Janssen M, Crijns HJ, Prinzen FW, Vernooy K. Feasibility and acute hemodynamic effect of left ventricular septal pacing by transvenous approach through the interventricular septum. Circ Arrhythm Electrophysiol. 2016 Mar;9(3):e003344

Mafi Rad M, van Stipdonk AM, Luermans JG, Crijns HJ, Prinzen FW, Vernooy K. Identifying delayed left ventricular lateral wall activation in patients with non-specific intraventricular conduction delay using coronary venous electroanatomical mapping. Neth Heart J. 2016 Jan;24(1):58-65

Mafi Rad M, Wijntjens GW, Engels EB, Blaauw Y, Luermans JG, Pison L, Crijns HJ, Prinzen FW Vernooy K. Vectorcardiographic QRS area identifies delayed left ventricular lateral wall activation determined by electroanatomic mapping in candidates for cardiac resynchronization therapy. Heart Rhythm. 2016 Jan;13(1):217-25

Kumar N, Bonizzi P, Mafi Rad M, Lankveld T. Left atrial dyssynchrony time measured by tissue Doppler imaging to predict atrial fibrillation recurrences after pulmonary vein isolation: is this mirage or the panacea? Anatol J Cardiol. 2015 Feb;15(2):123-4

Mafi Rad M, Blaauw Y, Dinh T, Pison L, Crijns HJ, Prinzen FW, Vernooy K. Left ventricular lead placement in the latest activated region guided by coronary venous electroanatomic mapping. Europace. 2015 Jan;17(1):84-93

Mafi Rad M, Blaauw Y, Dinh T, Pison L, Crijns HJ, Prinzen FW, Vernooy K. Different regions of latest electrical activation during left bundle-branch block and right ventricular pacing in cardiac resynchronization therapy patients determined by coronary venous electroanatomic mapping. Eur J Heart Fail. 2014 Nov;16(11):1214-22

Luermans JG, Mafi Rad M, Vernooy K. A call for re-evaluation of the guidelines for prophylactic ICD implantation. Neth Heart J. 2014 Oct;22(10):429-30

Mafi Rad M, Blaauw Y, Debie L, Brunner-La Rocca HP, Vernooy K. Evaluation of left ventricular endocardial cardiac resynchronization therapy in a non-responder with ventricular arrhythmias. Indian Pacing Electrophysiol J. 2014 Jan 1;14(1):32-6.

Mafi Rad M, Blaauw Y, Prinzen FW, Vernooy K. The role of acute invasive haemodynamic measurements in cardiac resynchronization therapy: looping towards prediction of long-term response and therapy optimization. Eur J Heart Fail. 2013 Mar;15(3):247-9

Mafi Rad M, Blaauw Y, van Opstal JM, Crijns HJ. Haemodynamic bradycardia in tachycardiomyopathy. Neth Heart J. 2012 Apr;20(4):184-5 